\title{
Global Ice Sheet Modeling
}

May 1994

Prepared by the Institute for Quaternary Studies

for Pacific Northwest Laboratory under Contract DE-AC06-76RLO 1830

with the U.S. Department of Energy

Pacific Northwest Laboratory

Operated for the U.S. Department of Energy

by Battelle Memorial Institute 


\title{
DISCLAIMER
}

This report was prepared as an account of work sponsored by an agency of the United States Government. Neither the United States Government nor any agency thereof, nor Battelle Memorial Institute, nor any of their employees, makes any warranty, expressed or implied, or assumes any legal liability or responsibility for the accuracy, completeness, or usefulness of any information, apparatus, product, or process disclosed, or represents that its use would not infringe privately owned rights. Reference herein to any specific commercial product, process, or service by trade name, trademark, manufacturer, or otherwise does not necessarily constitute or imply its endorsement, recommendation, or favoring by the United States Government or any agency thereof, or Battelle Memorial Institute. The views and opinions of authors expressed herein do not necessarily state or reflect those of the United States Government or any agency thereof.

\author{
PACIFIC NORTHWEST LABORATORY \\ operated by \\ BATTELLE MEMORIAL INSTITUTE \\ for the \\ UNITED STATES DEPARTMENT OF ENERGY \\ under Contract DE-AC06-76RLO 1830
}

Printed in the United States of America

Available to DOE and DOE contractors from the

Office of Scientific and Technical Information, P.O. Box 62, Oak Ridge, TN 37831;

prices available from (615) 576-8401. FTS 626-8401.

Available to the public from the National Technical Information Service, U.S. Department of Commerce, 5285 Port Royal Rd., Springfield, VA 22161. 
PNL-9414

UC-603

GLOBAL ICE SHEET MODELING

Terence J. Hughes

James L. Fastook

Institute for Quaternary Studies

The University of Maine

Orono, Maine 04469

W. H. Walters, PNL Project Manager

May 1994

Prepared by the Institute for Quaternary Studies for Pacific Northwest Laboratory under Contract DE-AC06-76RLO 1830 with the U.S. Department of Energy

Pacific Northwest Laboratory

Richland, Washington 99352 



\section{FOREWORD}

This report was prepared by the Institute for Quaternary Studies of the University of Maine at Orono, Maine, under contract to Pacific Northwest Laboratory (PNL) as part of a global climate modeling task. The task supports site characterization work required for a potential high-level nuclear waste repository and is part of the Performance Assessment Scientific Support (PASS) Program at PNL. The PASS Program is under the direction of the Yucca Mountain Project Office (YMPO), at Las Vegas, Nevada. The work is under the overall direction of the Office of Civilian Radioactive Waste Management (OCRWM), U.S. Department of Energy Headquarters, Washington, D.C.

The scope of the report is to present the results of the third (final) year's work on the global ice sheet modeling part of the global climate modeling task. The theory and equations used to develop the ice sheet models are presented. The three proposed glaciation scenarios are developed and modeling results are discussed. The modeling results are also presented in color graphics following the references section. Documentation of the ice sheet dynamics model with user information will be prepared under a separate report.

The task work involves the services of two other subcontractors: The Applied Research Corporation (ARC), College Station, Texas, and the Lamont-Doherty Geological Observatory (LDGO), Palisades, New York. ARC is conducting the global atmospheric part of the work and LDGO is developing the global climate change data base. These studies will be reported by the individual contractors. 



\section{EXCUTIVE SUMMARY}

The University of Maine conducted this study for Pacific Northwest Laboratory (PNL) as part of a global climate modeling task for site characterization of the potential nuclear waste repository site at Yucca Mountain, Nevada. The purpose of the study was to develop a global ice sheet dynamics model that will forecast the threedimensional configuration of global ice sheets for specific climate change scenarios.

The objective of the third (final) year of the work was to produce ice sheet data for glaciation scenarios covering the next 100,000 years. This was accomplished using both the map-plane and flowband solutions of our time-dependant, finite-element gridpoint model. Three future scenarios were simulated by the model.

The first scenario assumed that anthropogenic climatic warming would not significantly affect natural climatic change over the next 100,000 years. We further assumed that natural climatic change would continue through the Late Quaternary glaciations in which irregular growth of ice sheets proceeded for some 80,000 years, ended as rather abrupt terminations in 10,000 years or less, followed by an interglaciation lasting about 10,000 years before a new glaciation cycle began. We call this the Late Quaternary glaciation scenario which is our most probable scenario.

The second scenario assumed that anthropogenic climatic warming would moderate global climate change enough so that glaciations over the next 100,000 years would have the 41,000-year periodicity of high-latitude insolation controlled by the Earth's cycle of axial tilt. Ice sheets would advance and retreat in high latitudes. This seems to have been the case during the Early Quaternary and is called the Early Quaternary glaciation scenario. We consider this to be the next most probable scenario.

The third scenario assumed that anthropogenic climatic warming would substantially change global climate over the next 100,000 years. We assumed that this warming would eliminate ice sheets in the Northern Hemisphere, so that only the 
Antarctic ice sheet would exist and it would respond mainly to the 41,000-year cycle of axial tilt. This was apparently the case during the Late Tertiary and, therefore, we call this the Late Tertiary glaciation cycle. This is considered to be the least probable scenario.

For the Late Quaternary Glaciation Scenario in the Northern Hemisphere, our model could not reproduce Late Quaternary glaciation cycles, using the Wisconsin/Weichselian glaciation as our standard, if they were driven only by snowline elevation changes controlled by Milankovitch insolation variations keyed to the 41,000 year cycle of axial tilt at high latitude and the 21,000-year cycle of axial precession at mid latitude. The model did reproduce the Late Wisconsin/Weichselian glaciation by supplementing Milankovitch forcing with what we call the "dust machine."

In our dust machine hypothesis, katabatic winds blow almost continually off the southern margins of advancing Northern Hemisphere ice sheets, entraining dust into the lower atmosphere from glacially eroded rock flow and soil being continually supplied to the ice margin by regulation basal ice. This dust is transported into the upper atmosphere by the jet stream, which tracks along the southern margin of Northern Hemisphere ice sheets. Once in the upper atmosphere, dust particles are precipitation nuclei for water vapor and thereby provide upper atmosphere cloudiness that increases planetary albedo. Since precipitation continually removes upper atmospheric dust, it must be resupplied continually by the dust machine in order to cause a nearly instantaneous planetary response to changing vitality of the dust machine along the southern margins of Northern Hemisphere ice sheets. The dust machine is greatly weakened or turned off when these margins retreat, since glacial debris released at the ice-sheet margin is kept in suspension or settles as sediments in pro-glacial lakes that occupy isostatically depressed basins along retreating icesheet margins. Advances and retreat can be caused by insolation changes driven by the 21,000-year precession cycle, by internal ice-sheet dynamics related to glacial surges, or by other climatic processes that are not well understood. Hence, advance and retreat of ice-sheet margins, during which the dust machine is on (advance) or off (retreat) involve both predictable and unpredictable mechanisms that can be gradual or abrupt, and which generate a simultaneous global climatic response. Retreat 
becomes irreversible, and therefore produces a glacial termination, when slab calving into subglacial isostatic depression. Hence, terminations are a feature of the large Late Quaternary ice sheets that advanced into mid latitudes.

In our Late Quaternary Glaciation Scenario for Antarctica, advance and retreat of the Antarctic ice Sheet was linked through changing sea level to advance and retreat of Northern Hemisphere ice sheets. Changes in Antarctic snowline elevation caused by axial tilt or atmospheric dust had no substantial effect on the areal extent or volume of the ice sheet.

Our Early Quaternary Glaciation Scenario in the Northern Hemisphere simulated advance and retreat of ice sheets driven by the 41,000-year cycle of high-latitudes insolation controlled by axial tilt. Ice sheets never advanced beyond high latitudes during the cold hemicycle and, except for Greenland, vanished during the warm hemicycle. In the Antarctic, our Early Quaternary Glaciation Scenario simulated advance and retreat of the Antarctic Ice Sheet controlled by sea-level changes linked to Northern Hemisphere ice sheets and to snowline changes in Antarctica. Both changes are linked to the 41,000 -year insolation cycle controlled by axial tilt.

The Late Tertiary Glaciation Scenario was examined by applying our finite-element model to the Antarctic Ice Sheet. Without Northern Hemisphere ice sheets, changing sea level was not a factor. Changing Antarctic snowline elevations were linked to the axial-tilt insolation cycle, causing the West Antarctic Ice Sheet to advance and retreat with a 41,000-year periodicity, but the resulting changes in sea level were not enough to affect the ice dynamics. The Antarctic Ice Sheet had its present-day dimensions at the insolation minimum. At the insolation maximum, the West Antarctic Ice Sheet had collapsed and the East Antarctic Ice Sheet was less extensive but thicker. 


\section{CONTENTS}

FOREWORD $\ldots \ldots \ldots \ldots \ldots \ldots \ldots \ldots \ldots \ldots \ldots \ldots \ldots \ldots \ldots$ iii

EXCUTIVE SUMMARY $\ldots \ldots \ldots \ldots \ldots \ldots \ldots \ldots \ldots$

INTRODUCTION $\ldots \ldots \ldots \ldots \ldots \ldots \ldots \ldots \ldots \ldots \ldots \ldots \ldots \ldots$

FIRST YEAR WORK $\ldots \ldots \ldots \ldots \ldots \ldots \ldots \ldots \ldots \ldots \ldots$

SECOND YEAR WORK $\ldots \ldots \ldots \ldots \ldots \ldots \ldots \ldots \ldots \ldots$

THIRD YEAR WORK $\ldots \ldots \ldots \ldots \ldots \ldots \ldots \ldots \ldots \ldots$

THE DUST MACHINE HYPOTHESIS $\ldots \ldots \ldots \ldots \ldots \ldots \ldots \ldots \ldots$

BASAL MASS BALANCE OF AN ICE SLAB

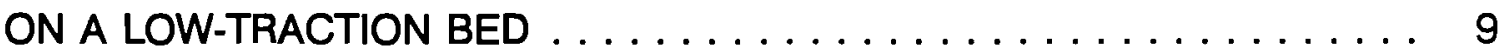

Velocity Field in the Ice Slab $\ldots \ldots \ldots \ldots \ldots \ldots \ldots \ldots \ldots$

Temperature Field in the Ice Slab . . . . . . . . . . . . . . . 12

Basal Freeze-Thaw Rates in the Ice Slab . . . . . . . . . . . 14

THE FINITE-ELEMENT FLOWBAND SOLUTION FOR ICE LOBES $\ldots \ldots \ldots 22$

Conditions for Advance and Retreat of an Ice Lobe ... . . . . . 25

Results for Advance and Retreat of an Ice Lobe $\ldots \ldots \ldots \ldots \ldots .27$

THE ROLE OF ICE CALVING IN GLACIAL TERMINATIONS $\ldots \ldots \ldots \ldots 29$

SIMULATION OF NORTHERN HEMISPHERE GLACIATION CYCLES $\ldots \ldots \ldots 33$

THE LATE QUATERNARY GLACIATION SCENARIO . . . . . . . . . 34

Forcing When Atmospheric Dust Dominates Axial Tilt $\ldots \ldots \ldots \ldots \quad 34$

Forcing When Axial Tilt Dominates Atmosperic Dust $\ldots \ldots \ldots \ldots .37$ 
THE EARLY QUATERNARY GLACIATION SCENARIO $\ldots \ldots \ldots \ldots \ldots$

The Northern Hemisphere Glaciation Cycle . . . . . . . . . . . 40

The Northern Hemisphere Glacial Maximum . . . . . . . . . 41

SIMULATION OF ANTARCTIC GLACIATION CYCLES $\ldots \ldots \ldots \ldots \ldots . \ldots 4$

CALIBRATION $\ldots \ldots \ldots \ldots \ldots \ldots \ldots \ldots \ldots \ldots \ldots \ldots \ldots \ldots \ldots$

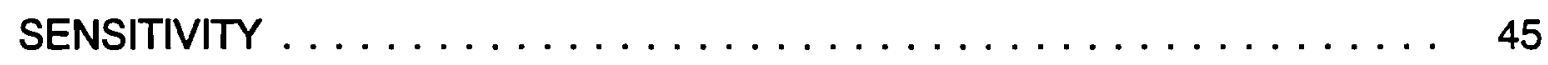

THE LATE QUATERNARY GLACIATION SCENARIO . . . . . . . 46

THE EARLY QUATERNARY GLACIATION SCENARIO $\ldots \ldots \ldots \ldots . \ldots 46$

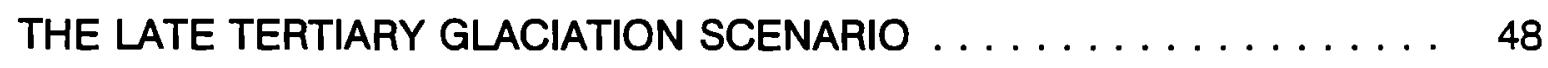

REFERENCES $\ldots \ldots \ldots \ldots \ldots \ldots \ldots \ldots \ldots \ldots \ldots \ldots \ldots \ldots \ldots \ldots \ldots \ldots \ldots \ldots$

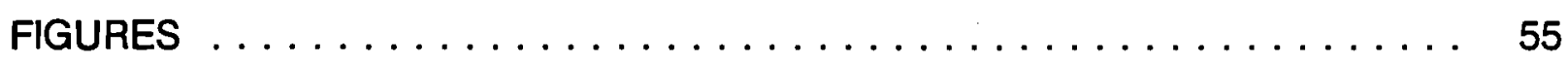

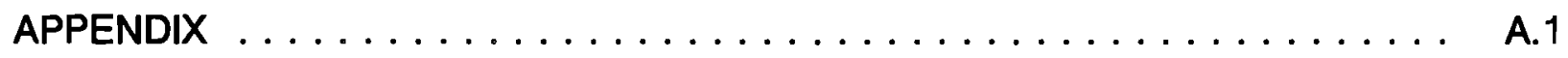




\section{FIGURES}

1 The Effect of Snowline Elevation on an Ice Lobe $\ldots \ldots \ldots \ldots 5$

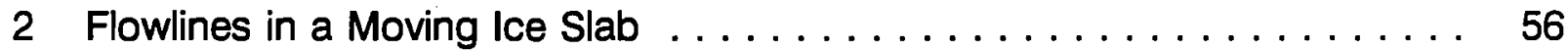

3 Temperatures in a Moving Ice Slab $\ldots \ldots \ldots \ldots \ldots \ldots \ldots \ldots \ldots$

4 Minimum Thicknesses for Basal Melting in a Moving Ice Slab . . . . . . 58

5 Comparison Between Basal Thawed and Sliding Fractions $\ldots \ldots \ldots \ldots 59$

6 An Ice Lobe on a Frozen Bed During the Precession Cycle $\ldots \ldots \ldots . .60$

7 An Ice Lobe on a Thawed Bed During the Precession Cycle . . . . . . . . 61

8 Ice Volume Changes in a Moving Ice Lobe $\ldots \ldots \ldots \ldots . \ldots 6$

9 Ice Margin Positions in a Moving Ice Lobe $\ldots \ldots \ldots \ldots \ldots$

10 An Ice Lobe When Temperature Lags Motion and Dust . . . . . . . . . . 64

11 An Ice Lobe When Temperature Tracks Motion and Dust . . . . . . . . 65

12 Calving from an Ice Wall Standing in Water $\ldots \ldots \ldots \ldots 66$

13 Arctic Model Input and Output When Dust Dominates . . . . . . . . . . . 67

14 Arctic Flotation Ice Volume Over Time When Dust Dominates . . . . . . . . 68

15 North American Topography, Today . . . . . . . . . . . . . . . 68

16 A North American Glaciation Cycle Driven by Dust . . . . . . . . . . . . . . 69

17 Ice Elevation at the Glacial Maximum in Figure $16 \ldots \ldots \ldots 2$

18 Velocity Fractions by Basal Sliding for Ice Sheets in Figure $17 \ldots \ldots . .83$

19 Mass Balance for the Ice Sheets in Figure $17 \ldots \ldots \ldots \ldots$. . . . . . 83

20 Ice-Sheet Transects Through Time For Figure $16 \ldots \ldots \ldots$. . . . . . 84

21 A Eurasian Glaciation Cycle Driven by Dust $\ldots \ldots \ldots \ldots \ldots$ 
22 Ice Elevation at the Glaciation Maximum in Figure $21 \ldots \ldots$. . . . . 97

23 Velocity Fractions by Basal Sliding for the Ice Sheets in Figure $22 \ldots \ldots \ldots \ldots \ldots \ldots \ldots$

24 Mass Balance for the Ice Sheets in Figure $22 \ldots \ldots \ldots \ldots$

25 Maximum Arctic Ice and Land Elevations for a Dust-Driven Glaciation . . . 99

26 Maximum Arctic lce Thicknesses for a Dust Driven Glaciation . . . . . . . 100

27 Arctic Basal Sliding Fractions for Figure $26 \ldots \ldots \ldots \ldots \ldots \ldots$

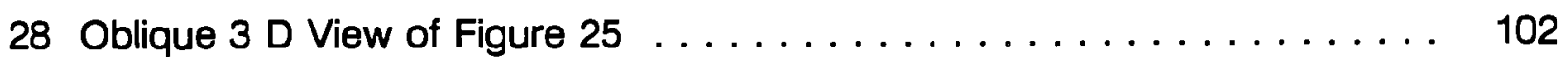

29 Oblique $3 \mathrm{D}$ View of North America from Figure $28 \ldots \ldots \ldots \ldots$

30 Oblique $3 \mathrm{D}$ View of Eurasia from Figure $28 \ldots \ldots \ldots \ldots \ldots$

31 Oblique 3 D Subglacial Topography for Figure $28 \ldots \ldots \ldots$

32 Oblique 3 D Subglacial Topography for Figure $29 \ldots \ldots \ldots$

33 Oblique 3 D Subglacial Topography for Figure $30 \ldots \ldots$

34 Maximum Arctic Ice Flow When Dust Dominates $\ldots \ldots \ldots \ldots \ldots$

35 A Version of Figure 34 Without Basal Sliding in Norway . . . . . . . . . 109

36 Arctic Model Input and Output When Tilt Modifies Dust . . . . . . . 110

37 Arctic Flotation Ice Volume Over Time When Tilt Modifies Dust . . . . . . 111

38 Arctic Glaciation Cycle When Tilt Modifies Dust . . . . . . . . . . . . . 112

39 Maximum Arctic Ice Flow When Tilt Modifies Dust $\ldots \ldots \ldots \ldots$

40 A Version of Figure 39 Without Basal Sliding in Norway . . . . . . . . . . 124

41 Arctic Model Input and Output When Tilt Dominates . . . . . . . . . 125

42 Arctic Flotation Ice Volume Over Time When Tilt Dominates $\ldots . \ldots \ldots 126$ 
43 Arctic Ice Thicknesses and Elevations

Over Time When Tilt Dominates ... . . . . . . . . . . . . . . . . . . 127

44 Maximum Arctic Ice Flow When Tilt Dominates . . . . . . . . . . . . . . . . 141

45 Oblique $3 \mathrm{D}$ View of Figure $44 \ldots \ldots \ldots \ldots \ldots \ldots \ldots \ldots \ldots \ldots \ldots$

46 The $x, y$ Coordinate System for Antarctica $\ldots \ldots \ldots \ldots \ldots \ldots \ldots$

47 Present-Day Ice Elevations in Antarctica . . . . . . . . . . . . . . . 144

48 Best-Fit of Modeled to Actual Antarctic Ice Elevations . . . . . . . . . . . 144

49 Elevation Difference Between Figures 47 and $48 \ldots \ldots \ldots \ldots \ldots$

50 Fractional Velocity by of Basal Sliding in Present-Day Antarctic . . . . . . . 145

51 Values of Flow Law Constants in Present-Day Antarctica . . . . . . . . . 146

52 Values of Sliding Law Constants in Present-Day Antarctica . . . . . . . . 146

53 Antarctic Ice Volume Changes Over Time . . . . . . . . . . . 147

54 Antarctica for a South Pole Snowline at $-3000 \mathrm{~m}$ and No Calving . . . . . . 148

55 Elevation Differences Between Figures 47 and $54 \ldots \ldots \ldots \ldots \ldots 148$

56 Antarctica for a South Pole Snowline at $-2000 \mathrm{~m}$ and No Calving . . . . . . . 149

57 Elevation Differences Between Figures 47 and $56 \ldots \ldots \ldots \ldots \ldots$

58 Antarctic Model Input and Output When Tilt Dominates . . . . . . . . . 150

59 Antarctic Flotation Ice Volume Over Time When Tilt Dominates . . . . . . 151

60 Antarctic Ice Thicknesses and Elevations

Over Time When Tilt Dominates ... . . . . . . . . . . . . . . . . . 152 


\section{TABLES}

1 Limiting Equations for Steady-State Temperature Profiles Through an Ice Slab Experiencing Various Creep Conditions . . . . . . . . . . 20

2 The Effect of Snowline Depression on the Dimensions of the Antarctic lce Sheet . . . . . . . . . . . . . . . . . . 46 


\section{INTRODUCTION}

The U.S. Department of Energy is currently involved in a search for a site to locate a high-level nuclear waste repository. At this time the Yucca Mountain site near Las Vegas, Nevada, is under initial consideration. To provide a basis for the selection of a repository location, an extensive amount of site characterization studies need to be completed. One of the concerns to be addressed by these studies is the impact of any long-term climate changes on ground-water recharge. Because of the long-term storage time period required of nuclear waste (thousands of years), global climate changes and their effect on precipitation must be considered.

To develop data and information on potential global climate changes, YMPO is funding PNL to design and manage a global climate modeling task to provide boundary condition data for regional climate modeling. Part of the PNL plan requires the development of a global ice sheet model to forecast the configuration of ice sheet advance and retreat for specific climate scenarios. This work was contracted to the University of Maine at Orono, ME for a three-year period. This report presents the final results of the three-year global ice sheet modeling work as discussed below:

\section{FIRST YEAR WORK}

During the first year we initially reconstructed ice sheets at the last glacial maximum using our steady-state, finite-difference flowband model, using massbalance equations fitted to data from present-day glaciers that occupy climatic zones appropriate to those associated with Wisconsin/Weichselian ice sheets. We presented the theoretical and programming basis for a time-dependent, finite-element gridpoint model that had both flowband and map-plane solutions that would be employed in our year-three modeling. We investigated calving dynamics for ice walls along ice-sheet margins grounded in water, so that these calving ice walls could be included with surface melting as ice ablation mechanisms when our mass-balance equations were incorporated into our finite-element model. 


\section{SECOND YEAR WORK}

A theory for the dynamics of ice streams was developed, since ice streams discharge some 90 percent of ice from present-day ice sheets and are therefore the key to understanding the dynamics of ice sheets. The mass-balance equations developed for the finite-difference model were modified for the finite-element model so that net accumulation and ablation rates could be specified model input at each gridpoint instead of along flowlines. Third, the time dependent, finite-element gridpoint model was used in its map-plane solution to reconstruct ice sheets at the last glacial maximum for comparison with those reconstructed by the steady-state, finite-difference flowband model, using the same mass-balance input for both models, as a reliability test for model input.

\section{THIRD YEAR WORK}

Analytical solutions were developed for heat flow through ice slabs moving on a fractionless bed for a variety of surface and basal mass-balance conditions. These solutions provided guidance for using the flowband solution of the time-dependent, finite-element gridpoint model to simulate advance and retreat of ice lobes in response to changing surface accumulation/ablation rates and basal freeze/thaw rates. Surface ablation rates were supplemented by ice calving rates from ice walls grounded in water of variable depth. This work was undertaken to provide the physical and mathematical basis from glaciology for a "dust machine hypothesis" we have proposed to enable the map-plane solution of our time-dependent, finite-element gridpoint model to duplicate the maximum extent of ice sheets during the Wisconsin/Weichselian glaciation cycle.

The map-plane solution of the time-dependent, finite-element gridpoint model was used to simulate advance and retreat of Northern Hemisphere ice sheets for glaciation cycles of both the Late Quaternary and the Early Quaternary. Late Quaternary glaciation cycles were about 100,000 years long and ended as abrupt terminations. Our model was able to duplicate these features only if insolation 
variations controlled by the 41,000-year and 21,000-year cycles of tilt and precession of Earth's rotation axis were strongly modified by upper-atmosphere variations in planetary albedo caused by the ice sheets themselves, based on the dust machine hypothesis. Early Quaternary glaciation cycles were about 40,000 years long, with advance and retreat of ice sheets restricted to high latitudes. Our model could duplicate these features using only the 41,000-year cycle of axial tilt to control the rise and fall of snowlines over the ice sheets. This implies that Milankovitch insolation forcing could account for Early Quaternary glaciations in the Northern Hemisphere, but it does not preclude additional forcing by the dust machine.

The map-plane solution of the time-dependent, finite-element gridpoint model was used to simulate advance and retreat of the Antarctic Ice Sheet for glaciation cycles in the Late Quaternary, Early Quaternary, and Late Tertiary. Late Quaternary fluctuations of the Antarctic Ice Sheet were controlled almost wholly by changing sea level in our model, since the snowline was too low for mass balance to be affected much by Milankovitch insolation cycles. Hence, mechanisms controlling advance and retreat of Northern Hemisphere ice sheets also controlled fluctuation of the Antarctic Ice Sheet were controlled by the 41,000-year Milankovitch insolation cycle, since ice sheets in both the Northern and Southern Hemispheres responded to changes in snowline elevations and sea level that were linked to the axial tilt cycle and were therefore synchronous in both hemispheres. Late tertiary fluctuations of the Antarctic Ice Sheet were controlled entirely by snowline variations linked to the 41,000-year cycle of axial tilt. Variations in sea level were linked only to the Antarctic Ice Sheet, since we did not permit Northern Hemisphere ice sheets in this simulation. The West Antarctic ice Sheet disintegrated during the warm hemi-cycle and reappeared during the cold hemicycle. Changes in the East Antarctic Ice Sheet were relatively minor.

The Late Quaternary, Early Quaternary, and Late Tertiary glaciation cycles simulated by the map-plane solution of our time-dependent, finite-element gridpoint model were meant to be analogs for glaciation cycles in the next 100,000 years for 
which anthropogenic climatic warming is nil, moderate, and excessive, respectively. These constitute our most probable, moderately probable, and least probable scenarios for future glaciations.

The most important unresolved questions arising from our study concern the validity of our dust machine hypothesis, and incorporating time-dependent isostatic adjustments into the model. Although beyond the scope of the present study, the second question is especially important for linking glacioisostatic rebound rates to changes in snowline elevation over ice sheets and water depth in proglacial lakes, so that ablation rates and calving rates during ice-sheet retreat can be modeled more accurately. 


\section{IHE DUST MACHINE HYPOTHESIS}

The distinguishing characteristics of Late Quaternary glaciations are their terminations at intervals of approximately 100,000 years (Broecker and van Donk, 1970). As reflected in the oxygen isotope stratigraphy of ocean-floor sediments, ice sheets built up in fits and starts, with advance and retreat episodes correlating with cycles of 41,000 and 21,000 years of insolation controlled by these respective periodicities of Earth's axial tilt and precession, referred to as Milankovitch forcing (Hays and others, 1976). The tilt insolation cycle dominates at high latitudes, whereas the precession insolation cycle dominates at mid latitudes and is the mean for insolation peaks at 23,000 and 19,000 years (Imbrie and others, 1984). After about 80,000 years of these glacial stadials and interstadials, however, all ice sheets but those on Greenland and Antarctica collapsed within 10,000 years, followed by an interglaciation lasting another 10,000 years before a new glaciation cycle began.

The most likely glaciation over the next 100,000 years would be a repetition of the seven Late Quaternary glaciation cycles, each of which lasted about 100,000 years and ended in a termination lasting 10,000 years or less. Making this our most probable future glaciation scenario, therefore, requires an ice-sheet model that produces terminations every 100,000 years as a first-order feature, upon which are superimposed stadials and interstadials having approximate periodicities of 40,000 years at high latitudes and 20,000 years at mid latitudes as a second-order feature. To control this ice-sheet model, we will use the dated history of the last Late Quaternary glaciation cycle, the Wisconsin/Weichselian glaciation, especially its termination from 14,000 to 6000 BP (years before present). Early Quaternary and Late Tertiary glaciations had a cycle of about 40,000 years that can probably be explained by the axial tilt cycle. Something more is required to explain Late Quaternary glaciations. We propose a dust machine.

As revealed by analyses of climatic records through the Greenland and Antarctic ice sheets, especially from the Soviet corehole at Vostok Station $\left(78.5^{\circ} \mathrm{S}\right.$, $108.5^{\circ} \mathrm{E}$ ) in Antarctica, the termination of the last glaciation has a strong correlation with a gradual increase in atmospheric carbon dioxide from 14,000 to $8000 \mathrm{BP}$ and an abrupt decrease in atmospheric dust from 14,000 to 12,000 BP, (Broecker and Denton, 1989). The low carbon-dioxide and high dust concentrations appeared somewhat 
after the beginning of the Wisconsin/Weichselian glaciation cycle, as recorded in the oxygen isotope stratigraphy of the Vostok core.

Mercer (1984) noted that the Wisconsin/Weichselian termination was synchronous in both the Northern and Southern Hemispheres, and in both mid and high latitudes, whereas the precession insolation cycle was out-of-phase in these hemispheres and was not completely in-phase with the tilt insolation cycle in the Northern Hemisphere, where collapse of continental ice sheets was complete. He concluded that insolation variations could not account for the global timing of the last termination, so other processes that were synchronous globally and were perhaps linked to Northern Hemisphere insolation were responsible. Broecker and Denton (1989) reinforced this conclusion and speculated that flip flops in deep ocean circulation originating in the North Atlantic may be one such process.

We propose the dust machine hypothesis as an alternative process originating in the Northern Hemisphere and producing a synchronous global climatic response. The dust machine is a possible consequence of the "dirt machine" that produced moraines along the southern margin of Northern Hemisphere ice sheets (Kotef, 1974). The dust machine hypothesis proposes that Late Quaternary glaciations have the following sequence of events.

1. Northern Hemisphere ice sheets originate as marine ice sheets on Arctic continental shelves, where reduction of insolation caused by the 41,000 year axial tilt cycle depresses the snowline enough to allow sea ice to thicken and ground in water less than $200 \mathrm{~m}$ deep in a few centuries. Marine ice domes then develop from surface precipitation because the snowline is below sea level on these continental shelves.

2. Marine ice sheets on Arctic continental shelves transgress onto the Eurasian and North American continents as the snowline continues to fall during the low-insolation hemicycle of axial tilt. The advancing continental ice sheets move southward across permafrost, so basal traction is high. High basal traction and a narrow summer ablation zone along the southern ice-sheet margins give these margins a steep surface slope.

3. As the continental ice sheets pass from the Angara, Baltic, and Laurentian granitic shields onto softer sedimentary rocks and their thicker soil cover, permafrost beneath the ice sheets begins to thaw as increasingly thick ice moves over a given area, causing increasing depression of the melting point at the bed and increasing insulation and frictional heating from overlying moving ice. South of the shields, the subglacial bed 
becomes a mix of sticky frozen spots and slippery thawed spots, in which thawed permafrost is slippery because melting interstitial ice produces a high pore water pressure that mobilizes the unconsolidated sediments being sheared by overlying ice. These are the conditions for a basal melting zone.

4. The southward gradation from sticky spots in a slippery matrix to slippery spots in a sticky matrix beneath the ice sheet as ice thins and slows toward the southern ice margin is the condition for a basal freezing zone. With net basal freezing, a thickening layer of debris-charged regelation (refrozen) ice forms at the base of the ice sheet. This layer outcrops in the surface ablation zone along the southern ice-sheet margin, which is still advancing over permafrost.

5. Glacial flour is a major constituent of regelation ice. It was produced in the basal melting zone where the ice sheets were sliding over exposed bedrock on the granitic shields, and was transported into the basal freezing zone further south. This glacial flour is carried in suspension from subglacial drainage channels and melting surface ice in the ablation zone, where it accumulates on outwash plains along the southern ice-sheet margin. This transport of eroded basal rock and soil to the ice-sheet margin in continuous conveyor-belt fashion has been called the "dirt machine" (Kotef, 1974).

6. Katabatic winds, possibly in excess of $100 \mathrm{~km} / \mathrm{hr}$ for weeks on end, probably flowed down the southern margins of Northern Hemisphere ice sheets just as they flow off the Antarctic lce Sheet today (Parish, 1980). These winds may have produced nearly continuous dust storms along the southern ice-sheet margins as they entrained glacial flour deposited in the outwash plains. Since the jet stream also tracked along the southern margin of North Hemisphere ice sheets, especially the Laurentide Ice Sheet (Manabe and Broccoli, 1985), glacial four in lower-atmosphere dust storms would become incorporated into global upper-atmospheric circulation, where it would increase planetary albedo by providing nuclei for upper-atmosphere cloud formation worldwide. We call this the "dust machine."

7. In contrast to lower-atmosphere cloudiness which absorbs long-wave terrestrial radiation and warms the atmosphere, upper atmosphere cloudiness reflects short-wave solar radiation and cools the atmosphere. This global cooling caused by atmospheric dust overpowers insolation cycles of warming and cooling caused by variations in the tilt and precession of Earth's rotation axis.

8. Insolation in mid-latitudes controlled by the precession cycle during the last glaciation began to increase by 22,000 BP and peaked at 11,000 BP in the Northern Hemisphere (Broecker and Denton, 1989), yet the Lau- 
rentide (Mayewski and others, 1981) and Scandinavian (Andersen, 1981 ) ice-sheet margins held close to their 20,000 BP maximum southern extents until 14,000 BP. A glaciological explanation for this would be a more rapid southern velocity of ice being offset by more rapid southern ablation, such that the ice margin neither advanced nor retreated by great amounts. The more rapid ice velocity would occur as the ice sheet advanced over permafrost that became less continuous and more sporadic toward warmer lower latitudes, so the bed became more slippery. The more rapid ice ablation would occur as the snowline rose in response to both lower latitudes and the warming hemicycle of precession-controlled insolation.

9. Decreased bed traction and increased surface ablation would transform the southern ice margin from sheet flow to stream flow, especially in Laurentide ice lobes south of the Great Lakes (Hughes, 1985, 1987), which would approach shelf flow if ice lobes merged. Boulton and Jones (1979) maintained that this was a common condition along southern margins of Northern Hemisphere ice sheets just prior to the last termination. This condition would produce a broad zone of thin, fast-moving ice on a slippery bed.

10. Termination of the last glaciation would occur when the broad zone of fast-moving ice became thin enough to conduct basal heat to the surface rapidly enough to extract the latent heat of freezing from the bed. At this critical ice thickness, the bed would freeze and suddenly provide traction too great to be overcome by the gravitational pulling force in the thin ice. The greatly reduced ice velocity along the southern ice-sheet margin would no longer offset the increasing melting rate, and the ice sheet would retreat.

11. Retreat of southern terrestrial ice-sheet margins in the Northern Hemisphere would be irreversible because the retreating margin would expose a bed that was isostatically depressed by the former overburden of ice. Hence ablation meltwater would accumulate in proglacial lakes where ablation rates would be accelerated by ice calving and glacial flour would remain suspended in water instead of being entrained into the atmosphere by katabatic winds and the jet stream. Dust flushed out of the upper atmosphere by precipitation would no longer be replaced because the dust machine was turned off, so upper-atmosphere cloudiness would decrease and Earth would warm globally. Hence, all glaciers in both hemispheres would begin to retreat simultaneously, as Mercer (1984) observed.

12. Retreat of northern marine ice-sheet margins would also be irreversible, as rising sea level from retreating southern terrestrial ice-sheet margins would float the grounding lines of marine ice streams over their sills on the outer continental shelf (Hughes and others, 1977; Denton and Hughes, 1981; Hughes, 1987). The marine grounding line would then 
retreat on a downsloping bed, collapsing marine ice and accelerating the rate of rising sea levél, in positive feedback.

We have made progress in quantifying most of the dozen steps in the dust machine hypothesis. We will concentrate on the glaciological mechanisms, for which we have some expertise, and leave the atmospheric mechanisms to experts in that arena. Steps 1 through 4 are quantified by our time-dependent, finite-element model in its gridpoint map-plane solution (Fastook and Chapman, 1989). Step 5 is quantified by our time-dependent, finite-element model in its flowband solution, which is presently being improved to allow temperature and velocity fields to be computed in longitudinal cross-sections (Lingle and others, 1989). We leave steps 6 and 7 to atmospheric scientists. Steps 8 through 10 are quantified by combining the map-plane and flowband solutions of our time-dependent, finite-element model. In step 11, we have quantified the rate of ice-sheet calving into proglacial lakes (Hughes, 1989; Hughes and Nakagawa, 1989). In step 12, we have quantified the rate of collapse for marine ice sheets (Stuiver and others, 1981; Fastook, 1984), as have others, notably Thomas (1977), Thomas and Bentley (1978); Lingle (1984), Budd and others, (1987), MacAyeal (1989), and Lindstrom and MacAyeal (1989). Steps 11 and 12 are incorporated into our time-dependent, finite-element model.

\section{BASAL MASS BALANCE OF AN ICE SLAB ON A LOW-TRACTION BED}

Results from the flowline longitudinal cross-section solution of the time-dependent, finite-element model for stream flow along southern margins of Northern Hemisphere ice sheets, in which regelation ice forms at the bed and an ablation zone exists on the surface, can be verified by comparison with the analytical steady-state solution of heat and mass transfer in a creeping ice slab of constant thickness on a low-traction bed. This solution and results from it will now be presented.

Stream flow develops when basal melting, either of basal ice or of the ice fraction in thawing subglacial permafrost, produces a low-traction bed that allows ice to creep rapidly. This converts the convex surface of sheet flow into the concave surface of stream flow, thereby reducing ice thickness and extending ice length along the flowline. An ice lobe of stream flow extends the ice-sheet margin, but basal meltwater is then able to drain around the perimeter of the ice lobe, thereby re-establishing basal traction that converts the concave surface of stream flow back to the convex surface of sheet flow at the lobe terminus (Hughes, 1981, 1985). The thinning ice toward the 
lobe terminus also allows basal heat to be conducted more rapidly to the surface, causing basal freezing and a further increase in basal traction. The increase of basal traction converts extending stream flow into compressive sheet flow toward the lobe terminus.

A first-approximation to the above conditions is provided by an analytical solution of a sliding ice slab in which the slab begins with surface accumulation and basal melting zones and ends with surface ablation and basal freezing zones. Rock ground into glacial flour in the basal melting zone is dragged by sliding ice at the ice-bed interface into the basal freezing zone, where it is incorporated with regelation ice into the sliding ice slab. The glacial flour is released to the atmosphere when regelation ice outcrops at the slab terminus and melts in summer or sublimates in winter.

Surface accumulation and ablation rates are typically much greater than based thawing and freezing rates, so the upslope part of the ice slab will be in extending flow and the downslope part of the slab will be in compressive flow. Creep in the slab will be controlled by the flow law for glacial ice (Glen, 1955; Budd, 1969):

$$
\dot{\varepsilon}=(\tau / A)^{n}=\left(\tau / A_{0}\right)^{n} \exp (\mathrm{a} \Delta T)
$$

where $\dot{\varepsilon}$ is the effective strain rate, $\tau$ is the effective shear stress, $n$ is a viscoplastic exponent, and $\mathrm{A}$ is an ice hardness parameter that depends on ice fabric, texture, and purity, represented by $A_{0}$, and ice temperature represented by thermal activation constant $a$ and temperature $\Delta T$ below the melting point.

When the ice slab rests on a bed having slope $\alpha$, the dominant component of $\tau$ is shear stress $\sigma_{x z}$, where $x$ is parallel to the bed slope and positive downslope, and $z$ is normal to the bed and positive upward. Therefore:

$$
\tau \approx \sigma_{x z}=\rho g(h-z) \sin \alpha
$$

where $\rho$ is ice density, $g$ is gravity acceleration, $h$ is slab thickness, and $z$ is distance above the bed. Constant slab thickness is maintained by upslope thinning caused by extending flow and basal melting being offset by surface accumulation, and downslope thickening caused by compressive flow and basal freezing being offset by surface ablation. These offsets are exact for steady-state conditions. 


\section{Velocity Field in the Ice Slab}

Velocity components parallel to the $x, y$, and $z$ rectilinear axes are $u, v$, and $w$, respectively, where $x$ and $y$ are parallel and transverse to flow and $z$ is vertical, $u_{0}$ is the basal velocity of the ice slab at $z=0, u_{c}$ is the creep velocity within ice thickness $h$, $u_{s}$ is the shear velocity within unlithified material (till) of depth $d$ to bedrock beneath the ice, $v$ is negligible, $w_{t}$ is the top accumulation $\left(-w_{t}\right)$ or ablation $\left(+w_{t}\right)$ rate for the slab at $z=h$, and $w_{b}$ is the bottom freezing $\left(+w_{b}\right)$ or thawing $\left(-w_{b}\right)$ rate for the slab at $z=0$. Figure 2 shows ice flowlines in the slab for various combinations of $w_{t}$ and $w_{b}$. For $a$ low-traction bed, $u$ is nearly constant with $z$ and $w$ changes linearly with $z$ in the range $0 \leq z \leq h$. These conditions are approached when $u_{c}$ is mostly due to longitudinal extension or compression in the ice. Therefore:

$$
\begin{aligned}
& u \approx u_{0} \approx u_{c} \\
& v \approx 0 \\
& w \approx w_{b}+\left(w_{t}-w_{b}\right) z / h
\end{aligned}
$$

Assume that $w$ is constant with $x$. Since conservation of volume requires that $(\partial u / \partial x)+(\partial v / \partial y)+(\partial w / \partial z)=0$, Equations $(3)$ require that:

$$
u \approx u_{0} \approx \int_{0}^{x}(\partial u / \partial x) d x=-\int_{0}^{x}(\partial w / \partial z) d x=-\left(w_{t}-w_{b}\right) x / h
$$

where the till becomes thawed at $x=0$, thereby initiating the creep condition $u_{c} \approx u_{0}$ in the ice slab. The ice slab moves as a rigid body when $w_{t}=w_{b}$, moves in extending flow when $w_{t}<w_{b}$, and moves in compressive flow when $w_{t}>w_{b}$.

Particle velocities along an ice flowline are always in a direction tangent to the flowline. Hence, the equation of a flowline has the form $d z / d x=w / u$, and using Equations (3c) and (4):

$$
\frac{d z}{d x}=\frac{w}{u}=\frac{h w_{b}+\left(w_{t}-w_{b}\right) z}{h u_{0}-\left(w_{t}-w_{b}\right) x}
$$


The flowline curves are then obtained by integrating Equation (5):

$$
z=\frac{h k}{h u_{0}-\left(w_{t}-w_{b}\right) x}-\frac{h w_{b}}{\left(w_{t}-w_{b}\right)}
$$

where $k$ is the constant of integration. As seen in Figure 2, these curves are hyperbolas which degenerate into straight lines of slope $w / u_{0}$ when $w_{t}=w_{b}$.

\section{Temperature Field in the Ice Slab}

Temperatures inside an ice slab creeping in the $x z$ plane on a low-traction bed must obey the heat balance equation (Paterson, 1981, p. 197-209):

$$
C\left(\frac{d T}{d t}\right)+K\left(\frac{d^{2} T}{d x^{2}}\right)+K\left(\frac{d^{2} T}{d z^{2}}\right)-C u\left(\frac{d T}{d x}\right)-C w\left(\frac{d T}{d z}\right)-\left(\frac{\dot{\varepsilon} \tau}{J}\right)=0
$$

where $t$ is time, $T$ is temperature, $C$ is heat capacity, $K$ is thermal conductivity, $\tau$ is effective shear stress, $\dot{\varepsilon}$ is effective strain rate, and $J=41.8 \times 10^{6} \mathrm{erg} / \mathrm{cal}$ is the mechanical equivalent of heat. Heat balance in Equation (7) includes heat transfer due to climate change (first term), longitudinal conduction (second term), vertical conduction (third term), longitudinal convection (fourth term), vertical convection (fifth term), and internal frictional heating (sixth term).

Steady-state heat transfer occurs when $(d T / d t)=0$. Longitudinal conduction can be ignored in a long slab since $\left(d^{2} T / d x^{2}\right)<<\left(d^{2} T / d z^{2}\right)$. Internal frictional heating is confined to shear in the basal till layer, above which $\dot{\varepsilon}$ is small enough to be ignored. If the coordinate origin moves downslope at velocity $u$, the effects of longitudinal heat flow for ice advecting from higher to lower elevations will be experienced as ice warming even in steady-state flow. In this case the substitution $u=d x / d t$ is made in Equation (7), which then becomes:

$$
C\left(\frac{d T}{d t}\right)_{c}-C\left(\frac{d T}{d t}\right)_{a}+K\left(\frac{d^{2} T}{d z^{2}}\right)-C w\left(\frac{d T}{d z}\right)=0
$$

where $(d T / d t)_{c}$ is from climatic change and $(d T / d t)_{a}$ is from ice advection. 
In the range $0 \leq z \leq h$ and in the absence of climatic change or significant advection, Equation ( 8 ) becomes:

$$
\frac{d^{2} T}{d z^{2}}=\frac{w}{k} \frac{d T}{d z}
$$

where $\kappa=K / C$ is the thermal diffusivity. Integrating Equation (9) from 0 to $z$;

$$
\frac{d T}{d z}=\frac{\left(T_{h}-T_{0}\right) \int_{0}^{z}(w / k) d z}{\int_{0}^{h}\left[\exp \int_{0}^{z}(w / \kappa) d z\right] d z}
$$

where $T_{h}$ and $T_{0}$ are temperatures at $z=h$ and $z=0$, respectively. Integrating Equation (10) from 0 to $z$ :

$$
\frac{T-T_{0}}{T_{h}-T_{0}}=\frac{\int_{0}^{z}\left[\exp \int_{0}^{z}(w / \kappa) d z\right] d z}{\int_{0}^{h}\left[\exp \int_{0}^{z}(w / \kappa) d z\right] d z}
$$

Solutions of Equation (11) using Equation (3c) will presently be given. The effects of climatic change and ice advection can be superimposed on these solutions by considering the temperature gradients at $z=0$ and $z=h$. These effects will be most pronounced near the top surface where they impart the temperature gradient:

$$
(d T / d z)_{t}=\left[(d T / d t)_{c}-(d T / d t)_{a}\right] / w_{t}=\left[(d T / d t)_{c}-G\left(w_{h}+u \sin \alpha\right)\right] / w_{t}
$$

Here $G$ is the gradient of mean ice surface temperature with elevation (the adiabatic lapse rate), $w_{t}$ is the ice surface accumulation or ablation rate needed to keep $h$ constant during steady-state flow (positive for ablation and negative for accumulation), $w_{h}$ is the rate of change of slab thickness due to departures from steady-state flow (positive for thickening and negative for thinning), $\alpha$ is ice surface slope (negative), and $(d T / d t)_{c}$ is the rate of change of mean climatic temperature at constant elevation 
above sea level which causes departures from steady-state flow (positive for climatic warming and negative for climatic cooling).

\section{Ice Slab Creeping in a Cooling Environment}

In this case $w_{h}$ is positive and $(d T / d t)_{c}$ is negative. Since $G$ is negative, $(d T / d z)_{t}$ in Equation (12) is maximized because advection cooling reinforces climatic cooling. This gradient is positive in the upslope accumulation region where $w_{t}$ is negative (temperature decreases with depth below the top surface), and negative in the downslope ablation region where $w_{t}$ is positive (temperature increases with depth below the top surface). Ice gained in the accumulation region upstream of the equilibrium line at $w_{t}=0$ exceeds ice lost in the ablation region downstream of the equilibrium line, so the ice slab advances from net extending flow.

\section{Ice Slab Creeping in a Stable Environment}

In this case both $w_{h}$ and $(d T / d t)_{c}$ are zero. Since $G$ is negative, $(d T / d z)_{t}$ in Equation (12) is moderate because only advection cooling exists. This gradient is positive in the upslope accumulation region and negative in the downstream ablation region. Ice gained in the accumulation region where $w_{t}<0$ equals ice lost in the ablation region where $w_{t}>0$, so the ice slab is in steady-state equilibrium.

\section{Ice Slab Creeping in a Warming Environment}

In this case $w_{h}$ is negative and $(d T / d t)_{c}$ is positive. Since $G$ is negative, $(d T / d z)_{t}$ in Equation (12) is minimized because advection cooling tends to cancel climatic warming. This gradient is positive in the upslope accumulation region and negative in the downslope ablation region. Ice lost in the ablation region exceeds ice gained in the accumulation region, so the ice slab retreats from net compressive flow.

\section{Basal Freeze-Thaw Rates in the Ice Slab}

In the absence of accumulation or ablation at the top and freezing or thawing at the bottom of a sloping slab of ice, creep will reduce the surface slope by lowering the upslope surface and raising the downslope surface. Downslope creep occurs only because gravity acceleration has a downslope component. Reduction of the surface slope reduces downslope creep. Downslope creep can only be maintained if the 
surface slope and the thickness of the slab are maintained by an upslope accumulation rate $-w_{t}$ at the top and freezing rate $+w_{b}$ at the bottom and by a down-slope ablation rate of $+w_{t}$ at the top and thawing rate $-w_{b}$ at the bottom. Upslope accumulation at the top is accomplished by depositing snow on the surface, and down-slope ablation at the top is accomplished by surface melting followed by evaporation or runoff of meltwater. On the other hand, upslope freezing at the bottom and down-slope thawing at the bottom require adding or removing a basal ice layer that either thins the basal till layer (freezing) or thickens and mobilizes it by adding water to it (thawing). Hence, $u_{s}$ is decreased by freezing and increased by thawing of basal ice. However, basal freeze-thaw rates cannot be treated in isolation from surface conditions of upslope creep thinning and accumulation and downslope creep thickening and ablation. These relationships will now be investigated.

When basal melting of the ice slab mobilizes the underlying till by saturating it with water, bed traction is lowered, thereby allowing an ice slab having a given thickness $h$ and surface slope $\alpha$ to thin by stream flow rather than sheet flow. Internal deformation of the type $\partial u / \partial z$ is probably concentrated in water-saturated till of depth $d$. Internal deformation of the type $\partial u / \partial x$ is probably constant through ice thickness $h$, and is extending flow in the upslope region of creep thinning offset by accumulation and compressive flow in the downslope region of creep thickening offset by ablation. Within the ice slab itself, deformation $\partial u / \partial x$ is approximated by shelf flow. This type of deformation can occur even if the slab is not sloping, provided that it has a free terminal boundary in the $x$ direction. The slab then creeps almost like a freely floating ice shelf, a solution published by Weertman (1957a). The longitudinal creep rate when the slab is an unconfined horizontal layer is:

$$
\partial u / \partial x=\left[\rho g h\left(1-\rho / \rho_{o}\right) / \hbar \bar{A}\right]^{n}
$$

where $\rho_{o}$ is the density of the material surrounding and underlying a slab of density $\rho$ such that $p_{0}>p, f=4$ when horizontal creep is along $x$ only, $f=2\left[3^{(n+1) / 2}\right]$ when horizontal creep is radially divergent, and $\bar{A}$ measures the hardness $A$ of the ice slab averaged through $\mathrm{h}$ :

$$
\bar{A} h=\int_{0}^{h} A d z
$$


In order to compute $\bar{A}$ from Equation (14), the variation of $A$ with $T$ is obtained from Equation (1) and the variation of $T$ with $z$ must be determined when $\partial u / \partial z$ is nil. This is done by solving Equation (11), where $T_{t}=T_{h}$ and $T_{b}=T_{0}$, so that:

$$
\theta=\frac{T-T_{b}}{T_{t}-T_{b}}=\frac{\int_{0}^{z}\left[\exp \int_{0}^{z}(w / k) d z\right] d z}{\int_{0}^{h}\left[\exp \int_{0}^{z}(w / \kappa) d z\right] d z}
$$

where $\theta$ is the normalized temperature. Zotikov $(1961,1963)$ solved this equation.

Solutions of Equation (15) need the variation of $w$ with $z$. The procedure involves error integrals and is outlined in the appendix. It is convenient to introduce the dimensionless ratios $r=w_{b} / w_{t}, R=w h / \kappa, R_{t}=w_{t} h / \kappa, R_{b}=w_{b} h / \kappa$, and $Z=z / h$.

\section{Temperature Profiles Through an Ice Slab in Extending Flow}

Surface accumulation greater than basal thawing, or basal freezing greater than surface ablation, is required to maintain constant thickness for an ice slab creeping in extending flow. This condition is satisfied for many combinations of $w_{t}$ and $w_{b}$. Each combination produces a characteristic temperature profile.

The ice slab cools from the top down when ice accumulates on the top faster than ice melts from the bottom, so that $r<1$. In this case

$$
w=-w_{b}+\left(w_{t}-w_{b}\right) z / h=-w_{t}[r-(1-r) Z]
$$

Substituting Equation (16) into Equation (15) and solving gives:

$$
\theta=\frac{\operatorname{erf}\left\{\left(R_{t} / 2\right)^{1 / 2}\left[Z(1-r)^{1 / 2}+r /(1-r)^{1 / 2}\right]\right\}-\operatorname{erf}\left\{\left(R_{t} / 2\right)^{1 / 2} r /(1-r)^{1 / 2}\right\}}{\operatorname{erf}\left\{\left(R_{t} / 2\right)^{1 / 2}\left[(1-r)^{1 / 2}+r /(1-r)^{1 / 2}\right]\right\}-\operatorname{erf}\left\{\left(R_{t} / 2\right)^{1 / 2} r /(1-r)^{1 / 2}\right\}}
$$

The ice slab warms from the bottom up when water freezes onto its bottom faster than ice ablates from its top, so that $r>1$. In this case:

$$
w=w_{b}-\left(w_{b}-w_{t}\right) z / h=w_{t}[r-(r-1) Z]
$$


Substituting Equation (18) into Equation (15) and solving gives:

$$
\theta=\frac{\operatorname{erf}\left\{\left(R_{t} / 2\right)^{1 / 2}\left[Z(r-1)^{1 / 2}-r /(r-1)^{1 / 2}\right]\right\}+\operatorname{erf}\left\{\left(R_{t} / 2\right)^{1 / 2} r /(r-1)^{1 / 2}\right\}}{\operatorname{erf}\left\{\left(R_{t} / 2\right)^{1 / 2}\left[(r-1)^{1 / 2}-r /(r-1)^{1 / 2}\right]\right\}+\operatorname{erf}\left\{\left(R_{t} / 2\right)^{1 / 2} r /(r-1)^{1 / 2}\right\}}
$$

The ice slab cools from the top down and warms from the bottom up when ice accumulates on the top and water freezes on the bottom. Ice moves down through thickness $h /(1+r)$ and moves up through thickness $r h /(1+r)$. The level where downward and upward flow converges has velocity $w=0$ and temperature $T=T_{0}$.

Substituting $r h /(1+r)$ for $z=h$ and setting $w_{t}=0$ in Equation (19) gives the temperature profile for $0 \leq z \leq r h /(1+r)$ when $T_{0}$ replaces $T_{t}$ :

$$
\frac{T-T_{b}}{T_{0}-T_{b}}=\frac{\operatorname{erf}\left\{\left(R_{t} / 2\right)^{1 / 2}\left(\frac{r}{1+r}\right)^{1 / 2}\left[z\left(\frac{1+r}{r}\right)-1\right]\right\}+\operatorname{erf}\left\{\left(R_{t} / 2\right)^{1 / 2}\left(\frac{r}{1+r}\right)^{1 / 2}\right\}}{\operatorname{erf}\left\{\left(R_{t} / 2\right)^{1 / 2}\left(\frac{r}{1+r}\right)^{1 / 2}\right\}}
$$

Substituting $r h /(1+r)$ for $z=0$ and setting $w_{b}=0$ in Equation (18) gives the temperature profile for $r h /(1+r) \leq z \leq h$ when $T_{0}$ replaces $T_{b}$ :

$$
\frac{T-T_{0}}{T_{t}-T_{0}}=\frac{\operatorname{erf}\left\{\left(R_{t} / 2\right)^{1 / 2}\left(\frac{r}{1+r}\right)^{1 / 2}\left[Z-\left(\frac{r}{1+r}\right)^{1 / 2}\right]\right\}}{\operatorname{erf}\left\{\left(R_{t} / 2\right)^{1 / 2}\left(\frac{r}{1+r}\right)^{1 / 2}\right\}}
$$

Differentiating Equations (20) and (21) and equating the resulting temperature gradients at $T=T_{0}$ gives a smooth continuous temperature profile for which:

$$
T_{0}=T_{t} \frac{\operatorname{erf}\left\{\left(R_{t} / 2\right)^{1 / 2}\left(\frac{r}{1+r}\right)^{1 / 2}\right\}+T_{b} \operatorname{erf}\left\{\left(R_{t} / 2\right)^{1 / 2}\left(\frac{1}{1+r}\right)^{1 / 2}\right\}}{\operatorname{erf}\left\{\left(R_{t} / 2\right)^{1 / 2}\left(\frac{r}{1+r}\right)^{1 / 2}\right\}+\operatorname{erf}\left\{\left(R_{t} / 2\right)^{1 / 2}\left(\frac{1}{1+r}\right)^{1 / 2}\right\}}
$$

In all these equations erf(f) is the tabulated function (Abramowitz and Stegun, 1965):

$$
\operatorname{erf}(f)=(2 / \sqrt{\pi}) \int_{0}^{f} \exp \left(-\lambda^{2} d \lambda\right)
$$




\section{Temperature Profiles Through an Ice Slab in Compressive Flow}

Surface ablation greater than basal freezing, or basal thawing greater than surface accumulation, is required to maintain constant thickness for an ice slab creeping in compressive flow. This condition is satisfied for many combinations of $w_{t}$ and $w_{b}$. Each combination produces a characteristic temperature profile.

The ice slab warms from the top down when ice ablates from the top faster than water freezes onto the bottom, so that $r<1$. In this case:

$$
w=w_{b}-\left(w_{t}+w_{b}\right) z / h=w_{t}[r+(1-r) Z]
$$

Substituting Equation (24) into Equation (15) and solving gives:

$$
\theta=\frac{\operatorname{int}\left\{\left(R_{t} / 2\right)^{1 / 2}\left[Z(1-r)^{1 / 2}+r /(1-r)^{1 / 2}\right]\right\}-\operatorname{int}\left\{\left(R_{t} / 2\right)^{1 / 2} r /(1-r)^{1 / 2}\right\}}{\operatorname{int}\left\{\left(R_{t} / 2\right)^{1 / 2}\left[(1-r)^{1 / 2}+r(1-r)^{1 / 2}\right]\right\}-\operatorname{int}\left\{\left(R_{t} / 2\right)^{1 / 2} r /(1-r)^{1 / 2}\right\}}
$$

The ice slab cools from the bottom up when ice melts on the bottom faster than it accumulates on the top, so that $r>1$. In this case:

$$
w=\left(w_{b}+w_{t}\right) z / h-w_{b}=w_{t}[(r-1) Z-r]
$$

Substituting Equation (26) into Equation (15) and solving gives:

$$
\theta=\frac{\operatorname{int}\left\{\left(R_{t} / 2\right)^{1 / 2}\left[Z(r-1)^{1 / 2}-r /(r-1)^{1 / 2}\right]\right\}+\operatorname{int}\left\{\left(R_{t} / 2\right)^{1 / 2} r /(r-1)^{1 / 2}\right\}}{\operatorname{int}\left\{\left(R_{t} / 2\right)^{1 / 2}\left[(r-1)^{1 / 2}-r /(r-1)^{1 / 2}\right]\right\}+\operatorname{int}\left\{\left(R_{t} / 2\right)^{1 / 2} r /(r-1)^{1 / 2}\right\}}
$$

The ice slab warms from the top down and cools from the bottom up when ice ablates on the top and melts on the bottom. Ice moves up through thickness $h /(1+r)$ and moves down through thickness $r h /(1+r)$. The level where upward and downward flow diverges has velocity $w=0$ and temperature $T=T_{0}$. Substituting $r h /(1+r)$ for $z=h$ and setting $w_{t}=0$ in Equation (26) gives the temperature profile for $0 \leq z \leq r h /(1+r)$ when $T_{0}$ replaces $T_{t}$ :

$$
\frac{T-T_{b}}{T_{0}-T_{b}}=\frac{\operatorname{int}\left\{\left(R_{t} / 2\right)^{1 / 2}\left(\frac{r}{1+r}\right)^{1 / 2}\left[Z\left(\frac{r}{1+r}\right)^{1 / 2}+1\right]\right\}+\operatorname{int}\left\{\left(R_{t} / 2\right)^{1 / 2}\left(\frac{r}{1+r}\right)^{1 / 2}\right\}}{\operatorname{int}\left\{\left(R_{t} / 2\right)^{1 / 2}\left(\frac{r}{1+r}\right)^{1 / 2}\right\}}
$$


Substituting $r h /(1+r)$ for $z=0$ and setting $w_{b}=0$ in Equation (25) gives the temperature profile for $r h /(1+r) \leq z \leq h$ when $T_{0}$ replaces $T_{b}$ :

$$
\frac{T-T_{t}}{T_{t}-T_{0}}=\frac{\operatorname{int}\left\{\left(R_{t} / 2\right)^{1 / 2}\left(\frac{r}{1+r}\right)^{1 / 2}\left[Z\left(\frac{r}{1+r}\right)^{1 / 2}+1\right]\right\}}{\operatorname{int}\left\{\left(R_{t} / 2\right)^{1 / 2}\left(\frac{r}{1+r}\right)^{1 / 2}\right\}}
$$

Differentiating Equations (28) and (29) and equating the resulting temperature gradients at $T=T_{0}$ gives a smooth continuous temperature profile for which:

$$
T_{0}=T_{t} \frac{\operatorname{int}\left\{\left(R_{t} / 2\right)^{1 / 2}\left(\frac{r}{1+r}\right)^{1 / 2}\right\}+T_{b} \operatorname{int}\left\{\left(R_{t} / 2\right)^{1 / 2}\right\}}{\operatorname{int}\left\{\left(R_{t} / 2\right)^{1 / 2}\left(\frac{r}{1+r}\right)^{1 / 2}\right\}+\operatorname{int}\left\{\left(R_{t} / 2\right)^{1 / 2}\right\}}
$$

In all these equations int(f) is the tabulated function (Abramowitz and Stegun, 1965):

$$
\operatorname{int}(f)=\int_{0}^{f} \exp \left(+\lambda^{2} d \lambda\right)
$$

Figure 3 plots $\theta$ versus $z$ through an ice slab for specified values of $r, R_{t}$, and $T_{0}$ in Equations (17), (19), (20), (21), (25), (27), (28), and (29). Table 1 gives the reduced forms of these equations when top surface mass flux is zero $(r=\infty)$, bottom surface mass flux is zero $(r=0)$, top surface mass flux equals bottom surface mass flux $(r=1)$, and when top surface and bottom surface mass fluxes are both zero. Creep can obviously significantly modify the steady-state linear temperature profile through a stationary ice slab. Creep in an ice slab depends on its thickness, slope, boundary conditions, and physical properties.

\section{Basal Heat Flow for an Ice Slab in Extending Flow}

Geothermal heat and frictional heat from shear deformation of basal till are supplied to unit area of basal ice at the rate:

$$
Q_{b}=\rho H_{M} w_{b}-K(\partial T / \partial z)_{b}
$$


IABLE1 Limiting Equations for Steady-State Temperature Profiles Through an Ice Slab Experiencing Various Creep Conditions*.

Creep Condition Boundary Condition

Extending Flow

Extending Flow

Compressive Flow

Compressive Flow

Plug Flow

No Flow $w_{t}=0$

$$
\theta=\frac{\operatorname{erf}\left\{\left(R_{b} / 2\right)^{1 / 2}(Z-1)\right\}+\operatorname{erf}\left\{\left(R_{b} / 2\right)^{1 / 2}\right\}}{\operatorname{erf}\left\{\left(R_{b} / 2\right)^{1 / 2}\right\}}
$$$$
\theta=\frac{\operatorname{erf}\left\{\left(R_{t} / 2\right)^{1 / 2} Z\right\}}{\operatorname{erf}\left\{\left(R_{t} / 2\right)^{1 / 2}\right\}}
$$

$w_{b}=0$

$\theta=\frac{\operatorname{int}\left\{\left(R_{b} / 2\right)^{1 / 2}(Z-1)\right\}+\operatorname{int}\left\{\left(R_{b} / 2\right)^{1 / 2}\right\}}{\operatorname{int}\left\{\left(R_{b} / 2\right)^{1 / 2}\right\}}$

$w_{t}=0$

$\theta=\frac{\operatorname{int}\left\{\left(R_{t} / 2\right)^{1 / 2} Z\right\}}{\operatorname{int}\left\{\left(R_{t} / 2\right)^{1 / 2}\right\}}$

$w_{b}=0$

$$
\theta=\frac{\exp \left(-R_{t}\right)-1}{\exp \left(-R_{t}\right)-1}
$$

$\theta=Z$

" see text for definitions of symbols used in this table.

where $\rho H_{M} w_{b}$ is the rate at which basal heat melts unit area at the base of the ice slab, $K(\partial T / \partial z)_{b}$ is the rate per unit area at which basal heat is conducted to the surface of the ice slab, $\rho$ is ice density, $H_{M}$ is latent heat of melting for ice, and $(\partial T / \partial z)_{b}$ is the basal temperature gradient, which is always negative in an ice sheet.

An expression for $(\partial T / \partial z)_{b}$ is obtained by differentiating Equation (17) and then setting $z=0$ :

$$
\left(\frac{\partial T}{\partial z}\right)_{b}=\left(\frac{T_{t}-T_{b}}{h}\right) \frac{(2 / \pi)^{1 / 2} R_{t}^{1 / 2}(1-r)^{1 / 2} \exp \left[-\left(R_{t} / 2\right) r^{2} /\left(1-r^{2}\right)\right]}{\operatorname{erf}\left\{R_{t}^{1 / 2}\left[(1-r)^{1 / 2}+r /(1-r)^{1 / 2}\right]\right\}-\operatorname{erf}\left\{R_{t}^{1 / 2} r /(1-r)^{1 / 2}\right\}}
$$


If $w_{b}=0$, then $r=0$, and $T_{b}$ can be below the basal melting temperature $T_{M}$. When $r=0$, Equation (33) reduces to:

$$
\left(\frac{\partial T}{\partial z}\right)_{b}=\left(\frac{T_{t}-T_{b}}{h}\right) \frac{(2 / \pi)^{1 / 2} R_{t}^{1 / 2}}{\operatorname{erf}\left(R_{t}^{1 / 2}\right\}}
$$

where $T_{b}=T_{M}$ when $r \neq 0$ in Equation (33), with both basal freezing (positive $w_{b}$ ) and basal melting (negative $w_{b}$ ) being possible.

The requirement that $T_{b}=T_{M}$ at $w_{b}=0$, and therefore at $r=0$, is that slab thickness $h=h_{M}$. Solving Equation (32) for $h=h_{M}$ at $T_{b}=T_{M}$ and $r=0$ in Equation (33) gives:

$$
\begin{aligned}
h_{M} & =\frac{T_{t}-T_{M}}{(\partial T / \partial z)_{M}} \frac{(2 / \pi)^{1 / 2}\left(R_{t}\right)_{M}^{1 / 2}}{\operatorname{erf}\left\{\left(R_{t}\right)_{M}^{1 / 2}\right\}} \\
& =\left(\frac{T_{M}-T_{t}}{Q_{b} / K}\right) \frac{(2 / \pi)^{1 / 2}\left(R_{t}\right)_{M}^{1 / 2}}{\operatorname{erf}\left\{\left(R_{t}\right)_{M}^{1 / 2}\right\}}
\end{aligned}
$$

where $\left(R_{t}\right)_{M}=w_{t} h_{M} / \kappa$. Basal melting takes place when $h>h_{M}$. An expression for $Q_{b}$ is:

$$
Q_{b}=Q_{G}+J u \tau_{0}=Q_{G}+J u \rho g h \alpha
$$

where $Q_{G}$ is the geothermal heat flux per unit basal area and $J u \tau_{0}$ is the rate per unit basal area at which frictional heat is generated. In ice streams, $u$ increases as $\tau_{0}$ decreases, but the product $u \tau_{0}$ is relatively stable, such that $Q_{G} \approx J u \tau_{0}$.

The geothermal heat flux around the Great Lakes of North America, where ice lobes formed along the southern margin of the Laurentide lce Sheet, is $Q_{G} \approx 1.25 \times 10^{-6} \mathrm{cal} / \mathrm{cm}^{2} \mathrm{sec}$ (Sugden, 1978). Frictional heat from shear deformation of subglacial till beneath the ice lobes would no more than double or triple this amount for the range of $\tau$ and $u$ values associated with these lobes $\left(J=25 \times 10^{3} \mathrm{cal} / \mathrm{bar} \mathrm{m}^{3}\right.$, 0.1 bar $<\tau<1.0$ bar, $500 \mathrm{~m} / \mathrm{a}>\mathrm{u}>50 \mathrm{~m} / \mathrm{a})$. Figure 4 shows the variation of $h_{M}$ with $T_{t}$ and $w_{t}$ for three values of $Q_{b}$. For the accumulation zone of the ice slab, 
$5 \mathrm{~m} / \mathrm{a}<\mathrm{w}_{\mathrm{t}}<10 \mathrm{~m} / \mathrm{a}$ and $-20^{\circ} \mathrm{C}<\mathrm{T}_{\mathrm{t}}<-10^{\circ} \mathrm{C}$ encompass the probable range of accumulation rate and mean annual temperature on the top surface. For the range of $Q_{b}$ in Figure 4, this gives $150 m<h_{M}<1250 m$ as the range of slab thickness below which the bed would be frozen.

\section{Basal Heat Flow for an lce Slab in Comoressive Flow}

Compressive flow exists in the ablation zone of the ice slab, where a basal freezing zone exists if the bed is not frozen. For the ablation zone of the ice slab, $h_{M}$ cannot be computed from Equation (35) because $w_{t}$ in $R_{t}$ is negative. In any case, Equation (35) shows that $h_{M} \rightarrow 0$ as $w_{t} \rightarrow 0$, regardless of $T_{t}$ and $Q_{b}$. This is compatible with retaining a frozen bed at the ice margin, so long as the ice sheet is advancing over a frozen bed.

If surface accumulation and basal melting rates for extending flow in the upslope part of the ice slab had not already modified the temperature profile, temperature profiles and the resulting basal heat flow in the downslope part of the ice slab could be computed from Equation (25) for surface ablation and basal freezing rates that cause compressive flow. This complication requires a steady-state solution in which changing temperature profiles are computed in a column of ice as it moves from the accumulation zone to the ablation zone of the ice slab. There is no analytical solution for this case, but a numerical solution has been developed by Budd and others (1971) and applied to flowlines of the Antarctic Ice Sheet. A major assumption is that $u$ does not vary with $z$ through the ice column, which is the case for our creeping ice slab on a low-traction bed. We are developing a time-dependent, finite-element model to replace their steady-state, finite-difference model. Our model will be able to reproduce the analytical steady-state solutions presented here. The numerical solutions allow $w_{t}$, $w_{b}, T_{t}, T_{b}$, and $h$ to vary along a flowline.

\section{IHE FINITE-ELEMENT FLOWBAND SOLUTION FOR ICE LOBES}

Our time-dependent, finite-element flowline cross-section model now being developed allows ice velocity and temperature to be computed at nodes in a longitudinal cross-section of an ice-sheet flowline, for known boundary conditions at the surface and the bed. From these data at nodes, ice flow trajectories, ice time lines, temperature contours, and heat flow vectors can be computed for the cross-section. 
Required boundary conditions are temperature and accumulation or ablation rates at the surface, and temperature or the temperature gradient at the bed. This model is being developed from a flowband version of our time-dependent, finite-element, gridpoint, map-plane model that computes column-averaged conditions in the vertical dimension. Results from this model for an ice lobe are presented here.

With our finite-element model, an ice slab of constant thickness in steady-state equilibrium for our analytical solutions becomes, more realistically, an ice lobe of variable thickness that can advance or retreat in our numerical solutions. We specify that sheet flow on a high-traction bed extends to the southern edge of the granitic shield (Laurentian Shield in North America, Baltic Shield in Europe, and Angara Shield in Asia), converts to stream flow on a low-traction melting bed on the sedimentary thawed permafrost south of these shields, and ends as lobe flow on a low-traction freezing bed on the sedimentary thawed permafrost further south, with permafrost restoring a frozen high-traction bed along the lobe margins.

Snowlines in our finite-element model radiate from the poles, and move up and down according to prescribed forcing. In our experiments, forcing has been insolation variations dominated in high latitudes by the 41,000-year cycle of axial tilt, and in low latitudes by the 21,000-year cycle of axial precession, by variations in atmospheric carbon dioxide or dust recorded in the stratigraphy of coreholes through the Greenland and Antarctic ice sheets (Broecker and Denton, 1989), or by combinations of these.

Following Hughes (1987), we describe the variation of snowline altitude with latitude by the equation for a straight line on a flat Earth:

$$
H=H_{P}+\left(x^{2}+y^{2}\right)^{1 / 2} S_{L}
$$

where $\mathrm{H}$ is the snowline elevation at distance $\left(x^{2}+y^{2}\right)^{1 / 2}$ from the pole along a meridian, $x$ is along $0^{\circ} \mathrm{E}$ (the Prime Meridian), $y$ is along $-90^{\circ} \mathrm{E}$ in the Northern Hemisphere and $+90^{\circ} \mathrm{E}$ in the Southern Hemisphere for right-handed coordinates, $\mathrm{HP}$ is snowline elevation above or depression below sea level at the pole, $S_{L}$ is snowline slope measured as latitude distance from the pole, $\mathrm{H}_{E}$ is snowline elevation above sea level at the Equator. For snowline variations controlled by insolation cycles, $\Delta \mathrm{H}_{\mathrm{P}}$ is the elevation amplitude for the 41,000 -year axial tilt period tP at the pole and $\Delta H_{E}$ is the 
elevation amplitude for the 21,000-year axial precession period $t_{E}$ at the Equator. Taking $L=10^{7} \mathrm{~m}$ as the latitude distance from the pole to the Equator, and letting $\delta \mathrm{H}_{\mathrm{p}}$ and $\delta \mathrm{H}_{E}$ be the fractions of $\Delta \mathrm{H}_{\mathrm{P}}$ and $\Delta \mathrm{H}_{\mathrm{E}}$ at time $\mathrm{t}$ after the start of a tilt or precession cycle:

$$
\begin{aligned}
S_{L}= & \left(H_{E}-H_{P}\right) / L=\left(H^{\circ} E+\delta H_{E}\right) / L-\left(H^{\circ}{ }_{P}+\delta H_{P}\right) / L \\
= & \left(H^{\circ} E^{\prime L}\right)+\left(\Delta H_{E} / L\right) \cos ^{2}\left(\pi t / t_{E}\right) \\
& -\left(H^{\circ} / L\right)-\left(\Delta H_{P} / L\right) \cos ^{2}\left(\pi t / t_{P}\right)
\end{aligned}
$$

where $H^{\circ}$ and $H^{\circ}$ are $H_{E}$ and $H_{P}$ at $t=0$.

Following Hughes (1985), the net rate $\dot{a}$ of accumulation or ablation assumed to vary with distance $r$ from an ice-sheet margin, with $r$ measured along a flowline, is:

$$
\dot{a}=a_{0}^{\prime} \exp \left(-\lambda^{\prime} r\right)+a_{0}^{n} \exp \left(-\lambda^{\prime \prime} r\right)
$$

where $a_{0}^{\prime}$ and $a_{0}{ }_{0}$ are respective accumulation and ablation rates at the ice margin and $\lambda^{\prime}$ and $\lambda^{\prime \prime}$ are their respective damping constants with distance along r. Basal shear stress $\tau_{0}$ along $r$ is:

$$
\tau_{0}=\rho g h_{1} \Delta h / \Delta r
$$

where $h_{1}$ is ice thickness and $\Delta h / \Delta r$ is ice surface slope. If $\tau_{0}$ is constant, the bed is horizontal along $r$, and $h_{1}=h-h_{0}$, where $h_{0}$ is height at $r=0$ (the ice-sheet margin), Equation (40) can be integrated to give a parabolic surface profile:

$$
r=\left(\rho_{1} g / 2 \tau_{0}\right)\left(h-h_{0}\right)^{2}
$$

Combining Equations (39) and (41):

$$
\dot{a}=a_{0}^{\prime} \exp \left[-\Gamma\left(h-h_{0}\right)^{2}\right]+a_{0}^{\prime \prime} \exp \left[-\Gamma^{n}\left(h-h_{0}\right)^{2}\right]
$$

where $\Gamma^{\prime}=\lambda^{\prime} \rho g / \tau_{0}$ and $\Gamma^{n}=\lambda^{n} \rho g / \tau_{0}$. In a more general form: 


$$
\dot{a}=a_{0}^{\prime} \exp \left(-\Gamma h^{c}\right)+a^{n}{ }_{0} \exp \left(-\Gamma^{m} h^{c}\right)
$$

where $c>1$ for convex surface profiles, $c=1$ for linear surface profiles, $c<1$ for concave surface profiles, and $\Gamma$ and $\Gamma^{*}$ are adjusted until Equation (43) gives a least-squares fit to mass-balance data (Pelto and others, 1990). Variations in bed topography and transitions from sheet flow to stream flow to lobe flow can be taken into account by specifying $\Gamma_{1}, \Gamma_{2}$, and $c$ at each step along a flowline.

Changes in mass balance through time are allowed by combining Equations (38) and (43). The equilibrium line on an ice sheet is defined by connecting points where snowlines intersect flowlines. Elevation $h_{e}$ of the equilibrium line is $h$ at $\dot{a}=0$ in Equation (43). The mass-balance curve defined by Equation (43) can be displaced to higher or lower altitudes to ensure that $h_{e}=\mathrm{H}$ as the snowline elevation changes through time. This is accomplished by modifying Equation (43) as follows:

$$
\dot{a}=a_{0}^{\prime} \exp \left[-\Gamma(h-H){ }^{c}\right]+a_{0}^{\prime \prime} \exp \left[-\Gamma^{\prime \prime}(h-H)^{c}\right]
$$

In earlier work (Pelto and others, 1990), we identified several climate zones on the present-day Earth, each of which had unique values for constants $a_{0}^{\prime}, a_{0}, \Gamma$, and $\Gamma^{*}$. Our ice sheets were modeled for zone 17 , which has a polar continental climate. Constants for zone 17 are, $a_{0}^{\prime}=-1.29 \mathrm{~m} / \mathrm{a}, \mathrm{a}_{0}=0.30 \mathrm{~m} / \mathrm{a}, \Gamma=1.50 \times 10^{-5}$, and $\Gamma^{\prime \prime}=3.66 \times 10^{-8}$, where $\mathrm{c}=2$. Equation (44) can now be solved using $\mathrm{H}$ from Equation (37) and, when $\mathrm{H}$ is responding to insolation controlled by axial tilt and precession, $S_{L}$ in Equation (37) is given by Equation (38).

\section{Conditions for Advance and Retreat of an lce Lobe}

In our finite-element simulation of the advance and retreat of an ice lobe in response to precession-driven insolation forcing for which $\mathrm{H}^{\circ} \mathrm{p}=-2100 \mathrm{~m}$, $\Delta \mathrm{H}_{\mathrm{P}}=1200 \mathrm{~m}, \mathrm{tp}=21,000 \mathrm{a}$, and $\mathrm{S}_{\mathrm{L}}=56 \mathrm{~m} / 100 \mathrm{~km}$, the slab advances and retreats over a distance of $555 \mathrm{~km}$, form $45^{\circ} \mathrm{N}$ to $50^{\circ} \mathrm{N}$, which is the average range of latitudes glaciated south of the Laurentian Shield in North America. Ice flux moving south from the shield is held constant at $10^{5} \mathrm{~m}^{2} /$ a per unit flowband width.

Whether the ice lobe moves over a high-traction bed or a low-traction bed depends on the thawed fraction $f$ of permafrost. In our finite-difference flowband model, the defining equation is: 


$$
\tau_{0}=f_{s} \tau_{w}+\left(1-f_{s}\right) \tau_{0}
$$

where $\tau_{0}$ is the basal shear stress, $\tau_{0}=\tau_{w}$ for a wet (thawed) bed, $\tau_{0}=\tau_{0}$ for a dry (frozen) bed, and is the measure of bed traction. In our finite-element flowband model, the defining equation is:

$$
u=f_{u} u_{o}+\left(1-f_{u}\right) \bar{u}_{c}
$$

where $u$ is the longitudinal ice velocity, $u=u_{0}$ is the sliding velocity over a wet (thawed) bed, $u=\bar{u}_{c}$ is the column-averaged creep velocity $u_{c}$, and is the measure of bed traction. Equations (45) and (46) are related through the sliding law of glacial ice:

$$
u_{0}=\left(\tau_{0} / B\right)^{m}
$$

where $B$ depends on bed roughness and $m$ is a viscoplastic exponent for sliding, and through the flow law of glacial ice:

$$
\dot{\varepsilon}_{x z}=\left(\tau_{x z} / A\right)^{n}
$$

where $A$ depends on ice hardness, $n$ is a viscoplastic exponent for creep, $\dot{\varepsilon}_{x z}=d u / d z$ for laminar flow, and $\tau_{x z}=\rho g(h-z) \alpha$ is the shear stress at height $z$ above the bed for ice of thickness $h$ and surface slope $\alpha$. The column-averaged creep velocity obtained by integrating Equation (48) twice is:

$$
\bar{u}_{c}=\left(\frac{\rho g \alpha}{A}\right)^{n} \frac{h^{n+1}}{n+2}
$$

Figure 5 compares $f_{s}$ when the thawed fraction controls stress with $f_{u}$ when the thawed fraction controls velocity.

From results of our analytical solutions obtained from Equation (35), we assume the bed beneath the ice lobe will be thawed for $h>1250 \mathrm{~m}$. The strong non-linearity of $f_{u}$ with respect to $f_{S}$ seen in Figure 5 requires that $f_{u}$ be changed in increments of 0.05 because ice flow controlled by creep at $f_{u}=0$ is controlled by sliding at $f_{u}=0.15$. Thawing only 15 percent of the bed is enough to allow sliding to dominate creep. In the finite-element program, therefore, the sliding condition is checked every 100 years such that, if $h>1250 \mathrm{~m}, f_{u}=1$, but if $h=1250 \mathrm{~m}$, basal melting and freezing occur in 
increments of $\Delta f_{U}=0.05$ for each time step of 100 years as $h$ increases or decreases, respectively. Hence, during melting, the transition from creep to sliding requires 300 years ( $f_{u}$ in-creases from 0 to 0.15 over 3 time steps at 0.05 per step); but during freezing, the transition from sliding to creep requires 1700 years $\left(f_{u}\right.$ decreases from 1.00 to 0.15 in 17 time steps at 0.05 per step).

\section{Besults for Advance and Retreat of an Ice Lobe}

Advance and retreat of an ice lobe in time steps of 100 years are shown in Figure 6 for a frozen bed and Figure 7 for a thawed bed. Forcing is precession-driven insolation that changes the snowline elevation over a cycle of 21,000 years. Advance is slower than retreat, giving a qualitative resemblance to a termination, but less abrupt. Ice surface slopes are steeper for advance than for retreat (steepening toward the end of retreat is an artifact of specifying a constant ice flux southward from the shield). Lobe thickness is less and much more uniform, and the "termination" is much more abrupt, when the bed is thawed than when the bed is frozen.

Lobe volumes and the position of lobe margins over time for advance and retreat over frozen and thawed beds are compared in Figures 8 and 9. As seen in Figure 8 , lobe volume is much greater and the termination is more gradual when the bed is frozen. As seen in Figure 10, the time of advance and retreat is shorter and the termination is more abrupt when the bed is thawed, but the maximum lobe advance is held longer when the bed is frozen.

Results in Figures 6 through 10 change significantly if the snowline elevation is kept constant and low during lobe advance, and is kept constant and high during retreat. This would be the case if climatic cooling caused by the dust machine dominated that caused by axial precession, with climatic warming when the dust machine is turned off. We simulated this in the flowband solution of our time-dependent , finite-element model by allowing the dust machine to lower the snowline to $\mathrm{H}^{\circ} \mathrm{P}=-3800 \mathrm{~m}$, and raising it by $\Delta \mathrm{HP}=2900 \mathrm{~m}$ when the dust machine is turned off. This is lower than $\mathrm{H}^{\circ} \mathrm{P}=-2100 \mathrm{~m}$ and $\Delta \mathrm{H}_{\mathrm{P}}=1200 \mathrm{~m}$ when axial precession controls the snowline elevation. In both cases, we used $S_{L}=50 \mathrm{~m} / 100 \mathrm{~km}$ as the snowline slope and $H_{P}=-900 m$ as the maximum snowline elevation at the North Pole (no dust, maximum axial tilt). 
We conducted two dust machine experiments. Results are shown in Figure 11 and 12. In Figure 11, the ice lobe advances over a thawed bed when the dust machine is on and retreats over a frozen bed when the dust machine is off. In Figure 12, the ice lobe advances over a frozen bed when the dust machine is on and retreats over a thawed bed when the dust machine is off. In both cases, when the dust machine is turned off, the sudden increase in ice ablation causes immediate thinning of the ice lobe, but the lobe margin holds fast in Figure 11 and even advances in Figure 12. The ice lobe advances for about $\mathbf{3 0 0 0}$ years and retreats for about 2000 years in both cases, beginning and ending at the southern edge of the granitic shield, which supplies a constant ice flux of $10^{5} \mathrm{~m}^{2} / \mathrm{a}$ per unit flowband width to the lobe. This is the essential asymmetry of a Late Quaternary glacial termination.

Figure 11 represents the case when heat flow from the bed to the surface of the ice lobe is in equilibrium during advance and retreat, so an advancing lobe over 1250 $\mathrm{m}$ thick slides on a thawed bed. However, when the dust machine is turned off, ablation thins the lobe below $1250 \mathrm{~m}$ in thickness so the bed freezes. Retreat of the lobe is delayed for about 600 years even though the thinning lobe on a frozen bed is almost stagnant.

Figure 12 represents the case when heat flow from the bed to the surface of the ice lobe lags behind advance and retreat of the lobe, so an advancing lobe over 1250 $m$ thick creeps over a bed that is still frozen. After the bed finally thaws when the dust machine is tumed off, ice thickness is too great for the sudden reduction of bed traction and the ice lobe thins by both ablation and sliding until a gravitational force balance with the low-traction bed is attained. After that, ablation controls thinning of a largely stagnant ice lobe, just as in Figure 11. The ice lobe holds its maximum position for about 700 years.

The major difference between Figures 11 and 12 is the rapid ice-lobe advance of about $170 \mathrm{~km}$ in 300 years when a frozen bed thaws. This is akin to a glacial surge of the ice lobe, and it may explain the readvance of Laurentide ice lobes south of the Great Lakes after the Erie interstade (Mayewski and others, 1981).

Figures 11 and 12 suggest the following scenario for a Late Quaternary glaciation, applied to the Late Wisconsin Laurentide Ice Sheet. (1) The ice sheet advances over a frozen bed with maximum depression of the snowline, making the ice margin steep and thick. (2) Insolation caused by precession begins to raise the 
snowline by $22,000 \mathrm{BP}$ and the bed becomes thawed, causing the ice to thin and advance to its maximum southward extent. (3) The bed freezes beneath the thin extended ice, turning off the dust machine and causing an upward jump of the snowline. (4) The increased ablation rate causes a rapid retreat of the ice margin, initiating termination of the Late Wisconsin glaciation. (5) Retreat becomes irreversible when proglacial lakes proliferate along the isostatically depressed ice margin, preventing the dust machine from being turned back on and adding ice calving to ice melting as ablation mechanisms.

\section{THE ROLE OF ICE CALVING IN GLACIAL TERMINATIONS}

Ice sheets retreat faster than they advance in all of our simulations using the time-dependent, finite-element model in both its flowband and map-plane solutions. The abrupt nature of Late Quaternary deglaciations, called terminations by Broecker and van Donk (1970), can be simulated by including ice calving as an ablation mechanism, especially calving into proglacial lakes that occupy the isostatically-depressed margins of retreating Northern Hemisphere ice sheets.

Hughes (1989) formulated a slab calving mechanism for an ice wall grounded in water of variable depth, based on his field work on Deception Island $\left(63.0^{\circ} \mathrm{S}\right.$, $60.6^{\circ} \mathrm{W}$ ), Antarctica. Hughes and Nakagawa (1989) reported observations that generalized the Deception Island calving mechanism. We have now incorporated it into our finite-element model.

The calving mechanism arises from a bending moment at the base of an ice wall. Bending produces shear bands that parallel the ice wall as it bends forward, with shear offset across each band decreasing to zero at the base of the ice wall, much as the shear offset between the bent pages of a book decreases to zero at the binding. For elastic bending, horizontal displacement $u_{x}$ of an initially vertical ice wall increases with vertical distance $z$ above the base of the ice wall according to the flexure formula:

$$
d^{2} u_{x} / d z^{2}=M(z) / E l
$$

where $E$ is the elastic modulus, $I=w \times 3 / 12$ is the moment of inertia for a rectangular slab of width $w$, and $M(z)$ is the bending moment: 
where $E$ is the elastic modulus, $I=w \times 3 / 12$ is the moment of inertia for a rectangular slab of width $w$, and $M(z)$ is the bending moment:

$$
M(z)=\frac{1}{6} \rho_{l} g w(h-z)^{3}-\frac{1}{6} \rho_{w} g w(d-z)^{3}
$$

for ice density $\rho_{I}$ and water density $\rho_{W}$ for an ice wall of height $h$ standing in water of depth $d$ (Hughes, 1989).

Substituting Equation (51) into Equation (50) and integrating twice, using I for a rectangular slab:

$$
u_{x}=\frac{\rho_{1} g h^{5}}{10 E x^{3}}\left[5\left(\frac{z}{h}\right)+\left(1-\frac{z}{h}\right)^{5}-1\right]-\frac{\rho_{W g d^{5}}}{10 E x^{3}}\left[5\left(\frac{z}{d}\right)+\left(1-\frac{z}{d}\right)^{5}-1\right]
$$

The counterpart of Equation (52) when bending is more viscoplastic than elastic is:

$$
v_{x}=\frac{\rho_{1} g h^{5}}{10 \eta x^{3}}\left[5\left(\frac{z}{h}\right)+\left(1-\frac{z}{h}\right)^{5}-1\right]-\frac{\rho w g d^{5}}{10 \eta x^{3}}\left[5\left(\frac{z}{d}\right)+\left(1-\frac{z}{d}\right)^{5}-1\right]
$$

where $v_{x}$ is the horizontal creep velocity at height $z$ above the base of the ice wall, and $\eta$ is the effective viscosity obtained from the flow law of ice for shear strain rate $\dot{\varepsilon}_{z x}$, shear stress $\sigma_{\mathrm{zx}}$, ice hardness parameter $\mathrm{A}$, and ice viscoplastic exponent $\mathrm{n}$ in the shear bands:

$$
\dot{\varepsilon}_{\mathrm{zx}}=\left(\sigma_{\mathrm{zX}} / \mathrm{A}\right)^{\mathrm{n}}
$$

By definition, the effective viscosity in shear bands is:

$$
\eta=\frac{d \sigma_{z x}}{d \dot{\varepsilon}_{z x}}=\frac{A^{n}}{n \sigma_{z x}{ }^{n-1}}
$$

Hughes (1989) made the assumption that $\sigma_{\mathrm{zx}}=\tau_{0}$, where $\tau_{0}$ is the shear stress at the base of an ice wall, defined as:

$$
\tau_{0}=g\left(\rho_{l} h^{2}-\rho_{W} d^{2}\right) / 2 x=\rho_{l} g\left[h-\left(\rho_{W} / \rho_{l}\right) d\right] \Delta h / \Delta x
$$


where $\Delta h$ is the elevation change over distance $\Delta x$ at the top of the ice wall caused by cumulative vertical offset in the shear bands. Observationally, if $\Delta x$ is the distance behind the ice wall at which a slab calves, $\Delta h$ gets smaller as $\Delta x$ gets larger.

Using Equation (56) to substitute for $x$ in Equation (53), and letting $v_{x}$ be its maximum value for $z=h$ in the $\rho_{I}$ term and $z=d$ in the $\rho_{W}$ term:

$$
\begin{aligned}
\left(v_{x}\right)_{\max } & =\frac{4 \rho_{I} g h^{5}}{10 \eta x^{3}}\left[1-\frac{\rho_{I}}{\rho_{W}}\left(\frac{d}{h}\right)^{5}\right] \\
& =\frac{32 n \rho_{I} g^{n} h^{5}\left[\left(\rho_{I} h-\rho_{W} d\right) \alpha\right]^{n+2}}{10 A^{n}\left(\rho_{I} h^{2}-\rho_{W} d^{2}\right)^{3}}\left[1-\frac{\rho_{I}}{\rho_{W}}\left(\frac{d}{h}\right)^{5}\right]
\end{aligned}
$$

In laboratory creep experiments that reproduced the shear bands on Deception Island, Hughes and Nakagawa (1989) found that $A=25.2 \mathrm{kPa} a^{1 / n}$ and $n \approx 2$ for $\tau_{0}=117 \mathrm{kPa}$. For the calving ice wall on Deception Island $d=0, h=40 \mathrm{~m}$, and $\Delta h / \Delta x=0.3$ (Hughes, 1989). Using these values, Equation (57) gives $\left(v_{x}\right) \max =500 \mathrm{~m} / \mathrm{a}$ when a calving ice wall is grounded on a beach.

Ice caps and mountain glaciers ending in calving ice walls grounded on beaches are commonplace on the subantarctic islands and along the northern part of the Antarctic Peninsula. Farther south along the Antarctic Peninsula, calving ice walls extend into increasingly deep water until the ice walls become floating ice shelves. The total bending moment decreases as the water deepens, but the bending moment above water level does not, and it is bending at the top that opens crevasses for slab calving. Whether slabs calve at increasingly larger separations $\Delta x$ and smaller cumulative offsets $\Delta h$ along shear bands, such that $\Delta h / \Delta x$ decreases as the ice wall begins to float, is unclear. Slab calving is supplemented by the calving of tabular icebergs, as analyzed by Fastook and Schmidt (1982) and by Lingle and others (1981), for example, and these calving mechanisms also depend on bending moments in ice shelves. Note that $\tau_{0}$ is still shear stress $\sigma_{z x}$ in shear bands even when the ice wall becomes afloat, because the bending moment remains finite. This is compatible with the observation that $\Delta h / \Delta x$ for floating ice shelves is largest at the calving front, which typically has pronounced forward tilt. 
In applying Equation (57) the ice walls of retreating ice sheets, $\left(v_{x}\right)_{\max }$ is greatest when the ice wall is grounded on a beach. However, since basal isostatic rebound rates lag behind the ice-sheet retreat rate, we can expect $d$ to increase over time. Hence, in our finite-element model, we should assume that $d=0$ at the start of retreat and that $d=\left(p_{w} / p_{l}\right) h$ for incipient flotation when the ice wall is grounded in water 400 $\mathrm{m}$ deep, since ice walls on beaches are about $40 \mathrm{~m}$ high.

Our present applications of the time-dependent, finite-element model are for degrees of isostatic compensation that do not vary over time and space. Specifically, we must specify a single amount of isostatic equilibrium for every grid point at every time step. With this constant, use of Equation (57) in our finite-element model provides a single retreat rate due to slab calving, bracketed between $d=0$ and $d=\left(p_{w} / p_{1}\right) h$ along the calving ice wall. A major improvement in the model would be to allow isostatic compensation to vary for each grid point and time step according to glacial rebound theory, so that realistic values of $d$ that vary with time and space are entered along the calving ice walls of retreating ice sheets. 


\section{SIMULATION OF NORTHERN HEMISPHERE GLACIATION CYCLES}

A scenario for generating a glacial cycle is described, and applied to Northern Hemisphere ice sheets. It involves certain simplifying assumptions about the basal and mass-balance conditions of the ice sheets.

First the basal conditions are discussed. All nodes whose bedrock elevations are below $-200 \mathrm{~m}$ are assigned a sliding condition. This creates a basal condition similar to that observed in the Antarctic calibration run, where sliding occurs mainly in defined channels in the bed around the margin of the ice sheet. For the Laurentide Ice Sheet, it produces sliding zones in the inter-island channels of the Canadian Arctic and extends into Hudson Bay. For the Eurasian Ice Sheet, it produces a sliding zone south and east of Spitzbergen, as well as along the northern margin near the continental shelf edge.

A second condition is that sliding occurs wherever bedrock elevations exceed $500 \mathrm{~m}$. It produces sliding in the Rockies of North America, over the Quebec Plateau east of Hudson Bay, and over the Putorana Plateau of western Siberia. This constraint is supported by glacial geology and it is needed to prevent excessive thickening of the Cordilleran Ice Sheet and to keep the dome more centered over the Eurasian Ice Sheet.

A final condition requires sliding for all nodes south of $40^{\circ} \mathrm{N}$. It produces a broad sliding zone along the southern margin of the Laurentide Ice Sheet, while having little affect on the less extensive Eurasian Ice Sheet.

Mass-balance zones described in our 1989 Annual Report are also simplified somewhat. All of the Eurasian Ice Sheet and most of the Laurentide Ice Sheet use a Polar Continental Zone (zone 17, exponential fit). A maritime zone (zone 5, linear ramp) with higher accumulation and ablation rates is used for the North American Cordillera and central Alaska. Coordinates $\dot{a}, \mathrm{~h}$ connecting straight-line segments for the ramp are, ice margin $(-2 \mathrm{~m} / \mathrm{a}, 0)$, equilibrium line $(0,1500 \mathrm{~m})$, peak accumulation $(1 \mathrm{~m} / \mathrm{a}, 1750 \mathrm{~m})$, and ice plateau $(0.15 \mathrm{~m} / \mathrm{a}, 2000 \mathrm{~m})$. It is in keeping with the limited ice complex expected in this area. All other regions are given an ablation-type zone (-5 m/a)which generally prevents ice growth in these regions. This way, we preserve the best of both the old finite-difference flowband model and the new finite-element, 
map-plane model. In the flowband model, ice-sheet margins and ice flowline directions were specified, based on glacial geology. The map-plane model does not require specification of either, but allows specification of maximum extent beyond which growth is not allowed. Guided by the glacial geology, we choose zones within which the ice sheet can grow and decay.

Both mass-balance schemes are based on accumulation/ablation rates which are a function of surface elevation. We further modify these by allowing a snowline depression or elevation which is a function of latitude and time. By specifying the snowline depression or elevation at the pole and a snowline elevation slope with distance from the pole we can modify the mass-balance curves. These types of conditions can be used to model Milankovitch-type forcing, in that changes in the snowline depression and elevation models tilt and precession driven insolation effects. A combination of the two yields the necessary snowline elevation slope as a function of distance from the pole. Both can be pulsed at the appropriate frequency for the different Milankovitch components and the response of the ice sheets to such a complex signal is monitored.

\section{IHE LATE QUATERNARY GLACIATION SCENARIO}

If increased atmospheric carbon dioxide caused by burning fossil fuels does not cause global warming for more than one or two millenia, global glaciations during the next 100,000 years will probably be a continuation of the Late Quaternary glaciation cycles. These glaciations terminated more or less abruptly every 100,000 years, and had major stadials and interstadials that correlated with the Milankovitch insolation cycles of about 41,000 years for axial tilt and about 21,000 years for axial precession (Hayes and others, 1976; Imbrie and others, 1984). We were able to simulate these features by postulating a dust machine that was produced by advancing Northern Hemisphere ice sheets, and that caused the fundamental 100,000-year harmonic of Late Quaternary ice volume changes recorded by oxygen isotope stratigraphy in ocean floor sediments.

\section{Forcing When Atmospheric Dust Dominates Axial Tilt}

For a glaciation cycle initiated by the Milankovitch tilt cycle but maintained by the dust machine, a simple transition from non-glacial to glacial conditions is used. 
The snowline depression at the pole is lowered (sinusoidally) over a 20,000-year period from 0 to $-2300 \mathrm{~m}$. Growth of the ice sheets does not occur until lowering has reached approximately $-1000 \mathrm{~m}$. Figure 13 shows how input and output variables in the finite-element model change over time. Figure 14 shows the approach to equilibrium over time of ice-sheet volume and the subsequent termination.

\section{Besults for North American lce Sheets}

Figure 15 shows present-day North American topography. Figure 16 shows 26 stages in the advance and retreat of North American ice sheets plotted as changing ice-thickness contours. Figure 17 shows North American surface elevations (ice and land) at the glacial maximum. Figure 18 shows fraction $f_{u}$ of the bed over which sliding ominates at the glacial maximum. Figure 19 shows the surface mass balance at the glacial maximum. Figure 20 shows cross-sections of North American ice sheets along various transects over time, including formation of an ice lobe at the southern Laurentide margin. Ice growth begins in the Canadian Arctic and extends south along the western side of Hudson Bay. By 20,000 years (full glacial conditions, snowline depression at $-2300 \mathrm{~m}$ ) Laurentide ice extends along the eastern Rockies, across the northern half of Hudson Bay, and extends into northern and central Quebec, with a small glacial complex in the Rocky Mountain Cordillera. Approximately half of the maximum ice volume is attained by this time. Ice thickness reaches just over $2000 \mathrm{~m}$ in the Canadian Arctic, just over $1500 \mathrm{~m}$ in Quebec, and just over $1000 \mathrm{~m}$ in the Cordillera.

Full glacial conditions are held for the next 50,000 years, perhaps by the dust machine. During that time the ice sheet continues to grow, both in extent and thickness, achieving near equilibrium conditions at approximately 65,000 years. At this time, ice extends well into New England, south of the Great Lakes, and into the Midwest, and the Rockies. The Laurentide dome consists of a crescent -shaped ridge extending from the southern tip of Hudson Bay to northwest of Hudson Bay, with a maximum elevation of $4000 \mathrm{~m}$. The ice under this dome exceeds $4500 \mathrm{~m}$ in thickness. Ice thicknesses over the Cordillera range from 1000 to $1500 \mathrm{~m}$, over Quebec from 1500 to $2500 \mathrm{~m}$, and over New England from 500 to $1500 \mathrm{~m}$. (These low thicknesses reflect the sliding condition imposed on these regions. In addition, their actual maritime character might require higher accumulation rates that would produce localized domes. However, the major features are produced with this simplified scheme.) 
Decay is initiated at 70,000 years, perhaps by gradually turning off the dust machine and by Milankovitch warming. At this time, a sinusoidal increase in snowline depression from $-2300 \mathrm{~m}$ back to 0 over a time span of 20,000 years occurs. There is very little change in the first 10,000 years. Interestingly, as the southern margin begins to retreat, the dome thickness increases slightly. By 85,000 years, ice has retreated from the Rockies, the ice sheet has split between the Canadian Arctic and Greenland, and the southern margin has pulled back to just south of Hudson Bay. Even at this time, we see a very thick dome west of Hudson Bay (still exceeding $5000 \mathrm{~m}$ thickness). By 110,000 years, all that remains is the Greenland lce Sheet, and a small ice sheet in Keewatin, to the northwest of Hudson Bay. Our slab calving mechanism would quickly remove the Keewatin marine ice sheet, but would leave the terrestrial Greenland Ice Sheet intact.

\section{Results for Eurasian lce Sheets}

Figure 21 shows 22 stages in the advance and retreat of Eurasian ice sheets plotted as changing ice-thickness contours. Figure 22 shows Eurasian surface elevations (ice and land) at the glacial maximum. Figure 23 shows fraction $f_{u}$ of the bed over which sliding dominates at the glacial maximum. Figure 24 shows the surface mass balance at the glacial maximum.

Ice growth begins when sea ice grounds on the shallowest and most northerly parts of the Eurasian polar continental shelf, especially northern island-fringed parts of the Barents Sea, Kara Sea, and East Siberian Sea, forming marine ice domes. Terrestrial ice forms first on the Putorana Plateau. Within 1000 years, these ice domes have merged to create a Eurasian lce Sheet. The ice sheet spreads southward and merges with a terrestrial ice dome on the highlands of northern Scandinavia. The major center of spreading is Novaya Zemlya for 7000 years, but thereafter moves across the Kara Sea and onto the Taymyr Peninsula. Scandinavian ice reaches Scotland 13,000 years after marine ice domes formed on the Arctic continental shelf, and a major terrestrial ice dome exists over Scandinavia. The glacial maximum is attained 65,000 years after inception of marine ice domes, with the high central dome located over the Ob River estuary in northwest Siberia.

Retreat begins with recession of Scandinavian ice from Scotland, followed by deglaciation of the Laptev Sea, leaving a separate marine ice sheet in the East 
Siberian Sea 15,000 years after the glacial maximum. The Scandinavian ice dome becomes a separate ice sheet 5000 years later, by which time the East Siberian Ice Sheet has vanished. The Scandinavian Ice Sheet vanishes less than 5000 years later. A small remnant ice sheet centered on the present-day northwest Siberian coast remains, but it would be rapidly disintegrated by our slab calving mechanism for ice walls.

\section{The Northern Hemisphere Glacial Maximum}

Figures 25, 26, and 27 are North Polar projections of contoured ice and rock surface elevation, ice thickness, and the fractional distribution of basal sliding at the glacial maximum, respectively. Figure 28 is a three-dimensional oblique view of ice and rock surface elevation for the Northern Hemisphere glacial maximum. Figure 29 is an enlargement of Figure 28 for North America. Figure 30 is an enlargement of Figure 28 for Eurasia. Figure 31 is a three-dimensional oblique view of present-day terrestrial and submarine topography that is glaciated in Figure 28. Figure 32 is an enlargement of Figure 31 for North America. Figure 33 is an enlargement of Figure 31 for Eurasia. Figure 34 shows ice velocity vectors at the glacial maximum in relation to ice-elevation contours. Figure 35 shows these vectors for a frozen bed in the Scandinavian Mountains, which moves the Scandinavian ice dome from FInland to the Gulf of Bothnia.

\section{Forcing When Axial Tilt Dominates Atmospheric Dust}

A glaciation cycle was simulated in which the Milankovitch tilt cycle initiated and terminated the glaciation, but atmospheric dust lowered the snowline enough to prevent deglaciation from having the 40,000 year cycle of axial tilt until the ice sheet approached mid latitudes where the dust machine can be turned off. Hence, dust modifies, but does not dominate, tilt. Basal sliding conditions are those used when dust dominated tilt, except for one minor exception along the Scandinavian Mountains. Here the high elevation sliding condition is relaxed to allow the local Scandinavian dome to be more centered over the Gulf of Bothnia and to align ice flow directions more closely with known geological indicators, as was done to produce Figure 35 . 
Mass-balance zones are also simplified somewhat. All of the Eurasian Ice Sheet and most of the Laurentide lce Sheet use a Polar Continental Zone (zone 17, exponential fit, unadjusted equilibrium line at $340 \mathrm{~m}$ ). A maritime zone (zone 5 , linear ramp, amarg $=-2$, apeak $=1$, adome $=0.15$, heq $=1250$, hpeak $=1500$, hdome $=$ 1750) with higher accumulation and ablation rates used for the Cordilleran Rockies and central Alaska. This is in keeping with the limited ice complex expected in this area. All other regions are given an ablation-type zone $(-5 \mathrm{~m} / \mathrm{yr})$ which generally prevents ice growth in these regions.

For this simulation, a simplified Milankovitch climate cycle is used. Figure 36 shows changes in input and output variables over time for the finite-element model in the simulation. Ice-sheet growth is initiated by lowering the snowline from 0 to $-2300 \mathrm{~m}$ at the North Pole while keeping the snowline slope constant at $56 \mathrm{~m}$ per $100 \mathrm{~km}$. This is done over 20,500 years, in keeping with the fundamental high latitude driving period of 41,000 years. Following this, there is one full cycle from $-2300 \mathrm{~m}$ to $-1000 \mathrm{~m}$ and back to $-2300 \mathrm{~m}$ followed by a return over one-half cycle to 0 .

The ice volume curve, displayed more prominently in Figure 37, follows the driving force. There is very little growth until approximately 10,000 years, at which time the snowline has been depressed almost $1300 \mathrm{~m}$. We consider this to correspond to present conditions, since snowline depression below it causes the Greenland Ice Sheet to decrease in size. The zero reference level was chosen because more negative values do not produce terminations. During this scenario, the ice sheets go through two cycles of growth and decay. The first cycle of growth ends at approximately 34,000 years, over 3000 years after maximum snowline depression is attained at 21,500 years. The volume at this time is $22.65 \mathrm{Mkm}^{3}$ and the areal extent of the combined ice sheets is $10.95 \mathrm{Mkm}^{2}$. During the next cycle, which reaches a snowline lowering of $-1000 \mathrm{~m}$ at 41,000 years, and then returns to -2300 years at 61,500 years, the ice sheets decrease in volume and areal extent. The minimum occurs at 48,000 years with a combined volume of $19.19 \mathrm{Mkm}^{3}$ and an areal extent of $9.19 \mathrm{Mkm}^{2}$. Individual volume curves for the two major ice sheets reveal a more drastic decline in the Laurentide Ice Sheet, while the Eurasian Ice Sheet maintains almost a uniform volume and area over this time period.

A second maximum in the snowline depression occurs at 61,500 years, but maximum volume of the ice sheets again lag behind the driving force, with maximum 
volume occurring at 70,000 years, this time with a combined volume of $25.5 \mathrm{Mkm}^{3}$ and a combined areal extent of $12.0 \mathrm{Mkm}^{2}$. At this point, the snowline depression has reached $-1450 \mathrm{~m}$ and volume and area again decrease. The Milankovitch driving force continues to decline, reaching 0 snowline depression at 82,000 years (again a 41,000 year half cycle). By 80,000 years volume is down to $15.4 \mathrm{Mkm}^{3}$ and area is down to $7.75 \mathrm{Mkm}^{2}$. By 90,000 years volume is down to $3.68 \mathrm{Mkm}^{3}$ and area is only $2.71 \mathrm{Mkm}^{2}$. By 100,000 years all ice sheets are gone except Greenland, and a remnant ice sheet remains as only an ice cap on the northwest coast of Siberia.

\section{Results For Northern Hemisphere Ice Sheets}

Figure 38 shows 21 stages in the advance and retreat of Northern Hemisphere ice sheets as changing ice thickness contours. Subordinating atmospheric dust to axial tilt prevents Laurentide ice from advancing toward the Great Lakes and prevents Scandinavian ice from advancing toward Scotland. Hence, glaciation advances to the Late Wisconsin/Weichselian limit everywhere except on lands bordering the North Atlantic. In addition, a substantial retreat of Laurentide ice halfway through the glaciation cycle is caused by the warm hemicycle of axial tilt. Figure 39 shows surface elevation contours of ice and land for the first glacial maximum during the cold hemicycle of axial tilt, and velocity vectors for ice. Figure 40 shows these same features for the glacial minimum during the warm hemicycle of axial tilt. The Laurentide dome over Keewatin and the Scandinavian dome over the Gulf of Bothnia remain in place during these hemicycles.

\section{IHE EARLY QUATERNARY GLACIATION SCENARIO}

If anthropogenic carbon dioxide causes long-term climatic warming, Northern Hemisphere ice sheets initiated by a 41,000-year high-latitude insolation cycle, controlled by axial tilt, may not be able to advance far enough south to turn on the dust machine. In this case, glaciations during the next 100,000 years may have the periodicity of high-latitude Milankovitch insolation. This would reproduce the Early Quaternary record of ice volume changes that is revealed by oxygen isotope stratigraphy in ocean-floor sediments. 


\section{The Northern Hemisphere Glaciation Cycle}

For a warmer global climate the following experiment is performed. The snowline depression at the North Pole is cycled from $+300 \mathrm{~m}$ to $-2000 \mathrm{~m}$ (so that the amplitude is the same, but the signal is shifted to higher, and presumably warmer conditions) with a period of 41,000 years, analogous with the polar tilt cycle. Figure 41 shows changes in input and output variables over time for the finite-element model in this simulation. Figure 42 is a more prominent display of the tilt-controlled ice-volume variation.

Figure 43 shows 28 stages in the advance and retreat of Northern Hemisphere ice sheets as changing ice-elevation contours. As with the cooler cycles there is little growth initially (indeed, the Greenland Ice Sheet shrinks slightly before growth begins) until the snowline depression at approximately 12,500 years. Growth begins in the northern Canadian Arctic, as well as on Spitzbergen and along the northern edge of the Kara and Barents Seas.

Over the next 16,000 years, the ice-sheet complex grows to its maximum extent, attained at 28,500 years. At this point, the total volume is $16.51 \mathrm{Mkm}^{3}$ and the areal extent is $8.87 \mathrm{Mkm}^{2}$. The Kara and Barents Seas Ice Sheets are fully formed, with ice $4000 \mathrm{~m}$ thick centered over the northwest Siberian coast. Ice over the East Siberian Sea lce Sheet exceeds $1500 \mathrm{~m}$ in thickness.

Ice in Europe is less extensive, only extending about halfway down the Scandinavian peninsula. Ice in North America is centered northwest of Hudson Bay and is approximately $3500 \mathrm{~m}$ thick. The ice crosses Hudson Strait, but does not extend across Hudson Bay. There is only very limited growth (about $1500 \mathrm{~m}$ ) over the Cordillera, and areal extent is very limited.

Over the next 19,500 years, the ice sheets shrink as the snowline climbs back to $+300 \mathrm{~m}$, reaching its minimum size at 50,000 years. All that remains is a local ice cap centered on the northwest Siberian coast, and a Greenland Ice Sheet slightly less extensive than today. Total volume is just $1.23 \mathrm{Mkm}^{3}$ with areal extent of $1.02 \mathrm{Mkm}^{2}$. Our ice-wall calving mechanism would eliminate the local Siberian ice cap.

As the snowline depression continues its 41,000 year cycle, the ice sheets again grow, reaching a maximum extent again at 69,500 years and declining to a 
minimum at 91,000 years. These configurations are similar to the first maximum and minimum.

\section{The Northern Hemisphere Glacial Maximum}

Figure 44 shows ice-velocity vectors in relation to ice-elevation contours at the glacial maximum. Figure 45 is a three-dimensional oblique view of the glacial maximum. As an aside, several other experiments were performed with various tilt-cycle amplitudes. All started with the present Northern Hemisphere ice (just Greenland) and had periods of 41,000 years. Some had clear terminations (decline in size to less than or equal to the present) while others did not. Clearly some other mechanism besides tilt is active to produce the 100,000 year ice-age cycle. Amplitude 0 to $-1500 \mathrm{~m}$ yields maximum $7.37 \mathrm{Mkm}^{3}$ volume, $5.03 \mathrm{Mkm}^{2}$ area, and minimum $1.32 \mathrm{Mkm}^{3}$ volume, 1.06 $\mathrm{Mkm}^{2}$ area, (essentially just Greenland). Amplitude 0 to $-1800 \mathrm{~m}$ yields maximum 13.14 $\mathrm{Mkm}^{3}$ volume, $7.17 \mathrm{Mkm}^{2}$ area, minimum $4.15 \mathrm{Mkm}^{3}$ volume, $2.53 \mathrm{Mkm}^{2}$ area. Amplitude 0 to $-2300 \mathrm{~m}$ yields maximum $22.32 \mathrm{Mkm}^{3}$ volume, $10.99 \mathrm{Mkm}^{2}$ area, minimum $7.50 \mathrm{Mkm}^{3}$ volume, $4.22 \mathrm{Mkm}^{2}$ area. Amplitude 0 to $-3000 \mathrm{~m}$ yields maximum $29.92 \mathrm{Mkm}^{3}$ volume, $14.14 \mathrm{Mkm}^{2}$ area (this is maximum configuration, extending to full glacial extent), minimum $10.81 \mathrm{Mkm}^{3}$ volume, $5.40 \mathrm{Mkm}^{2}$ area. And finally, amplitude $-1000 \mathrm{~m}$ to $-1500 \mathrm{~m}$ yields maximum $8.54 \mathrm{Mkm}^{3}$ volume, $5.63 \mathrm{Mkm}^{2}$ area, minimum $7.51 \mathrm{Mkm}^{3}$ volume, $4.80 \mathrm{Mkm}^{2}$ area. 


\section{SIMULATION OF ANTARCTIC GLACIATION CYCLES}

In contrast with Northern Hemisphere glaciation cycles, those in the Antarctic do not involve terminations, only changes in size and shape of the present-day Antarctic Ice Sheet. Therefore, Antarctic glacial cycles simulated by the map-plane solution of our time-dependent, finite-element gridpoint model are based on calibrating the model and conducting sensitivity tests using a best-fit between the present-day ice sheet and an equilibrium ice sheet generated by the model in order to evaluate variable parameters in the model. Figure 46 shows our $x, y$ coordinate system for Antarctica.

Figure 47 shows the present-day surface elevation contours of the Antarctic Ice Sheet (Drewry, 198). Figure 48 shows the best fit to Figure 47 obtained by our finite-element model for the same surface elevation contours. Figure 49 compares Figures 47 and 48 as contours showing elevation differences between the two. Figure 50 contours the fraction $f_{u}$ of the bed over which sliding dominates that must be specified in order to obtain the best fit in Figure 49. Figures 51 and 52 contour values of parameter $A$ (which varies with ice hardness) and parameter $B$ (which varies with bed roughness) in the respective flow law (Glen, 1955) and sliding law (Weertman, 1957b) of glacial ice that are needed to obtain the best fit in Figure 49. Note that the only departure from reasonable values for $A$ are where sliding dominates (high values of $f_{u}$ ) and for $B$ are where flow dominates (low values of $f_{u}$ ). Therefore, these departures play no significant role in producing the best fit, or in controlling ice-sheet dynamics in the finite-element model.

\section{CALIBRATION}

A grid with $100 \mathrm{~km}$ spacing for Antarctica was generated by accepting the nearest points from the Budd data set $(281$ by $281,20 \mathrm{~km}$ gridded data for surface elevation, bedrock, thickness, and accumulation rate). All data points with no present ice and bedrock depths deeper than -2000 m were rejected, leaving a grid with 1772 nodes and 1664 elements.

The solution was fitted to the present surface by an iterative procedure involving adjusting the fraction of the column-average velocity due to sliding, the flow constant $A$, and sliding constant $B$ to continuously improve the solution at each point. In this 
procedure, the initial surface is taken to coincide with the present surface. The sliding fraction, flow constant, and sliding constant are taken initially to be uniform with values of $0.01,22.0$ bar $a^{1 / 3}$, and 0.02 bar $a^{1 / 2}$, respectively, for nodes which have ice presently covering them. These nodes were assigned a climate-zone type corresponding to Polar Continental, and a mass-balance relationship with the equilibrium line at 340 $\mathrm{m}$ (when unadjusted). Nodes which have no ice and with bedrock below sea level (continental shelf) have initial values of $1.0,2.0$ bar $\mathrm{a}^{1 / 3}$, and 0.02 bar $\mathrm{a}^{1 / 2}$, with ablation rates of $-5 \mathrm{~m} / \mathrm{yr}$. This high ablation rate models the removal of ice by calving of icebergs. It essentially does not allow ice to grow out onto the continental shelf. Nodes which from the Budd data set had ice thicknesses less than the ice surface to bedrock distance were considered to be ice shelf, and were assigned initial values of $1.0,2.0$ bar $\mathrm{a}^{1 / 3}$, and 0.02 bar $\mathrm{a}^{1 / 2}$ with ablation rates of $-0.1 \mathrm{~m} / \mathrm{yr}$, again to model mass removal by calving.

The solution is allowed to run for ten 100-year time steps, and then each nodal value of surface elevation is compared with the present surface value.

Each of the three parameters may be adjusted in such a way as to improve the fit. In other words, a calculated surface elevation that is too high will result in an increase in the sliding fraction (to allow more sliding which will lower the surface), or a decreases in the flow or sliding law constants (to allow ice to be softer or to slide more easily). This iteration is repeated until an adequate solution and set of parameters is obtained. Certain limitations on the variation of the parameters are imposed. For instance, the sliding fraction cannot exceed 1.0 nor be less than 0.0 . Reasonable values of the flow constant lie between 0.0 and 10.0 bar $a^{1 / 3}$, while the sliding constant is between 0.0 and 0.2 bar $a^{1 / 2}$. These are somewhat arbitrary limits, but serve as guidelines for the iterative process.

Very good agreement was obtained with the R.M.S. error being approximately $180 \mathrm{~m}$. Most of the interior of the ice sheet has a sliding fraction near or at zero, with significant regions of sliding along the coast, and in channels which coincide with known ice streams. In particular, large regions of sliding occur along the Siple Coast in the area of Ice Streams A, B, C, D, and E, upstream of the Lambert Glacier, and to the west of the Ronne Ice Shelf. There are also smaller regions that seem to coincide with major ice streams passing through the Transantarctic Mountains. All ice-shelf 
regions were fitted with sliding fractions of 1.0 and very low values of the sliding

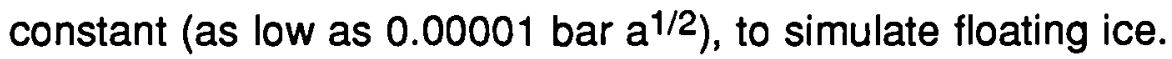

In regions where flow dominates, the flow constant is between 1.5 and 3.5 bar $a^{1 / 3}$. Very low fitted values are not significant since they fall in regions where sliding dominates, and hence they do not affect the calculation. A small region of high flow constants upstream of the sliding regions along the Siple Coast is necessary to generate the higher surface slopes evident in this area. Similar small regions exist upstream or adjacent to ice-stream features. Some of this may be due to the way in which element values of the various constants are obtained from an average of the nodal values for a particular element. Localized nodes with very low surfaces will require high amounts of sliding with low sliding and flow constants. An adjacent node with a higher elevation will require smaller sliding fractions with commensurate flow and sliding constants. Elements which straddle these regions of flow and sliding will use averages of their nodal values, and since sliding dominates over flow, they will act like sliding elements. Hence, adjacent elements will need lower values of the sliding fraction, and higher values of the flow constant to compensate for the low surface in the transition element. These types of problems only occur in a very limited area of the total ice sheet, and so should not cause concern.

\section{SENSITIVITY}

The fitted solution is for a South Pole snowline depression of $-2000 \mathrm{~m}$ and a snowline slope of $56 \mathrm{~m} / 100 \mathrm{~km}$. This results in a mass-balance curve with an equilibrium line at $-1660 \mathrm{~m}$ at the pole, rising to approximately sea level at $65^{\circ} \mathrm{S}$. Different values for the snowline depression lead to different equilibrium configurations for the ice sheet. Since the accumulation/ablation dependence on elevation produces an ablation zone at low elevations, a peak accumulation zone at intermediate elevations, and a low accumulation zone at higher elevations, the response to changing snowline depression can be complex. As can be seen from Table 2, lowering snowline can actually decrease equilibrium volume, as the low accumulation zone moves to lower elevations, hence delivering less snowfall to the high dome. Conversely, certain higher elevation snowlines can produce a larger volume ice sheet (although smaller in areal extent) because the peak accumulation zone is moved to higher elevations and hence produces a higher dome. 
IABLE2: The Effect of Snowline Depression on the Dimensions of the Antarctic Ice Sheet.

\begin{tabular}{|c|c|c|c|c|}
\hline $\begin{array}{c}\text { Snowline } \\
\text { Depression }(\mathrm{m})\end{array}$ & Volume $\left(\mathrm{Mkm}^{3}\right)$ & Area $\left(\mathrm{Mkm}^{2}\right)$ & $\begin{array}{c}\text { Average } \\
\text { Thickness }(\mathrm{m})\end{array}$ & Dome $(\mathrm{m})$ \\
\hline-3000 & 22.78 & 12.81 & 1545 & 3895 \\
\hline-2600 & 23.84 & 13.34 & 1528 & 3955 \\
\hline-2300 & 24.64 & 13.61 & 1534 & 4001 \\
\hline-2000 & 25.17 & 13.63 & 1564 & 4045 \\
\hline-1800 & 25.52 & 13.66 & 1581 & 4072 \\
\hline-1600 & 26.05 & 13.71 & 1606 & 4103 \\
\hline-1400 & 26.22 & 13.69 & 1618 & 4128 \\
\hline-1200 & 26.35 & 13.60 & 1638 & 4155 \\
\hline-1000 & 26.36 & 13.50 & 1654 & 4181 \\
\hline-800 & 25.85 & 12.98 & 1698 & 4207 \\
\hline-600 & 24.60 & 11.89 & 1819 & 4231 \\
\hline-400 & 23.73 & 11.09 & 1917 & 4255 \\
\hline-200 & 23.61 & 11.07 & 1914 & 4274 \\
\hline 0 & 21.74 & 10.00 & 2003 & 4295 \\
\hline 200 & 20.77 & 9.43 & 2040 & 4313 \\
\hline 400 & 18.66 & 8.70 & 2018 & 4323 \\
\hline 800 & 11.52 & 6.02 & 1876 & 4262 \\
\hline 1200 & 6.58 & 3.66 & 1768 & 4174 \\
\hline 1600 & 0.00 & 0.00 & 0 & $\star \star \star \star$ \\
\hline
\end{tabular}

\section{THE LATE QUATERNARY GLACIATION SCENARIO}

Our most probable scenario assumes no long-term anthropogenic climatic warming in the next 100,000 years, so that future glaciations in this timespan will be like Late Quaternary glaciations. In the Antarctic, this would involve climatic cooling during the glacial hemicycle, so we lowered the snowline at the South Pole from a present-day $-2000 \mathrm{~m}$ to a full glacial $-3000 \mathrm{~m}$ in our time-dependent, finite-element model. We also simulated the lowered full glacial sea level, required for the full-glacial ice volume of Late Quaternary ice sheets in the Northern Hemisphere, by reducing the 
ice-shelf ablation rate to zero. This allowed the Antarctic Ice Sheet to advance to the edge of the Antarctic continental shelf, as was the case during the late Wisconsin/Weichselian glacial maximum in Antarctica. However, unlike the ice sheet reconstructed by Stuiver and others (1981) using our finite-difference, flowline model, we used very low values of sliding-law parameter $B$ for ice grounded beyond present-day grounding lines in our finite-element gridpoint model. This prevented ice from getting thicker than glacial geology warranted in the Ross Sea and Weddell Sea embayments.

Figure 53 shows the variation over time of ice volume contributing to changing sea level in this simulation. Figure 54 shows Antarctic ice-elevation contours at the glacial maximum for comparison with present-day elevation contours in Figure 46. Figure 55 contours the change of ice thickness from interglacial to glacial conditions in Figures 47 and 54 . Lowering the snowline $1000 \mathrm{~m}$ from interglacial to glacial conditions produces smaller ice volume and ice thicknesses because peak accumulation occurs at lower ice-surface elevations. The full glacial conrfiguration in Figure 54, for a snowline depression of $-3000 \mathrm{~m}$ yields an ice volume of $28.93 \mathrm{Mkm}^{3}$ and an ice areal extent of $15.88 \mathrm{Mkm}^{2}$. Average ice thickness is about $100 \mathrm{~m}$ less and the high dome elevation is about $150 \mathrm{~m}$ lower, compared to the present-day ice sheet.

\section{IHE EARLY QUATERNARY GLACIATION SCENARIO}

Moderate anthropogenic climatic warming in the next 100,000 years might create Antarctic conditions at the glacial maximum in which the snowline retains the -2000 m depression at the South Pole that we specified to obtain a best fit between the present-day ice sheet and one simulated by the finite-element model in our calibration experiments, but in which sea level is lowered by formation of Northern Hemisphere ice sheets. This situation may have existed during the Early Quaternary, so we call this our Early Quaternary glaciation scenario.

To simulate Early Quaternary full glacial conditions, during which the ice margin advances to the edge of the continental shelf, and the ice shelves around Antarctica ground and thicken, the high ablation rates used in the calibration to model calving of icebergs were reduced to zero. With this situation, the margin advances out onto the continental shelves, and thickens by 500 to $900 \mathrm{~m}$ over the present ice shelves. For a snowline depression of $-2000 \mathrm{~m}$ (as in the present calibration) the volume increases to $30.60 \mathrm{Mkm}^{3}$ and the areal extent increases to $15.88 \mathrm{Mkm}^{2}$ (as in the Late Quaternary 
simulation). Average thickness changes very little (lower by about $20 \mathrm{~m}$ ) and the dome elevation only increases by $7 \mathrm{~m}$. Figure 53 shows the variation over time of ice volume contributing to changing sea level in this simulation. Figure 56 shows Antarctic ice-elevation contours at the glacial maximum, and Figure 57 contours elevation changes from Figure 47 to Figure 56.

\section{IHELATE TERTIARY GLACIATION SCENARIO}

A possibility for the future involves anthropogenic climatic warming over the next 100,000 years that would reproduce the warm global climate that existed during the Late Tertiary. In this scenario, global warming due to release of carbon dioxide into the atmosphere does not allow ice sheets to exist in the Northern Hemisphere, so the only variations in the cryosphere involve changes in size of the Antarctic Ice Sheet. Previous to 2.5 million years ago, there were no extensive glaciations in the Northern Hemisphere, even though there were major changes in the oxygen isotope record of deep sea cores. The variation in isotopic content presumably reflects changes in the configuration and size of the Antarctic lce Sheet.

Because the present-day Antarctic lce Sheet exists in a cold, dry environment that is above the snowline, changes in the mass balance due to temperature changes are not clearly defined. A warming at the pole can result in an increase in the volume of the ice sheet as the warmer, more moisture-laden air provides increased precipitation over the polar plateau.

With this in mind, a Milankovitch cycle from the present -2000 n snowline depression to $+300 \mathrm{~m}$ with a 41,000 year period was applied to the present Antarctic configuration. Figure 58 shows changes in input and output variables over time for the finite-element model in our simulation, and Figure 59 is a more prominent display of the tilt-controlled variation of ice volume contributing to changing sea level over time. As expected, the volume of the ice sheet increases for approximately 10,000 years, reaching a maximum volume of $25.90 \mathrm{Mkm}^{3}$ (an approximately 3 percent increase in volume), even as the snowline depression goes above $-1000 \mathrm{~m}$ (corresponding to a snowline elevation $1000 \mathrm{~m}$ higher than today). At this point, both volume and areal extent (which till 10,000 years had held constant) begin to decline. Minimum volume and areal extent are reached at 24,500 years, at which time volume is $20.7 \mathrm{Mkm}^{3}$ 
and areal extent is $9.48 \mathrm{Mkm}^{2}$ (approximately 80 and 70 percent of their respective present-day values). Note that the snowline reaches its highest value $2300 \mathrm{~m}$ above initial conditions at 21,500 years. This minimum configuration has a largely ice-free West Antarctica, with a slightly thicker East Antarctic Ice Sheet. As the snowline depression sinks back to its present $-2000 \mathrm{~m}$, volume and areal extent again increase beyond their present values to a second peak, by which time the snowline has again begun to rise and the cycle repeats. Figure 60 presents 10 stages in advance and retreat of the Antarctic Ice Sheet, shown as changing ice-elevation and ice-thickness contours. 



\section{REFERENCES}

Andersen, B.G. 1981. Late Weichselian ice sheets in Eurasia and Greenland. In The Last Great Ice Sheets. Edited by G. H. Denton and T. J. Hughes. New York: WileyInterscience. 1-65

Boulton, G.S., and A.S. Jones. 1979. Stability of temperate ice caps and ice sheets resting on beds of deformable sediment. Journal of Glaciology $24: 29-43$.

Broecker, W.S., and G.H. Denton. 1989. The role of ocean-atmosphere reorganizations in glacial cycles. Geochimica et Cosmochimica Acta 50 (10) : 24652501.

Broecker, W.S., and J. van Donk. 1970. Insolation changes, ice volumes, and the ${ }^{18} \mathrm{O}$ record in deep-sea cores. Reviews of Geophysics and Space Physics 8 (1) : 169-198.

Budd, W.F. 1969. The Dynamics of Ice Masses. Antarctic Division, Department of Supply. Australian National Antarctic Research Expeditions (ANARE) Interim Reports, Series A (IV), Glaciology. 108. City: 216 pages.

Budd, W. F., D. Jensen, and U. Radok. 1971. Derived physical characteristics of the Antarctic lce Sheet. Antarctic Division, Department of Supply. Australian National Antarctic Research Expeditions (ANARE) Interim Reports, Series A (IV), Glaciology. 120. City: 178 pages

Budd, W.F., B.J. McInnes, D. Jenssen, and I.N. Smith. 1987. Modeling the response of the West Antarctic lce Sheet to a climatic warming. In Dynamics of the West Antarctic Ice Sheet. Edited by C. J. van der Veen and J. Oerlemans. Dordrecht: D. Reidel. 321358

Denton, G.H., and T.J. Hughes. 1981a. The Arctic lce Sheet: An outrageous hypothesis. In The Last Great Ice Sheets. Edited by G. H. Denton and T. J. Hughes. New York: Wiley-Interscience. 437-467

Denton, G.H., and T.J. Hughes. 1981b. The Last Great Ice Sheets. New York: WileyInterscience. 484 pages.

Fastook, J.L. 1984. West Antarctica, the sea-level controlled marine instability: Past and Future. In Climate Processes and Climate Sensitivity. Edited by J. E. Hansen and T. Takahashi. American Geophysical Union Monograph 29. 275-287.

Fastook, J.L., and J.E. Chapman. 1989. A map-plane finite-element model: three modelina experiments. Journal of Glaciology 35 (119) : 48-50. 
Fastook, J.L., and W.F. Schmidt. 1982. Finite-element analysis of calving from ice fronts. Annals of Glaciolegy $3: 103-106$.

Glen, J.W. 1955. The creep of polycrystalline ice. Proceedings of the Royal Society of London Series A (228) : 519-538.

Hays, J.D., J. Imbrie, and N.J. Shackleton. 1976. Variations in the Earth's orbit:

Pacemaker of the ice ages. Science $1974: 1121-1132$.

Hughes, T. 1981. Numerical reconstructions of paleo ice sheets. In The Last Great Ice Sheets. Edited by G. H. Denton and T. J. Hughes. New York: Wiley-Interscience. 221261.

Hughes, T. 1989. Calving ice walls. Annals of Glaciology $12: 74-80$.

Hughes, T., and M. Nakagawa. 1989. Bending shear: The rate-controlling mechanism for calving ice walls. Journal of Glaciology 35 (120) : 260-266.

Hughes, T.J. 1985. The Great Cenozoic Ice Sheet. Palaeogeography. Palaeoclimatology. Palaeoecology $50: 9-43$.

Hughes, T.J. 1987. Ice dynamics and deglaciation models when ice sheets collapsed. In North America and Adjacent Oceans During the Last Deglaciation. The Geology of North America. Edited by W. F. Ruddiman and H. E. Wright Jr. K-3. Boulder: Geological Society of America. $183-220$

Hughes, T.J., G.H. Denton, and M.G. Grosswald. 1977. Was there a late Wurm Arctic Ice Sheet? Nature $266: 596-602$.

Imbrie, J., J.D. Hays, D. Martinson, A. Mclntyre, A. Mix, J. Morley, N. Pisias, W. Prell, and N.J. Shackleton. 1984. The orbital theony of Pleistocene climate: support for a revised chronology of the marine $\delta 180$ record. In Milankovitch and climate. Part 1. Edited by A. L. Berger, I. Imbrie, A. Hays; G. Kukla and B. Saltzman. Dordrecht: D. Reidel. 269-305.

Kotef, C. 1974. The morphologic sequence concept and deglaciation of southern New England. In Glacial Geomorphology. Edited by D.R. Coates. Binghamton, New York. State University of New York: 121-144. Lindstrom, D.R. 1990. The Eurasian Ice Sheet: formation and collapse resulting from natural atmospheric $\mathrm{CO}_{2}$ concentration variations. Journal of Paleoeanography 5 (2) : 207-227.

Lindstrom, D.R., and D.R. MacAyeal. 1989. Scandinavian, Siberian and Arctic Ocean glaciation: effect of Holocene atmospheric $\mathrm{CO}_{2}$ variations. Science $245: 628-631$. 
Lingle, C.S. 1985. A numerical model of interactions between a marine ice sheet and the solid Earth: Application to a West Antarctic ice stream. Journal of Geophysical Research 90 (C1) : 1100-1114.

Lingle, C.S., T. Hughes, and R.C. Kollmeyer. 1981. Tidal flexure of Jakobshavns Glacier, west Greenland. Journal of Geophysical Research 86 (B5) : 3960-3968.

MacAyeal, D.R. 1989. Large-scale ice flow over a viscous basal sediment: theory and application to ice stream B, Antarctica. Journal of Geophysical Research 94 (B4) : 4071-4087.

Manabe, S., and A.J. Broccoli. 1985. The influence of continental ice sheets on the climate of an ice age. Journal of Geophysical Research $90: 2167-2190$.

Mayewski, P.A., G.H. Denton, and T.J. Hughes. 1981. Late Wisconsin ice sheets of North America. In The Last Great Ice Sheets. Edited by G. H. Denton and T. J. Hughes. New York: Wiley-Interscience. 67-178.

Mercer, J.H. 1984. Simultaneous climatic change in both hemispheres and similar bipolar interglacial warming: Evidence and implications. In Climate Processes and Climatic Sensitivity. Edited by M. Ewing. 5. Washington, D.C.: American Geophysical Union. 307-313.

Parish, T.R. 1980. Surface Winds in East Antarctica. Madison: Department of Meteorology, University of Wisconsin, 121 pages.

Paterson, W.S.B., 1981. The Physics of Glaciers. Oxford, Pergamon. 380 pages.

Pelto, M., S.M. Higgins, T.J. Hughes, and J.L. Fastook. 1990. Modeling mass-balance changes during a glaciation cycle. Annals of Glaciology $14:$ in press.

Stuiver, M., G.H. Denton, T.J. Hughes, and J.L. Fastook. 1981. History of the marine ice sheet in West Antarctica during the last glaciations: A working hypothesis. In The Last Great Ice Sheets. Edited by G. H. Denton and T. J. Hughes. New York: Wiley-Interscience. 319-436.

Sugden, D.E. 1978. Glacial erosion by the Laurentide Ice Sheet. Journal of Glaciology $20(83): 367-391$.

Thomas, R.H. 1977. Calving bay dynamics and ice sheet retreat up the St. Lawrence valley system. Geographie Physique et Quaternaire 31 (3-4) : 347-356.

Thomas, R.H., and C.R. Bentley. 1978. A model for Holocene retreat of the West Antarctic ice sheet. Quaternary Research $10: 150-170$.

Weertman, J. 1957a. Deformation of Floating Ice Shelves. Journal of Glaciology. 3(21) : 38-42.

Weertman, J. 1957b. On the sliding of Glaciers. Journal of Glaciology 3 (21) : 33-38. 
Zotikov, I.A. 1961. Teplovoi rejim lednika tsentralnoi Antarktidy (Heat regime of the Central Antarctic glacier). Informatsionny Bulleten Sovetskoy Antarktich eskoy Ekspeditsii (28)

Zotikov, I.A. 1963. Bottom melting in the central zone of the ice shield on the Antarctic continent and its influence upon the present balance of the ice mass. Bulletin of the International Association of Scientific Hydrology VIlle (Annee No. 1) : 36-44. 


\section{EIGURES}
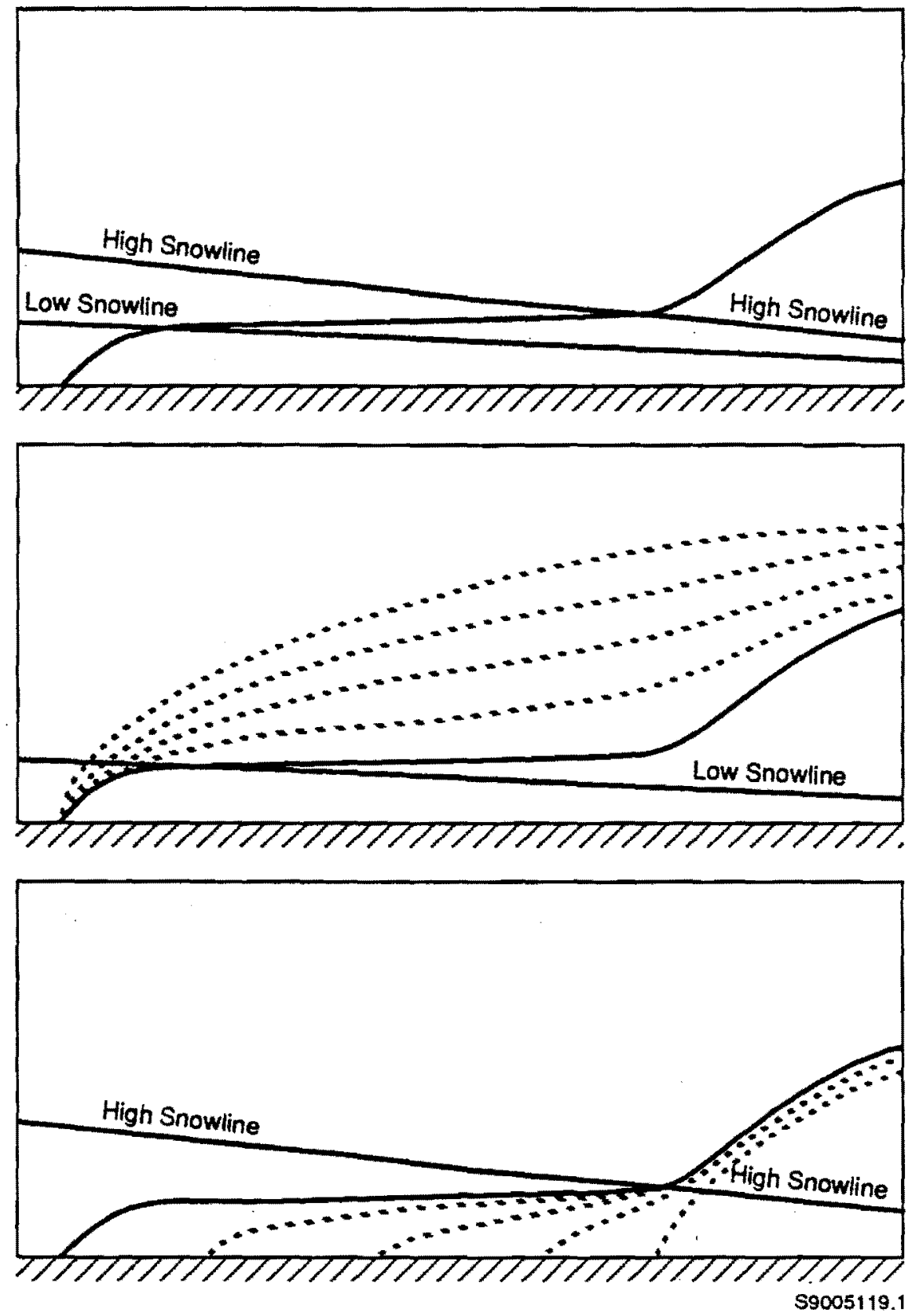

FIGURE 1. The Effect of Snowline Elevation on an Ice Lobe. Changes in snowline elevation (top) place an ice lobe in an accumulation zone that freezes the bed and thickens the lobe (middle) or an ablation zone that makes the lobe retreat (bottom). 

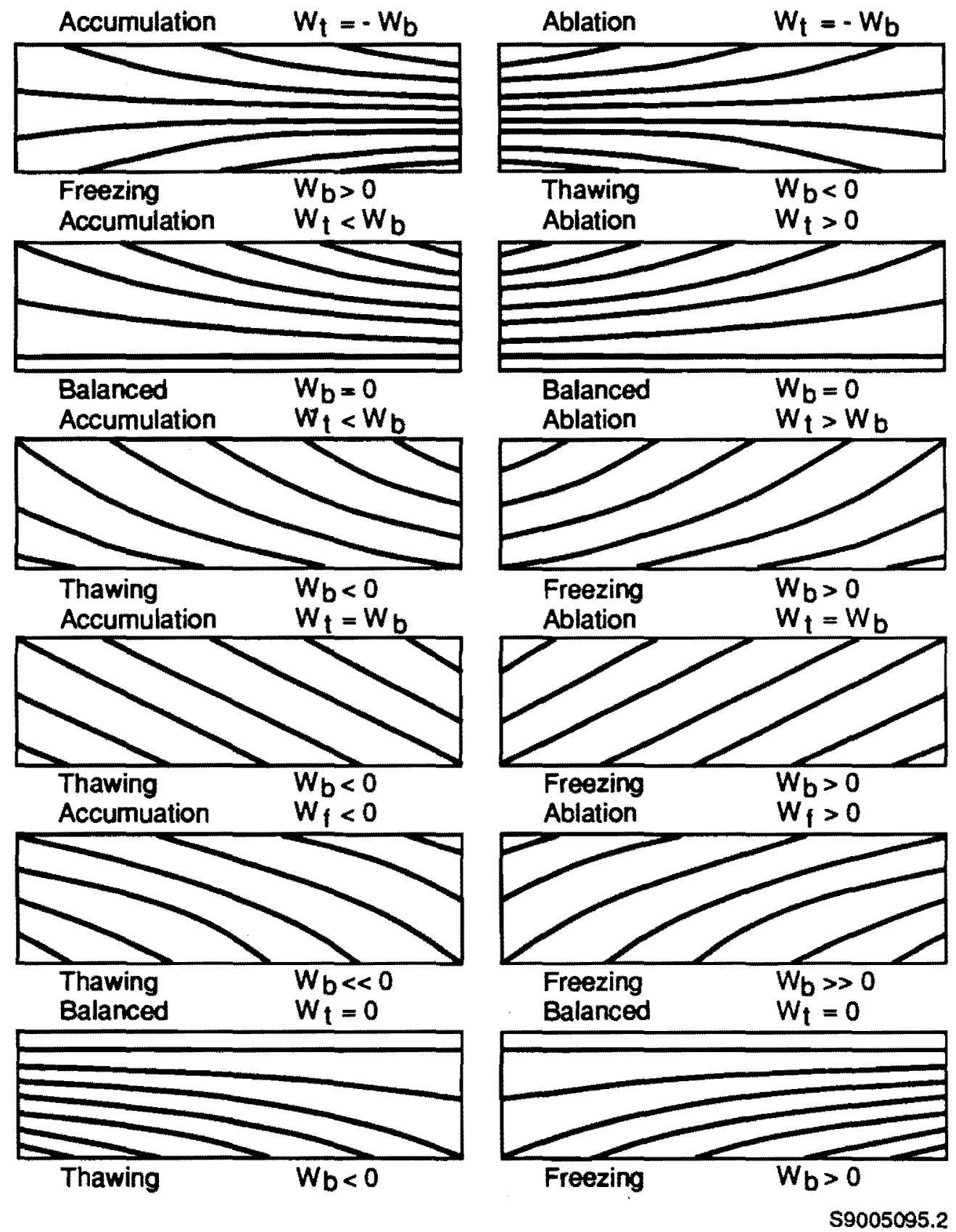

EIGURE2. Flowlines in a Moving Ice Slab. Flowlines in longitudinal cross-section for an ice slab with various top accumulation or ablation rates and bottom freezing or thawing rates. 

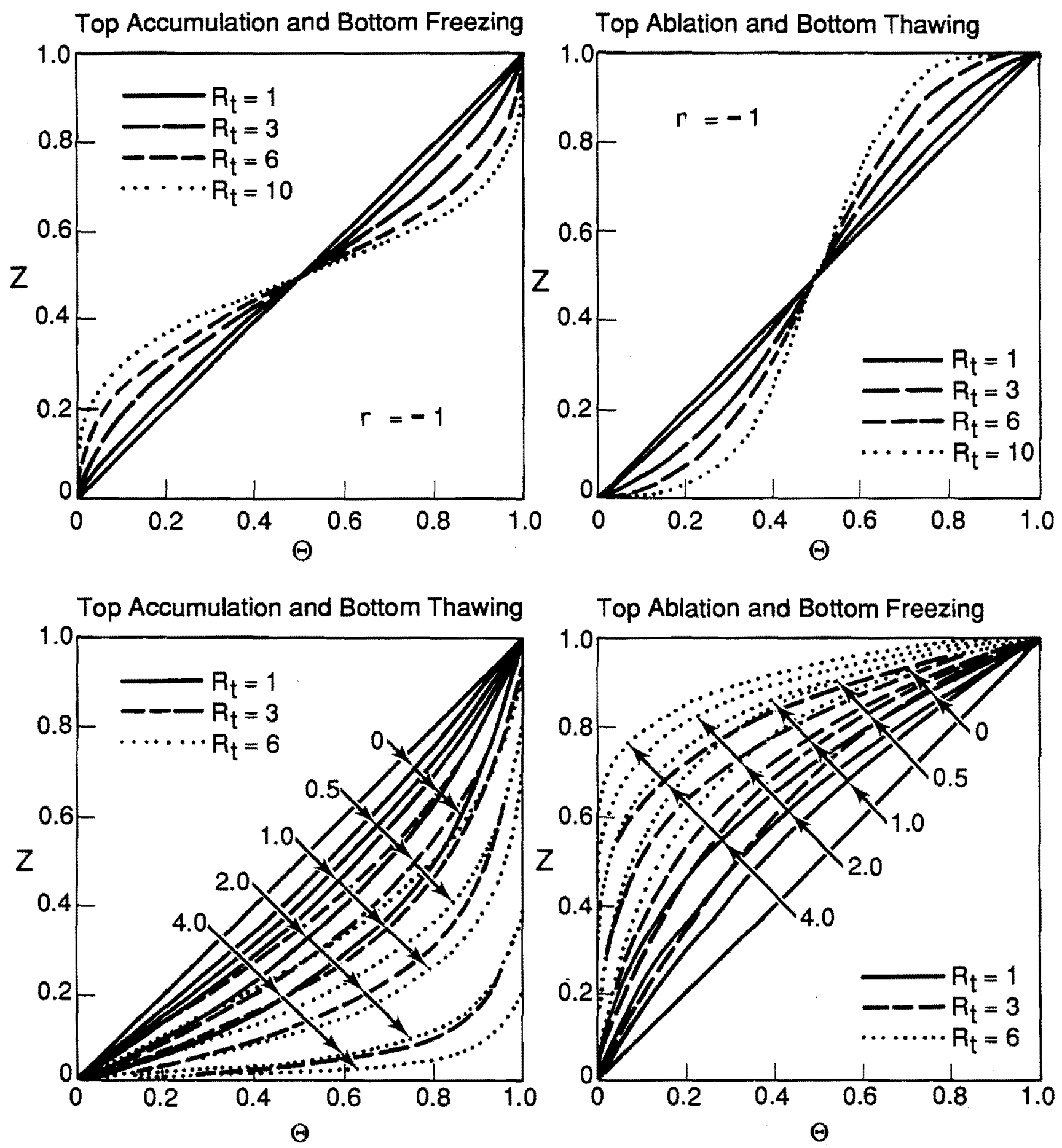

ElGURE 3. Temperatures in a Moving Ice Slab. Plots of normalized temperature $\theta$ for various ratios $r=w_{b} / w_{t}$ and $R_{t}=w_{t} h / k$ for the ice slab in Figure 2. 


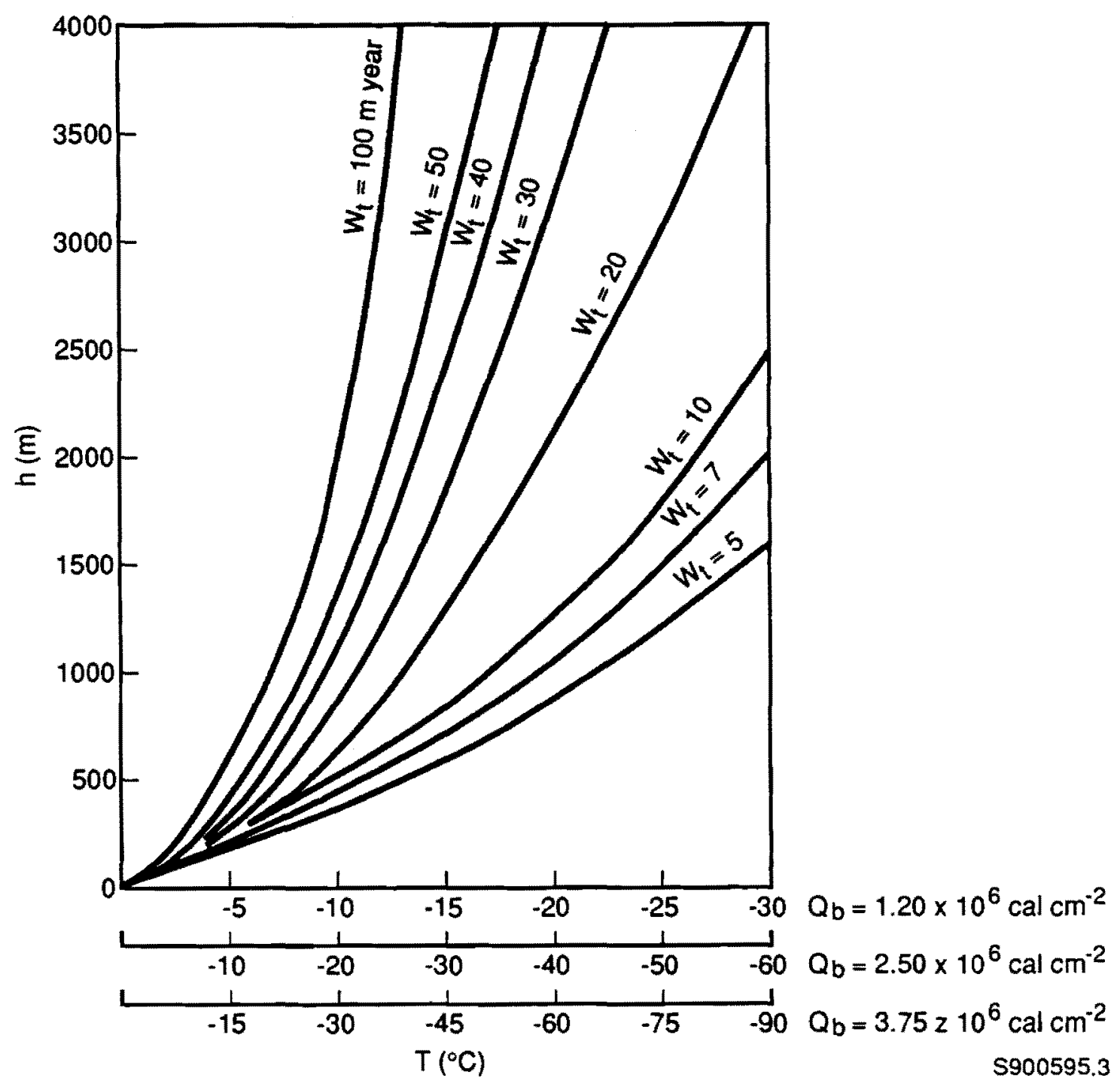

FIGURE 4. Minimum Thicknesses for Basal Melting in a Moving Ice Slab. Variations of minimum thickness $h_{M}$ with top surface temperature $T_{t}$ for the ice slab in Figure 2 that permits basal melting for reasonable values of top surface accumulation rate $w_{t}$ and bottom surface heat flux $Q_{b}$. 


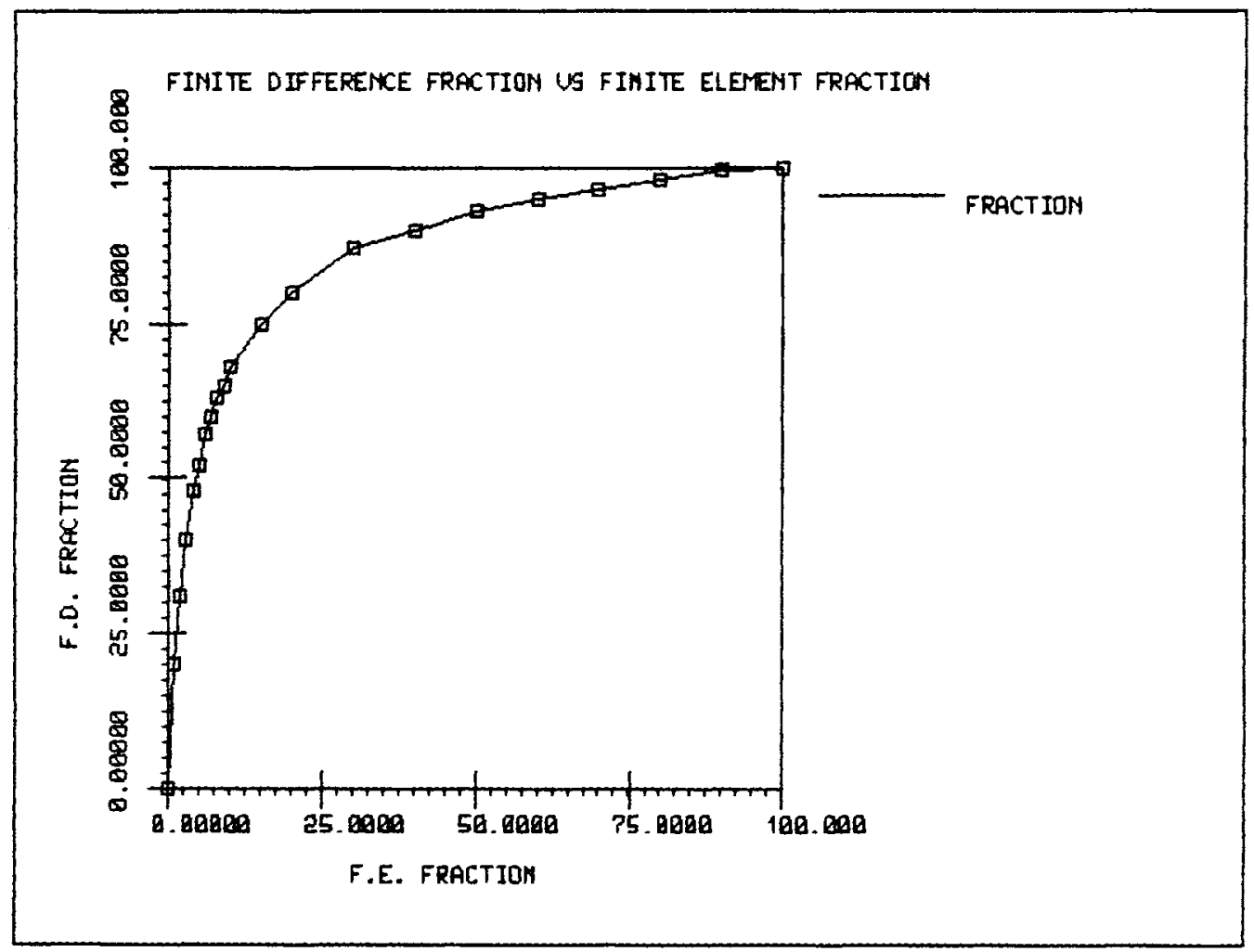

FIGURE 5. Comparison Between Basal Thawed and Sliding Fractions. The variation of basal thawed fraction $f_{s}$ defined for basal shear stress $\tau_{0}$ in the finite-difference model with basal sliding fraction $f_{u}$ defined for basal sliding velocity $u_{o}$ in the finite-element model used in modeling ice sheets. 


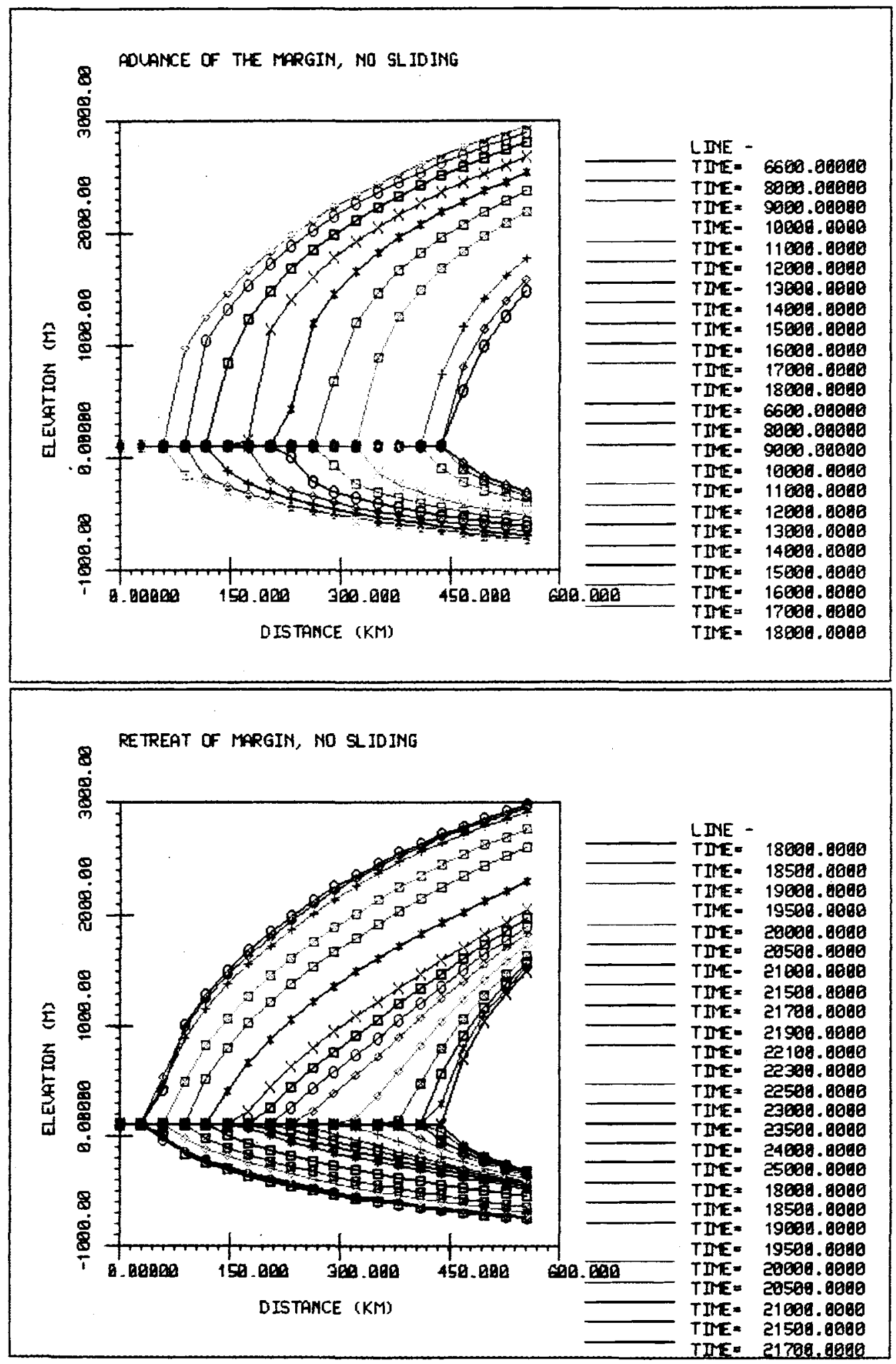

FIGURE 6. An Ice Lobe on a Frozen Bed During the Precession Cycle. Advance (top) and retreat (bottom) of an ice lobe on a frozen bed for constant rear input flux and a snowline elevation driven by the 21,000-year axial precession cycle. 

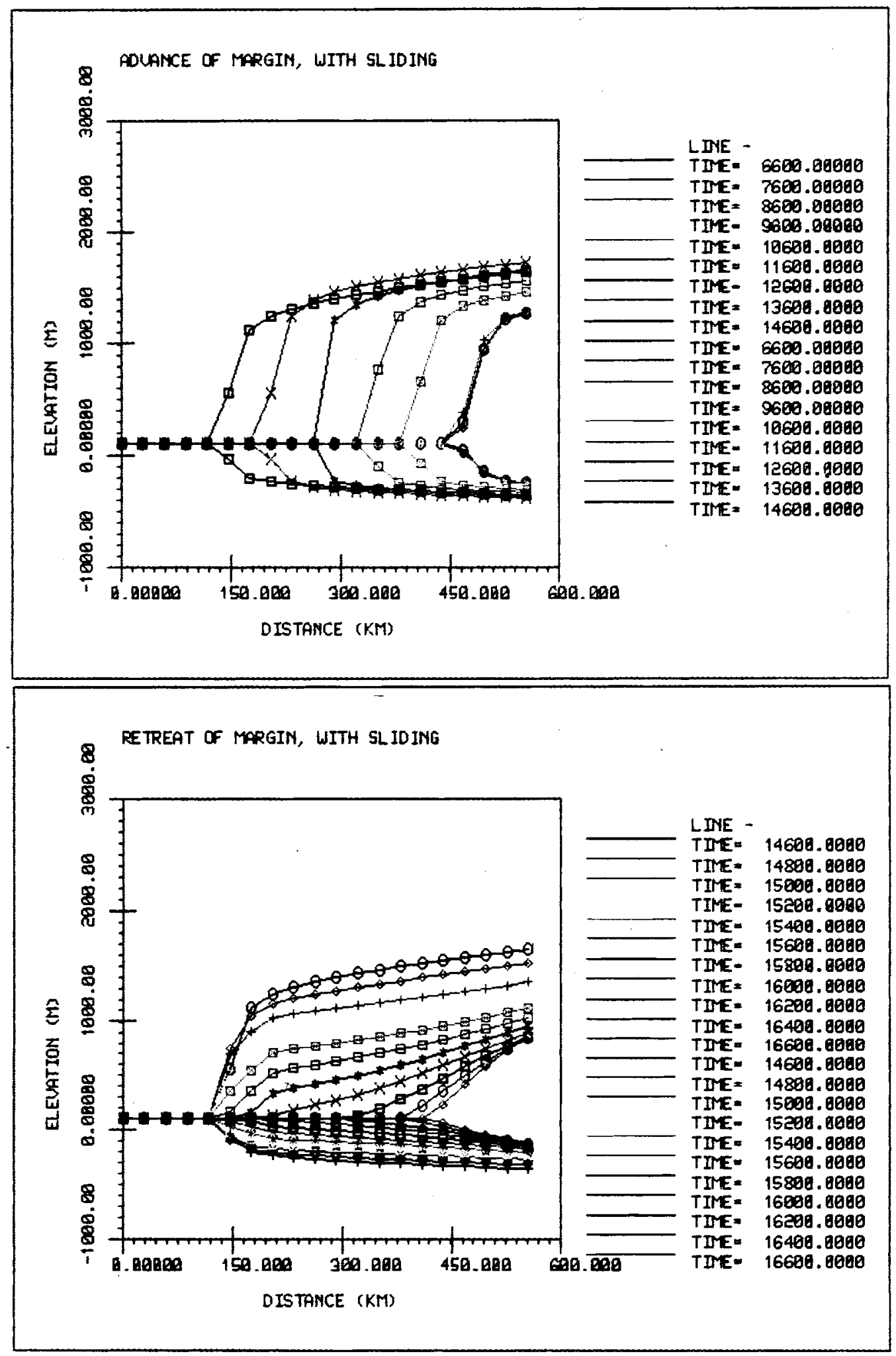

FIGURE 7. An Ice Lobe on a Thawed Bed During the Precession Cycle. Advance (top) and retreat (bottom) of an ice lobe on a thawed bed for constant rear input flux and a snowline elevation driven by the 21,000-year axial precession cycle. 


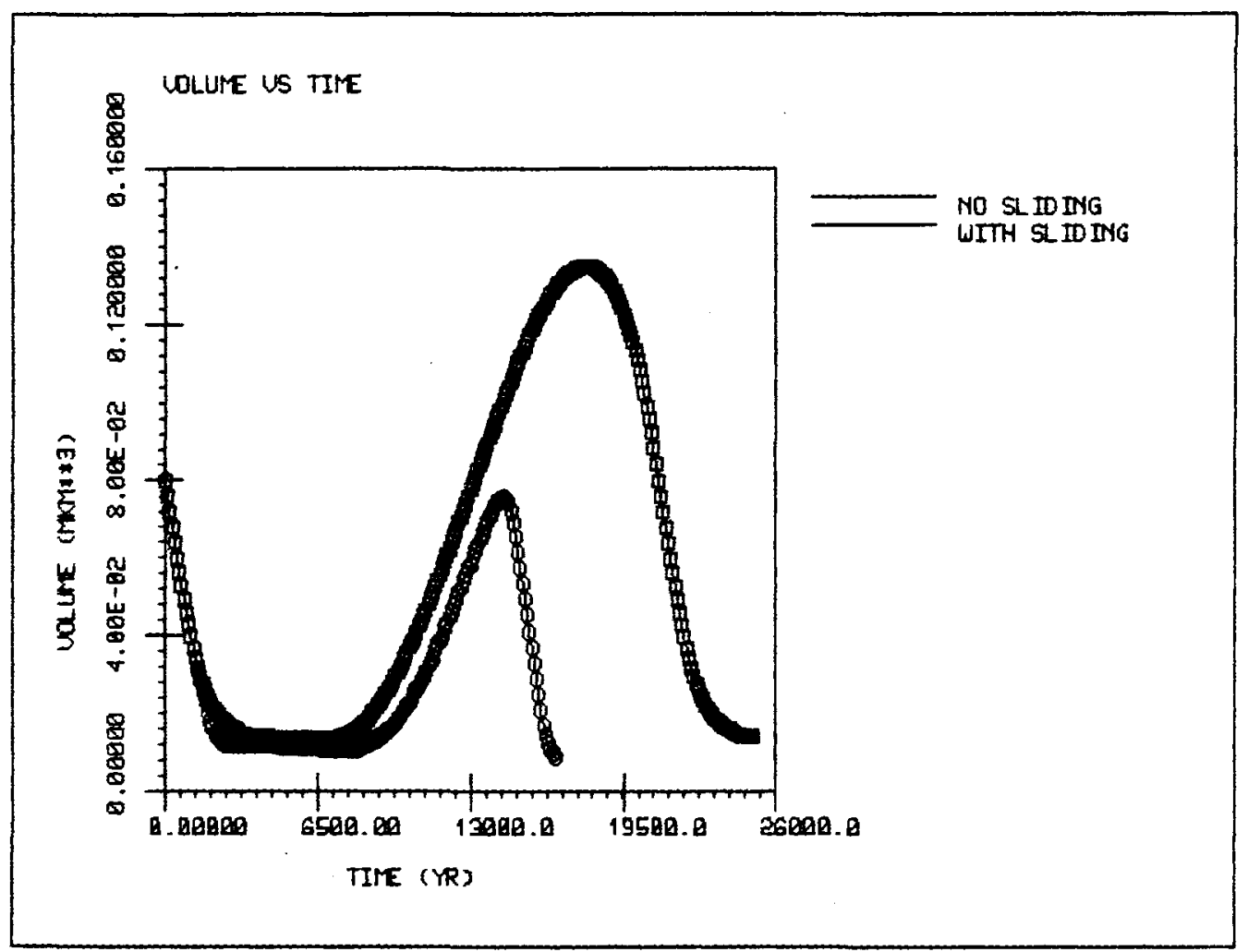

EIGURE 8. Ice Volume Changes in a Moving Ice Lobe. Ice volume change with time for advance and retreat of ice lobes in Figure 6 (upper curve) and in Figure 7 (lower curve) when snowline elevations are controlled by the 21,000-year cycle of axial precession. 


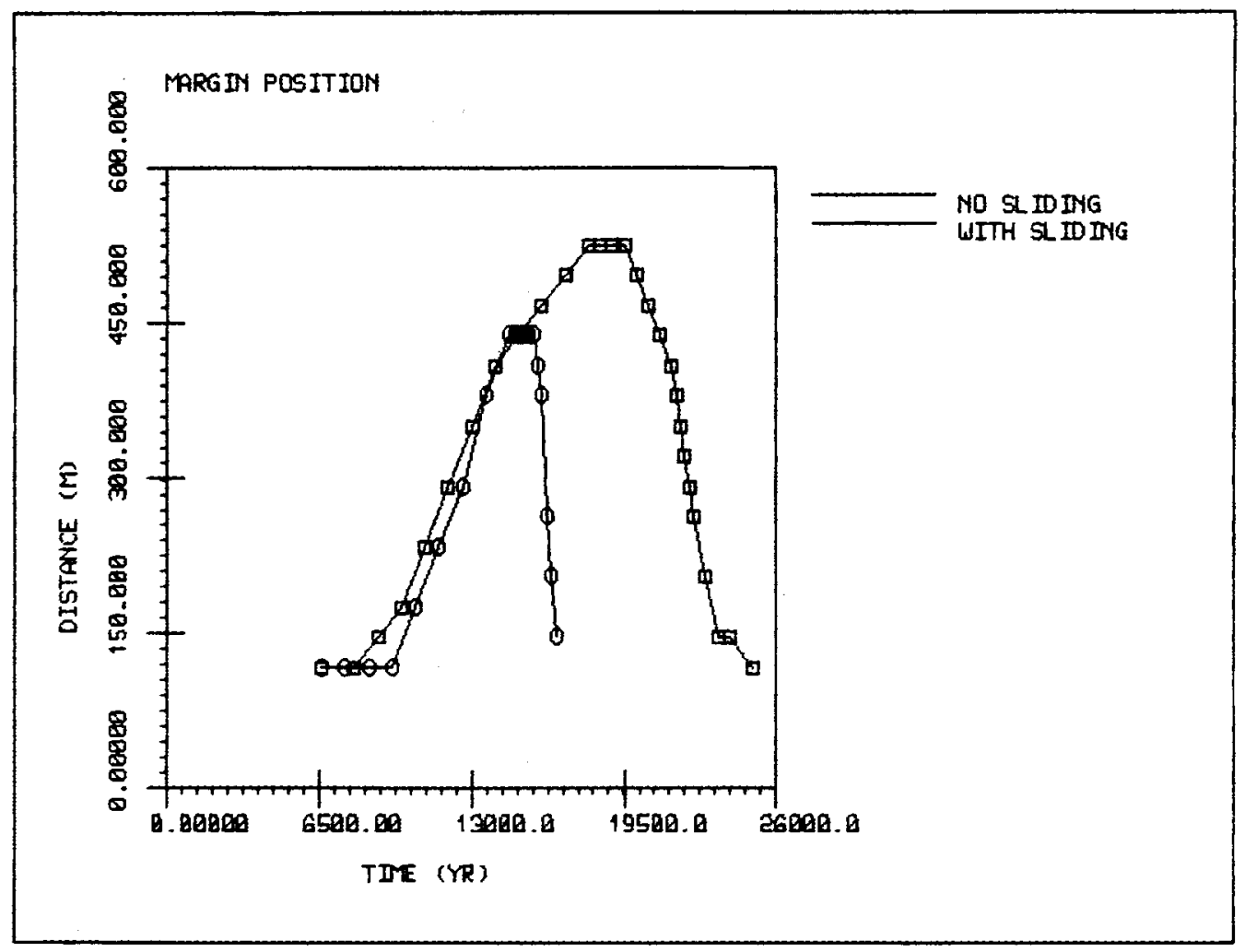

EIGURE 9. Ice Margin Positions in a Moving Ice lobe. Ice margin positions with time for advance and retreat of ice lobes in Figure 6 (upper curve) and in Figure 7 (lower curve) when snowline elevations are controlled by the 21,000-year cycle of axial precession. 

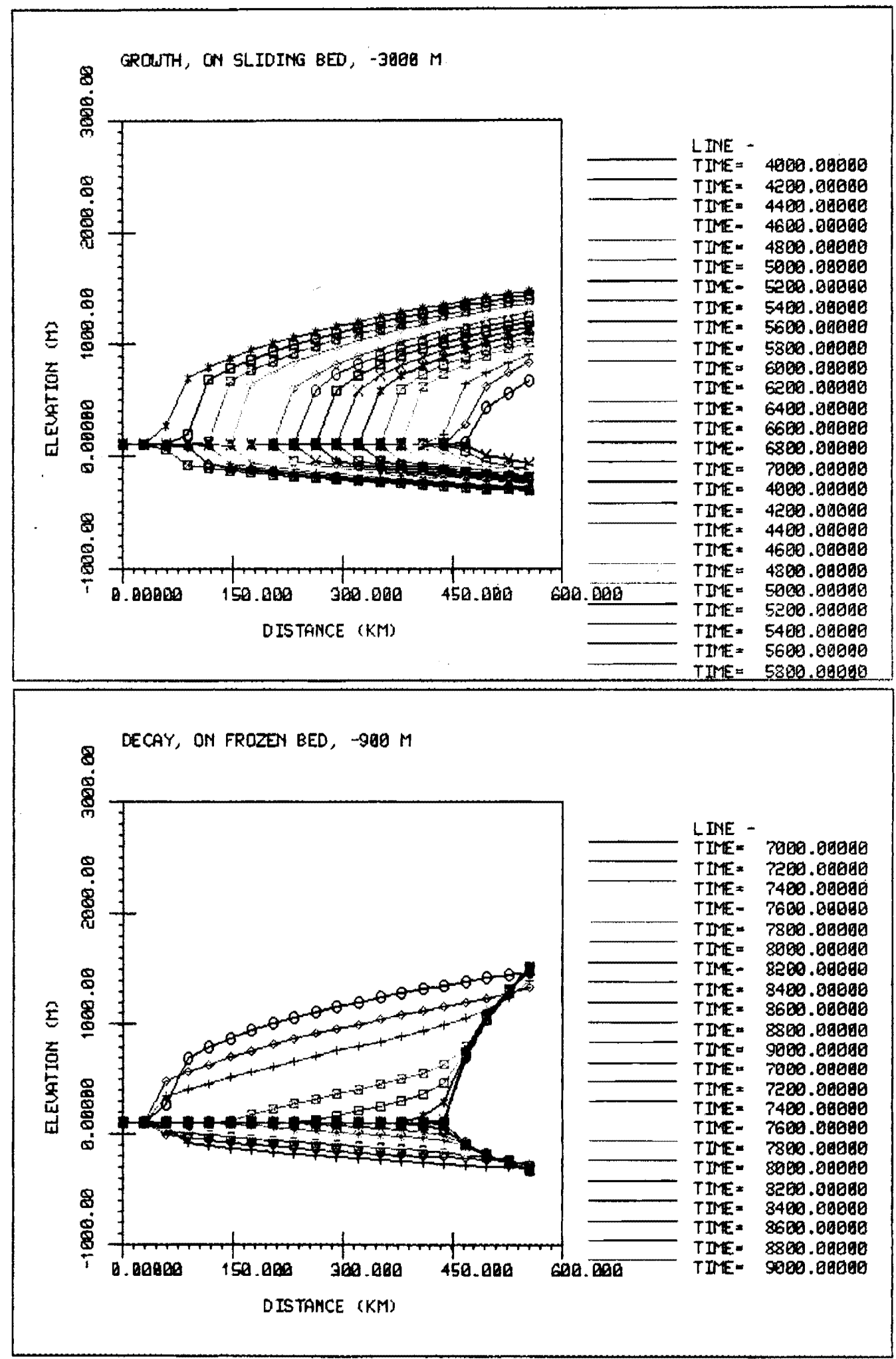

FIGURE 10. An Ice Lobe When Temperature Lags Motion and Dust. Advance on a thawed bed (top) and retreat on a frozen bed (bottom) of an ice lobe for constant rear input flux and a sudden rise in snowline elevation caused by turning the dust machine off. 

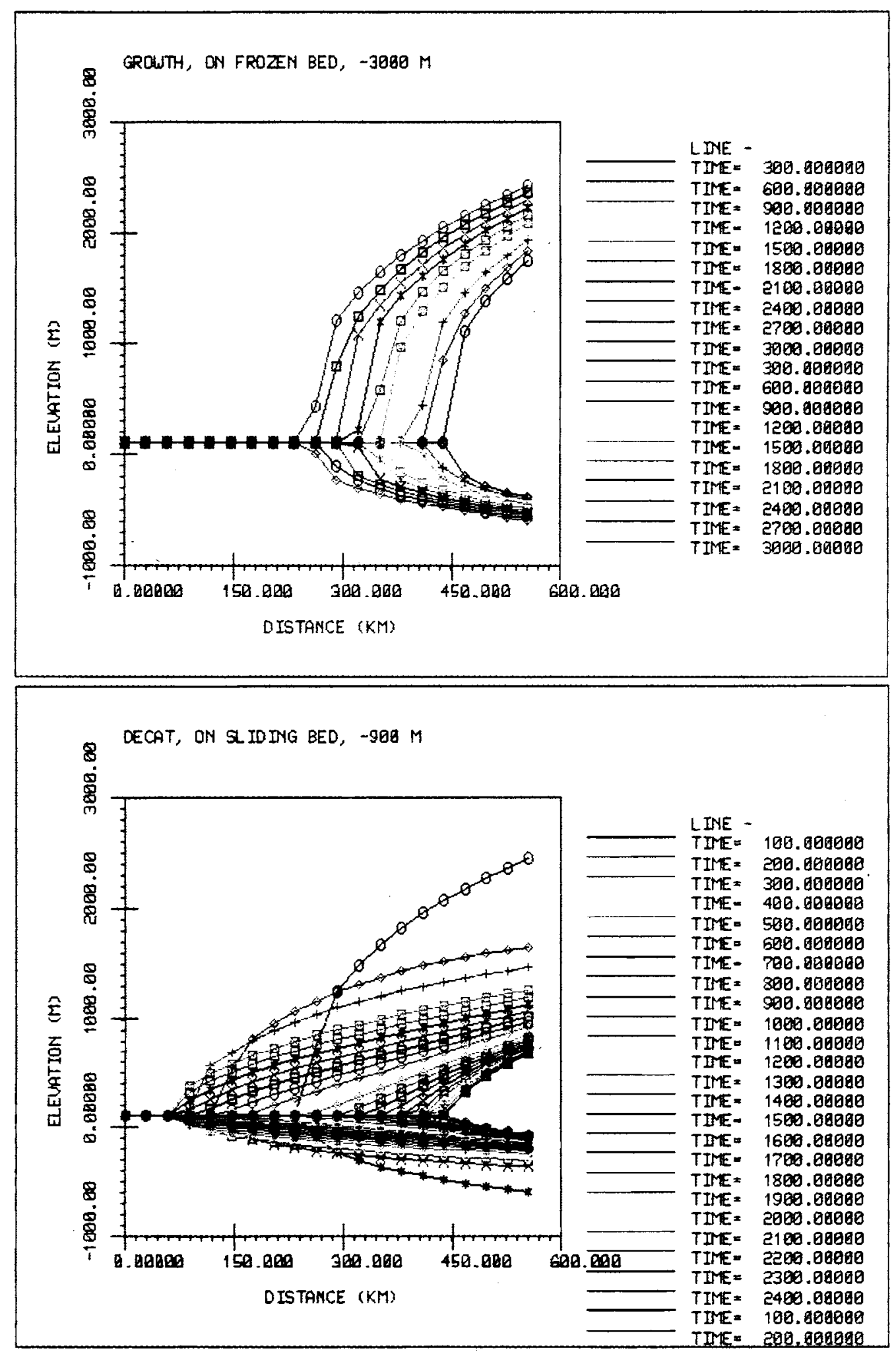

ElGURE 11. An Ice Lobe When Temperature Tracks Motion and Dust. Advance on a frozen bed (top) and retreat on a thawed bed (bottom) of an ice lobe for constant rear input flux and a sudden rise in snowline elevation caused by turning the dust machine off. 


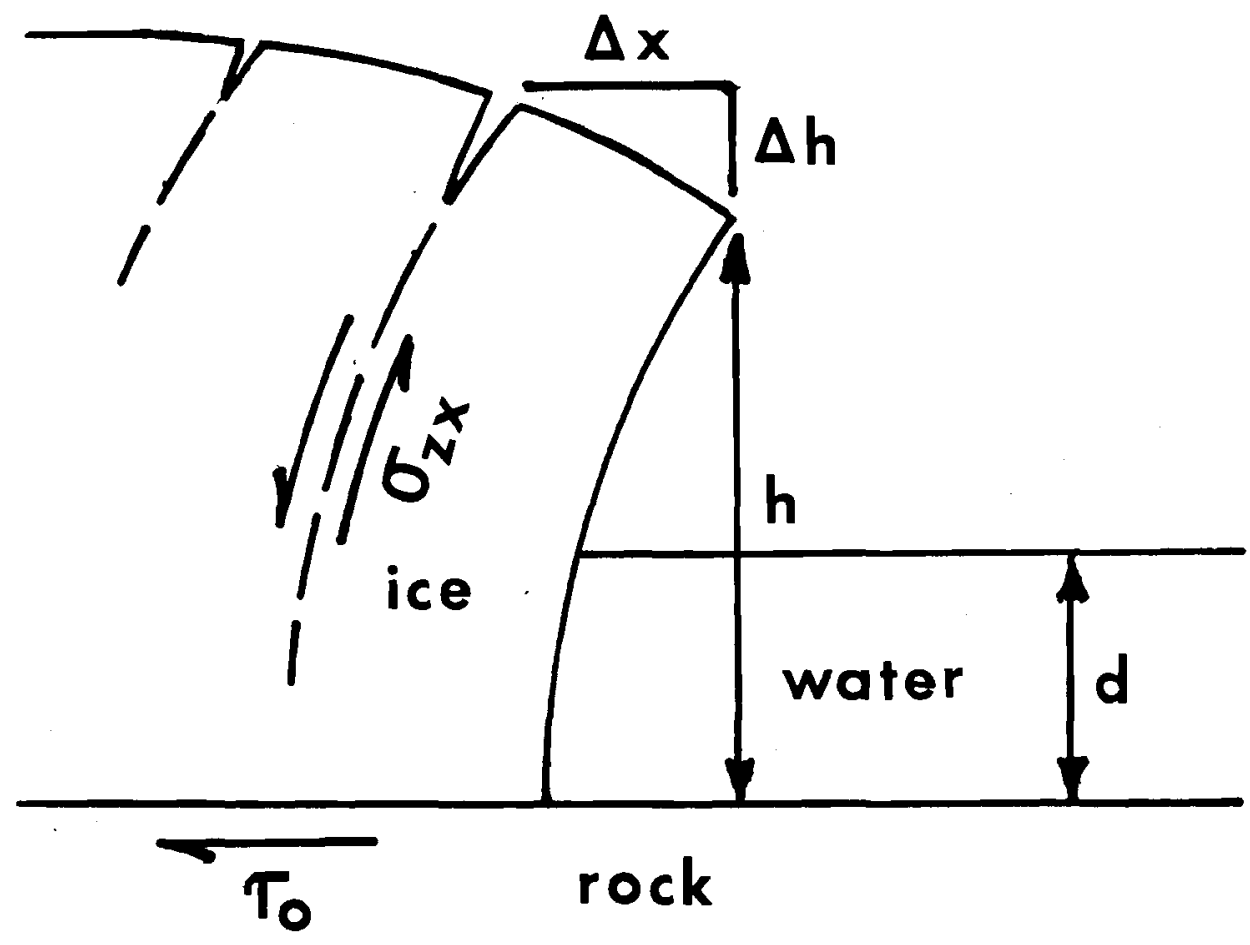

ElGURE 12. Calving from an Ice Wall Standing in Water. A bending shear mechanism initiates calving of slabs from an ice wall of height $h$ grounded in water of depth $d$. 


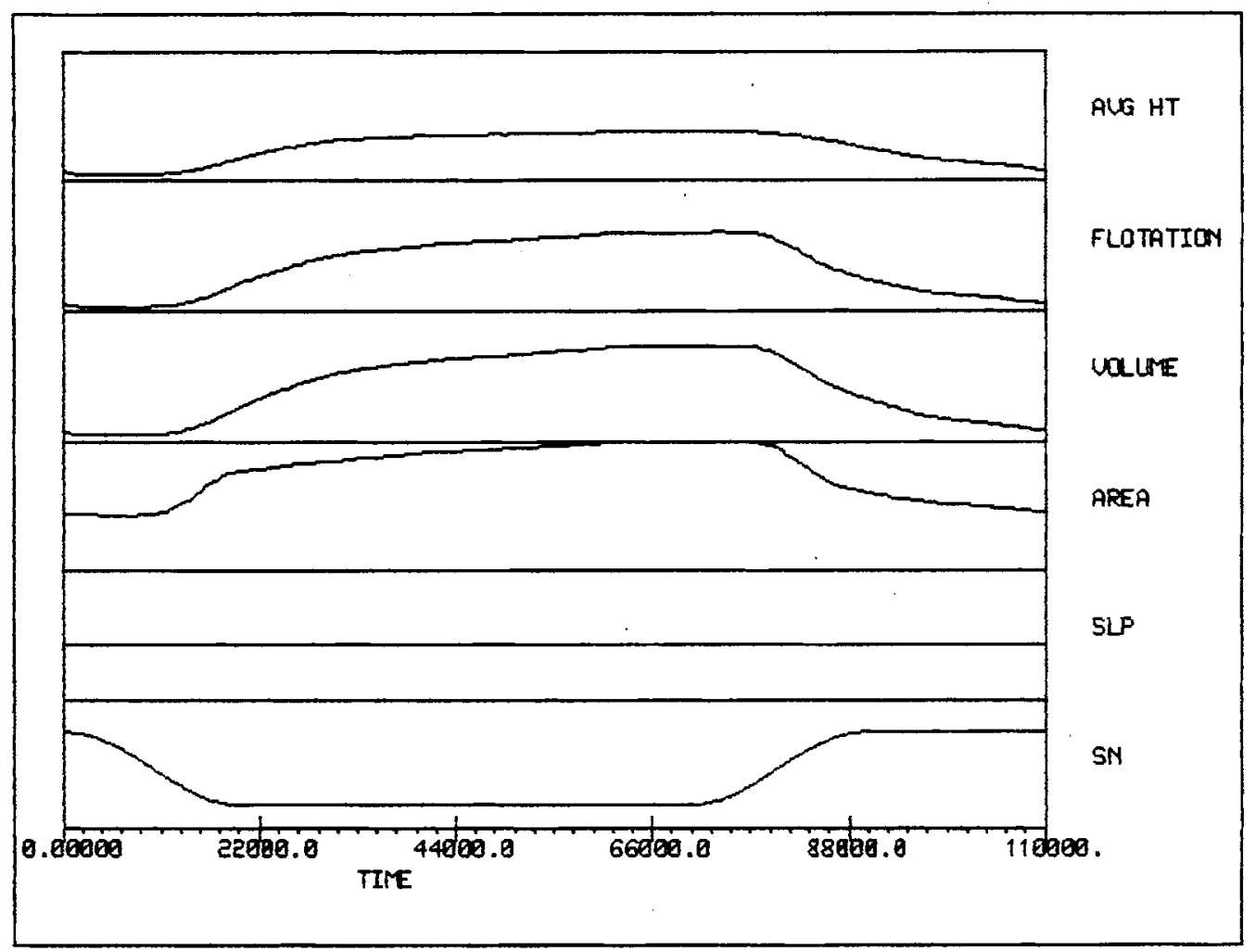

FlGURE 13. Arctic Model Input and Output When Dust Dominates. Variations over 110,000 years are shown for average ice-sheet height (AVG HT), icesheet volume contributing to sea level (FLOTATION), total ice-sheet volume (VOLUME), ice-sheet areal extent (AREA), sliding law parameter (SLP), and North Pole snowline elevation (SN). 


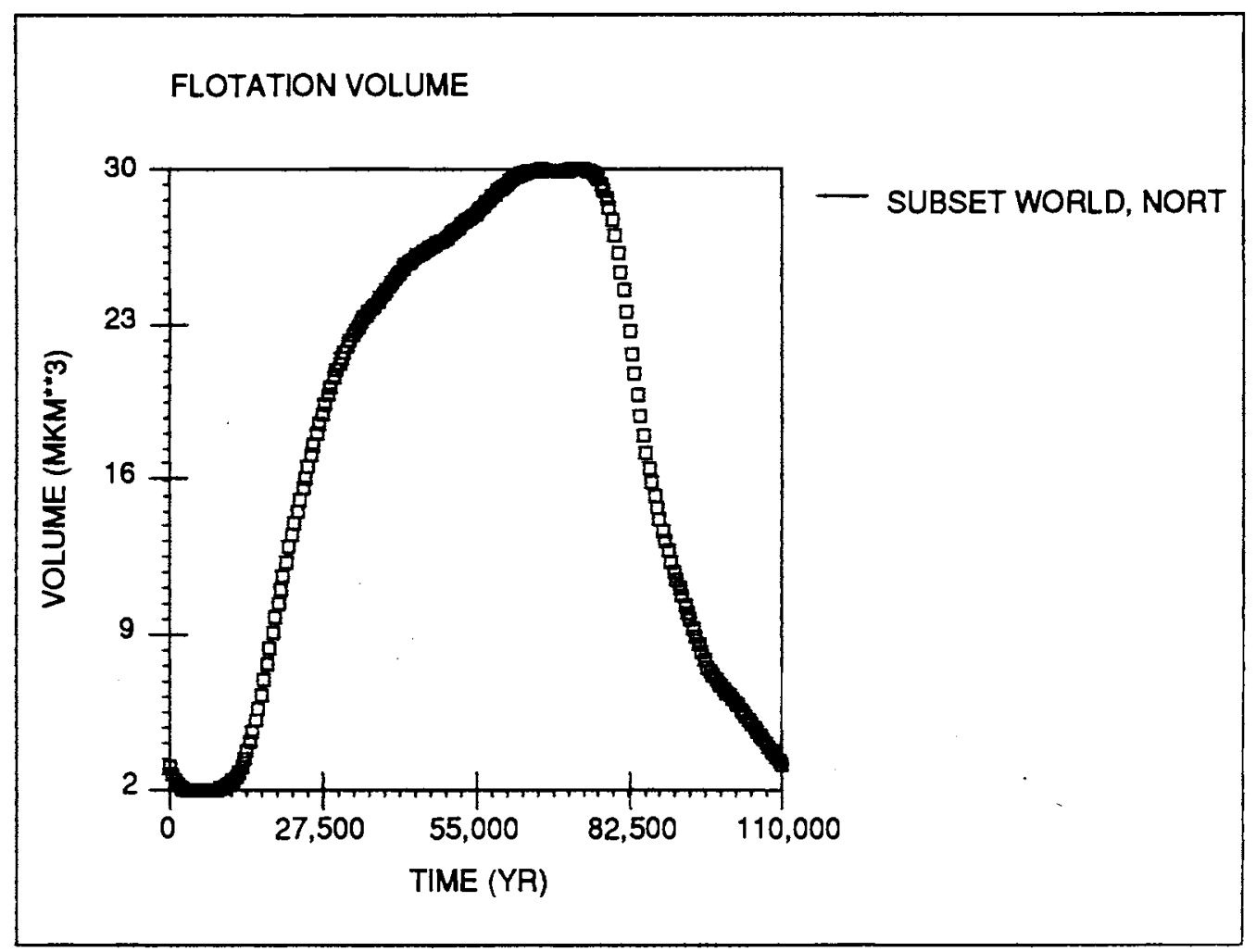

FIGURE 14. Arctic Flotation Ice Volume Over Time When Dust Dominates.

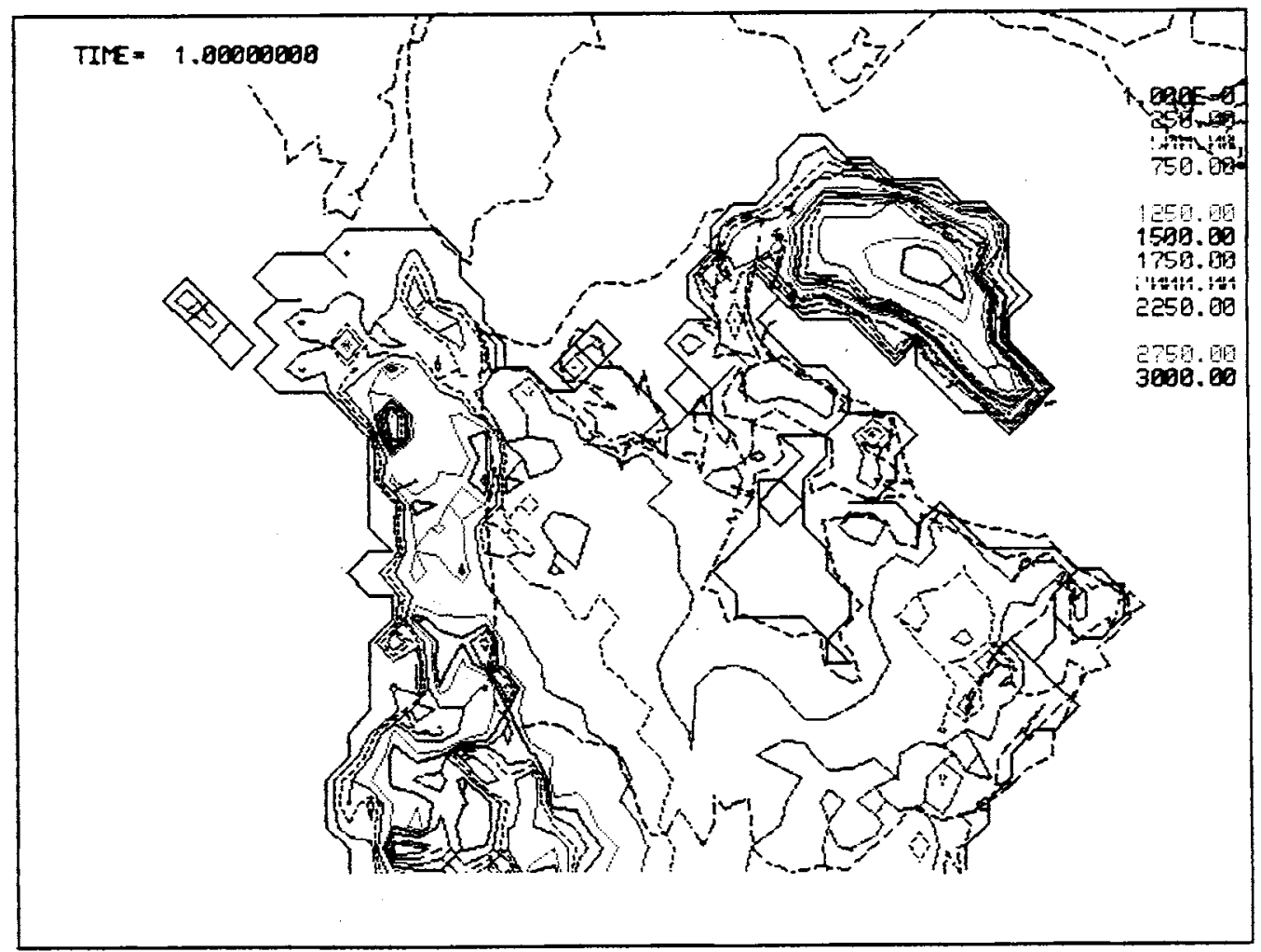

ElGURE 15. North American Topography, Today. Present-day land (North America) and ice (Greenland) surface elevations are contoured every $250 \mathrm{~m}$. 


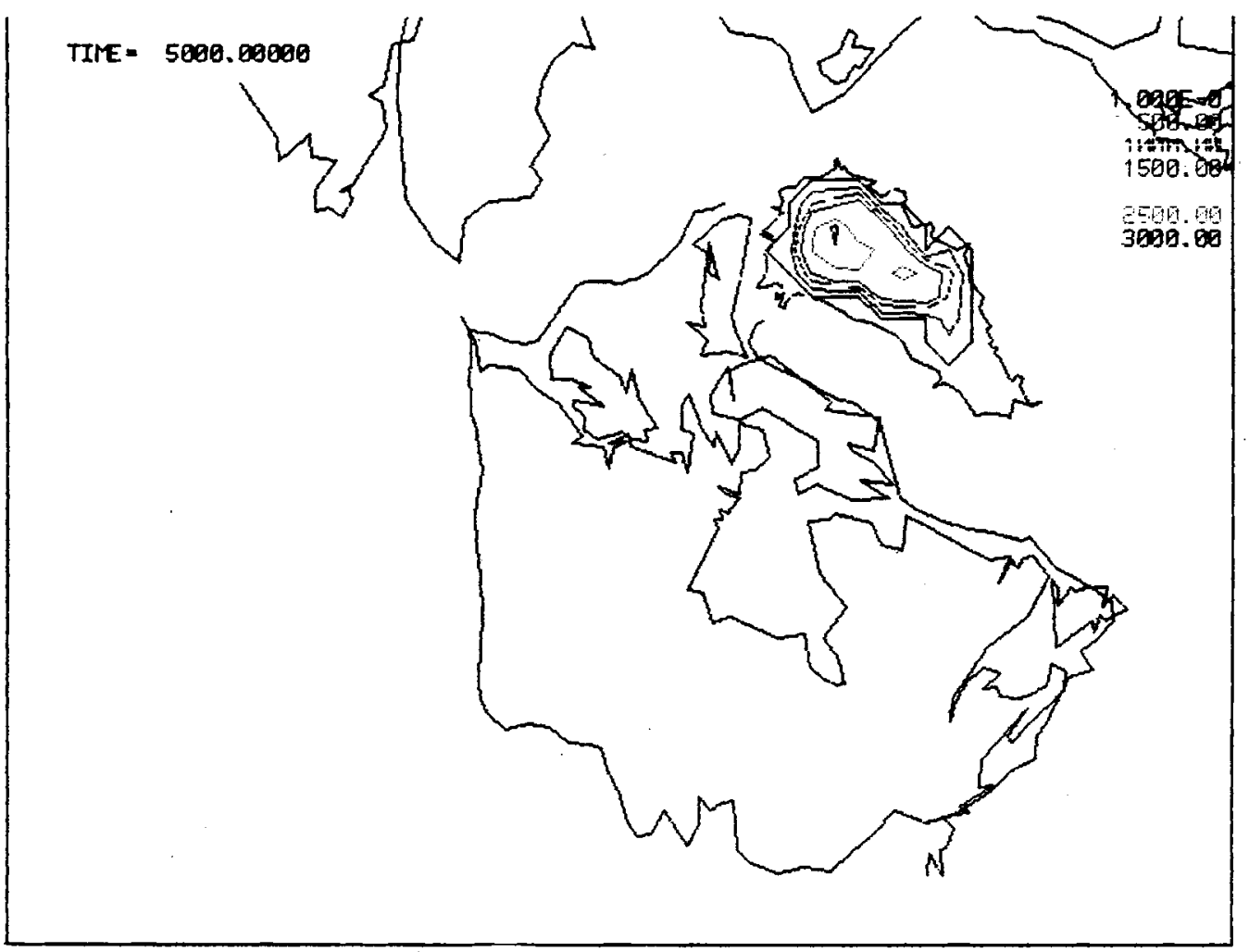

a) After 5000 Years

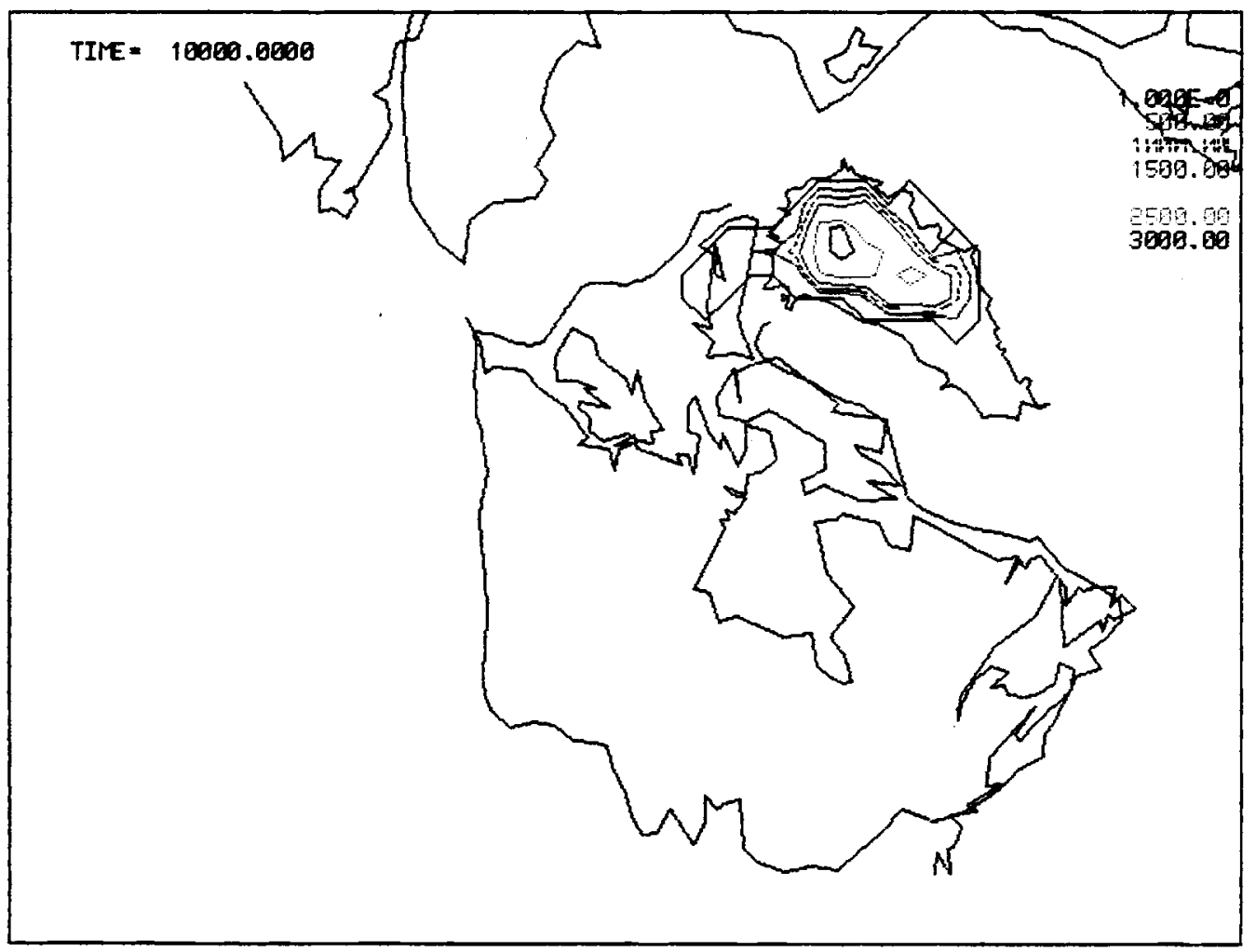

b) After 10,000 Years

FIGURE 16. A North American Glaciation Cycle Driven by Dust. Ice thicknesses contoured every $500 \mathrm{~m}$. 


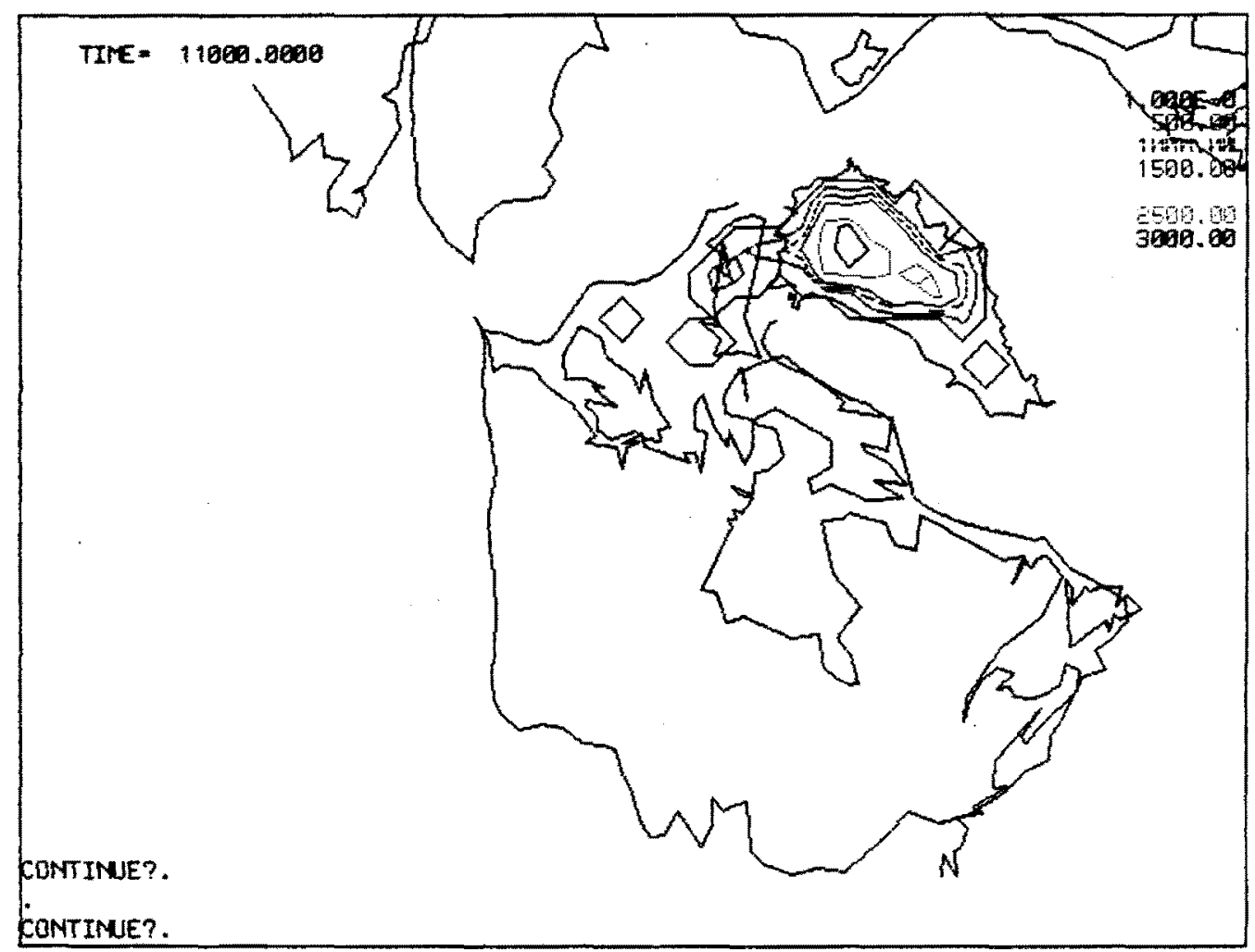

c) After 11,000 Years

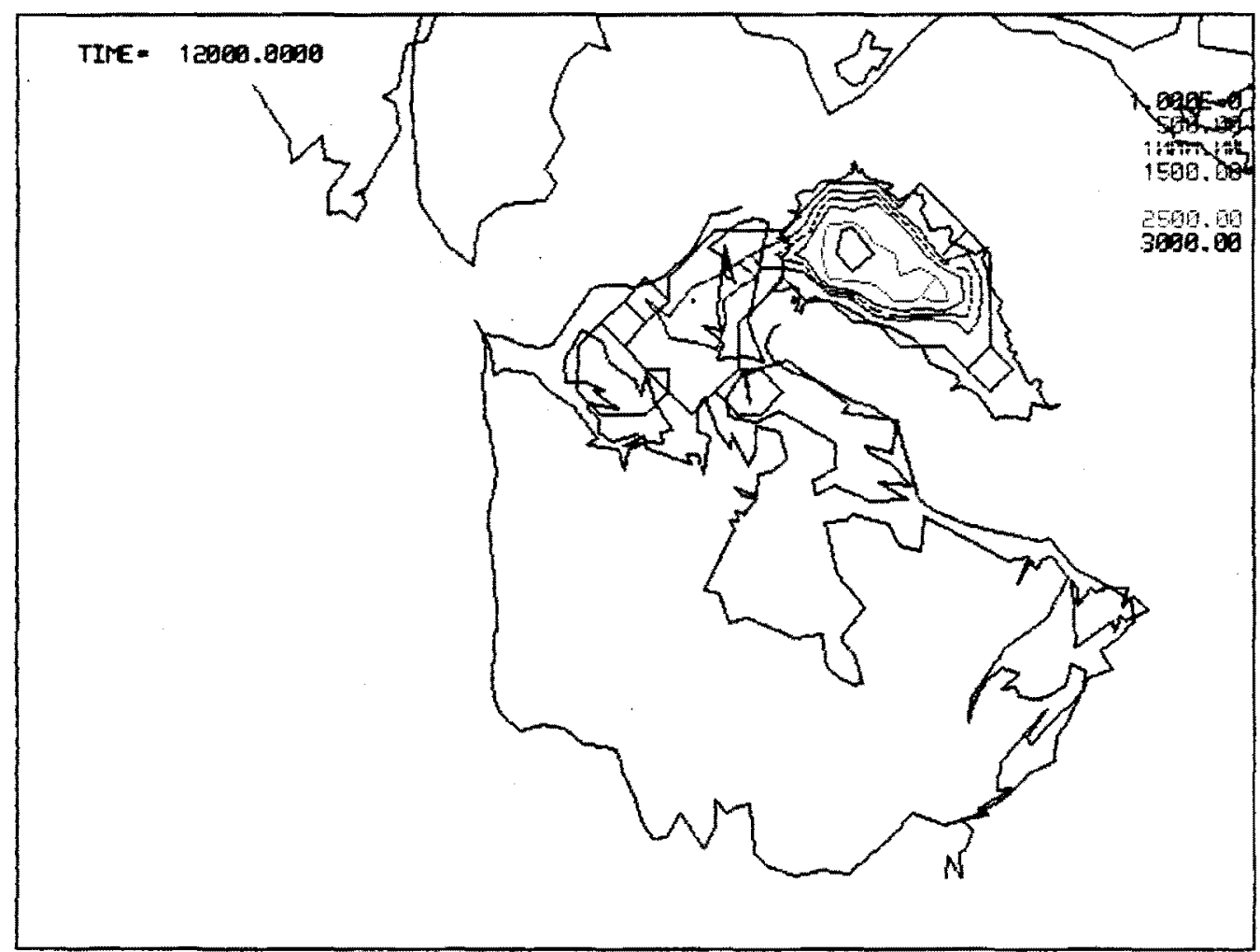

d) After 12,000 Years 


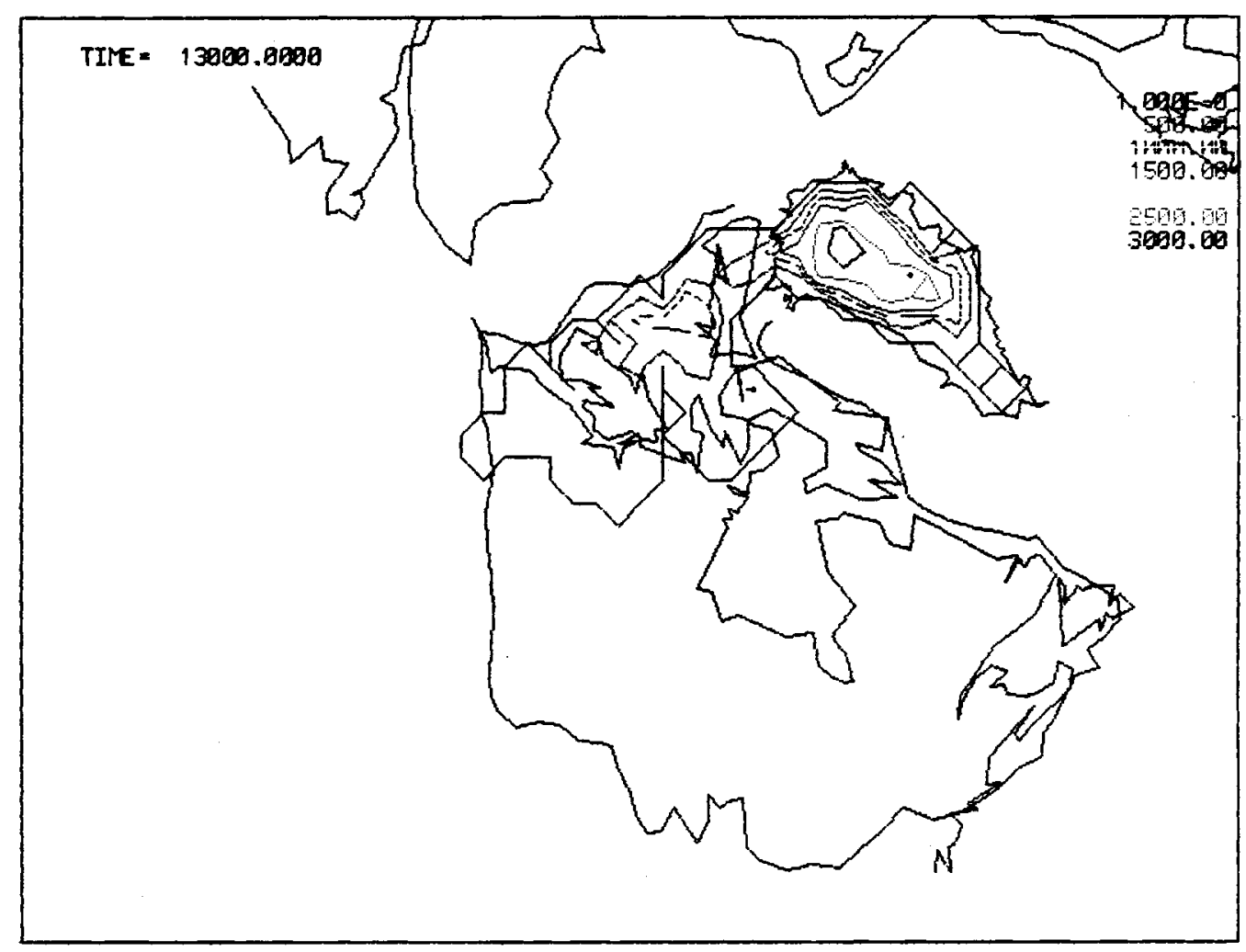

e) After 13,000 Years

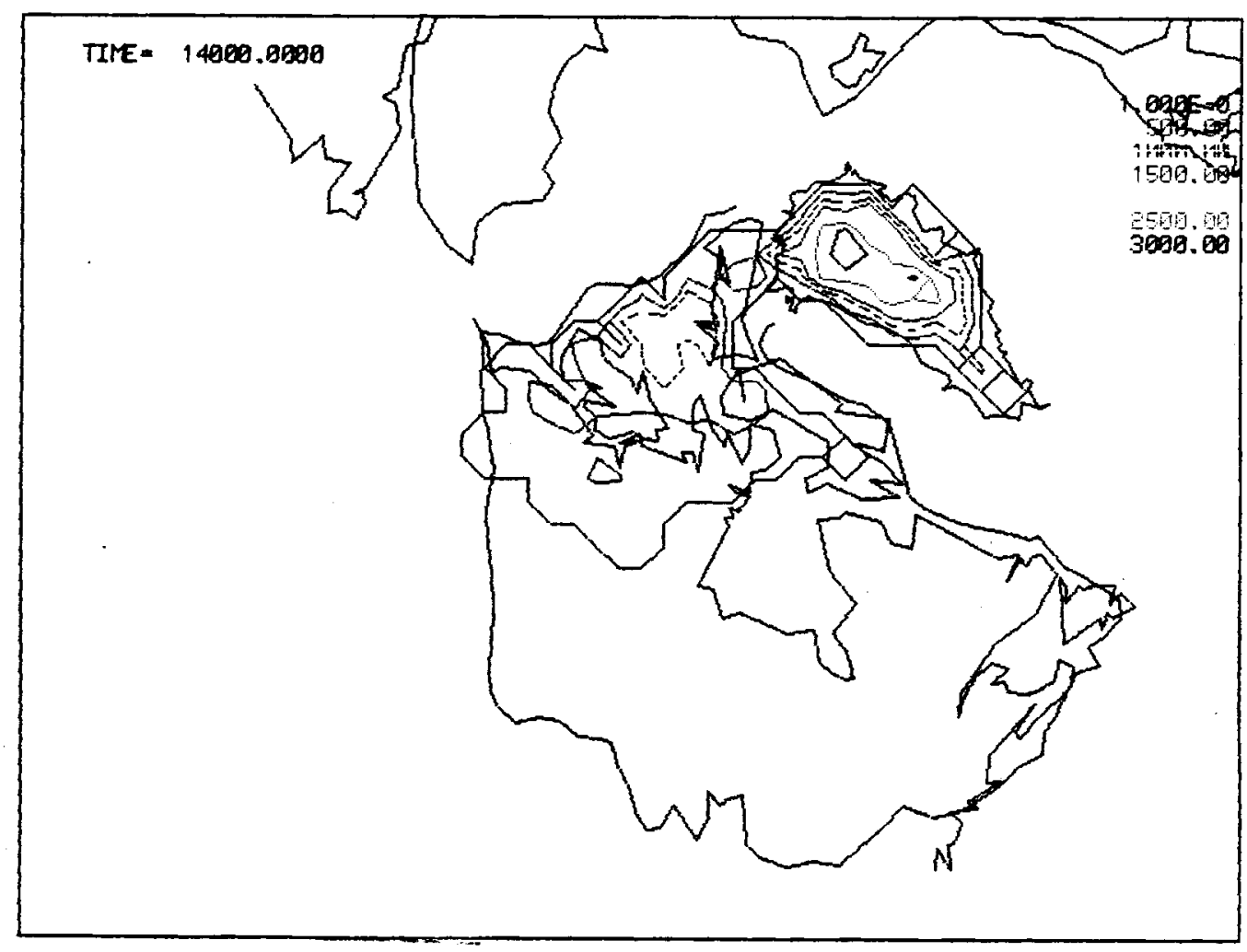

f) After 14,000 Years 


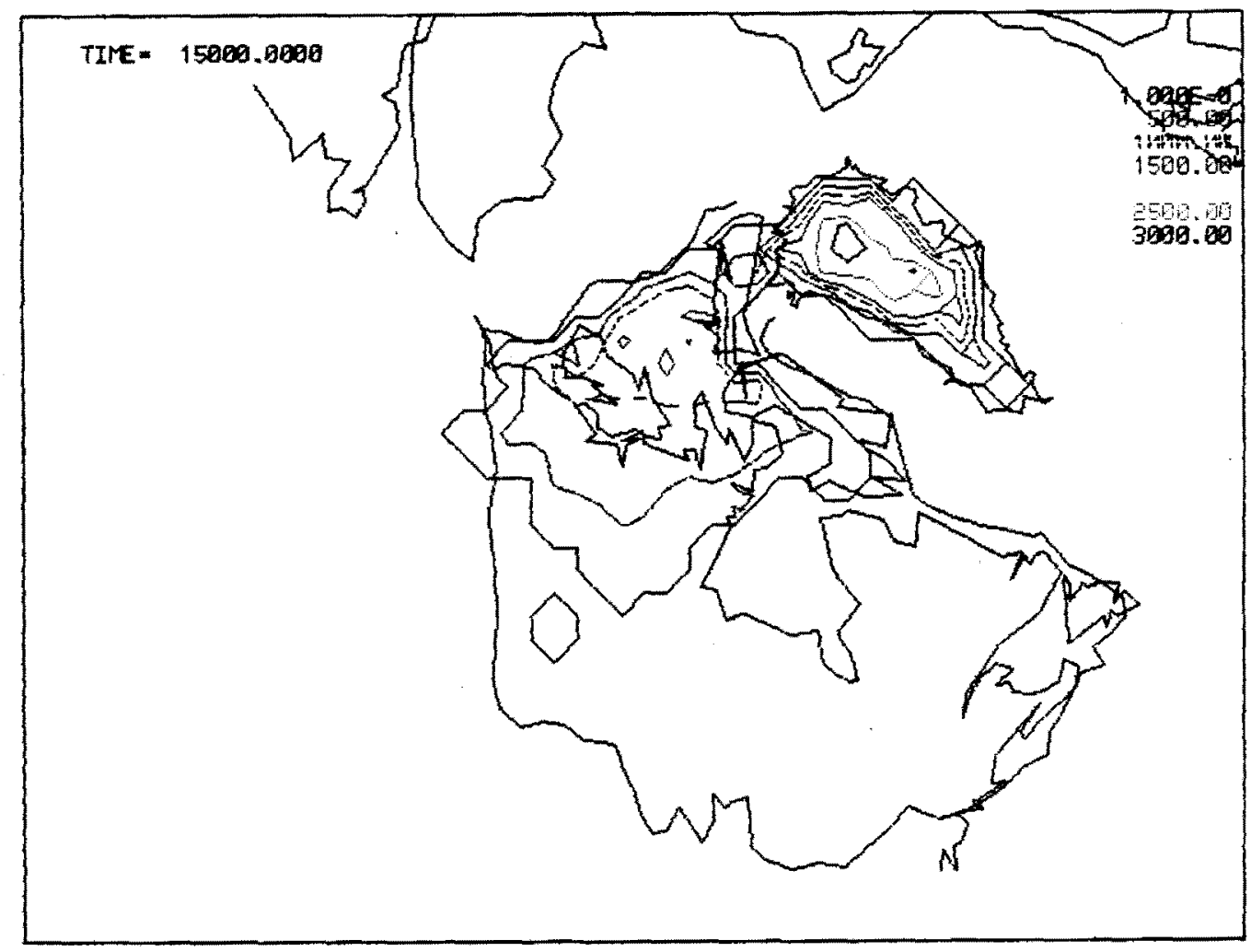

g) After 15,000 Years

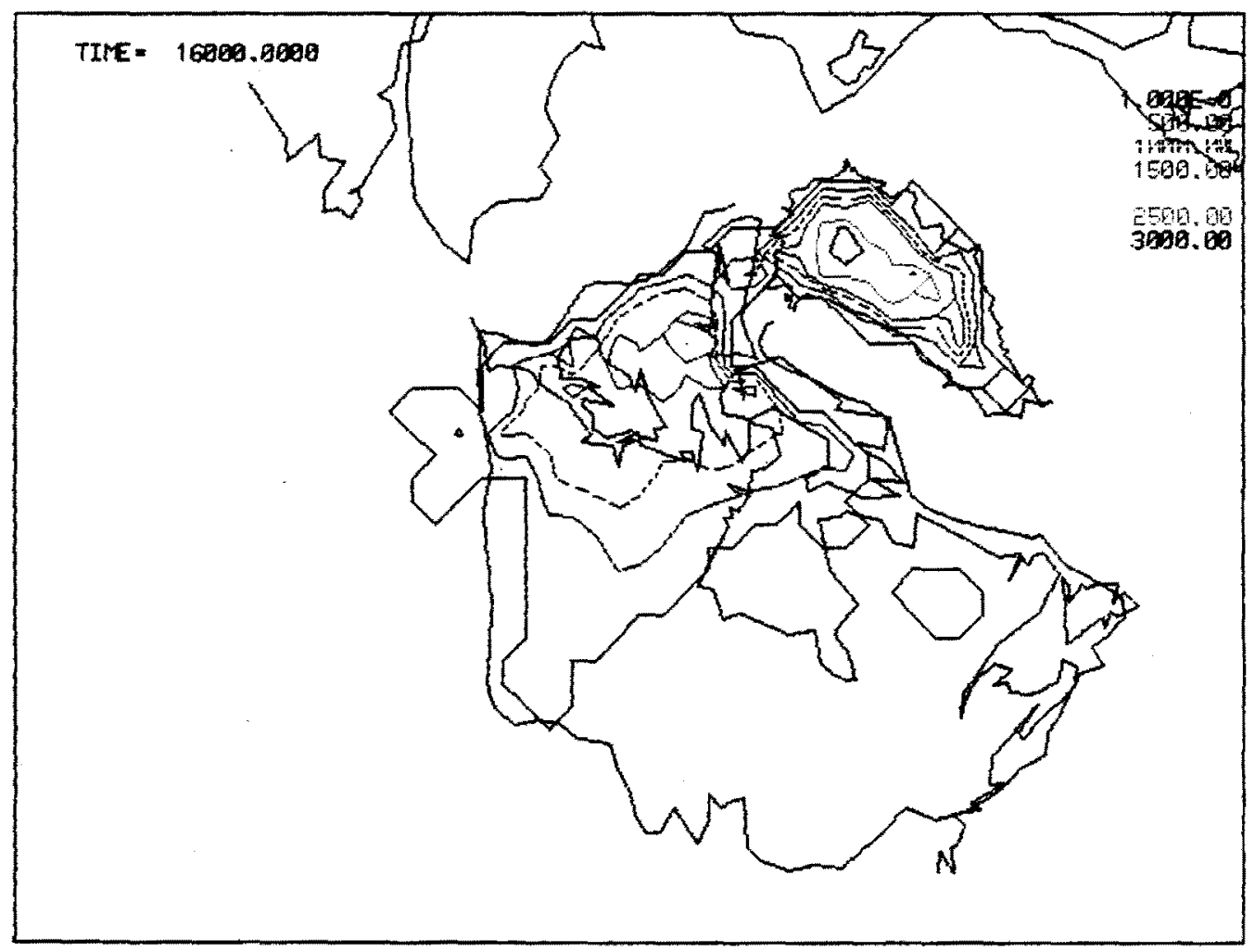

h) After 16,000 Years 


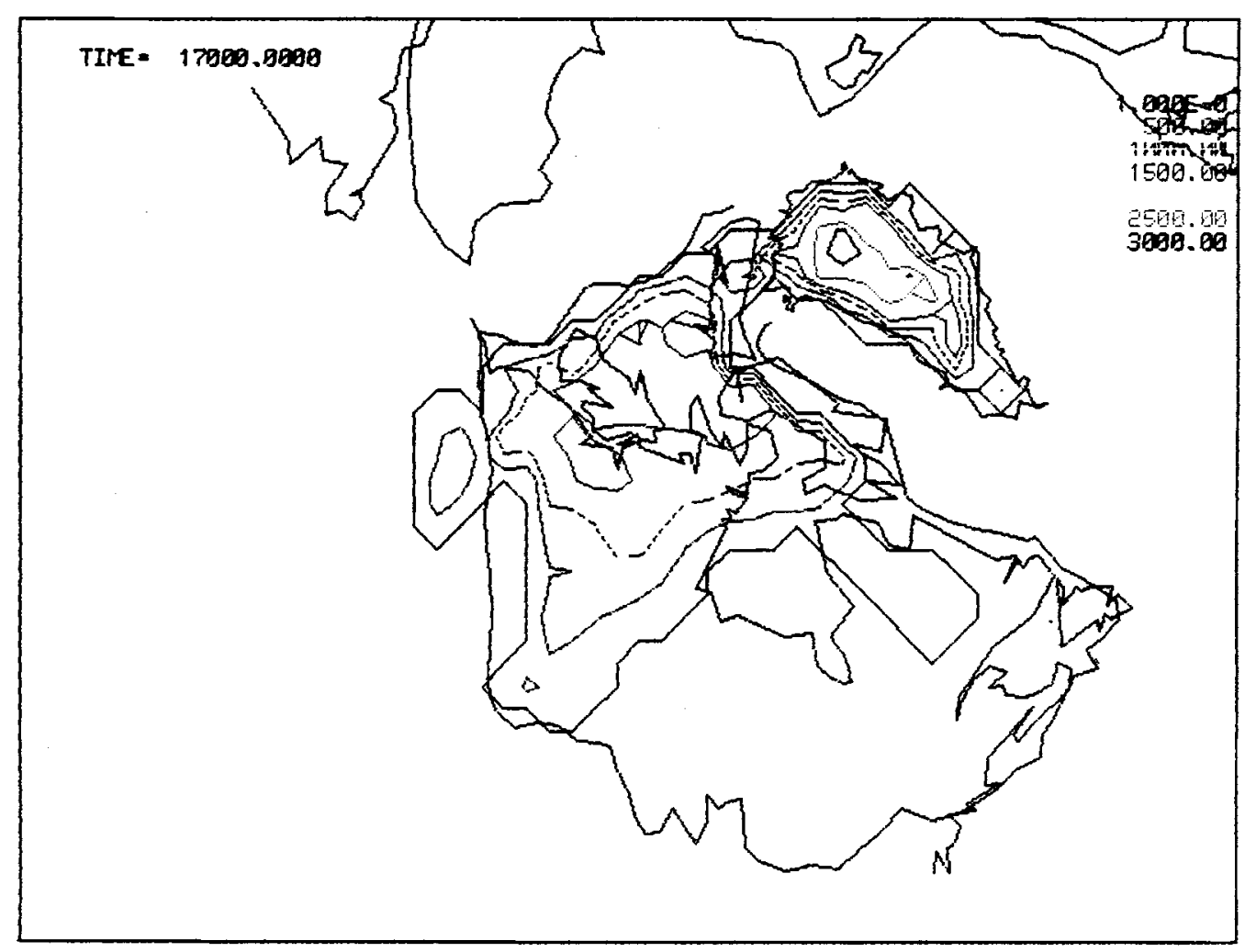

i) After 17,000 Years

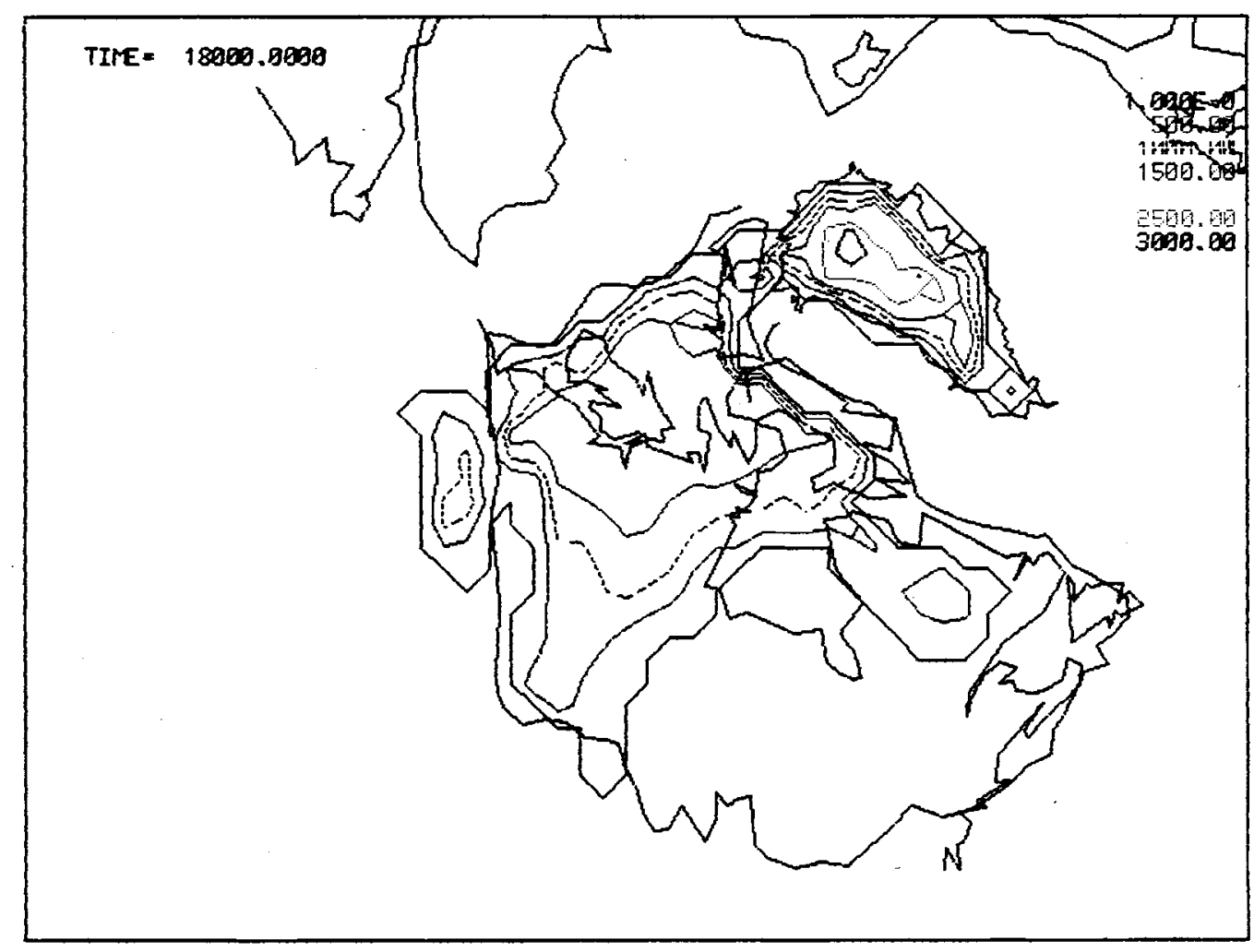

j) After 18,000 Years 


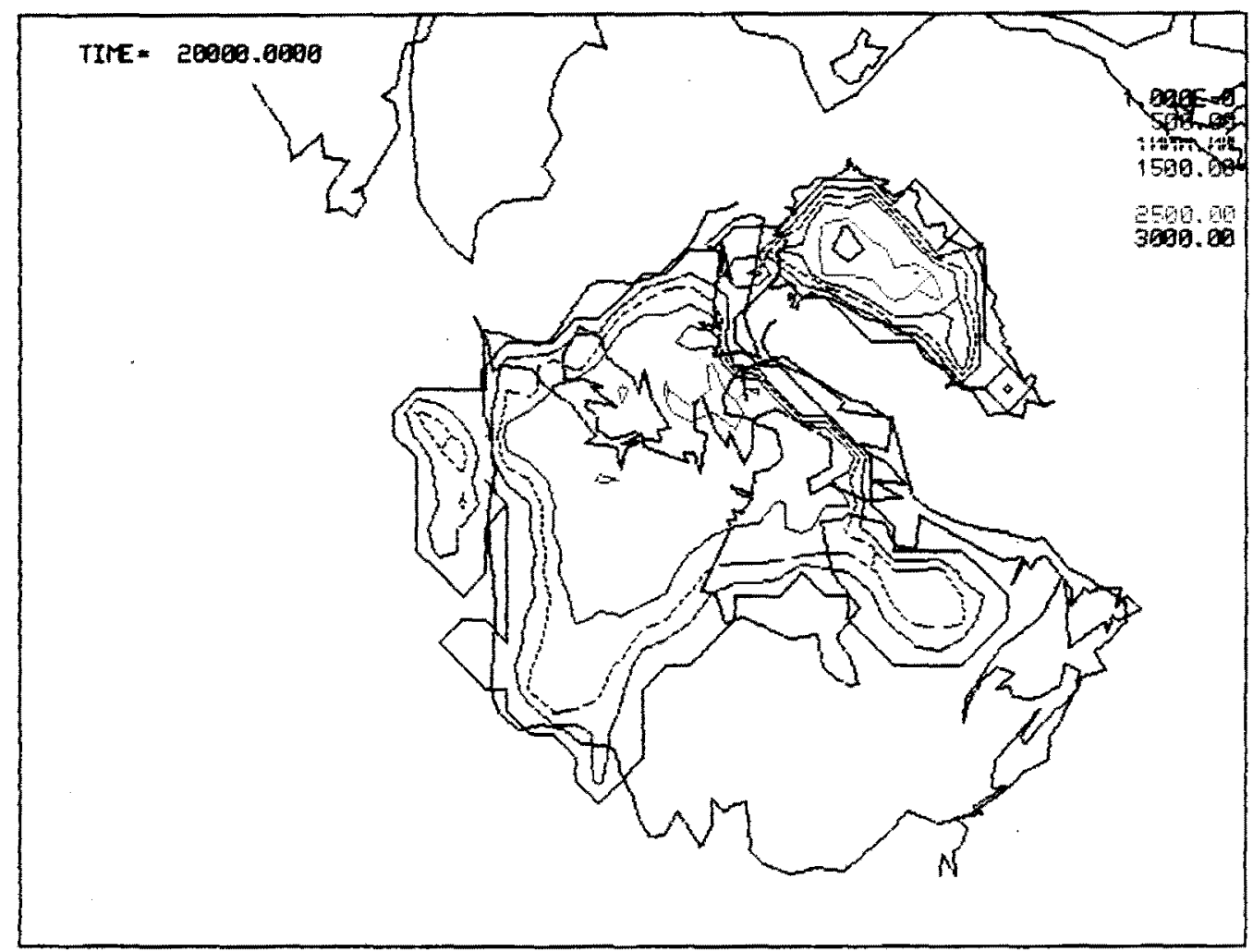

k) After 20,000 Years

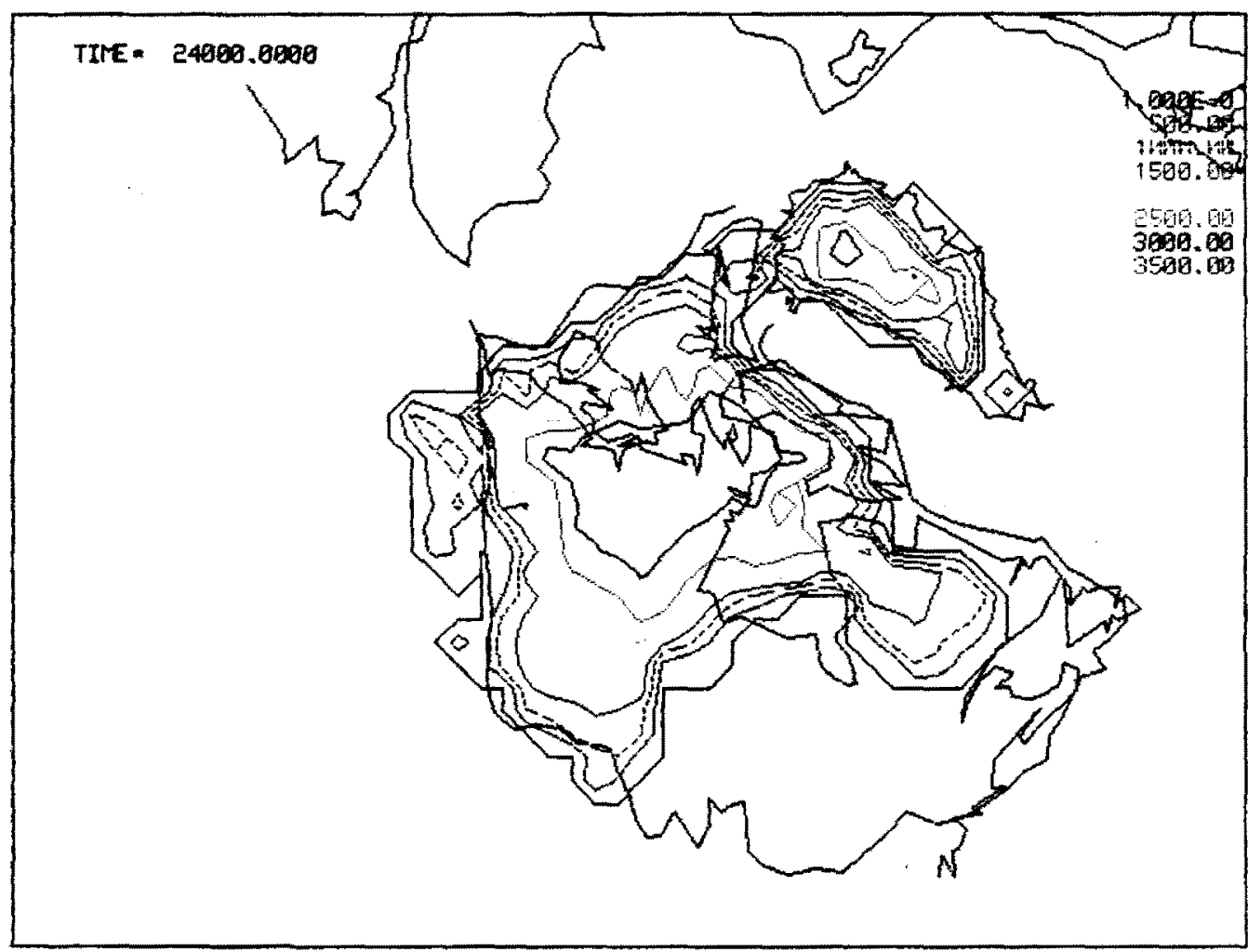

1) After 24,000 Years 


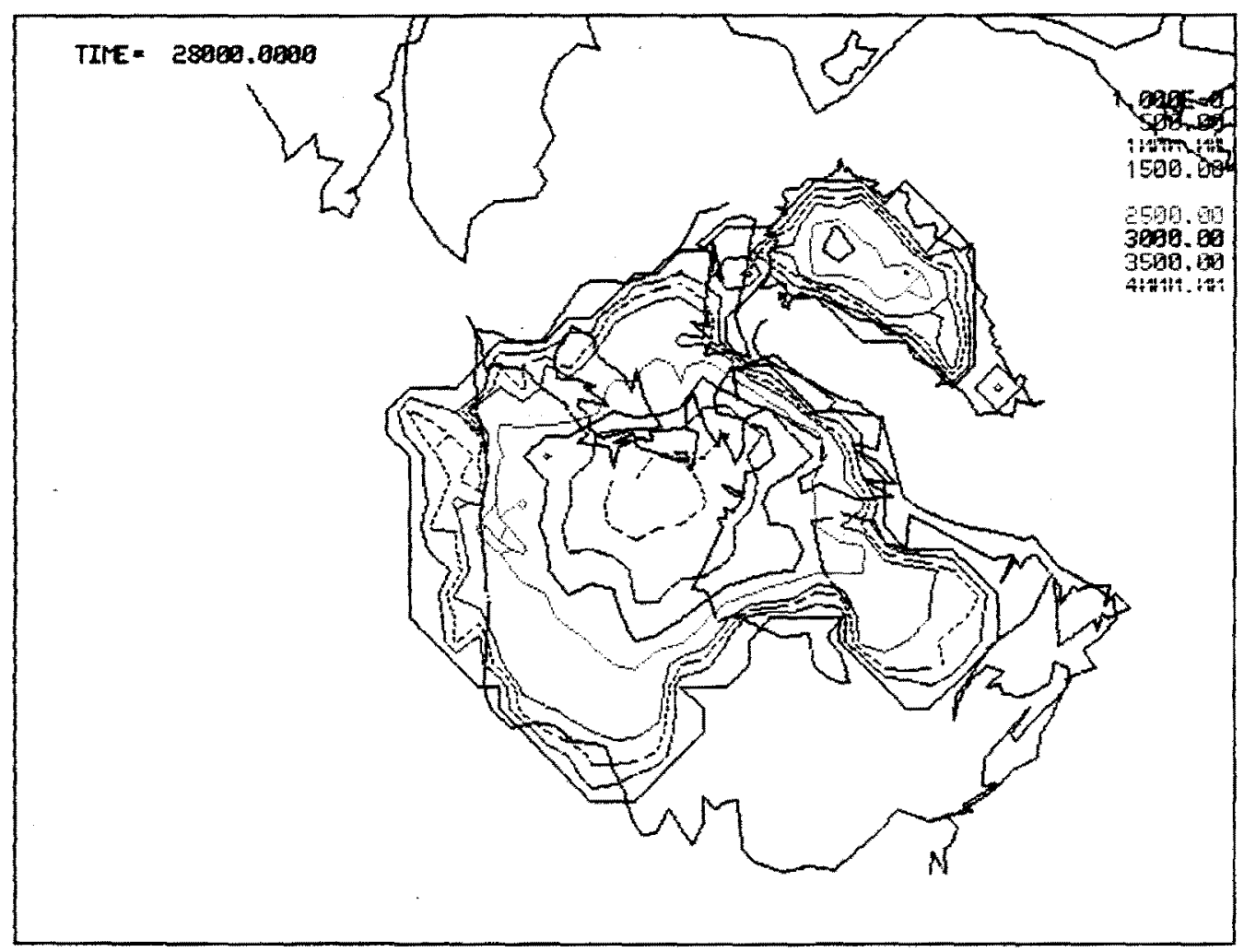

m) After 28,000 Years

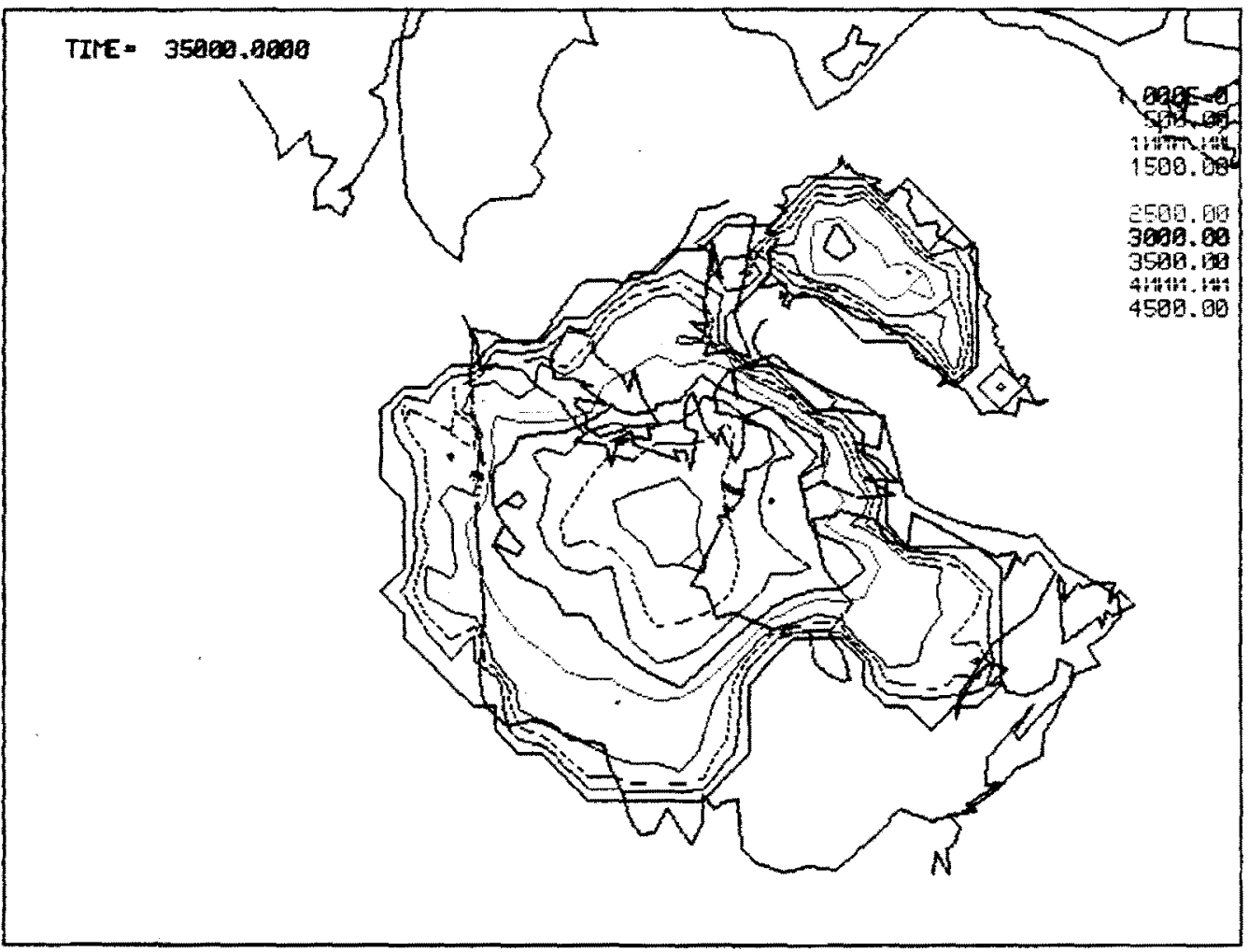

n) After 35,000 Years 


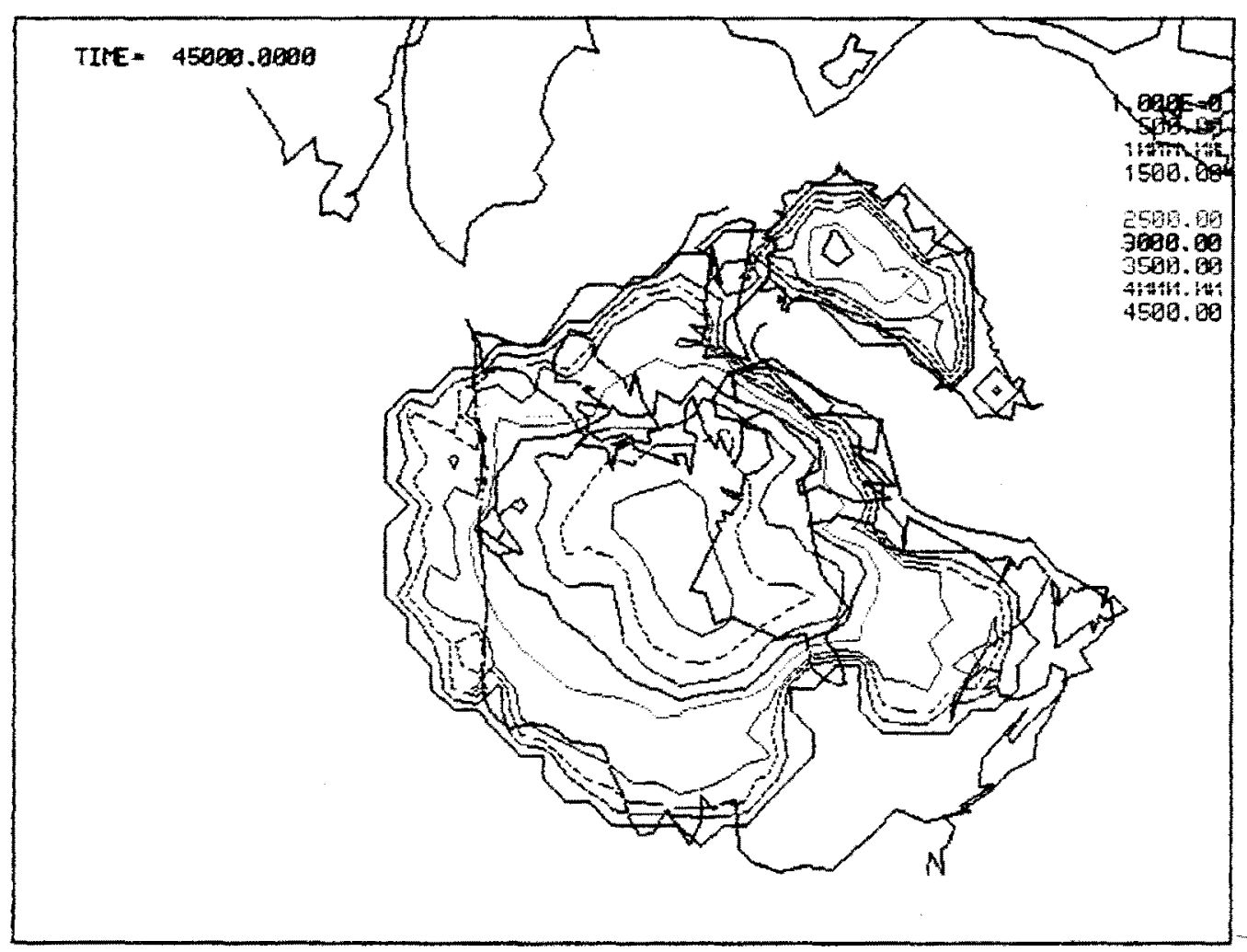

o) After 45,000 Years

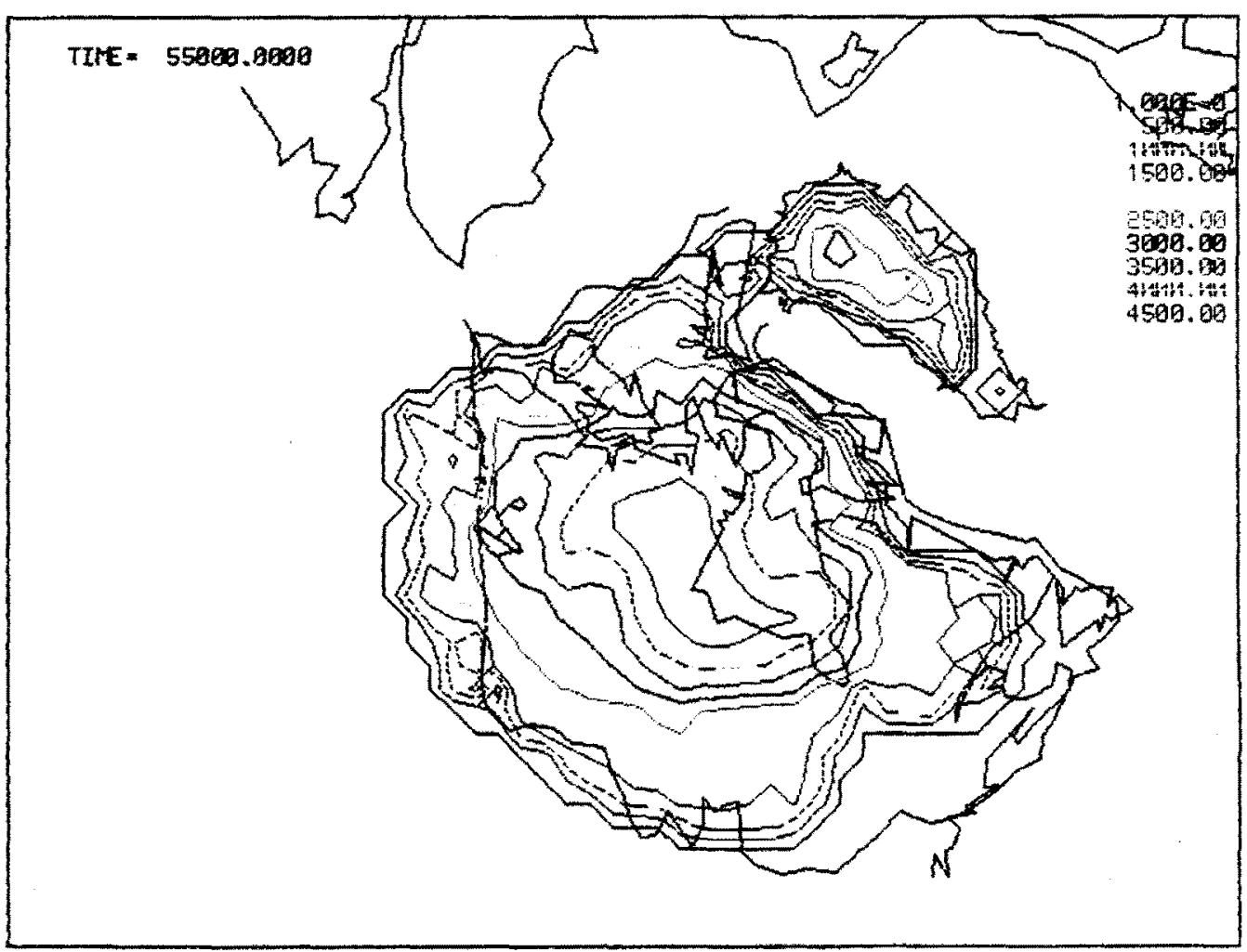

p) After 55,000 Years 


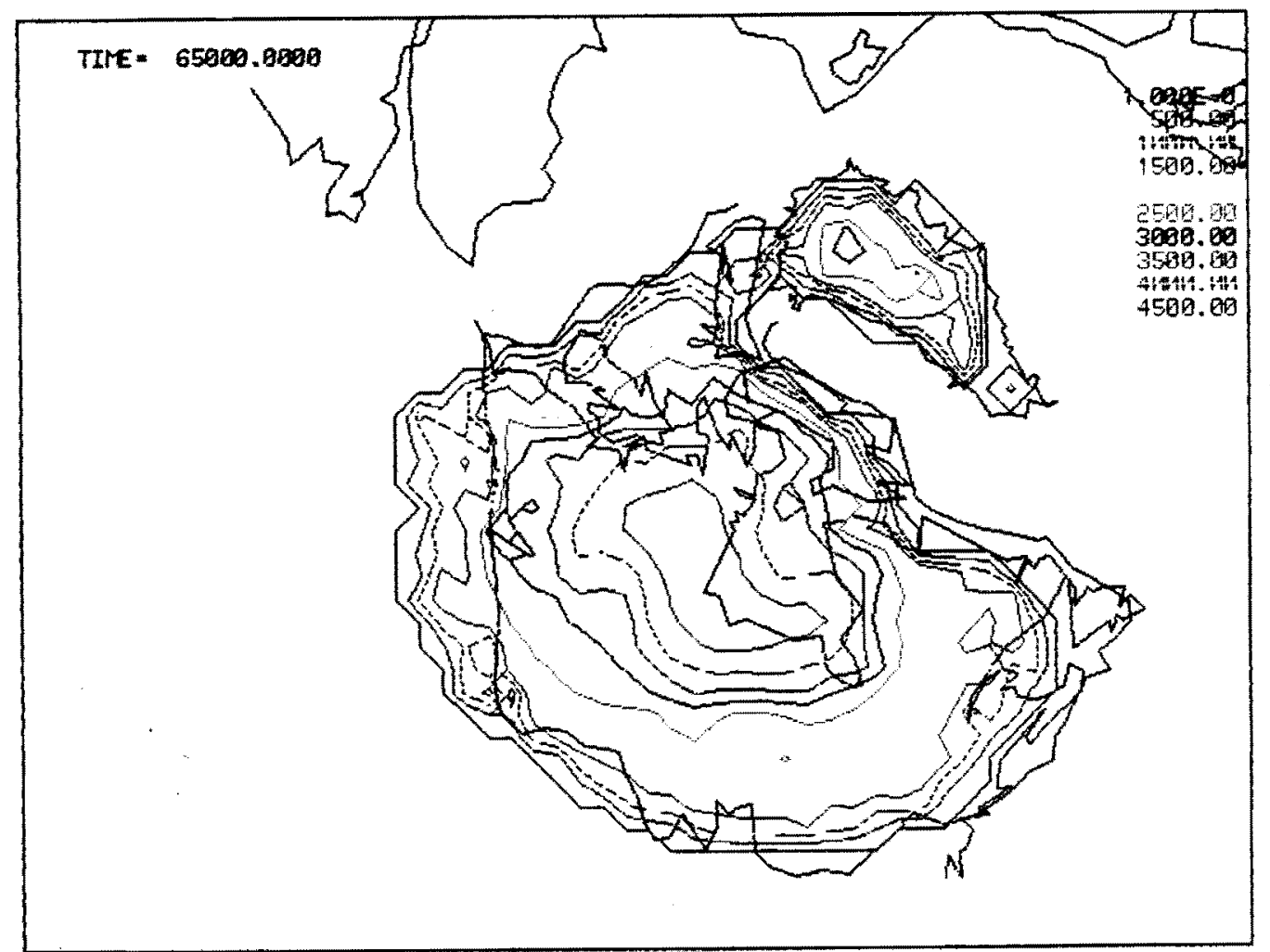

q) After 65,000 Years

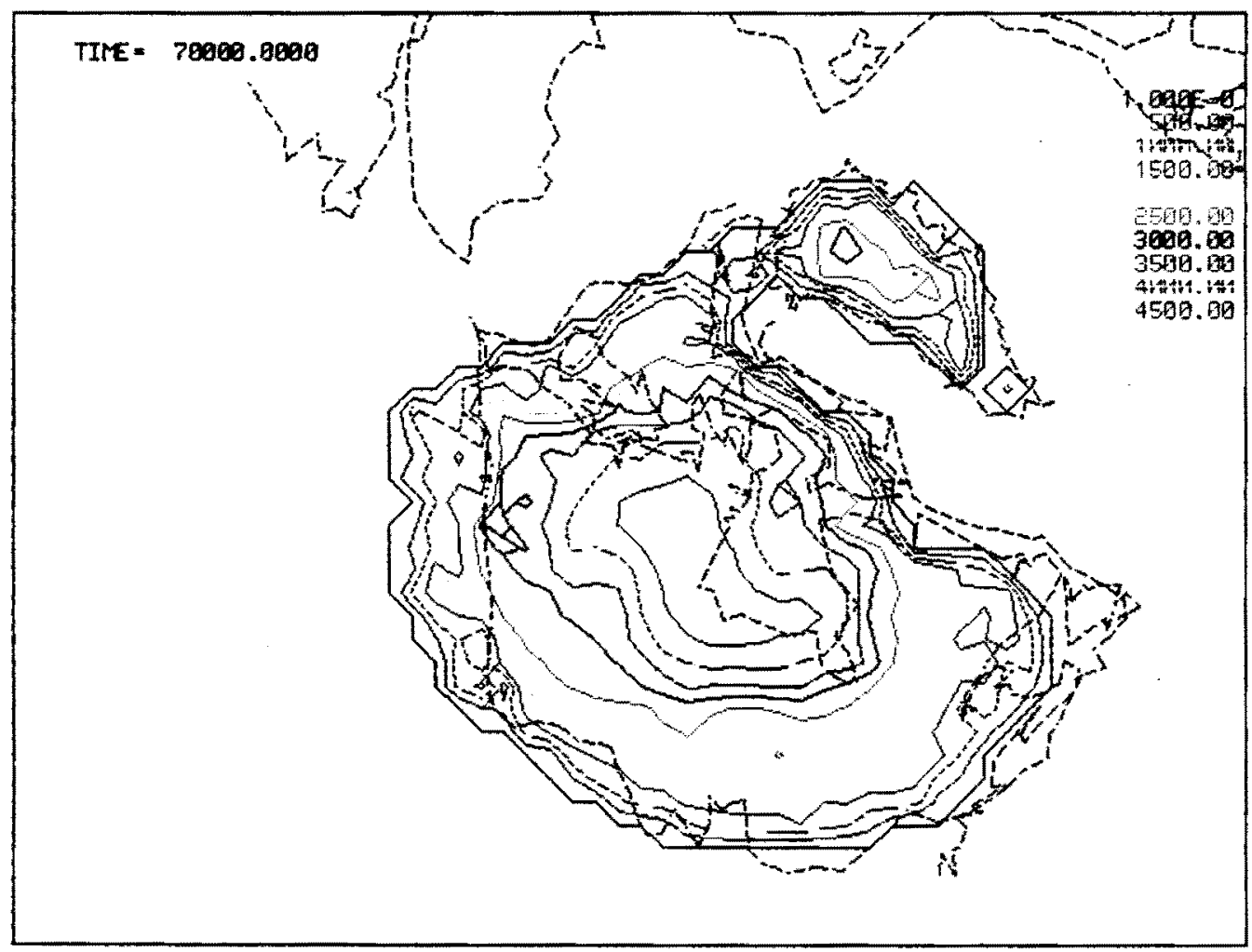

r) After 70,000 Years 


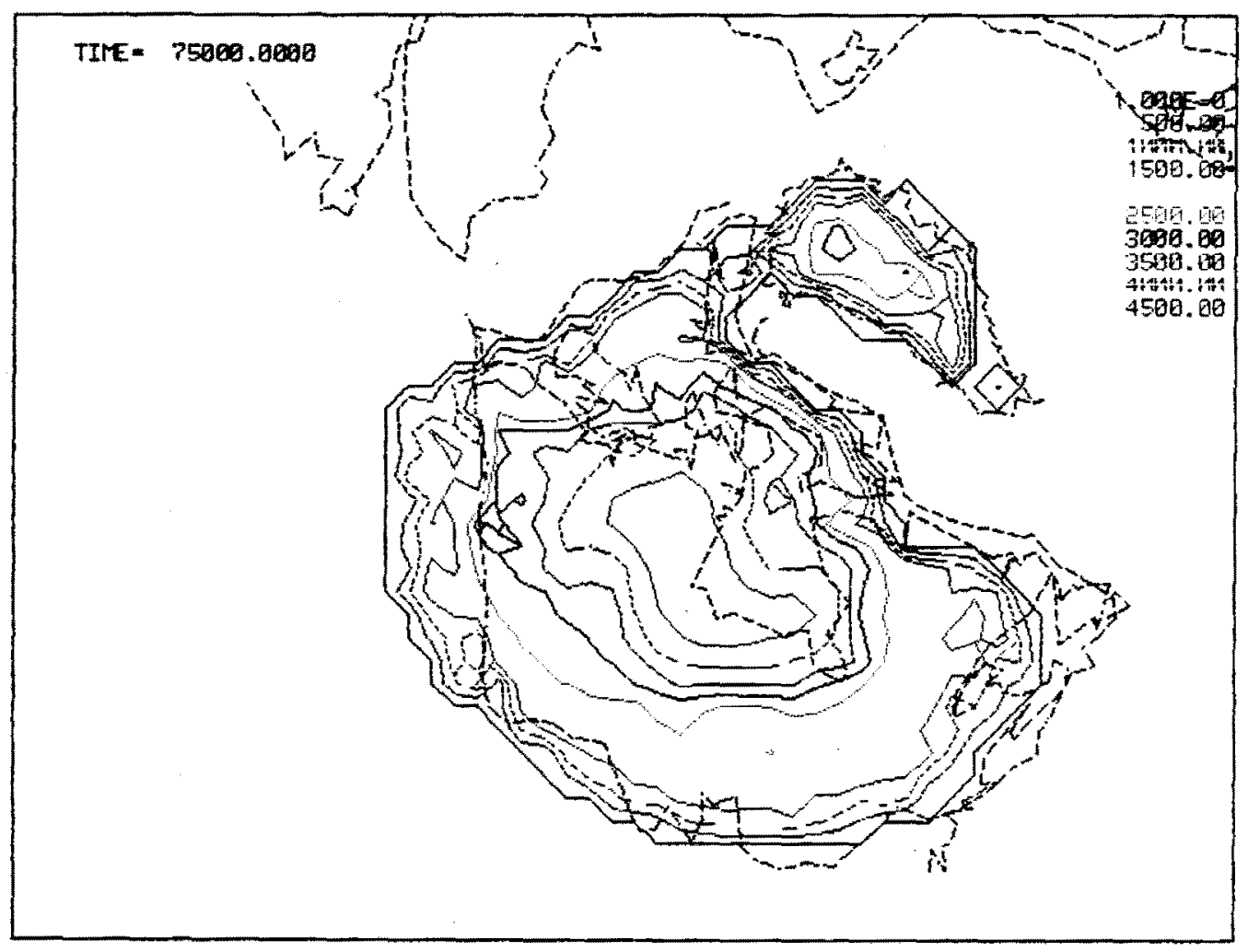

s) After 75,000 Years

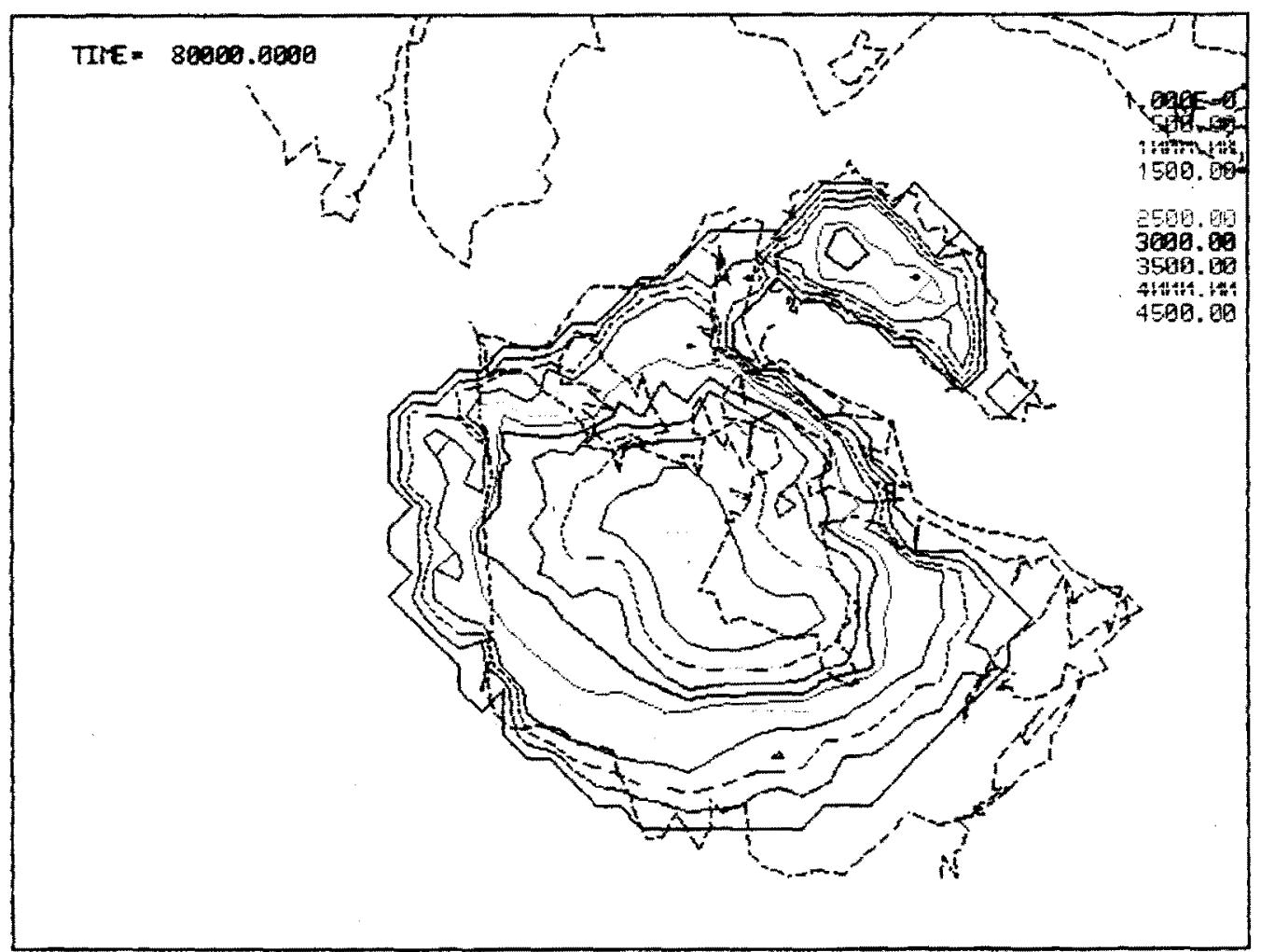

t) After 80,000 Years 


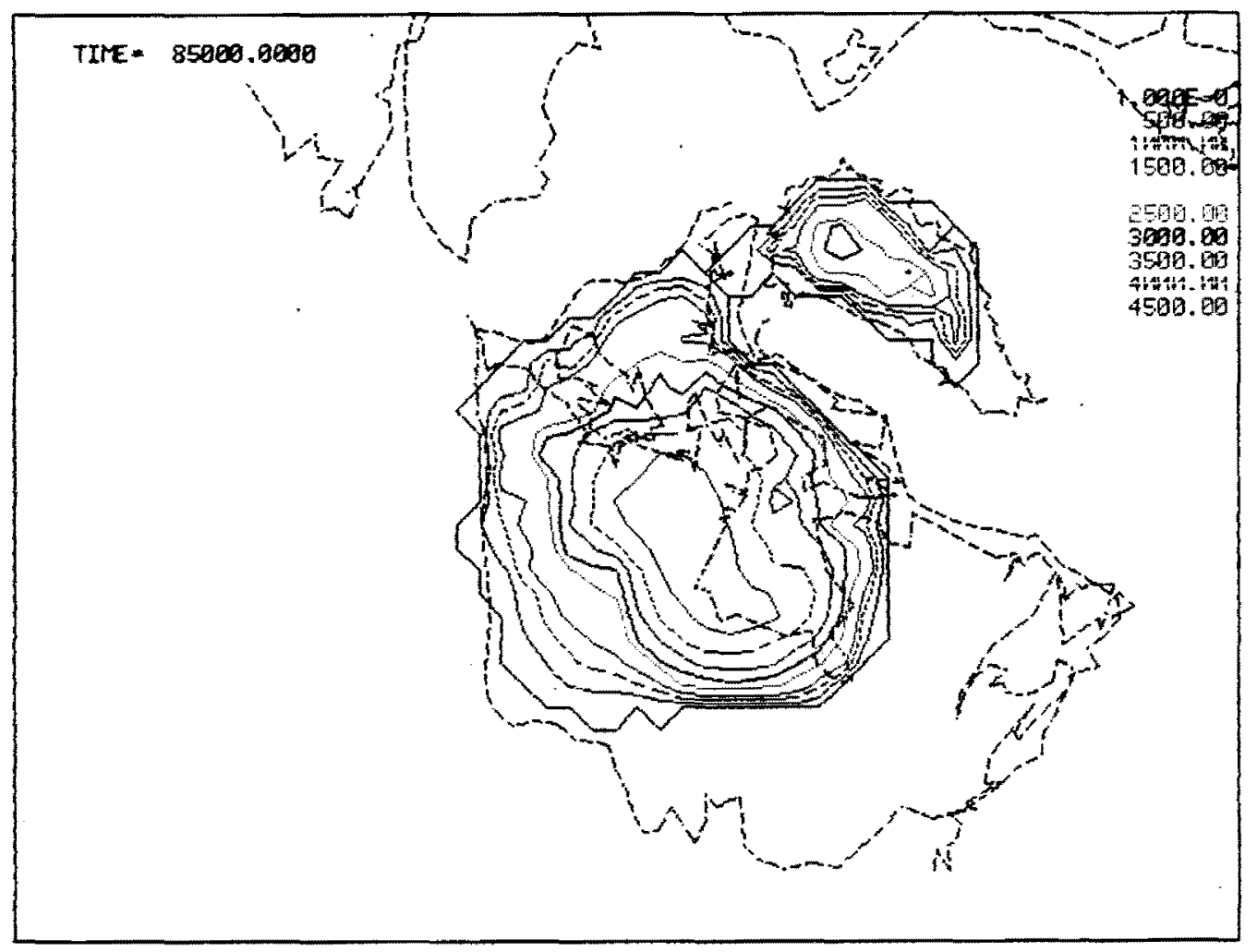

u) After 85,000 Years

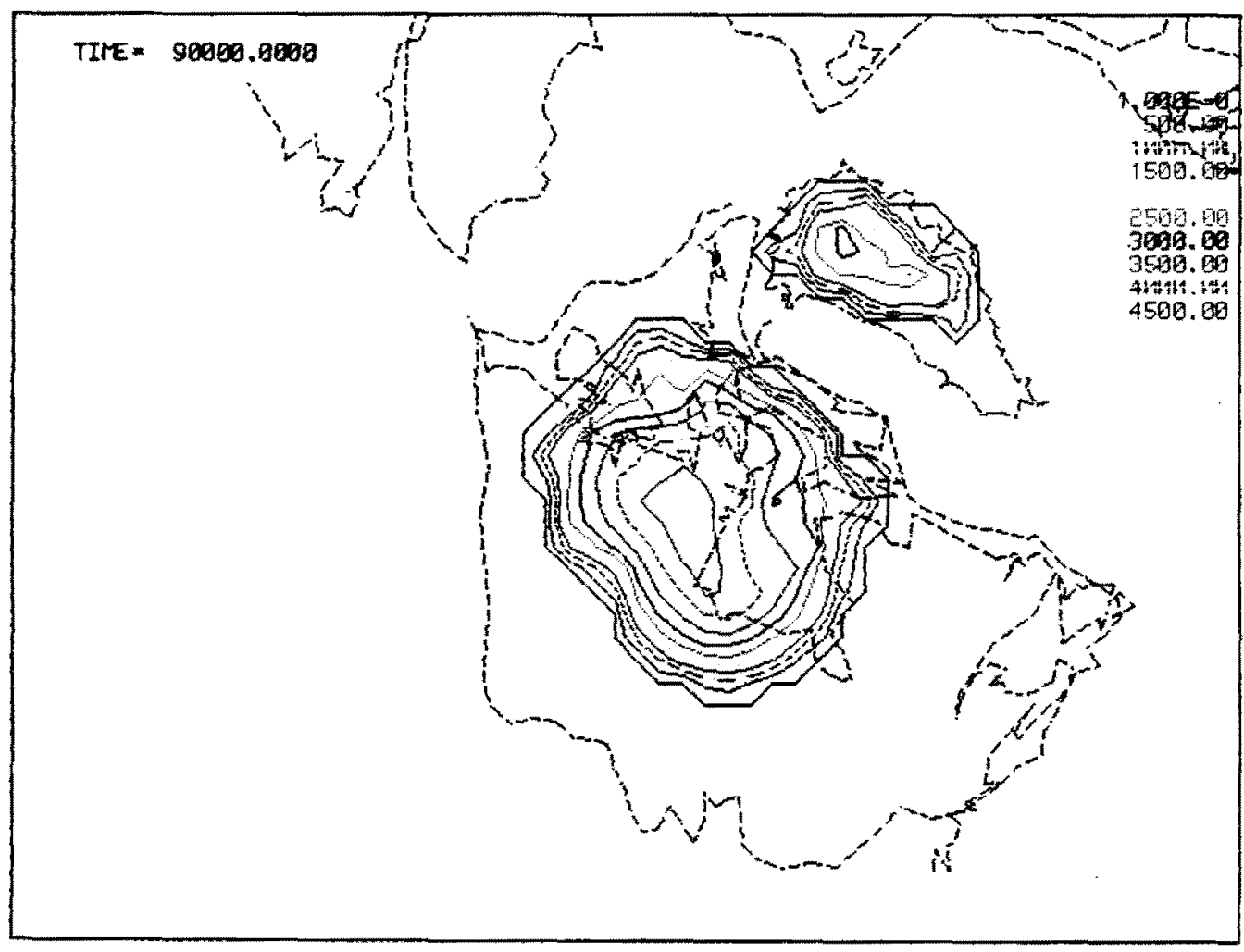

v) After 90,000 Years 


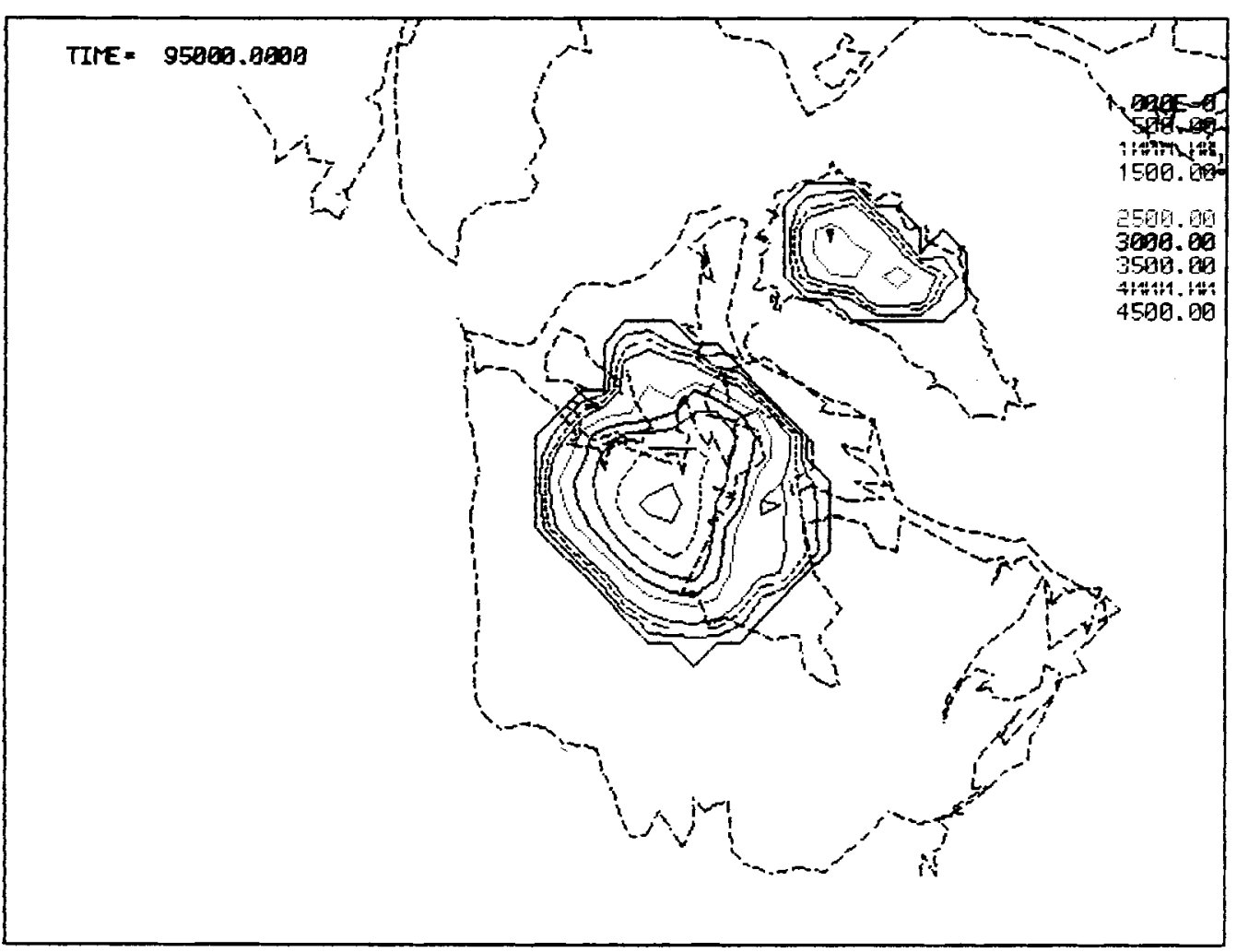

w) After 95,000 Years

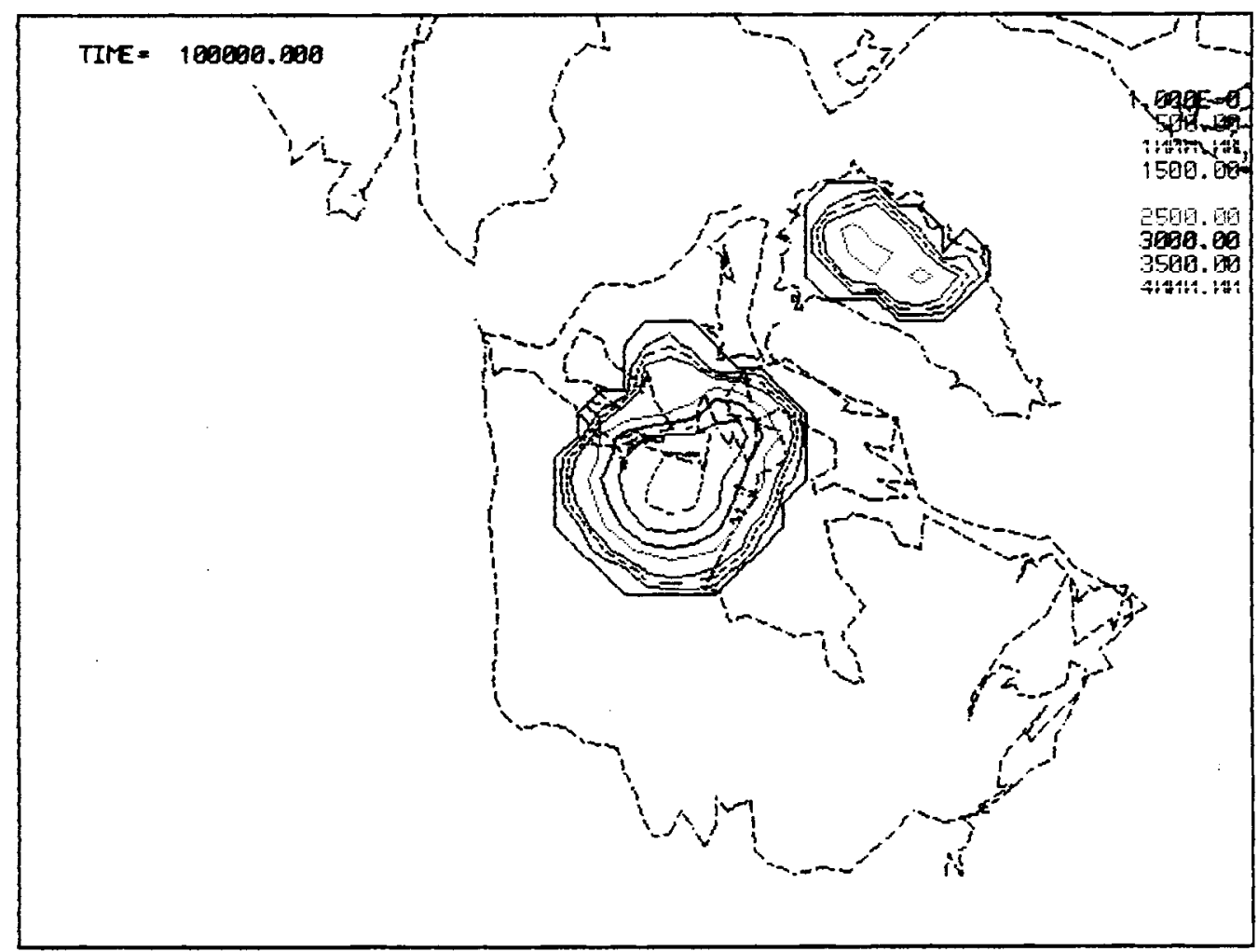

x) After 100,000 Years 


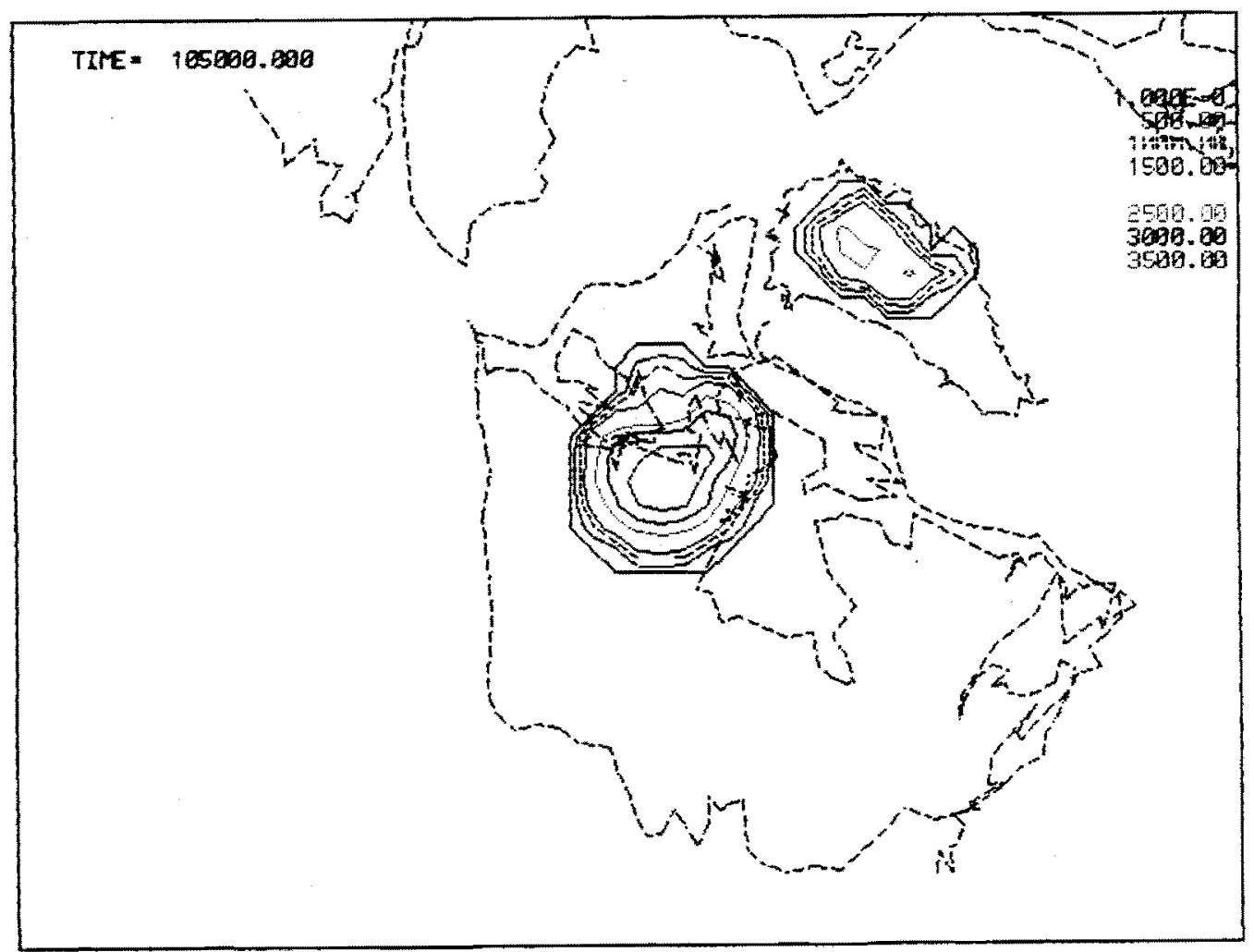

y) After 105,000 Years

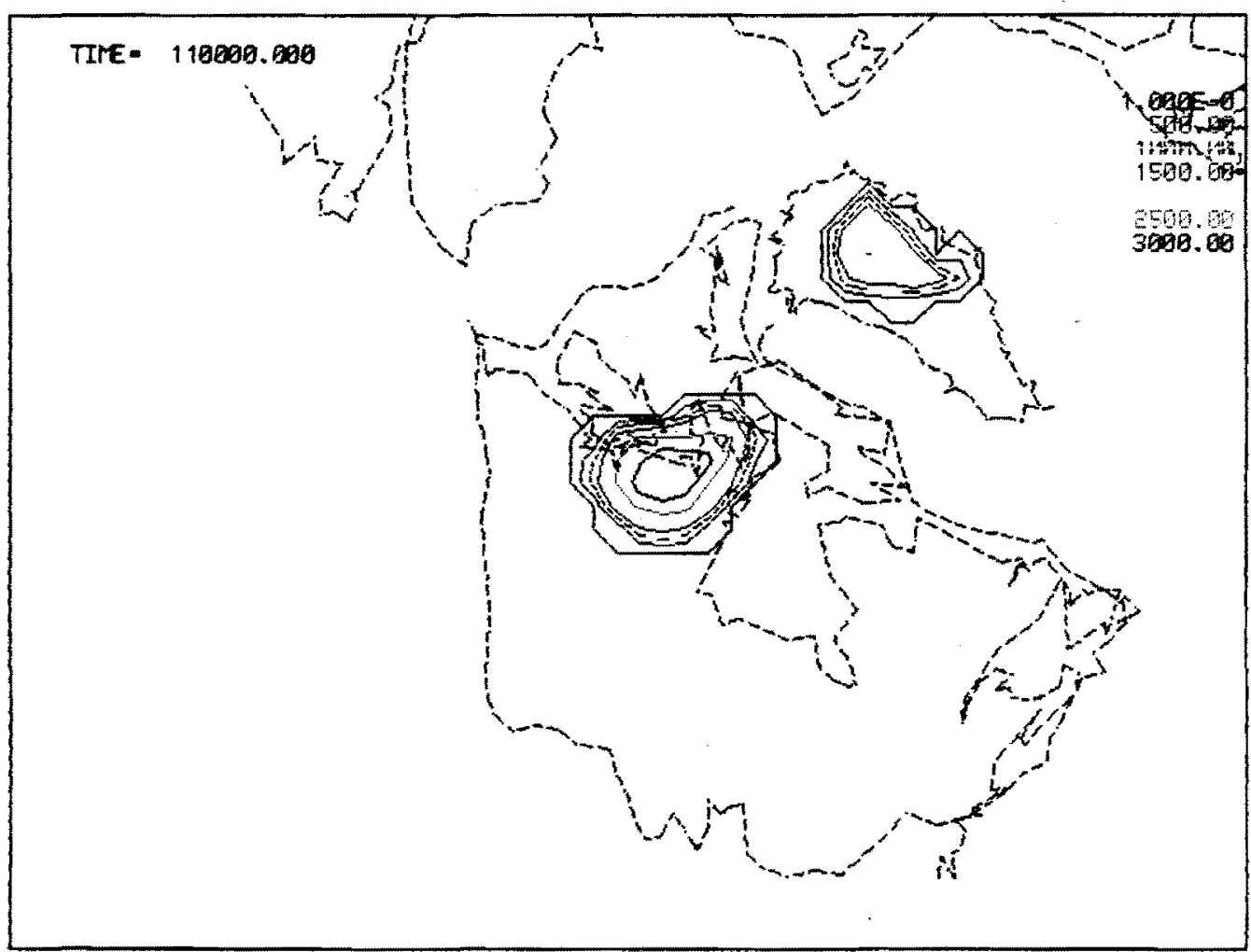

z) After 110,000 Years 


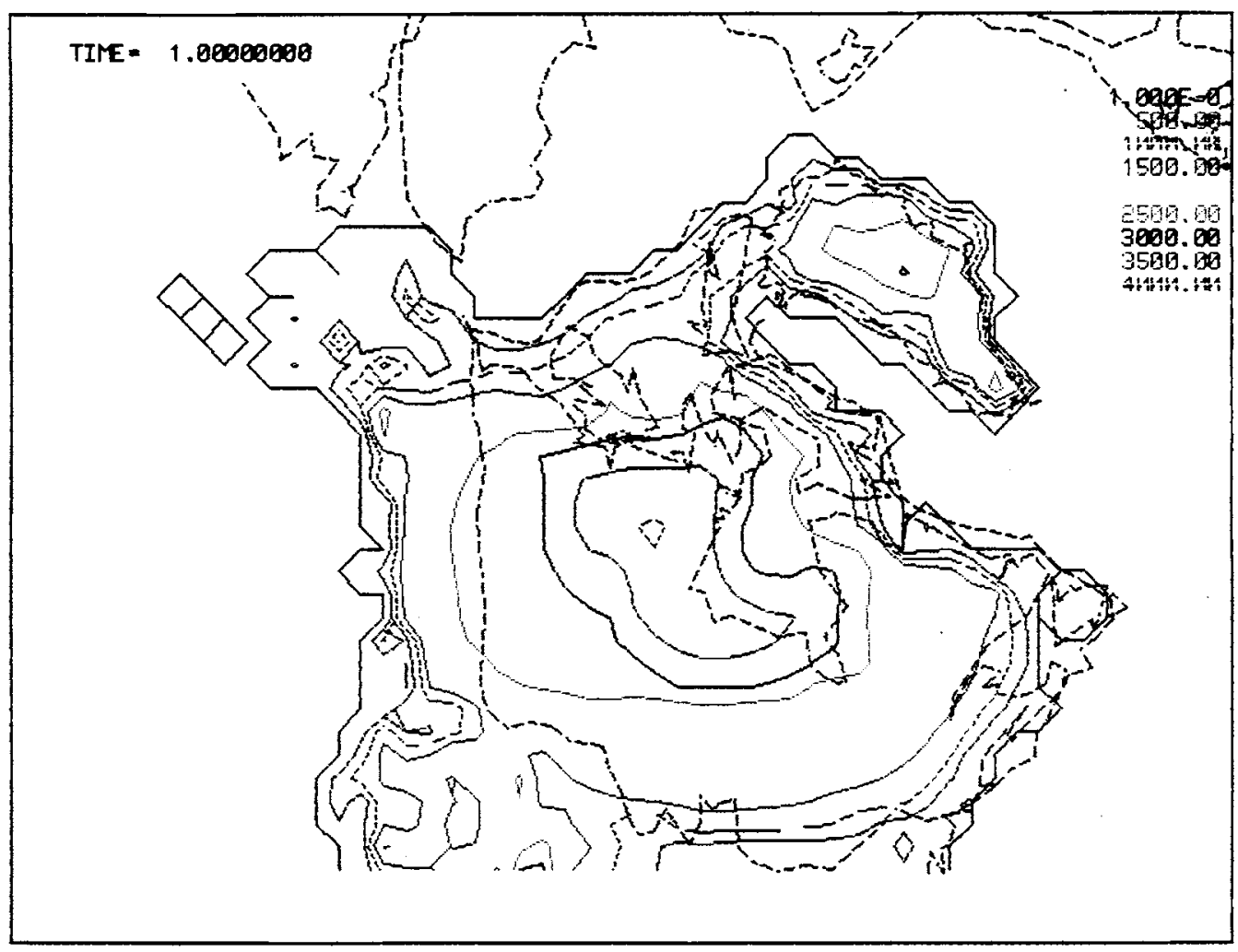

EIGURE 17. Ice Elevation at the Glacial Maximum in Figure 16. Ice elevations contoured every $500 \mathrm{~m}$ for the glacial maximum after 70,000 years. 


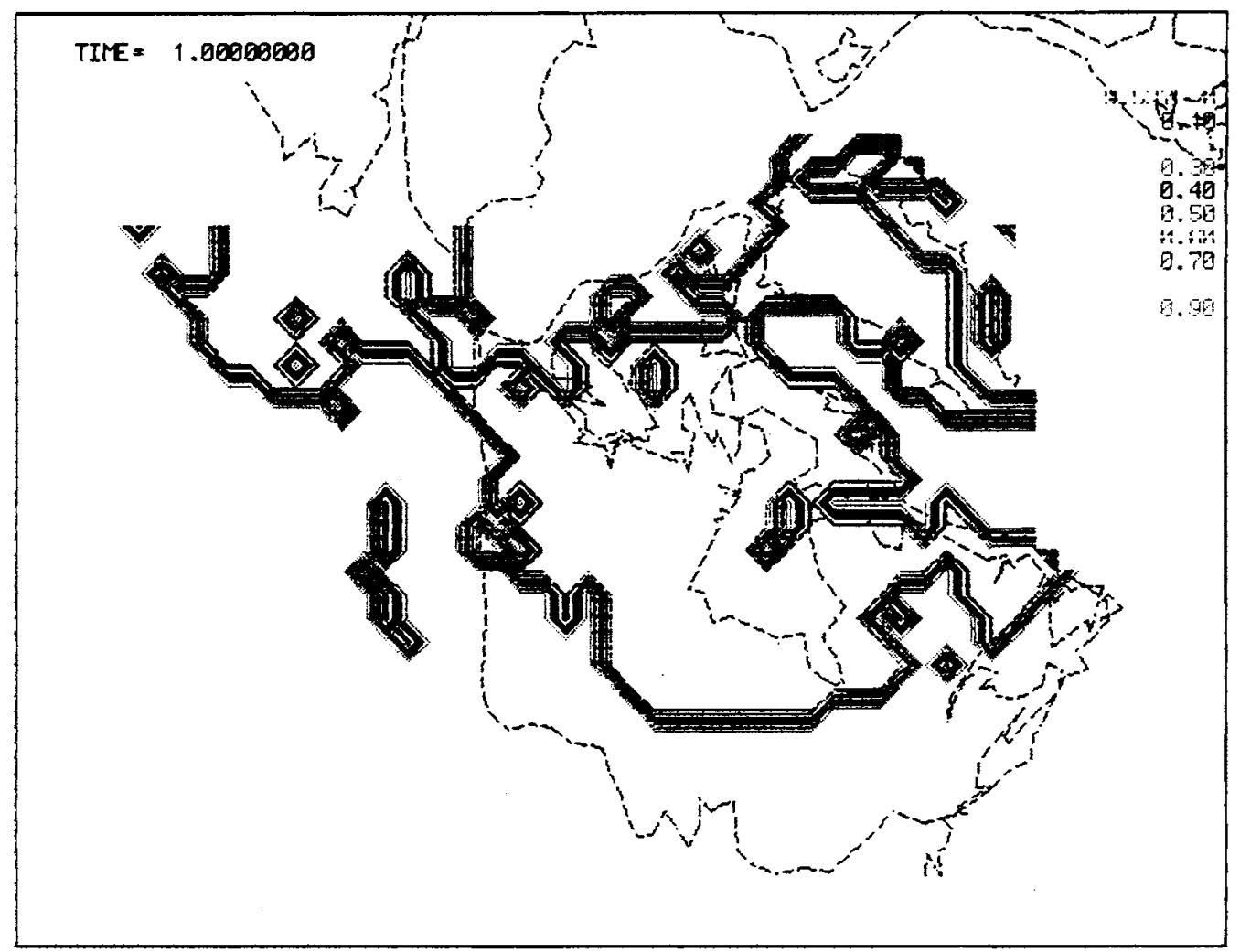

FIGURE 18. Velocity Fractions by Basal Sliding for Ice Sheets in Figure 17. Contour lines are the fraction of ice velocity due to sliding.

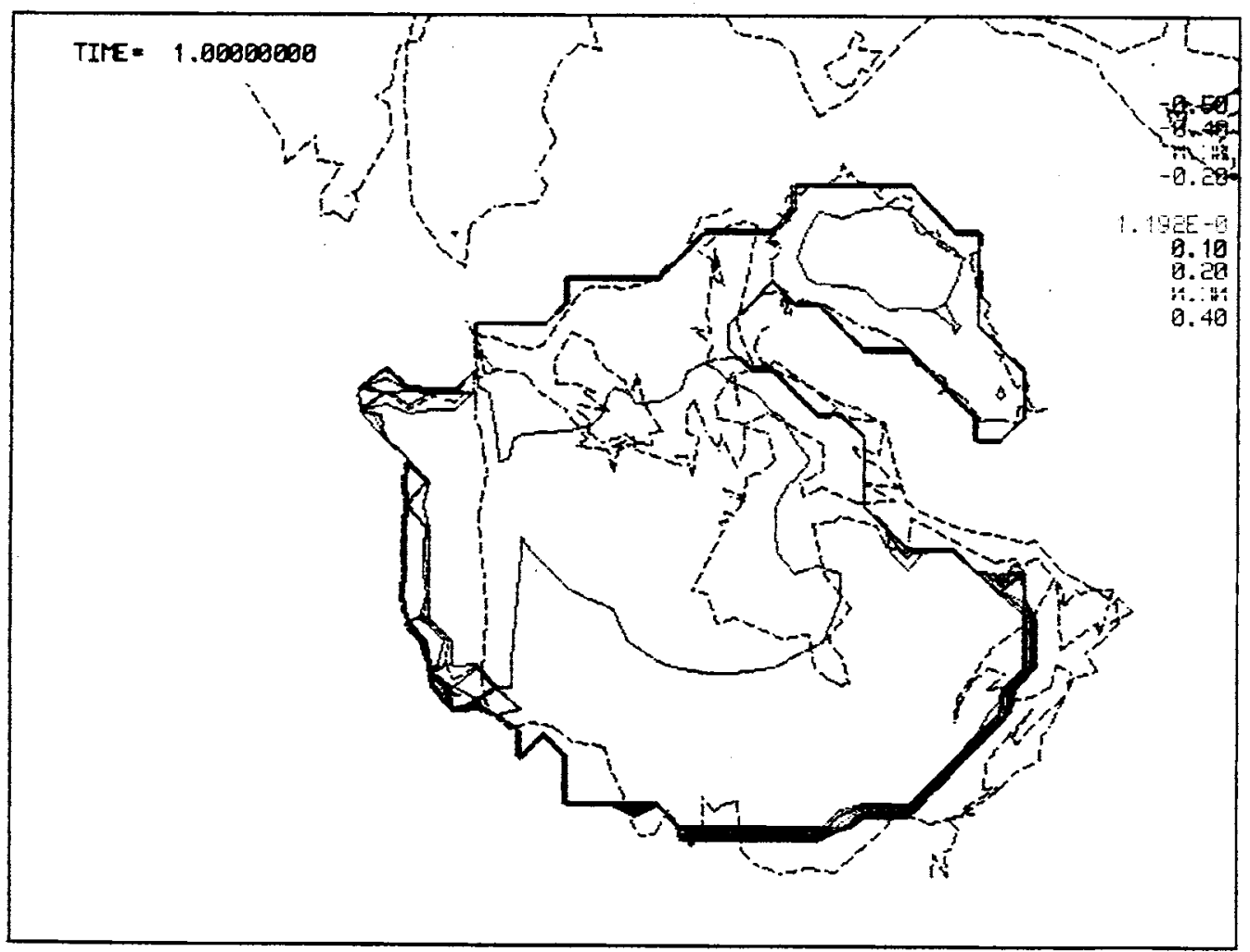

ElGURE 19. Mass Balance for the Ice Sheets in Figure 17. Surface accumulation (+) and ablation $(-)$ rates $(\mathrm{m} / \mathrm{a})$ are contoured. 


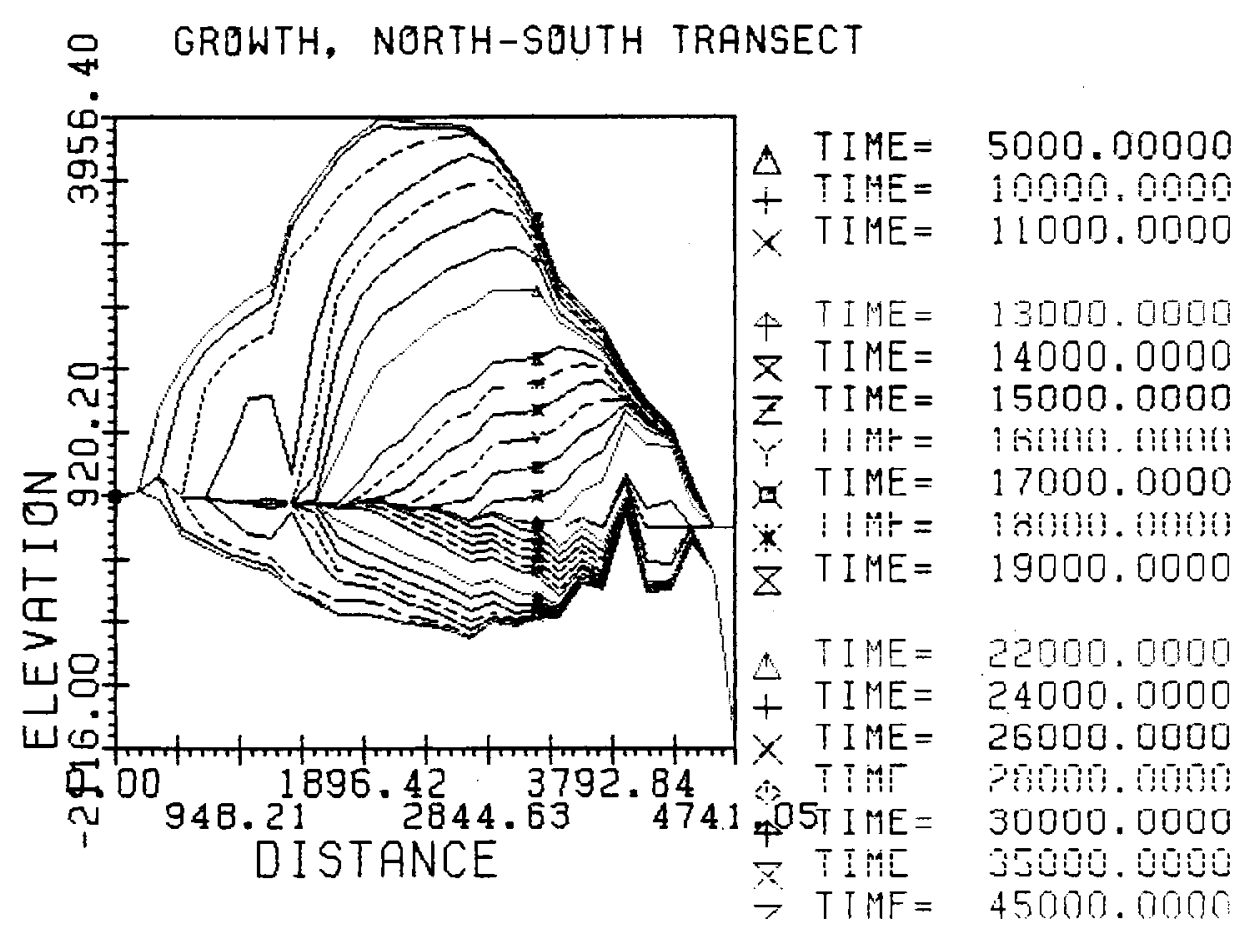

a) N-S Ice Advance

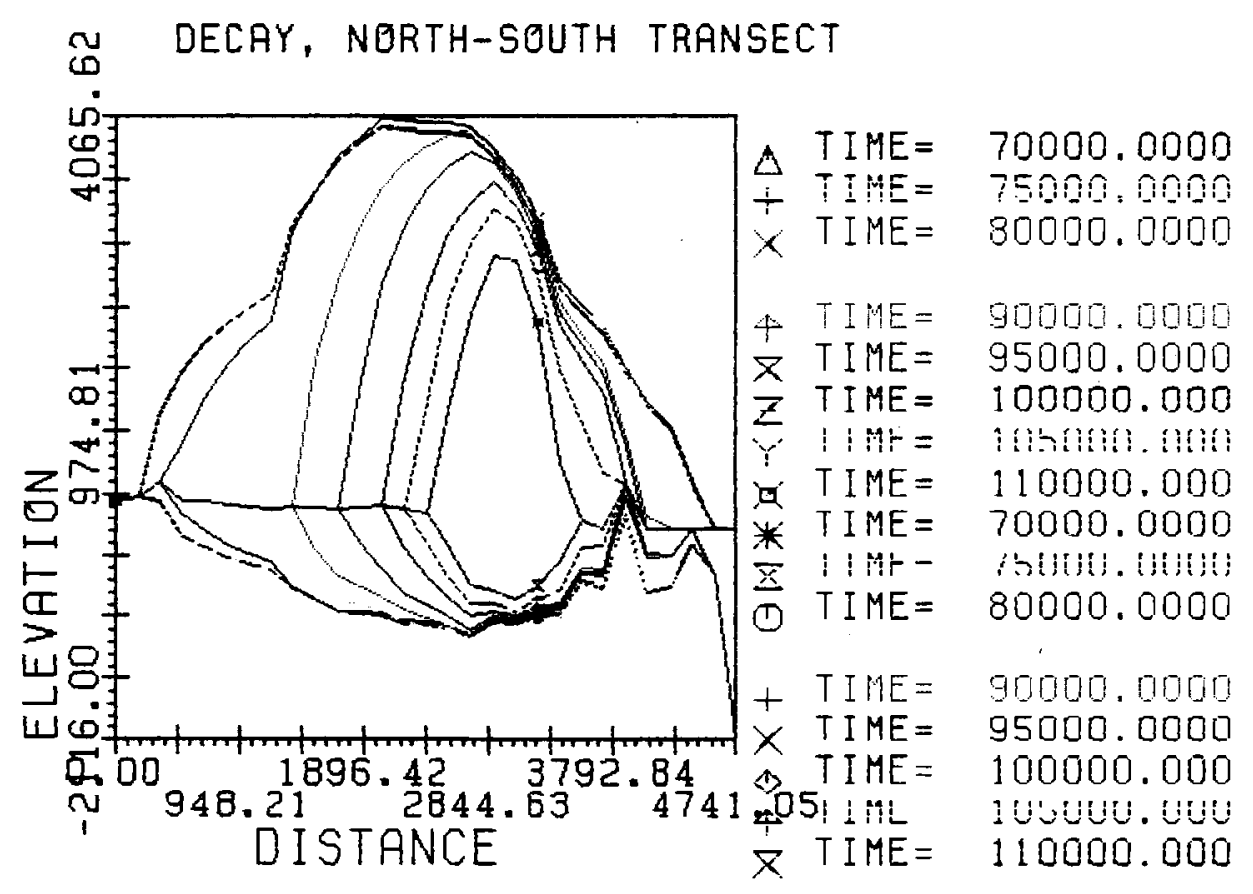

b) N - S lce Retreat

ElGURE 20. Ice-Sheet Transects Through Time For Figure 16. 


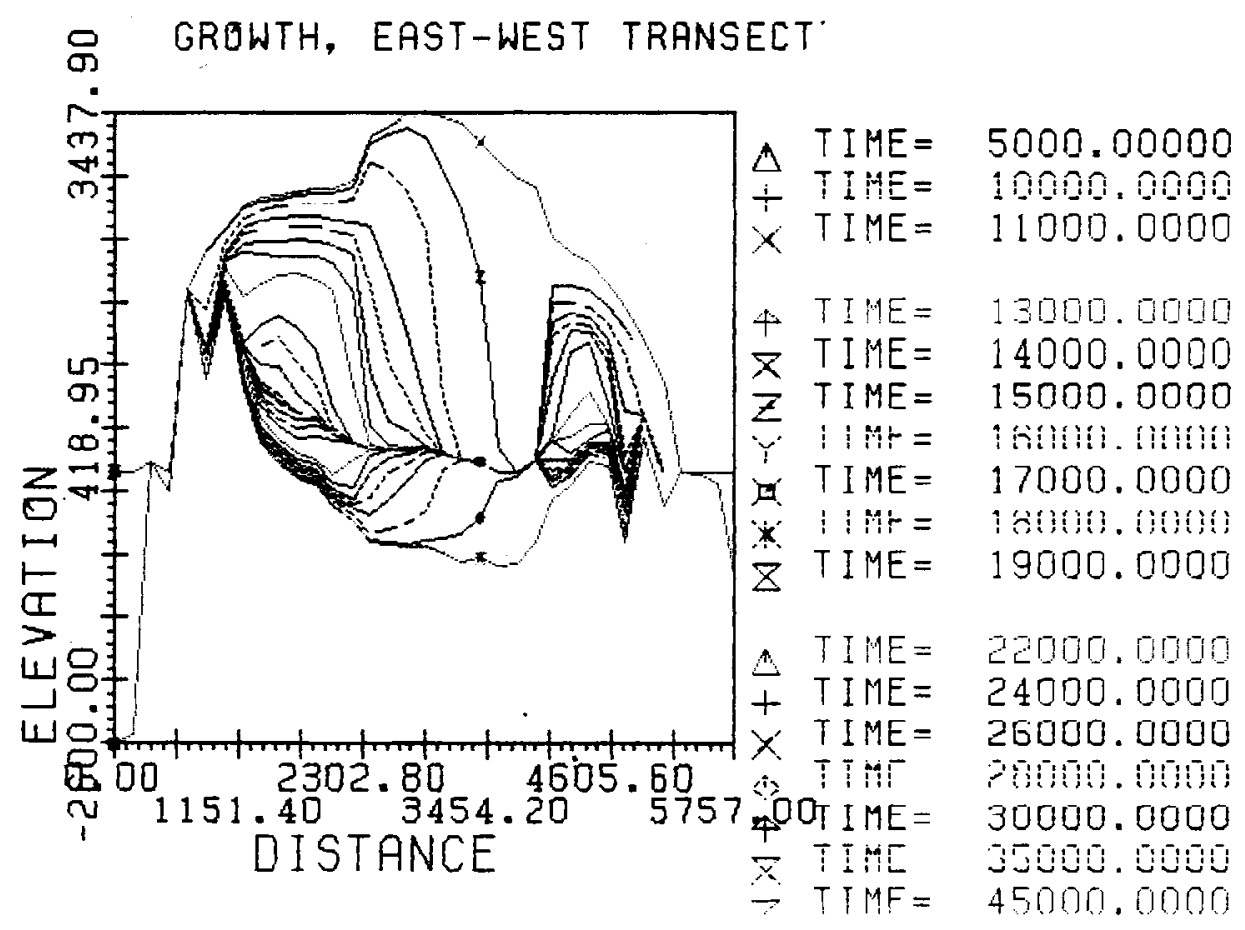

c) E - W Ice Advance

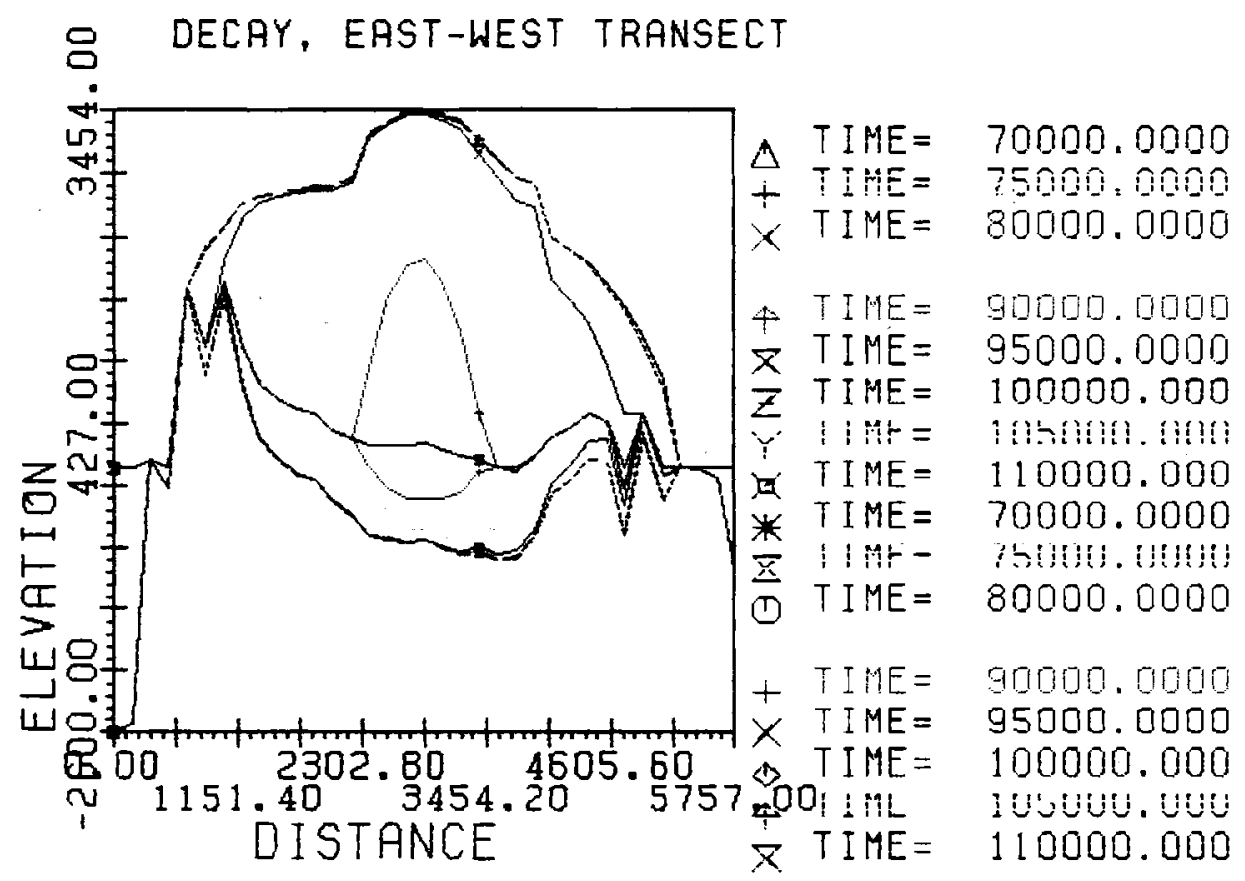

d) E - W Ice Retreat 


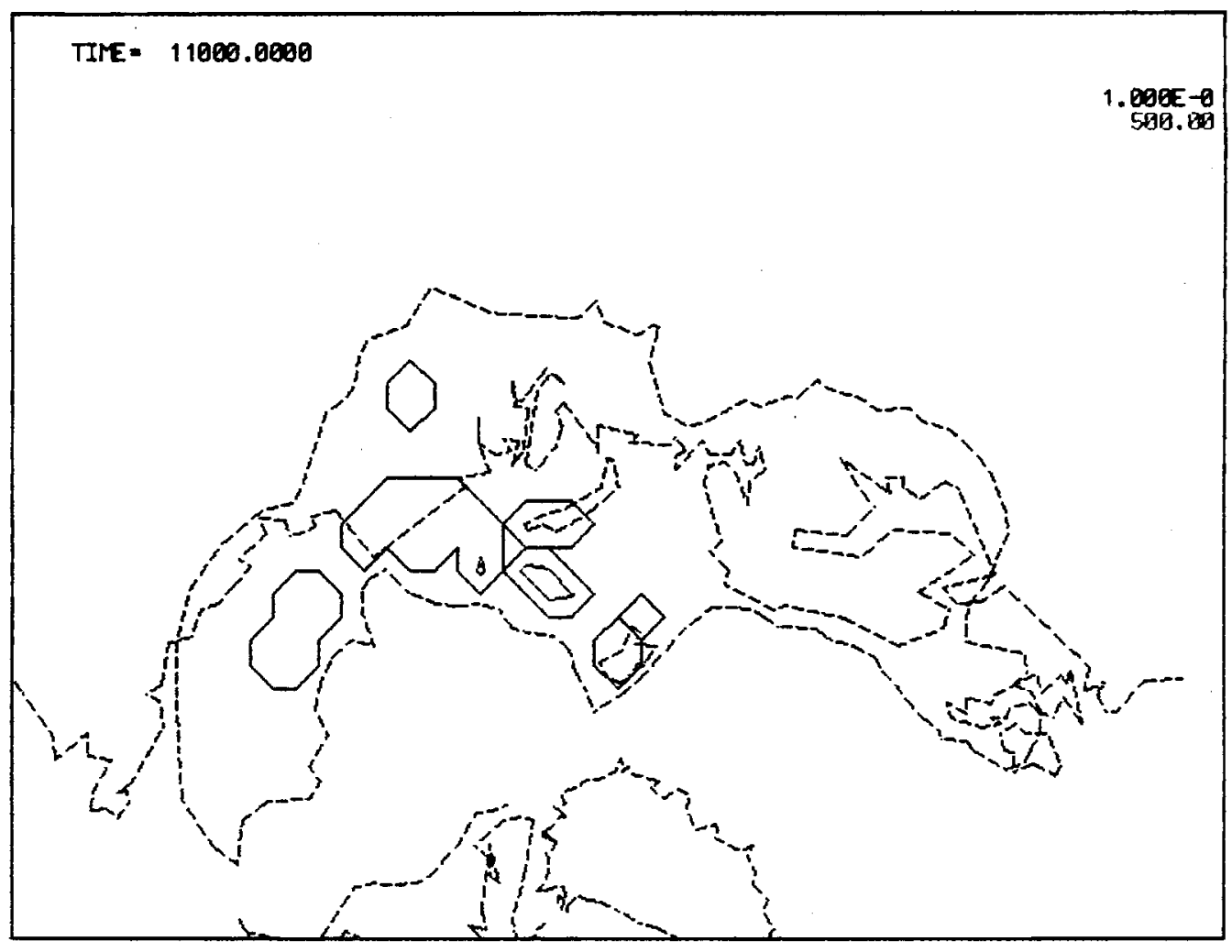

a) After 11,000 Years

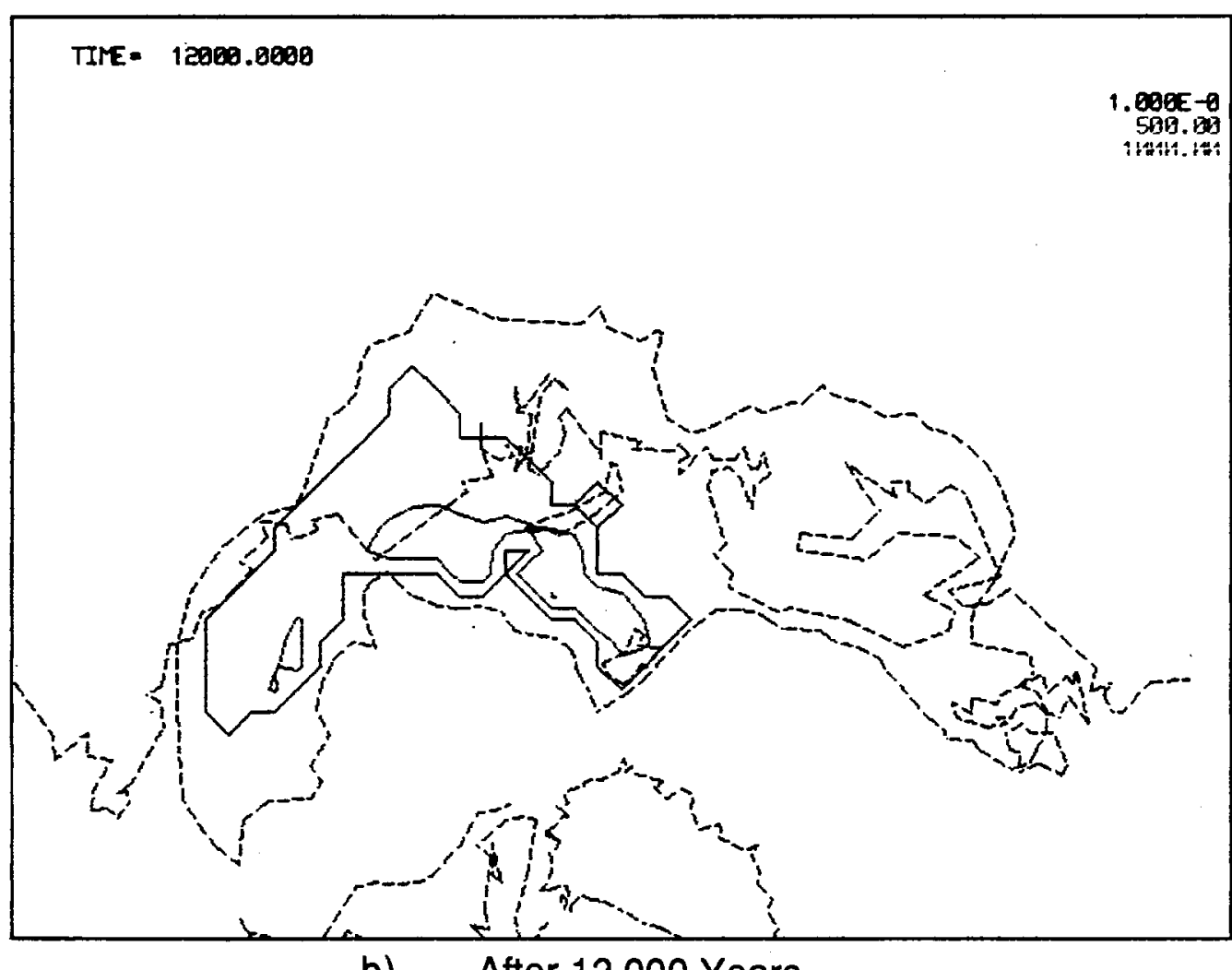

b) After 12,000 Years

ElGURE 21. A Eurasian Glaciation Cycle Driven by Dust. Ice thickness contoured every $500 \mathrm{~m}$. 


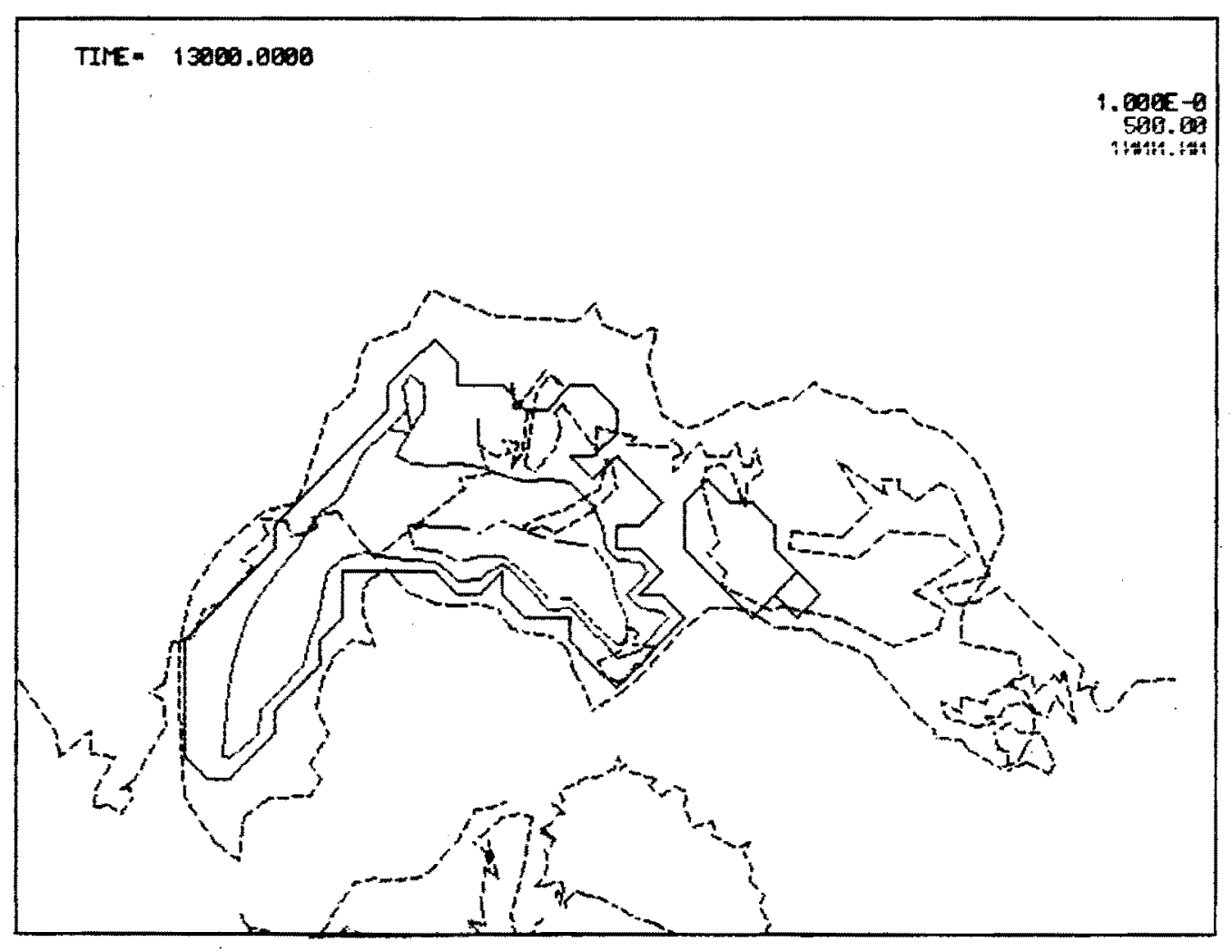

c) After 13,000 Years

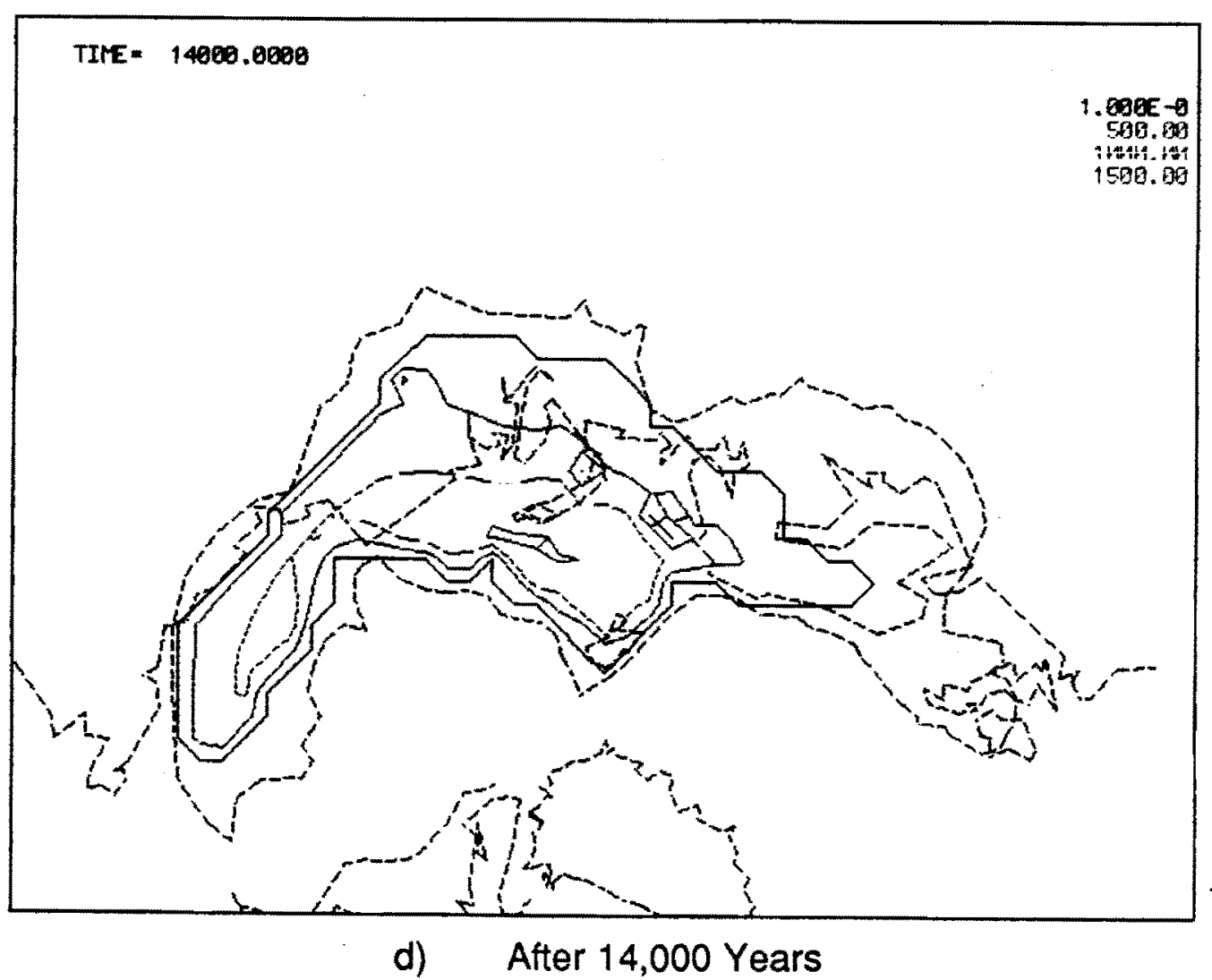




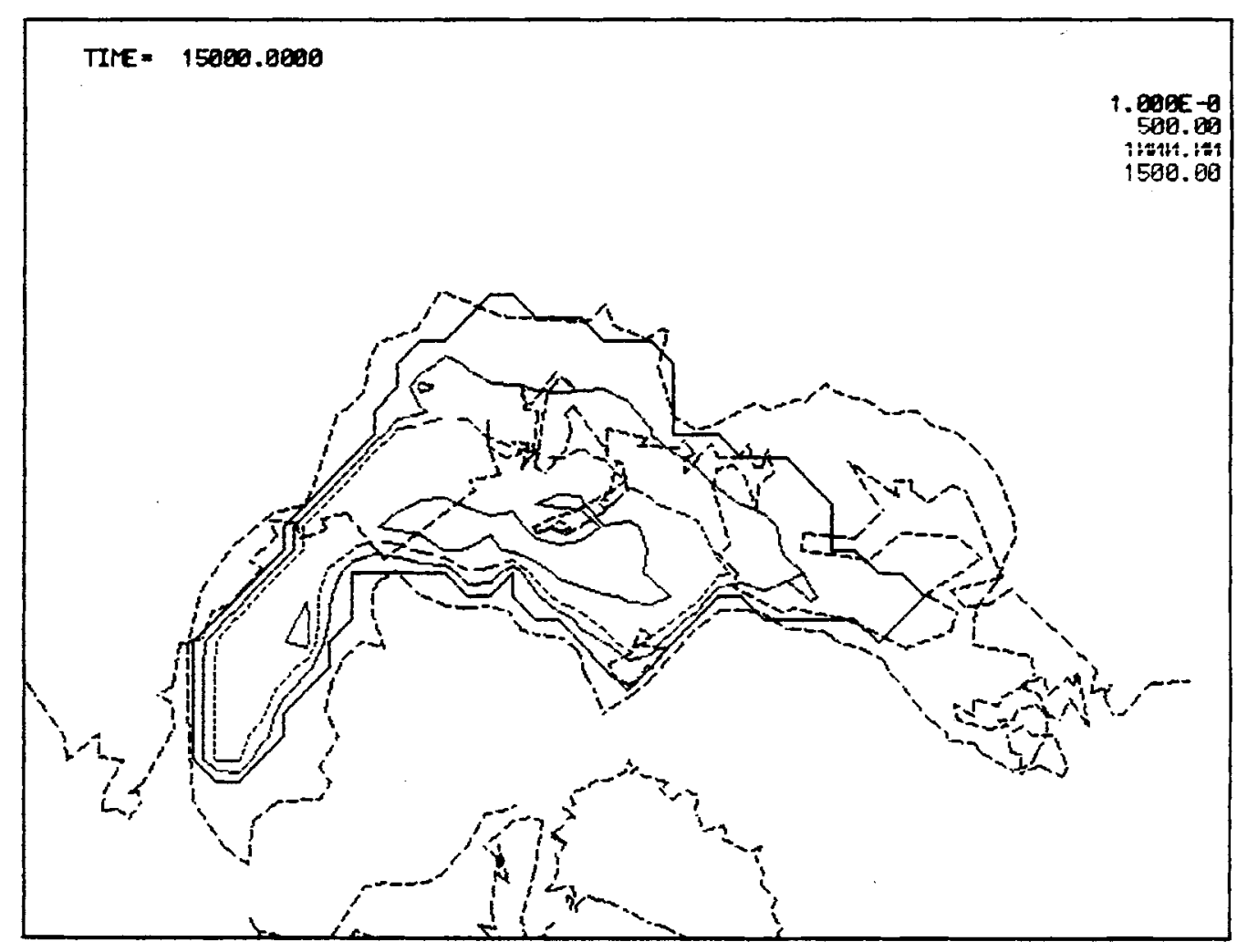

e) After 15,000 Years

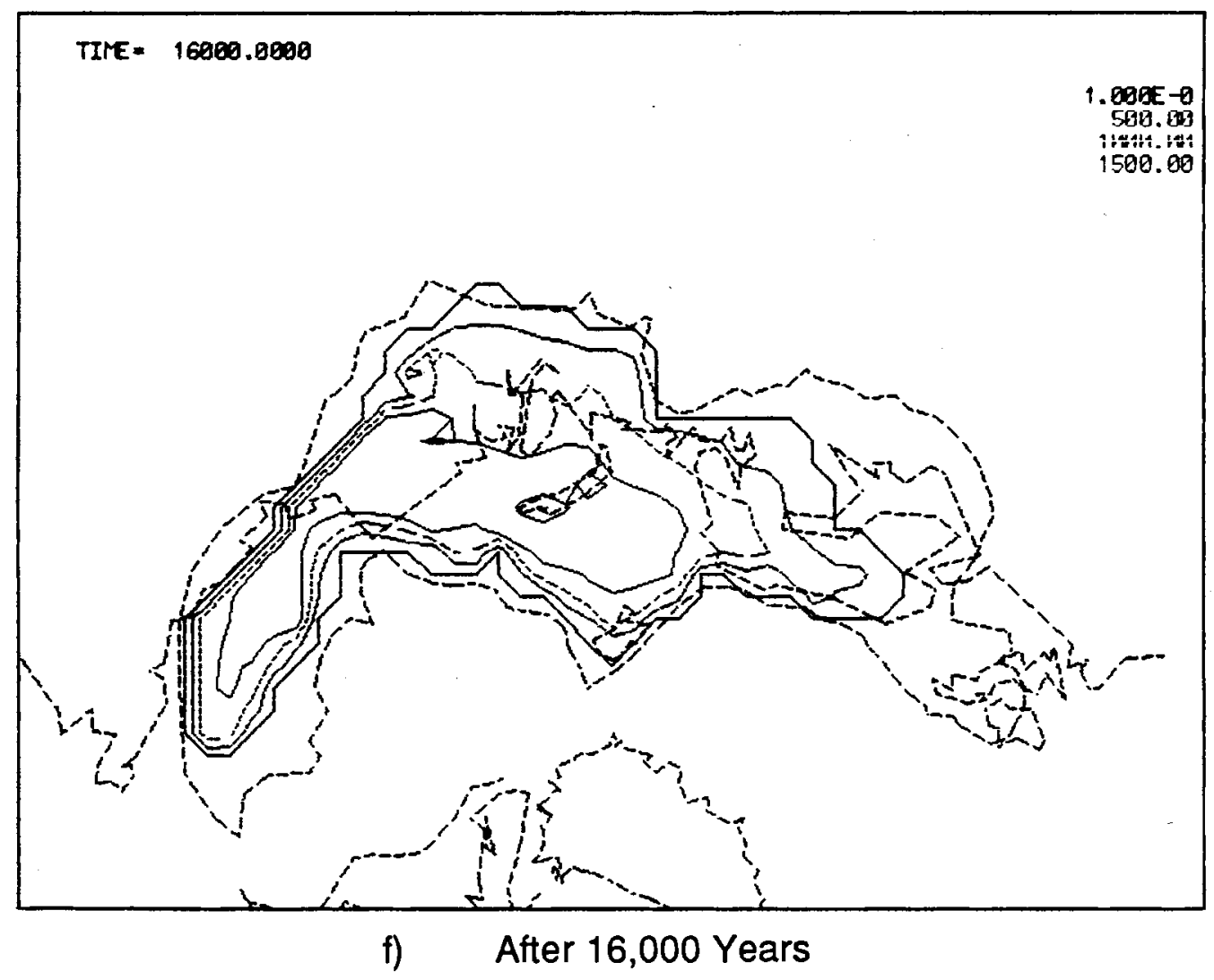




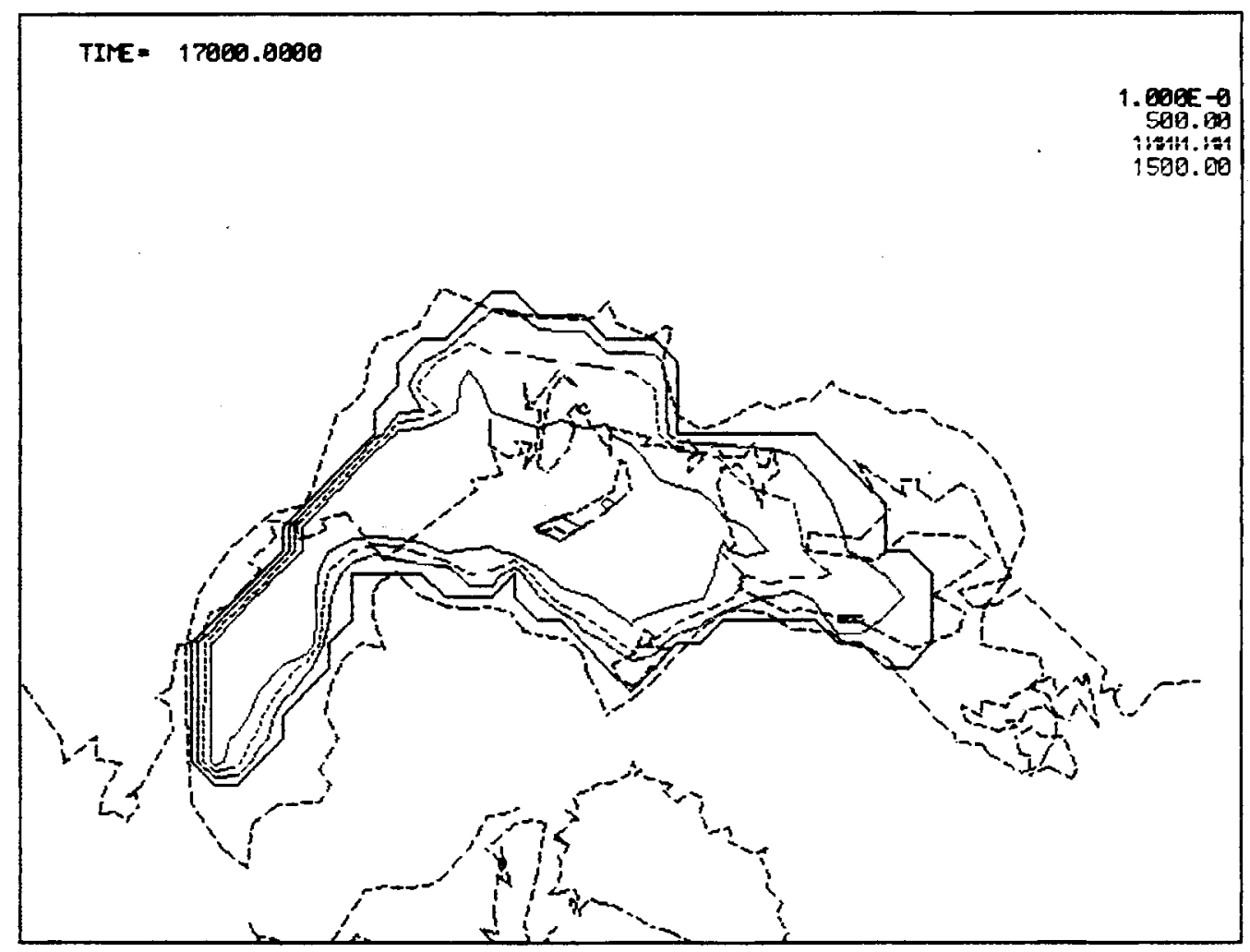

g) After 17,000 Years

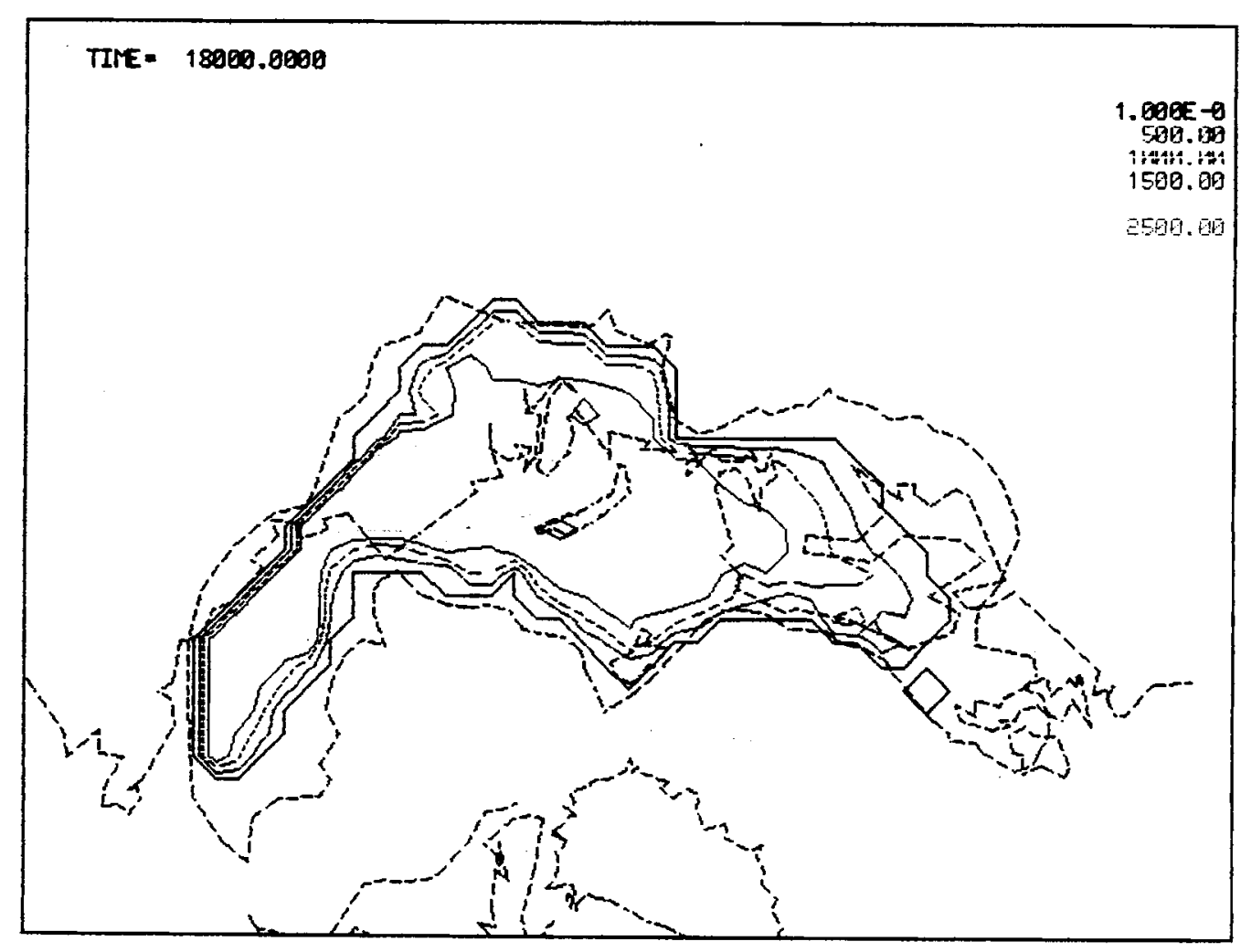

h) After 18,000 Years 


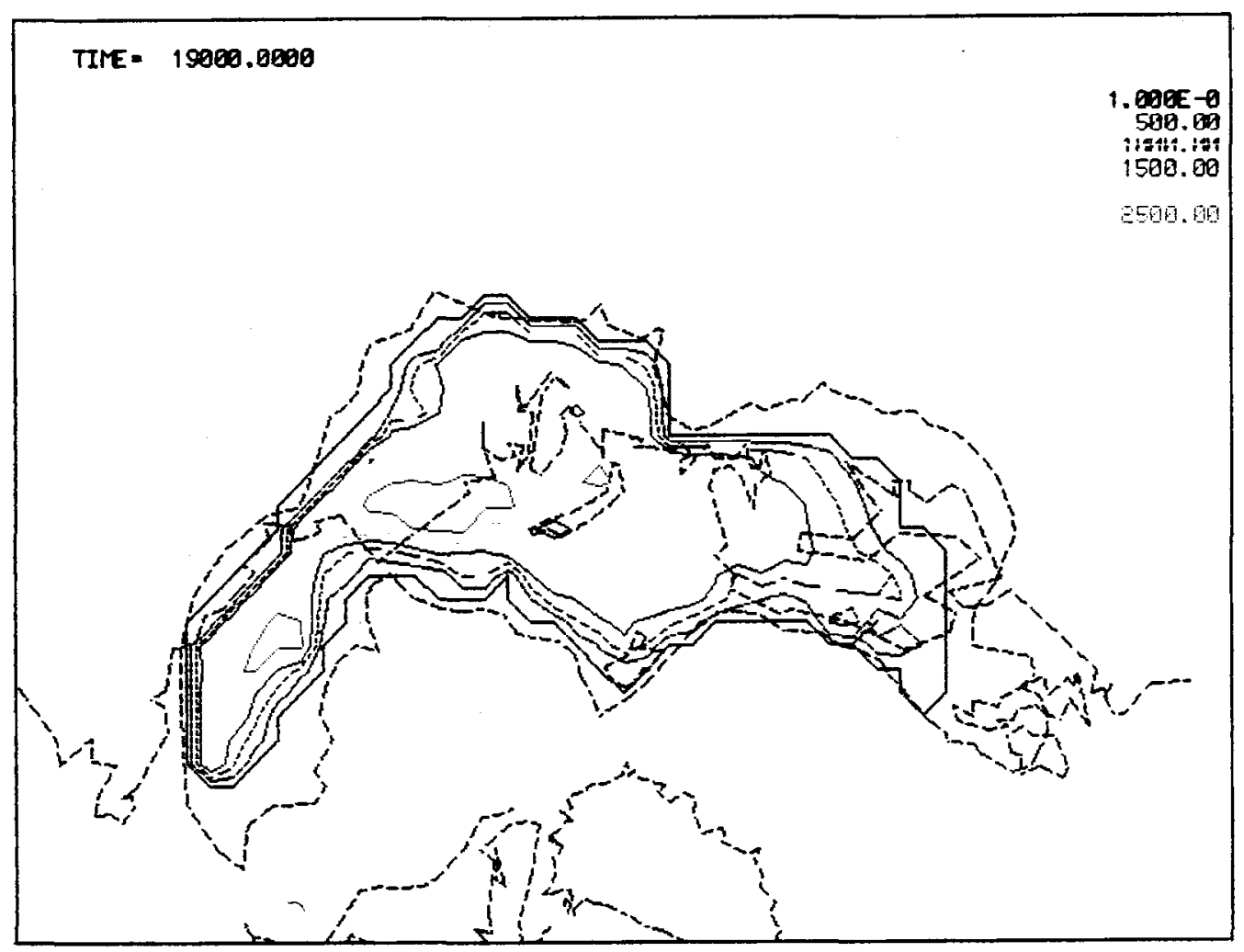

i) After 19,000 Years

TIME $=20080.0600$
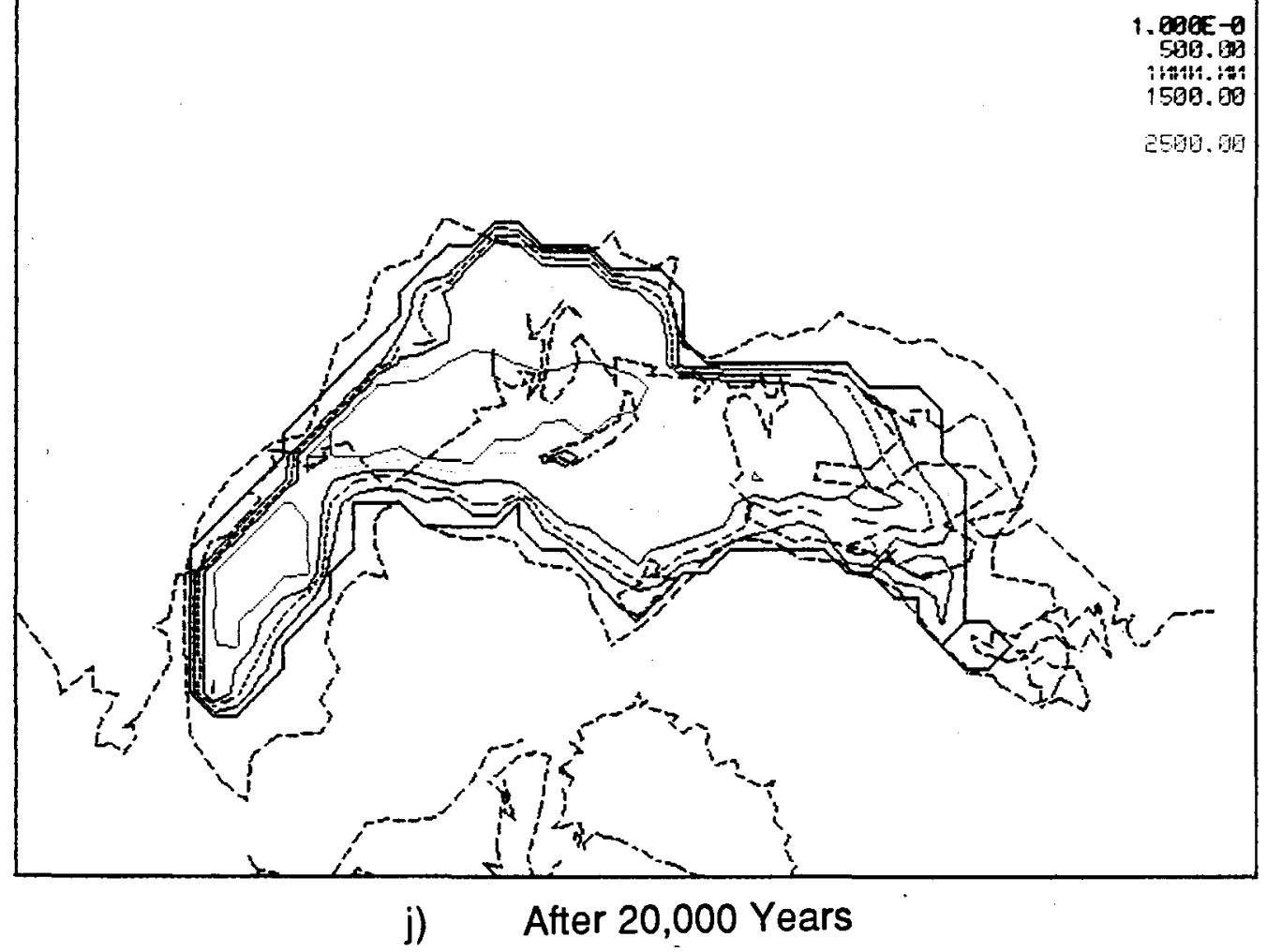


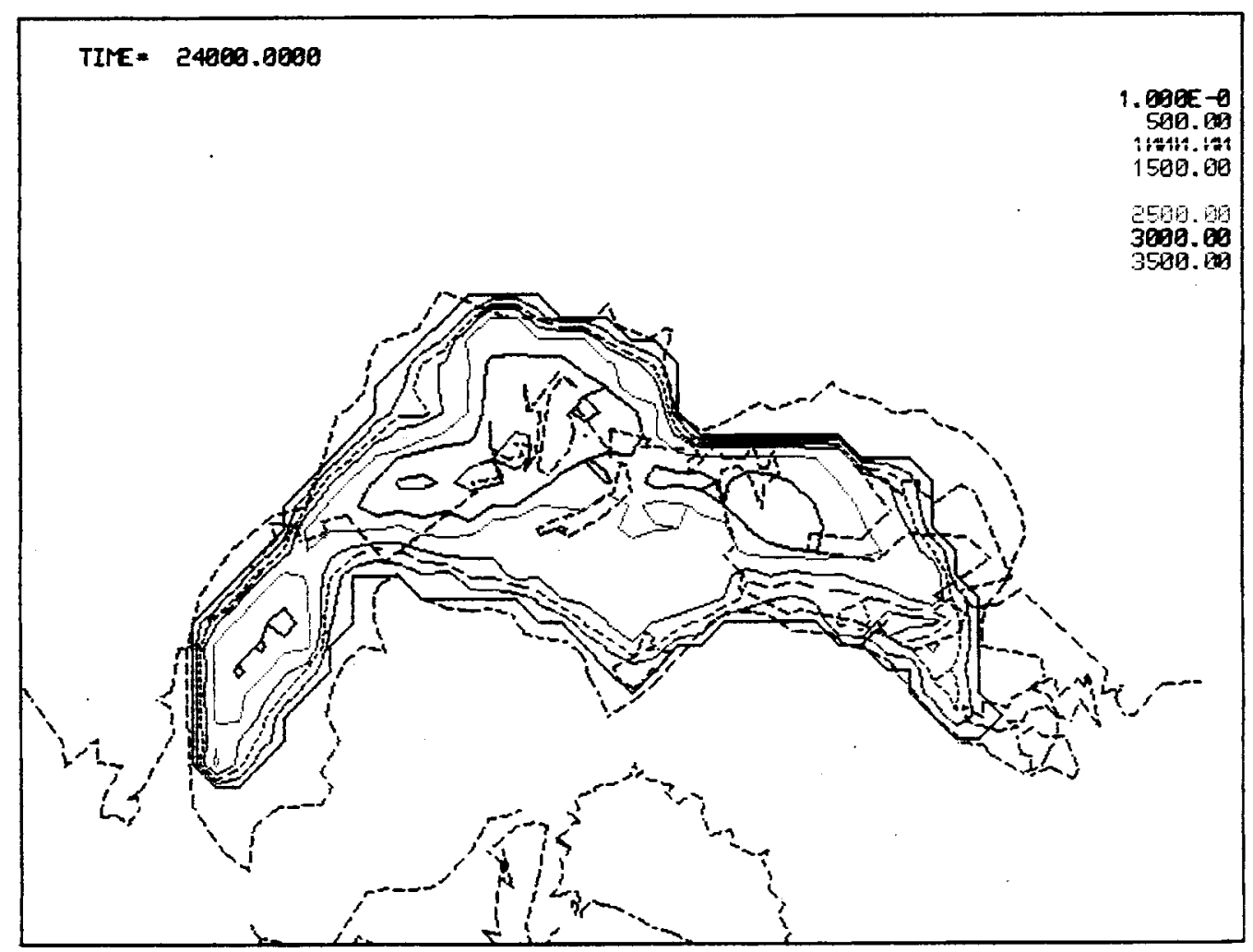

k) After 24,000 Years

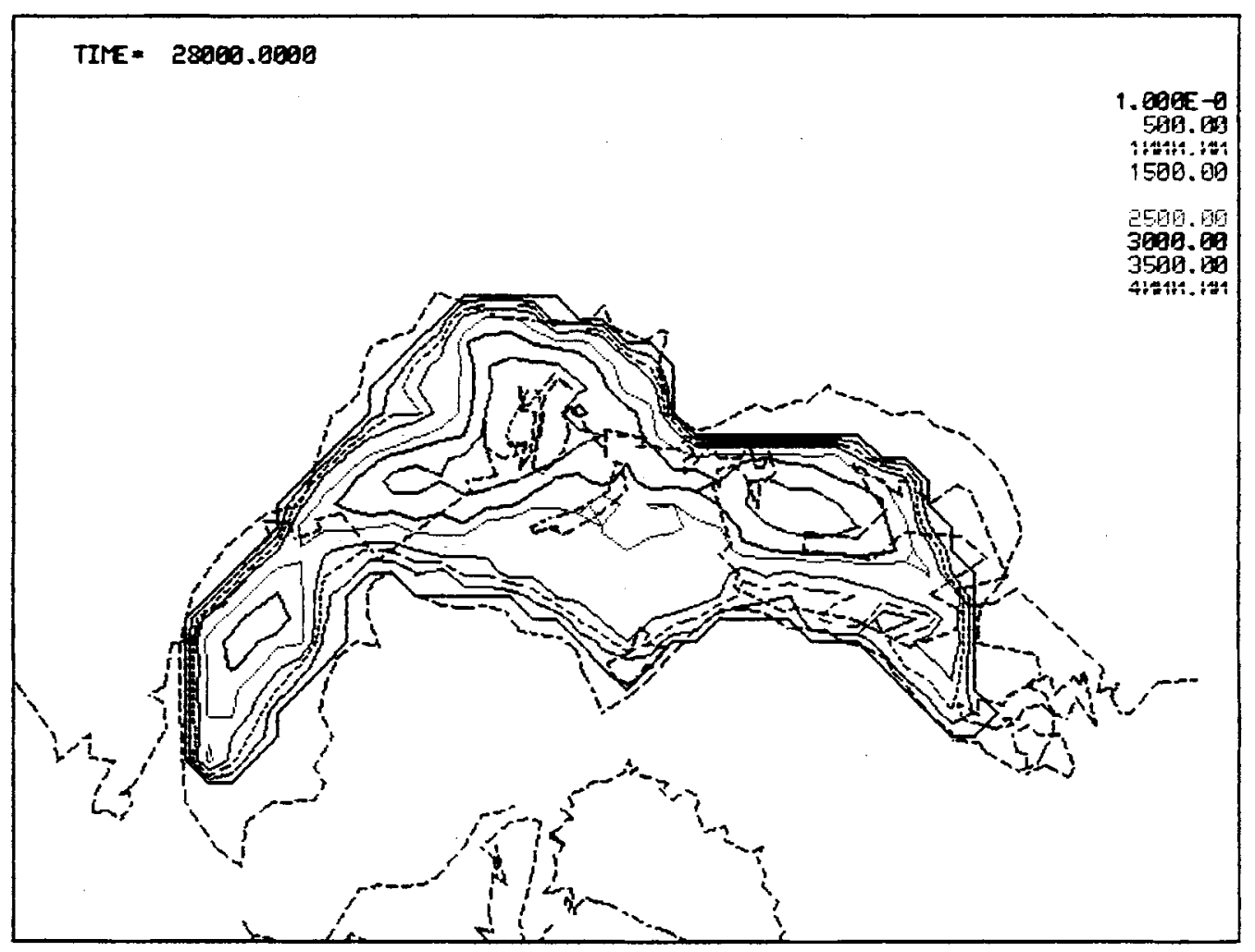

1) After 28,000 Years 


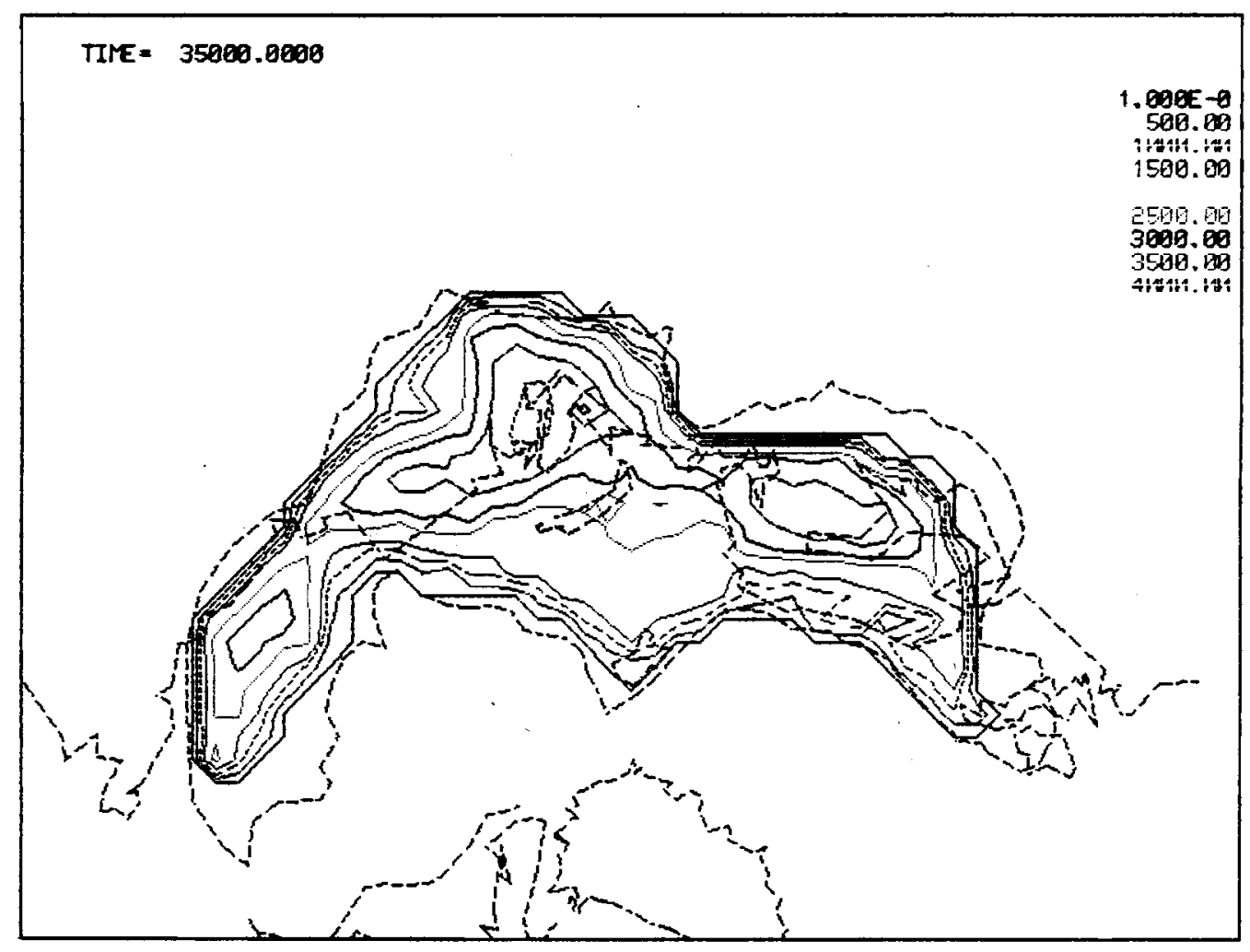

m) After 35,000 Years

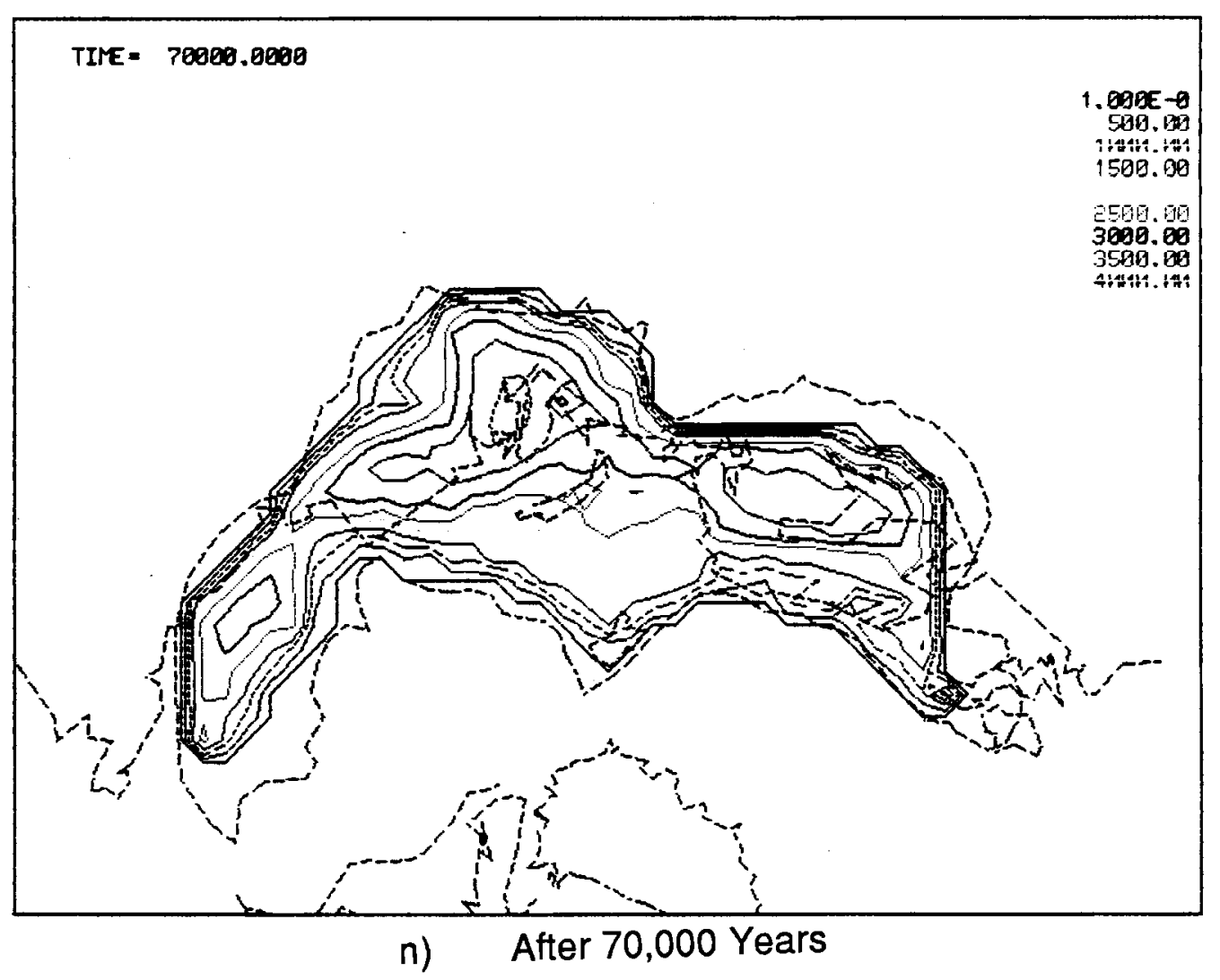




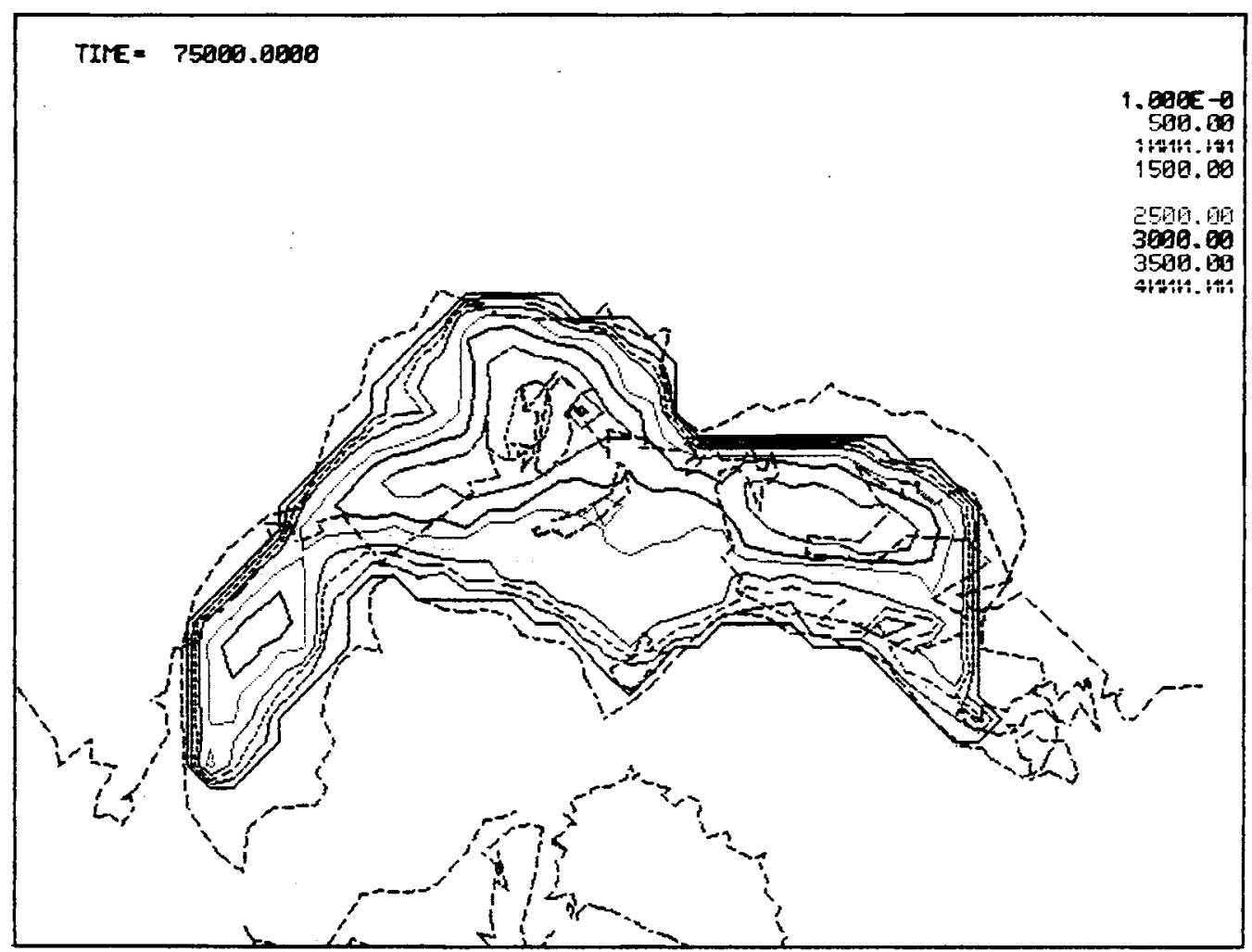

o) After 75,000 Years

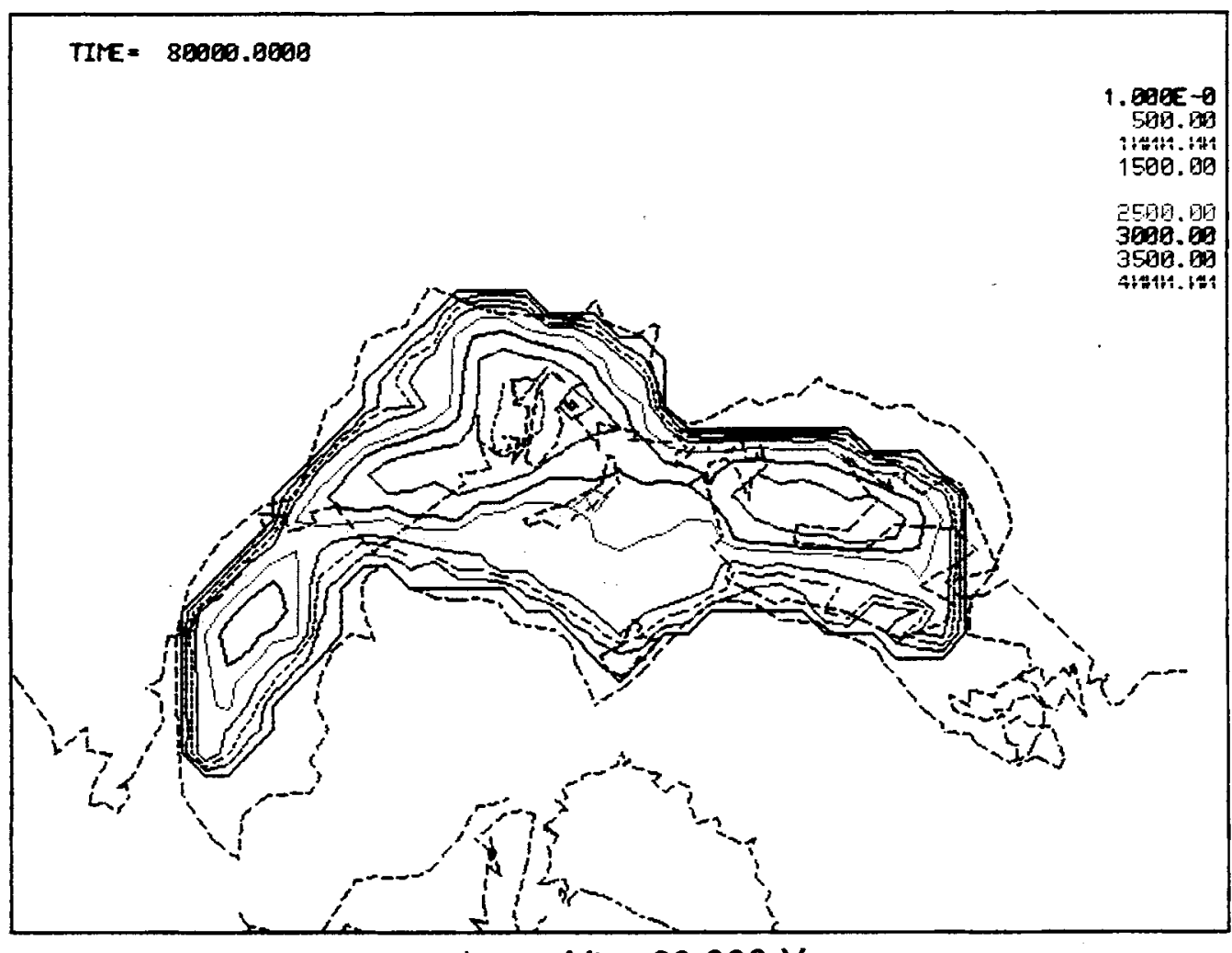

p) After 80,000 Years 


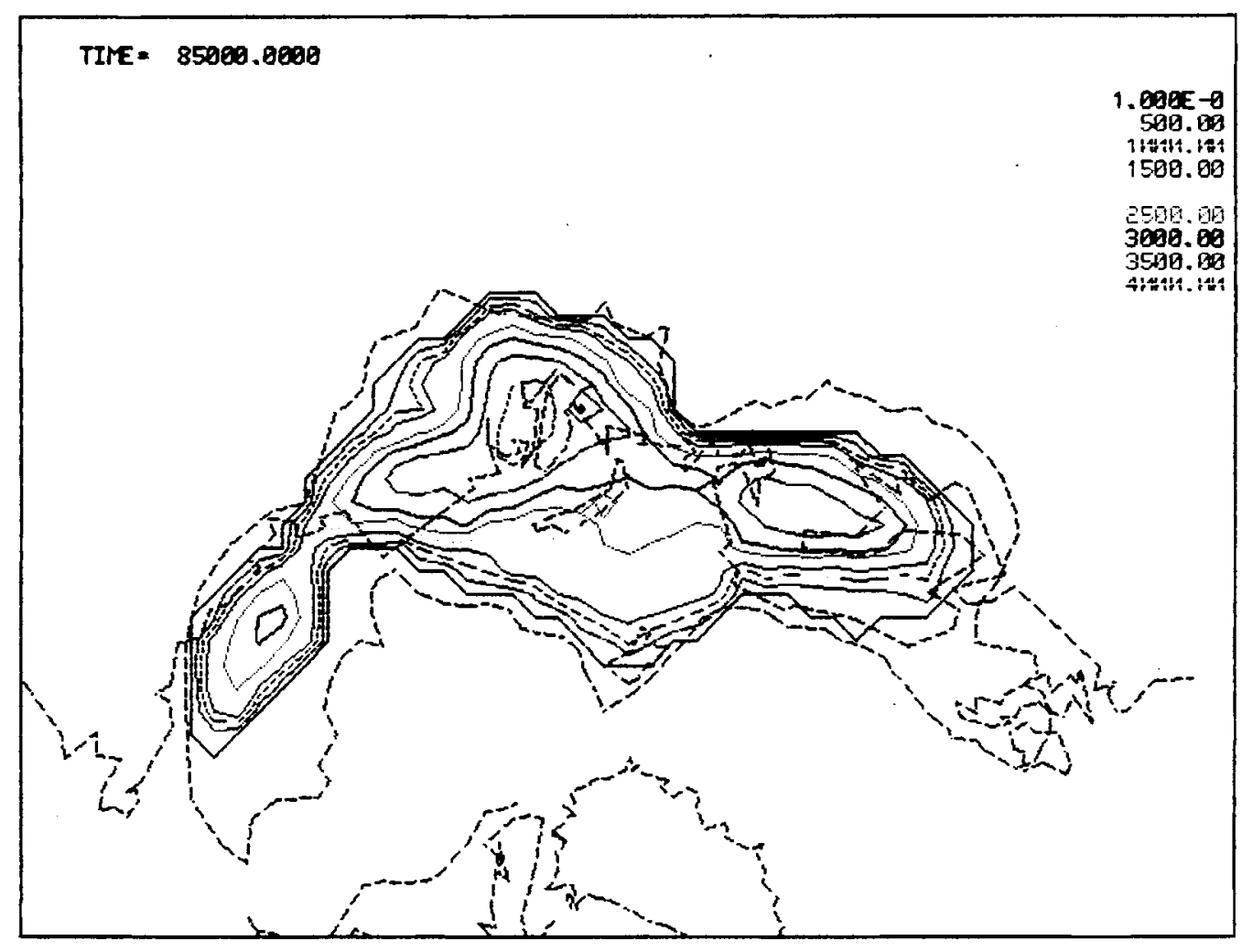

q) After 85,000 Years

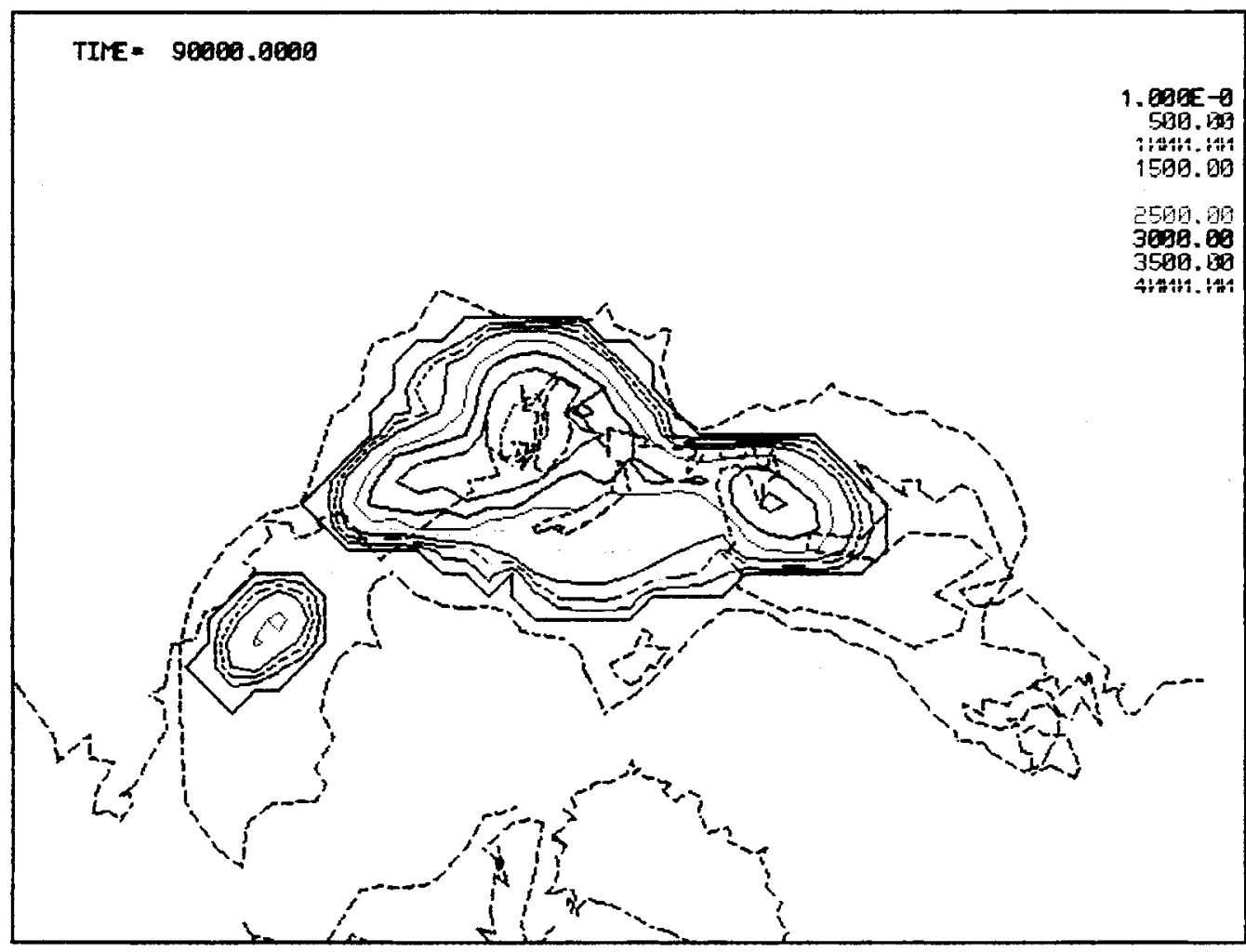

r) After 90,000 Years 


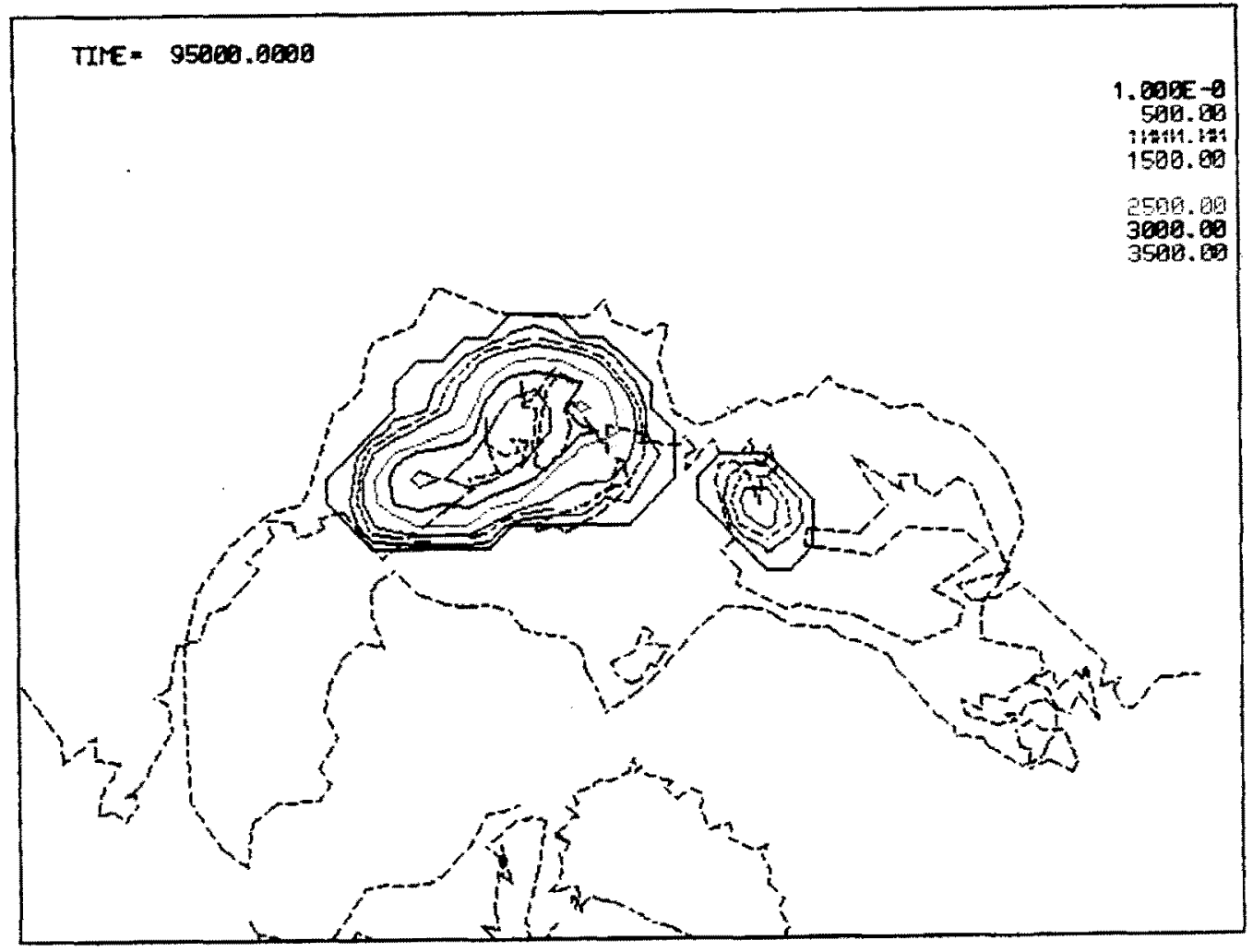

s) After 95,000 Years

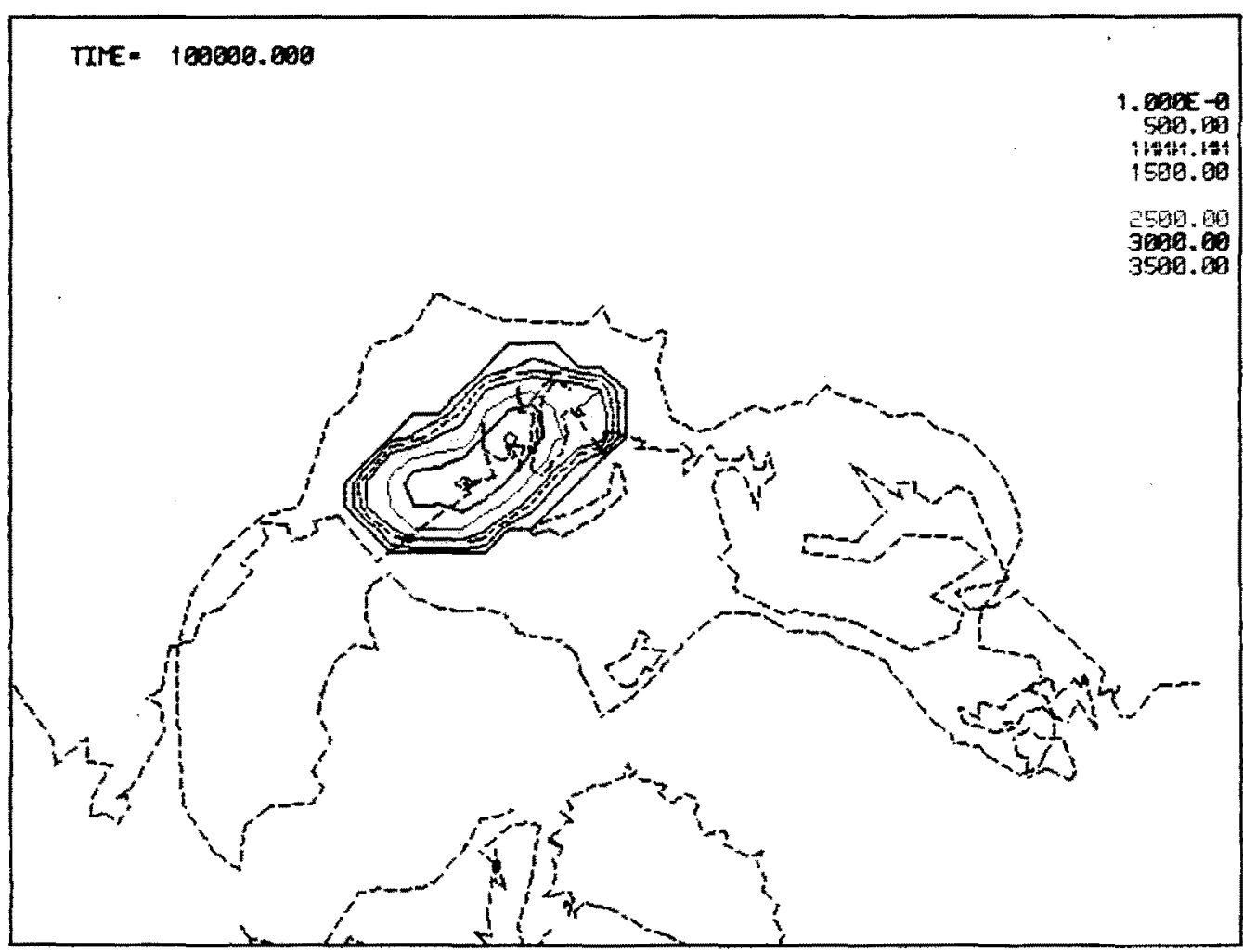

t) After 100,000 Years 


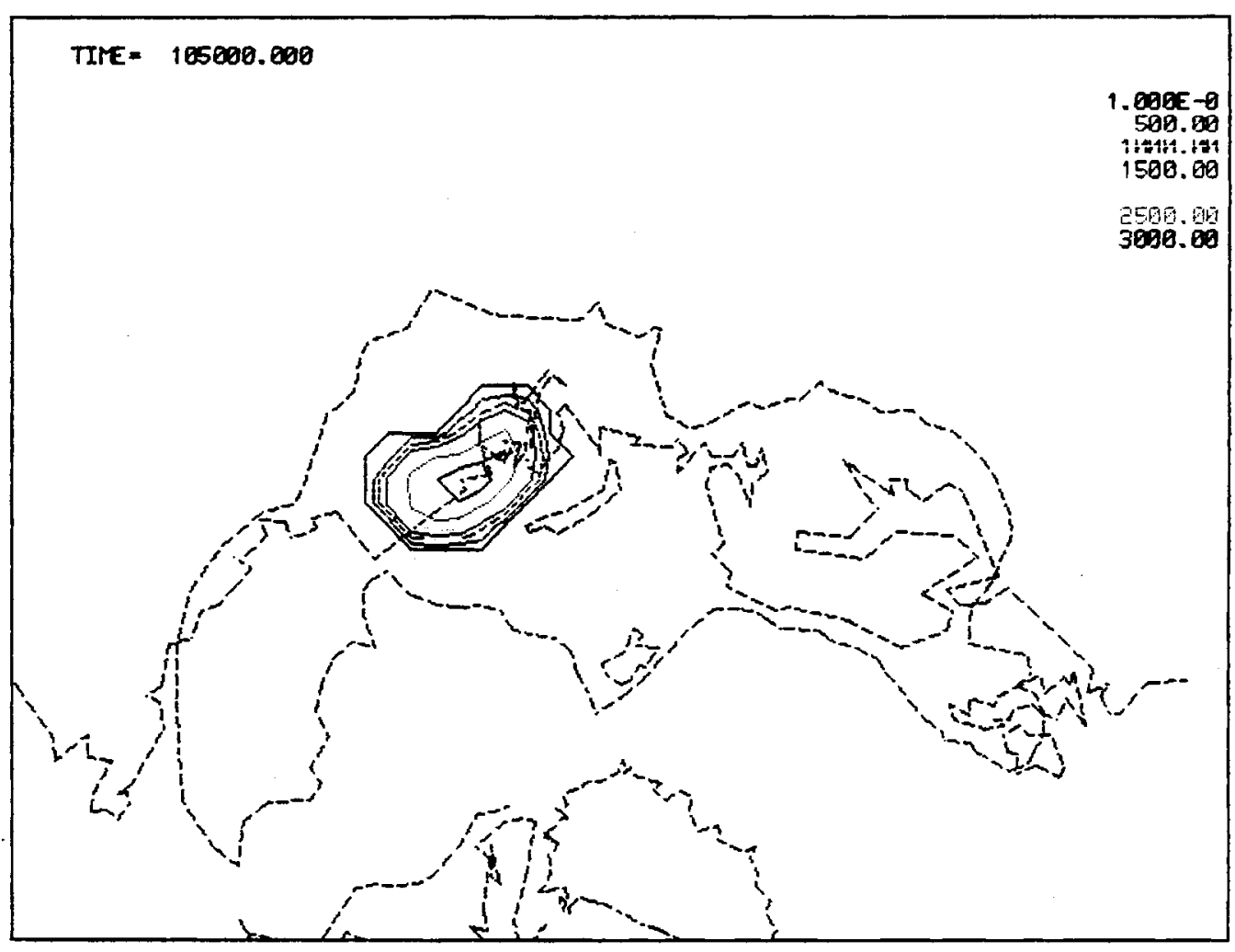

u) After 105,000 Years

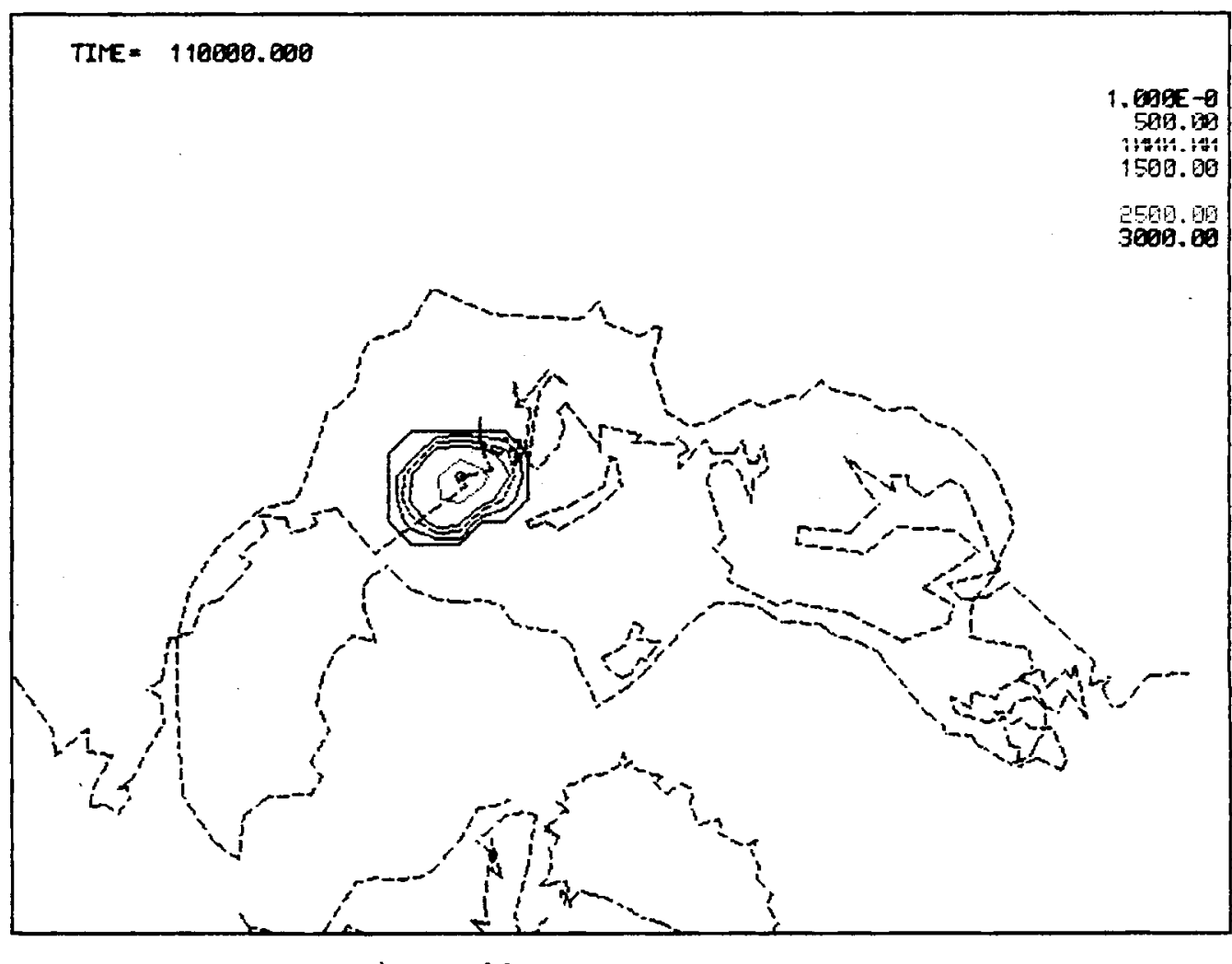

v) After 110,000 Years 


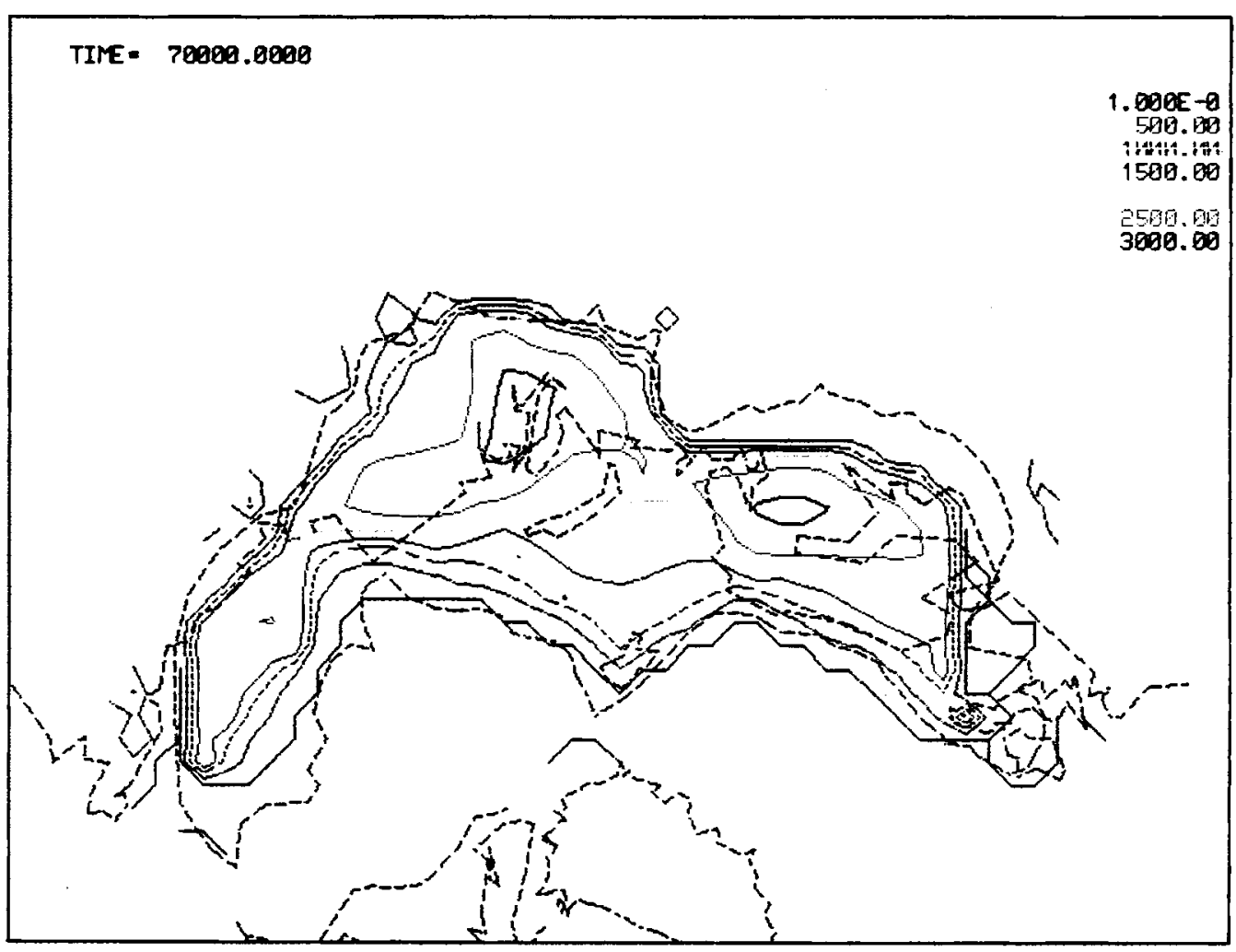

EIGURE 22. Ice Elevation at the Glacial Maximum in Figure 21. Ice elevations contoured every $500 \mathrm{~m}$ for the glacial maximum after 70,000 years. 


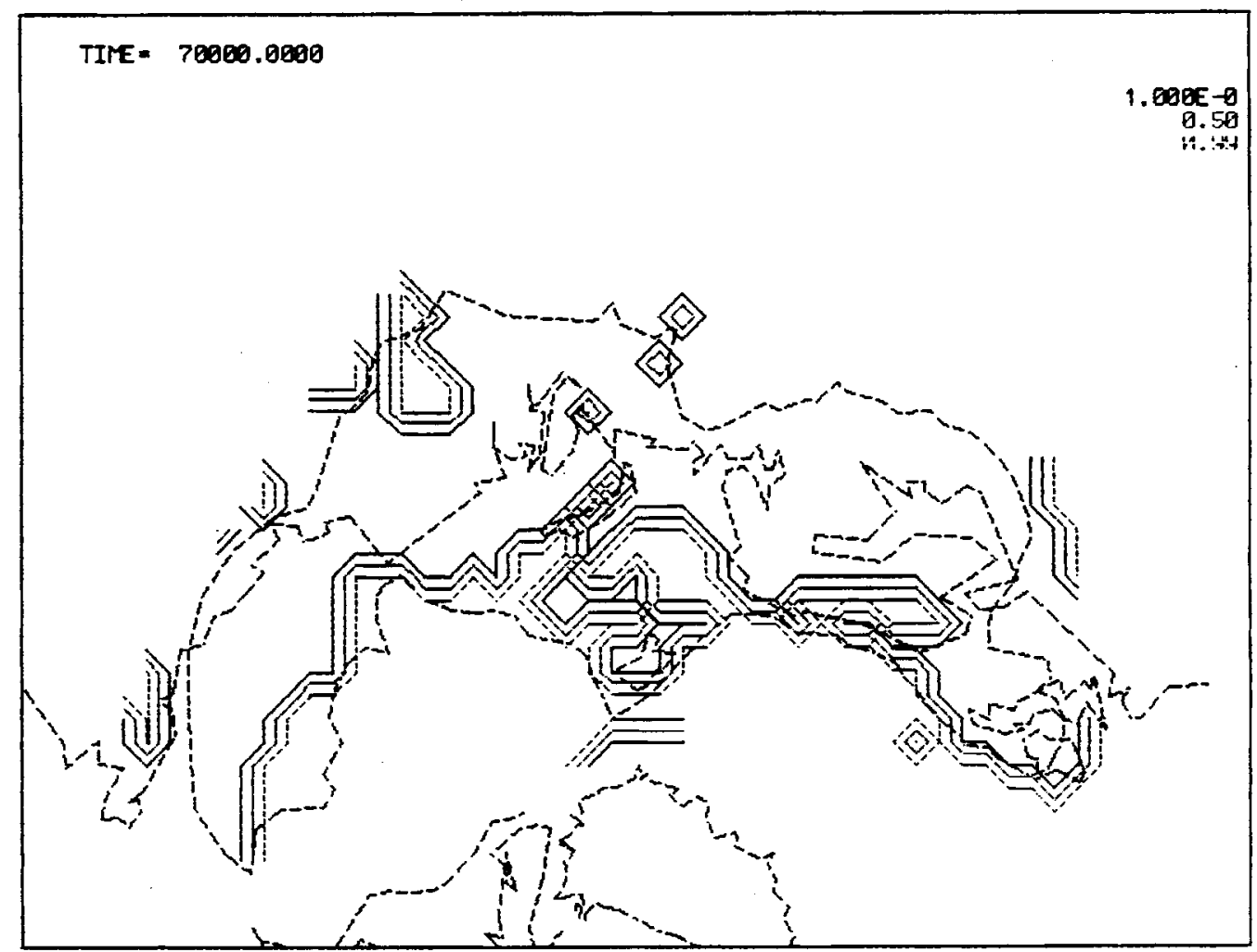

FIGURE 23. Velocity Fractions by Basal Sliding for the Ice Sheets in Figure 22. Contour lines are the fraction of ice velocity due to sliding.

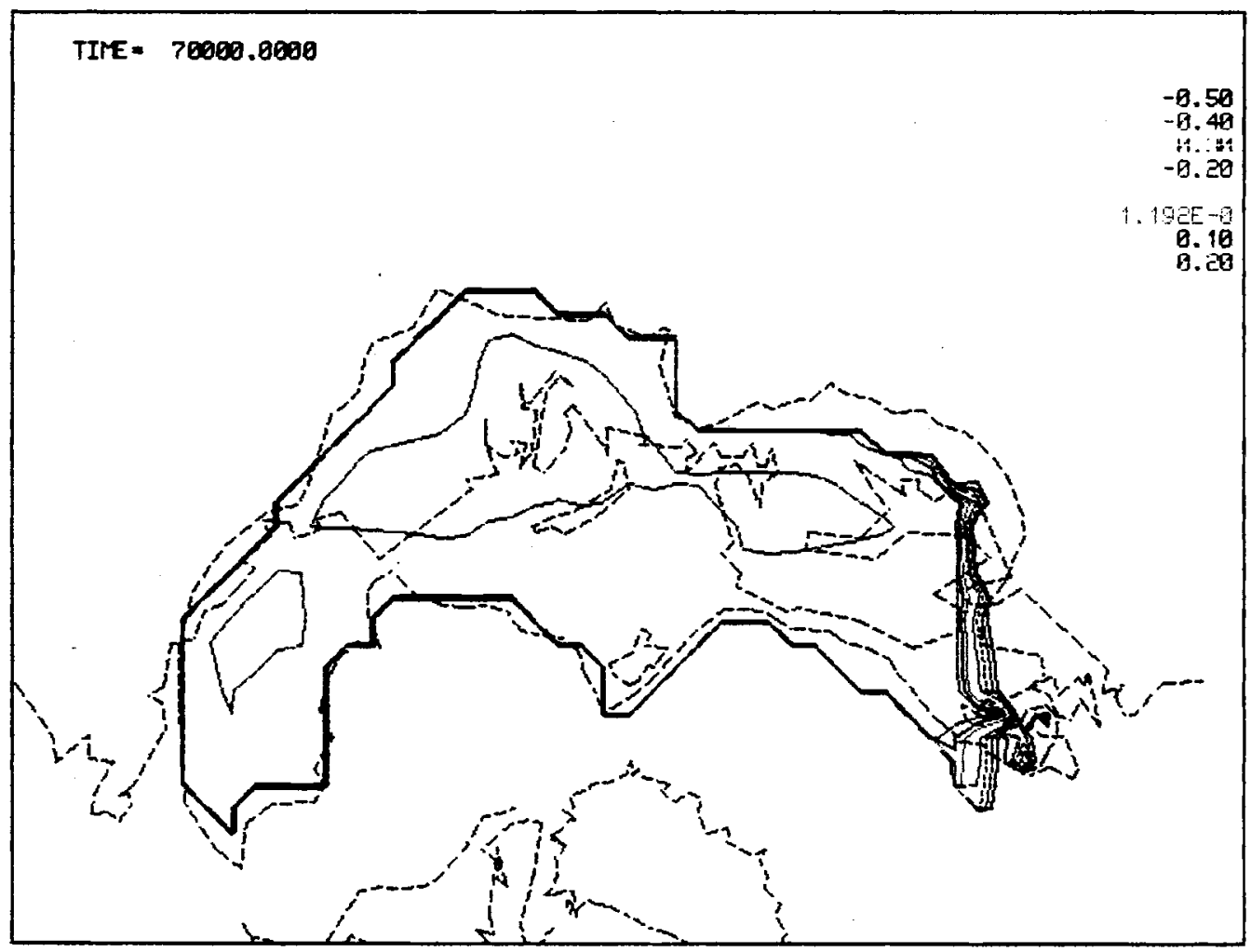

ElGURE 24. Mass Balance for the Ice Sheets in Figure 22. Surface accumulation (+) and ablation $(-)$ rates $(\mathrm{m} / \mathrm{a})$ are contoured. 
TIME $=70000.0000$

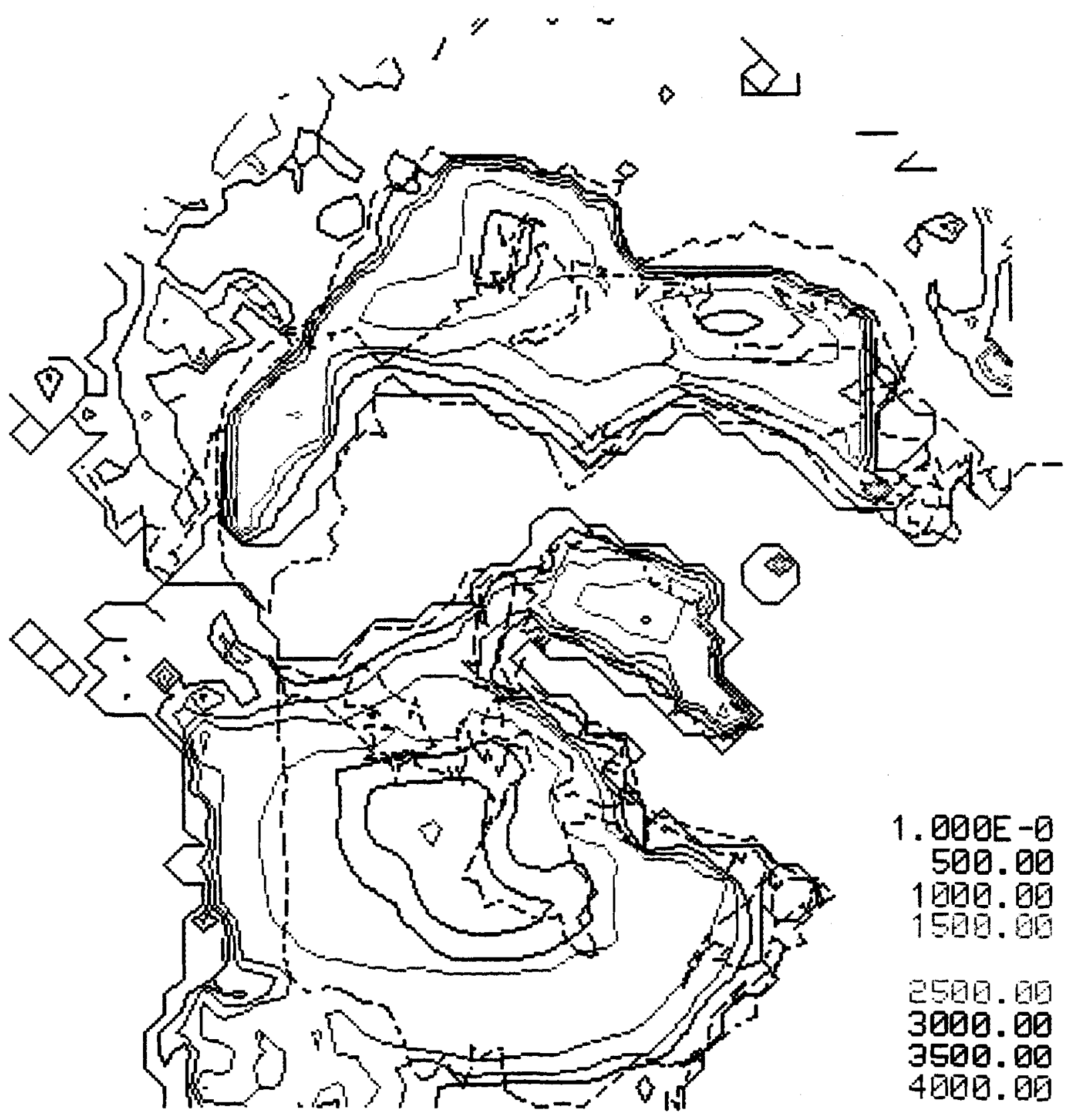

FIGURE 25. Maximum Arctic Ice and Land Elevations for a Dust-Driven Glaciation. Contours every $500 \mathrm{~m}$. 
TIME $=70000.0000$

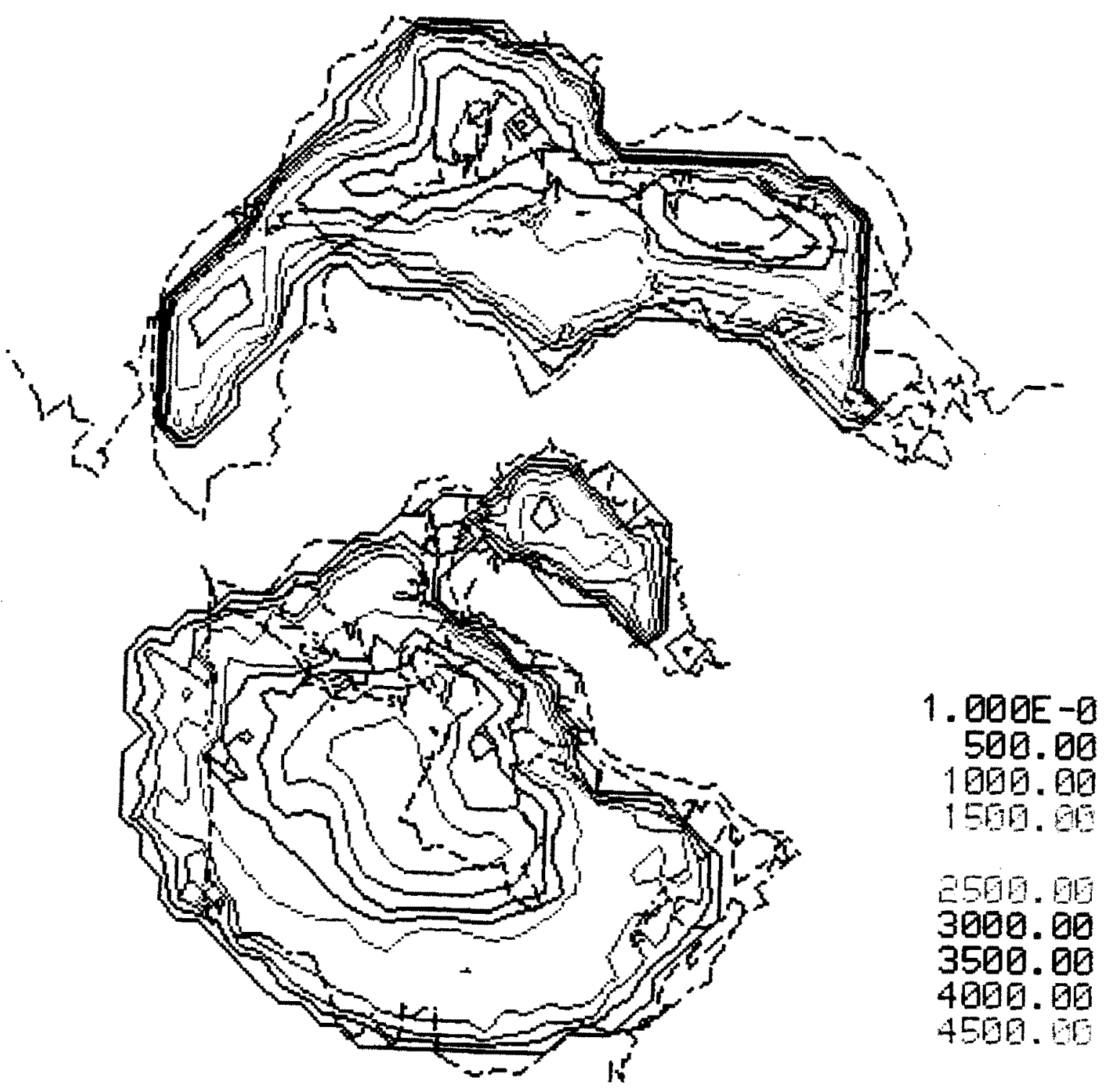

EIGUBE 26. Maximum Arctic Ice Thicknesses for a Dust Driven Glaciation. Contours every $500 \mathrm{~m}$. 
TIME $=70000.0000$

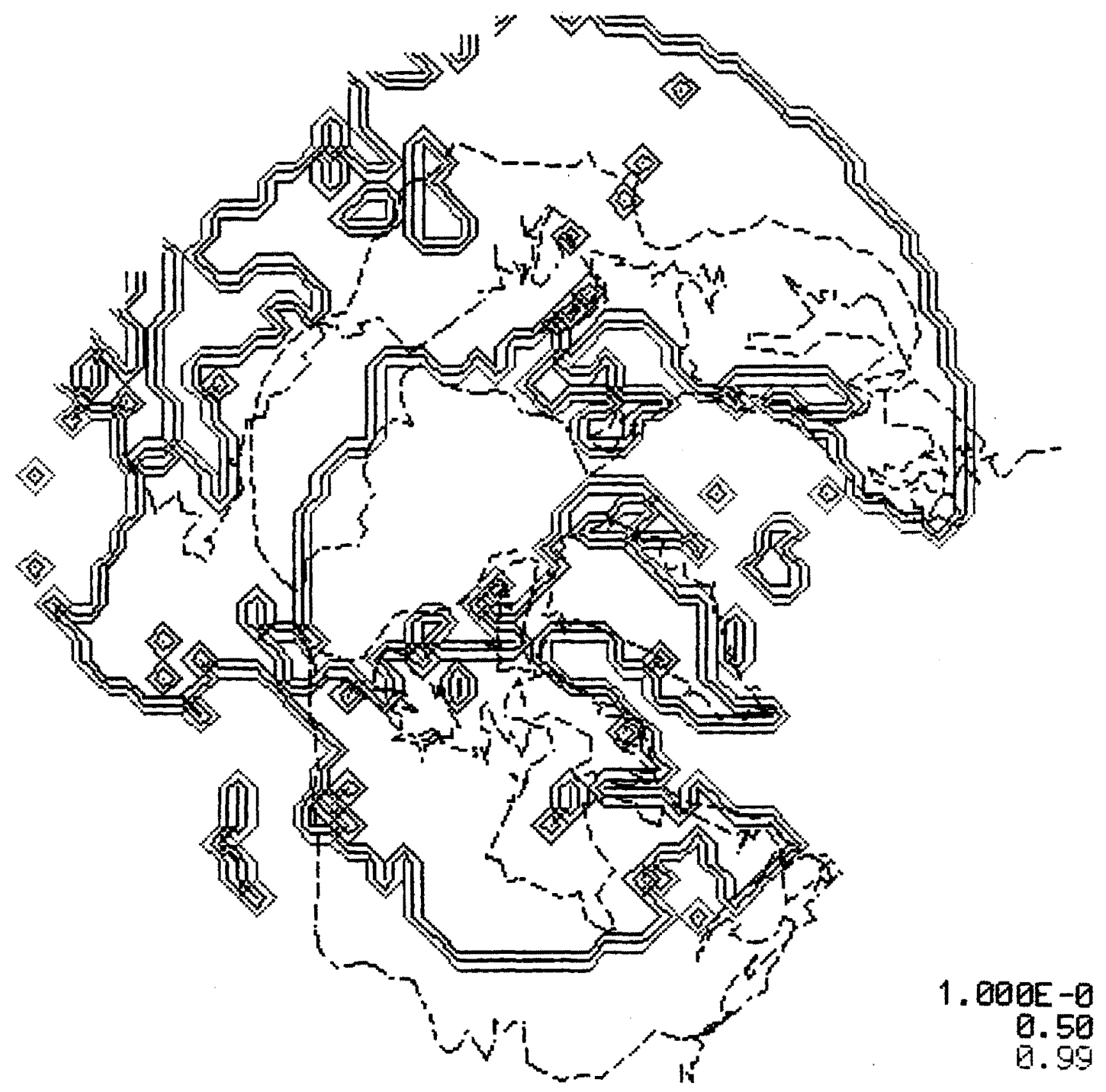

FIGURE 27. Arctic Basal Sliding Fractions for Figure 26. 


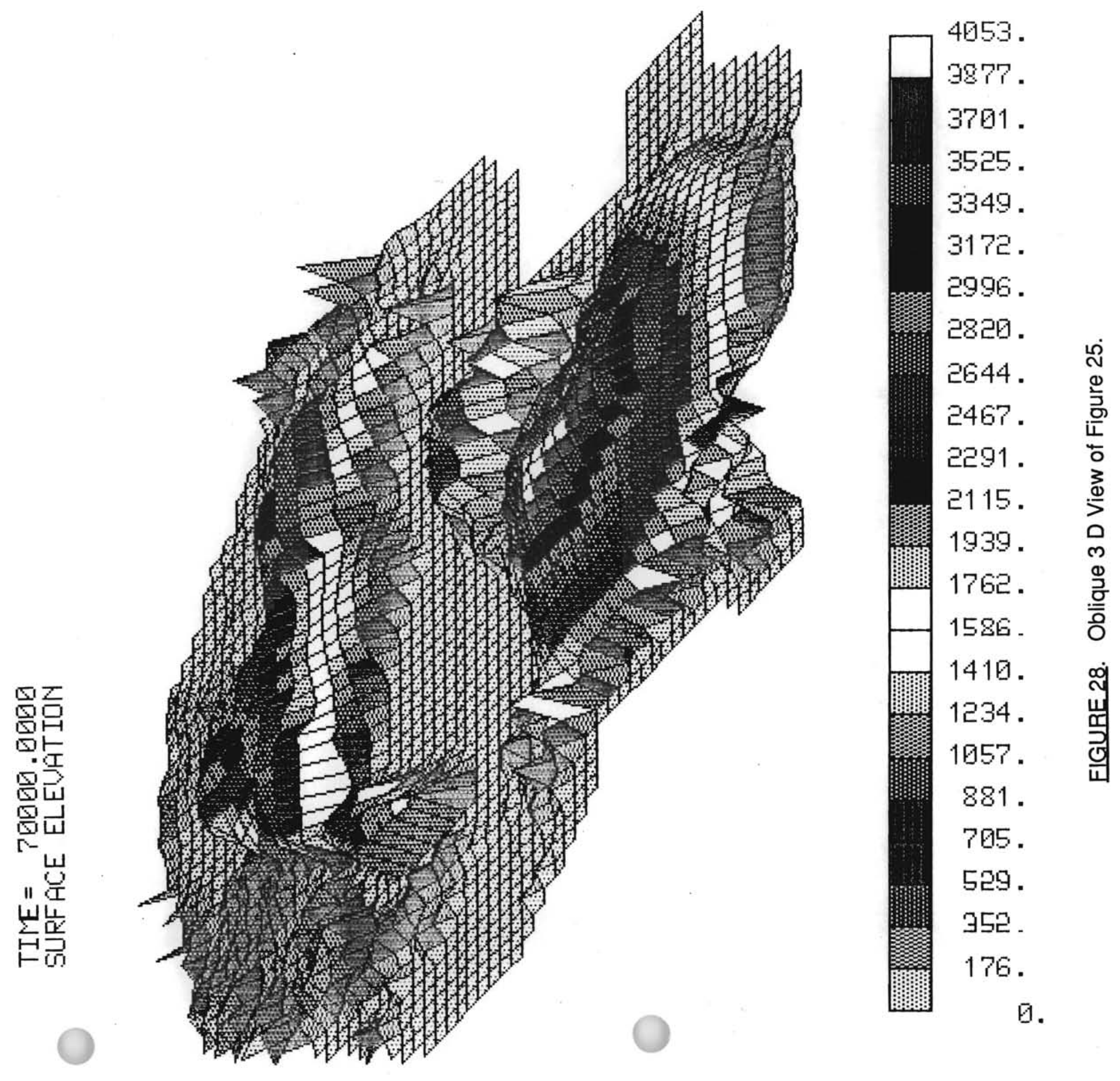




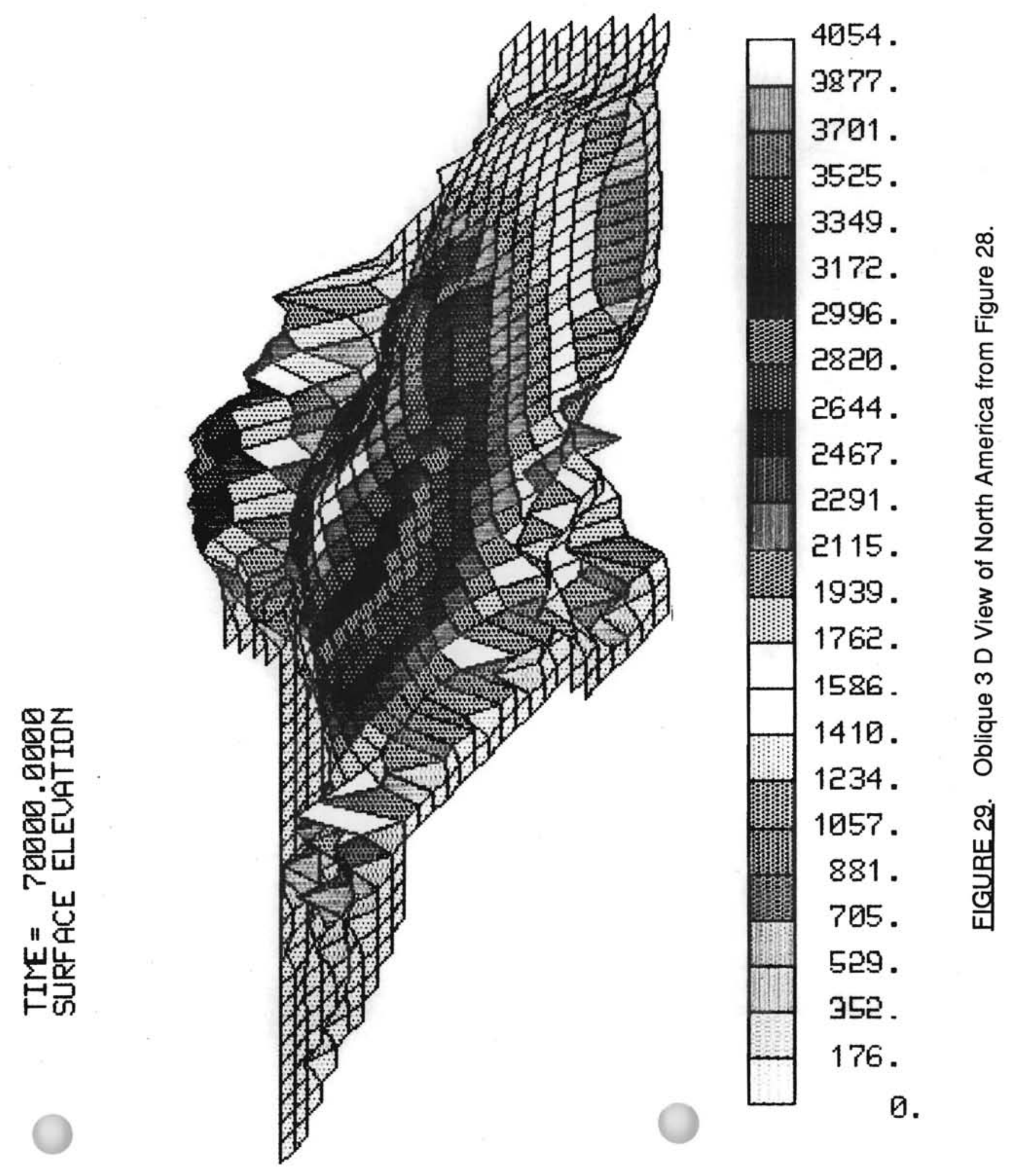




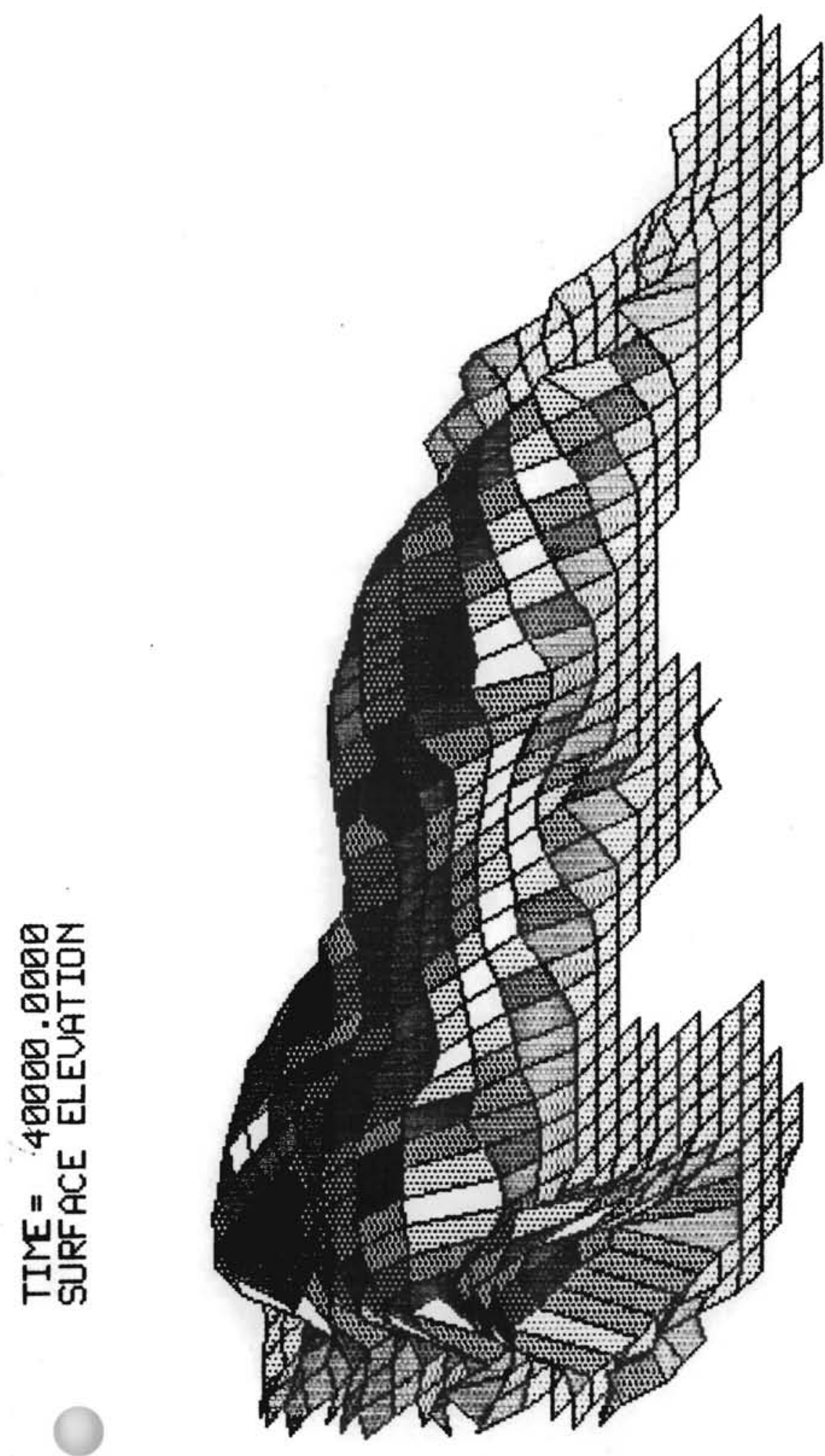

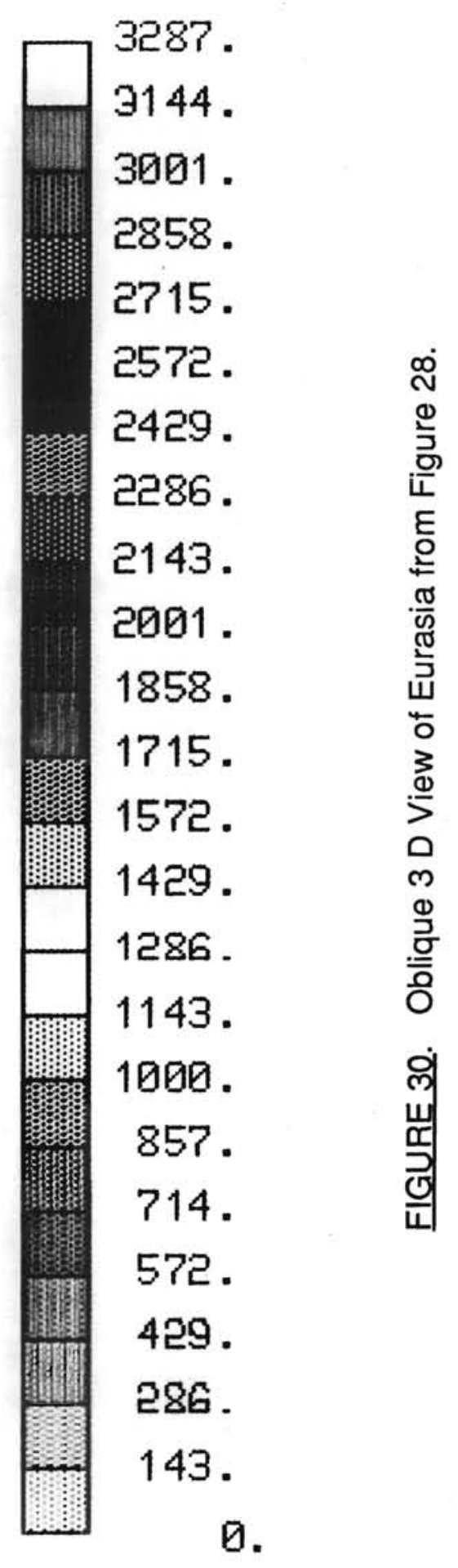




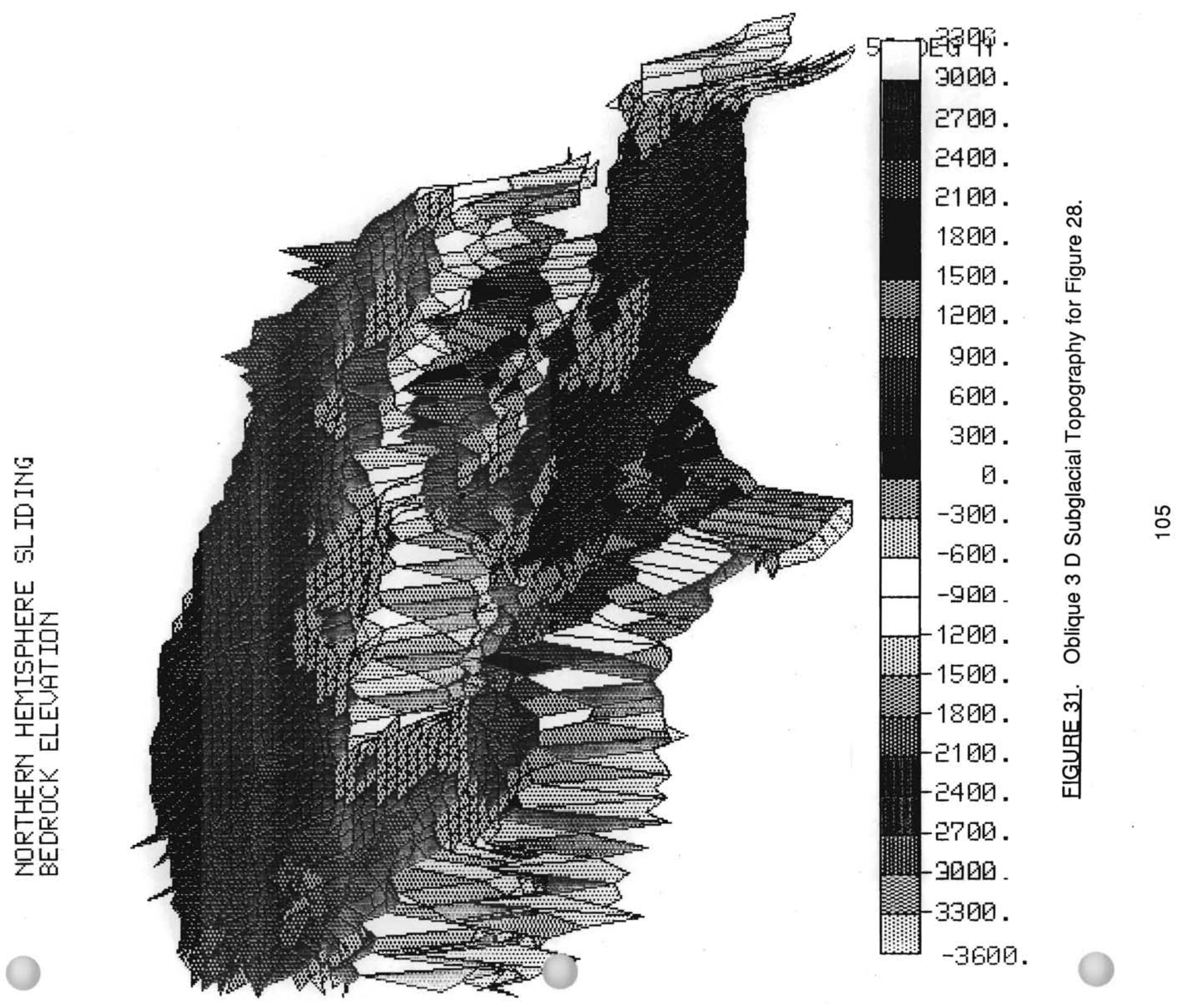



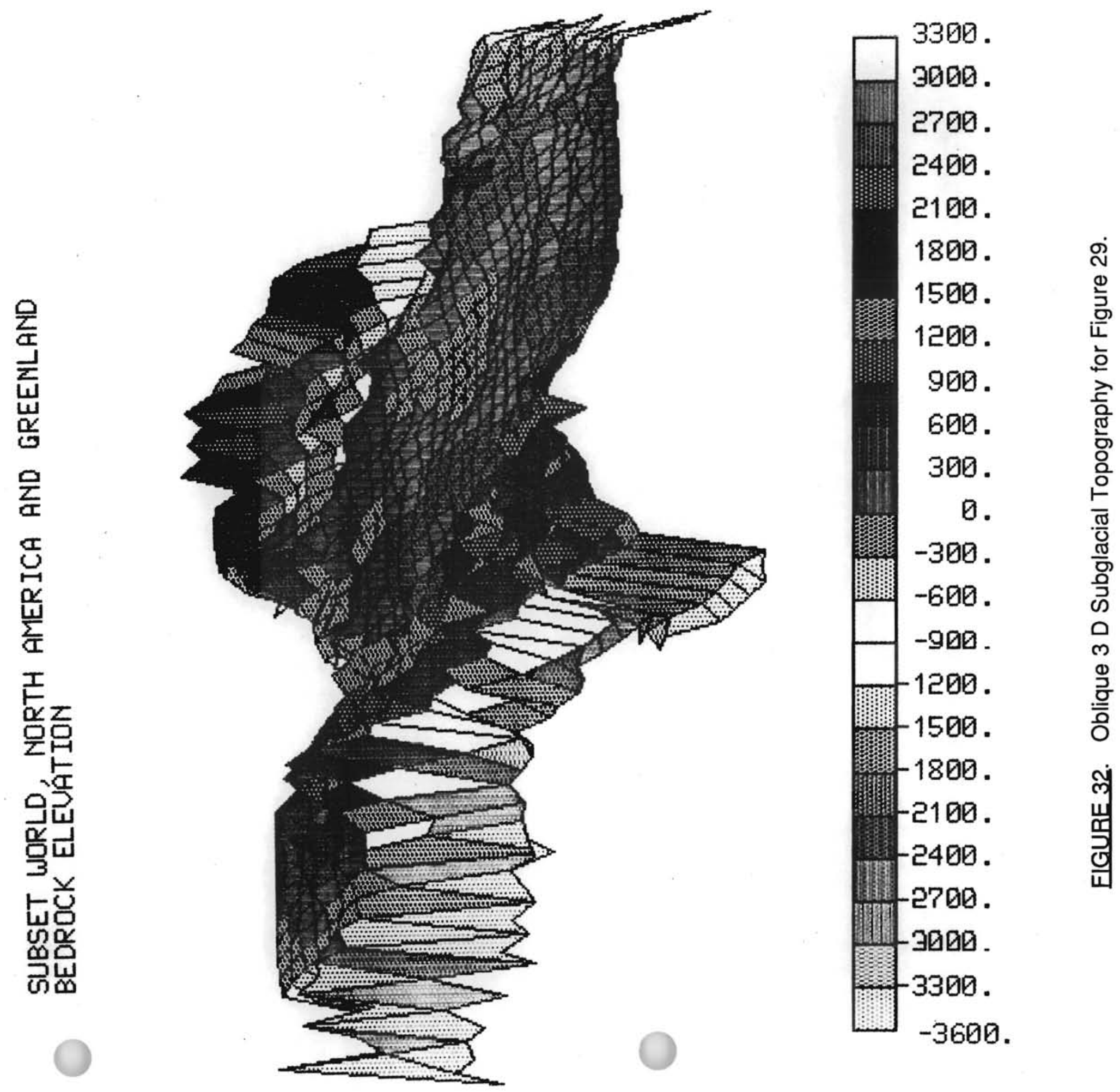


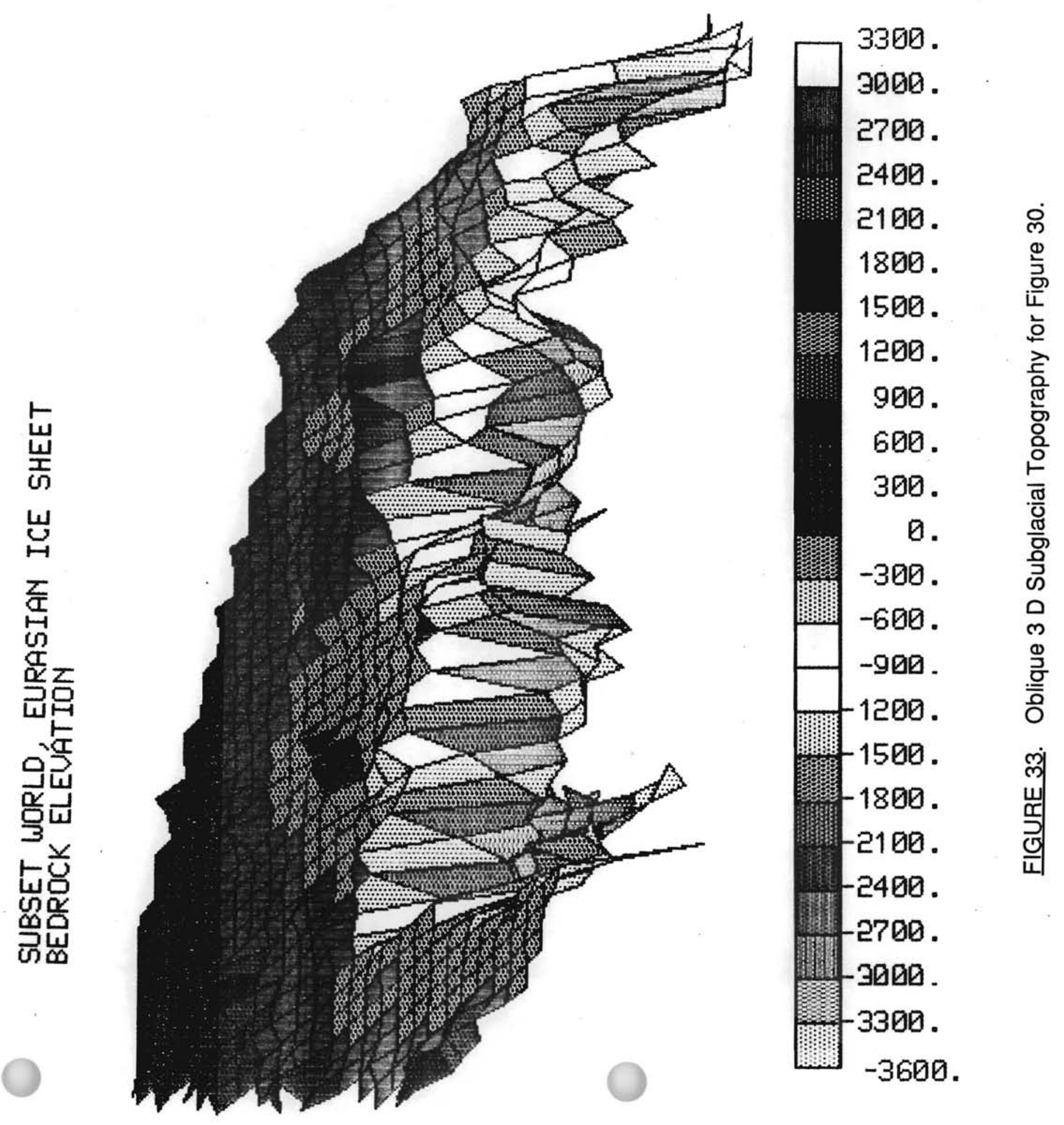



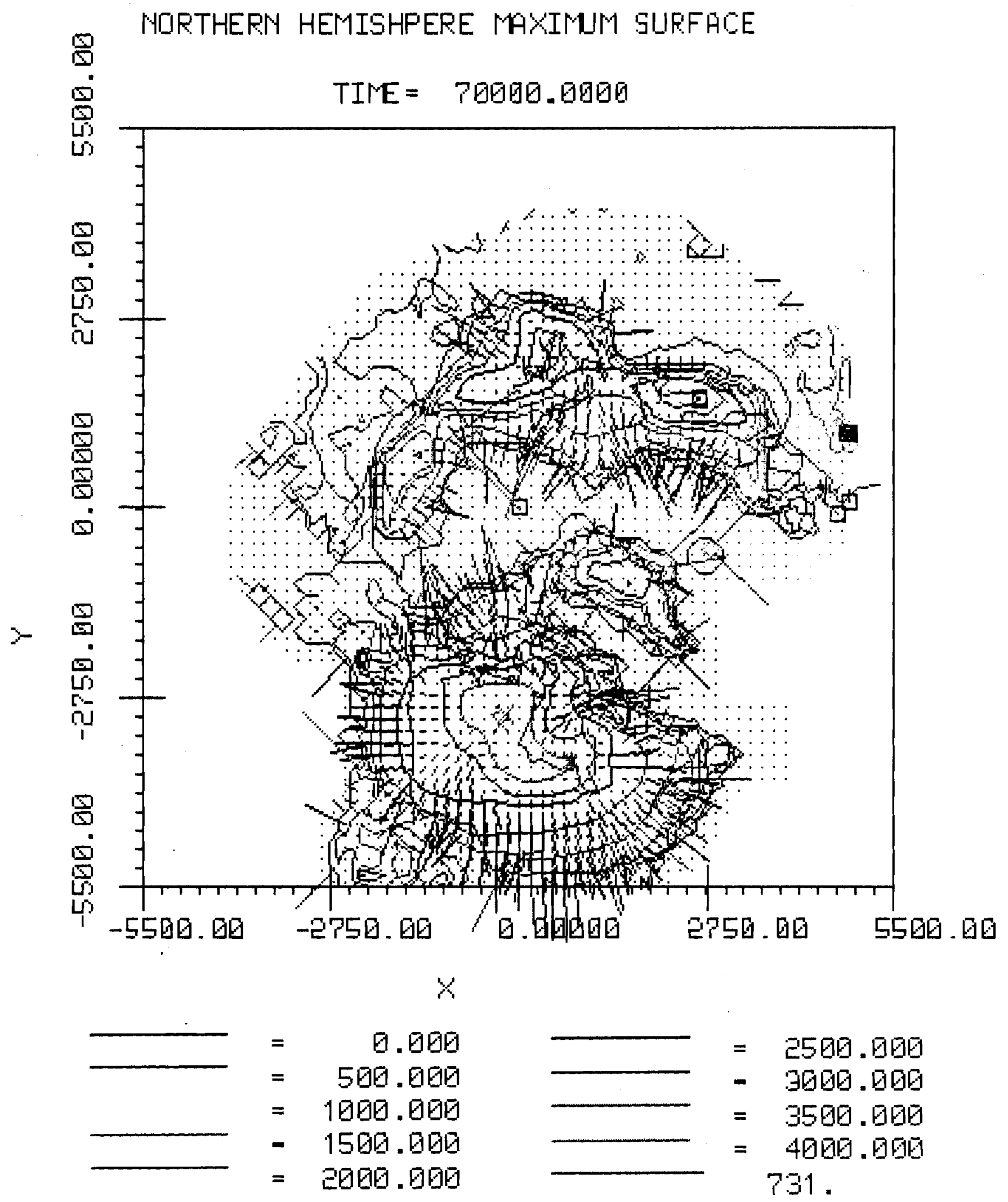

ElGURE 34. Maximum Arctic Ice Flow When Dust Dominates. Ice velocity vectors $(\mathrm{m} / \mathrm{a})$, ice elevation contours $(\mathrm{m})$, and $x, y$ coordinates $(\mathrm{km})$ are shown. 
REUISED NORTHERY HEMISPHERE, NO SLIDING IN SCANDIMAUIA

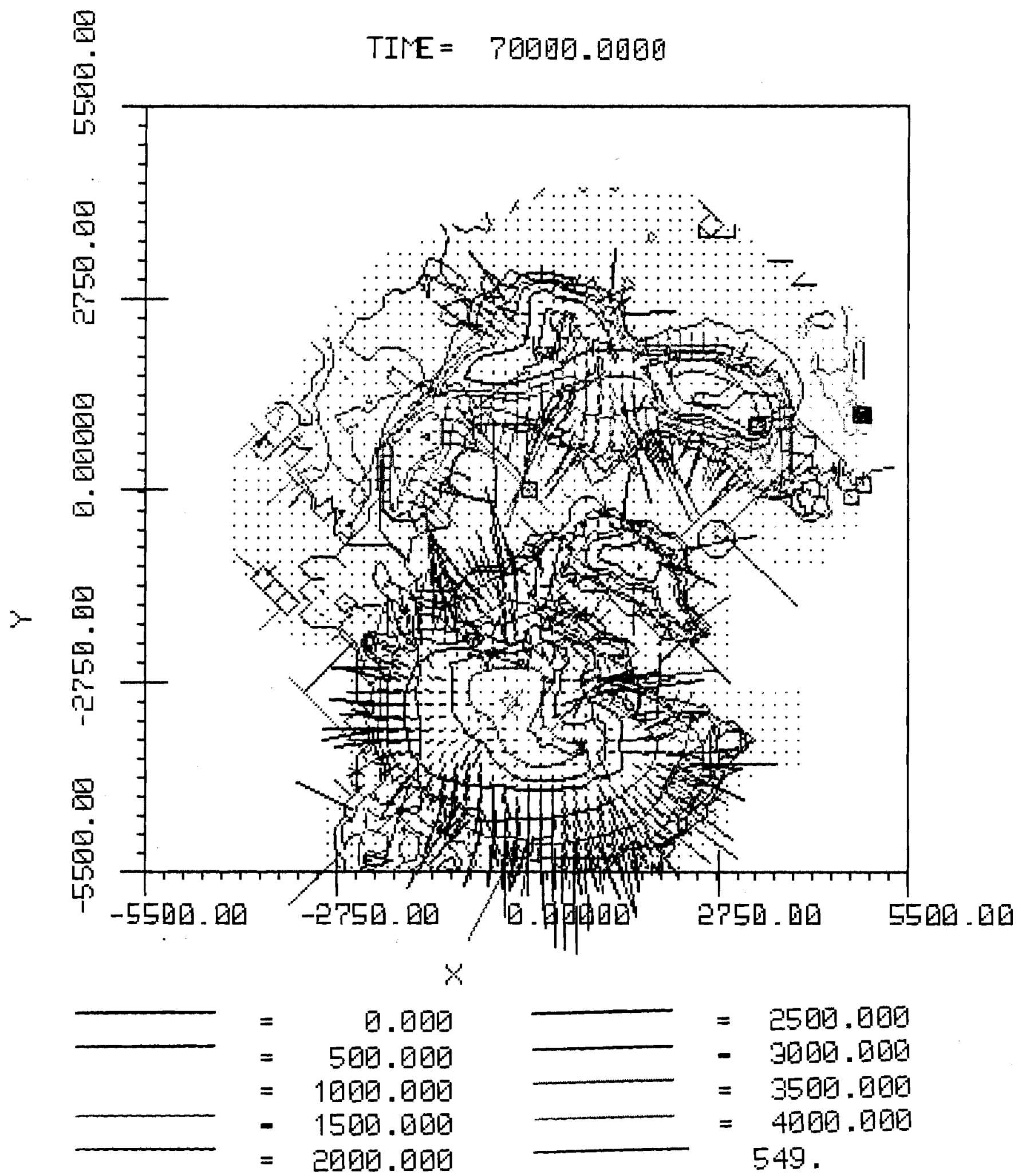

FIGURE 35. A Version of Figure 34 Without Basal Sliding in Norway. The model then puts the Scandinavian ice dome over the Gulf of Bothnia. 


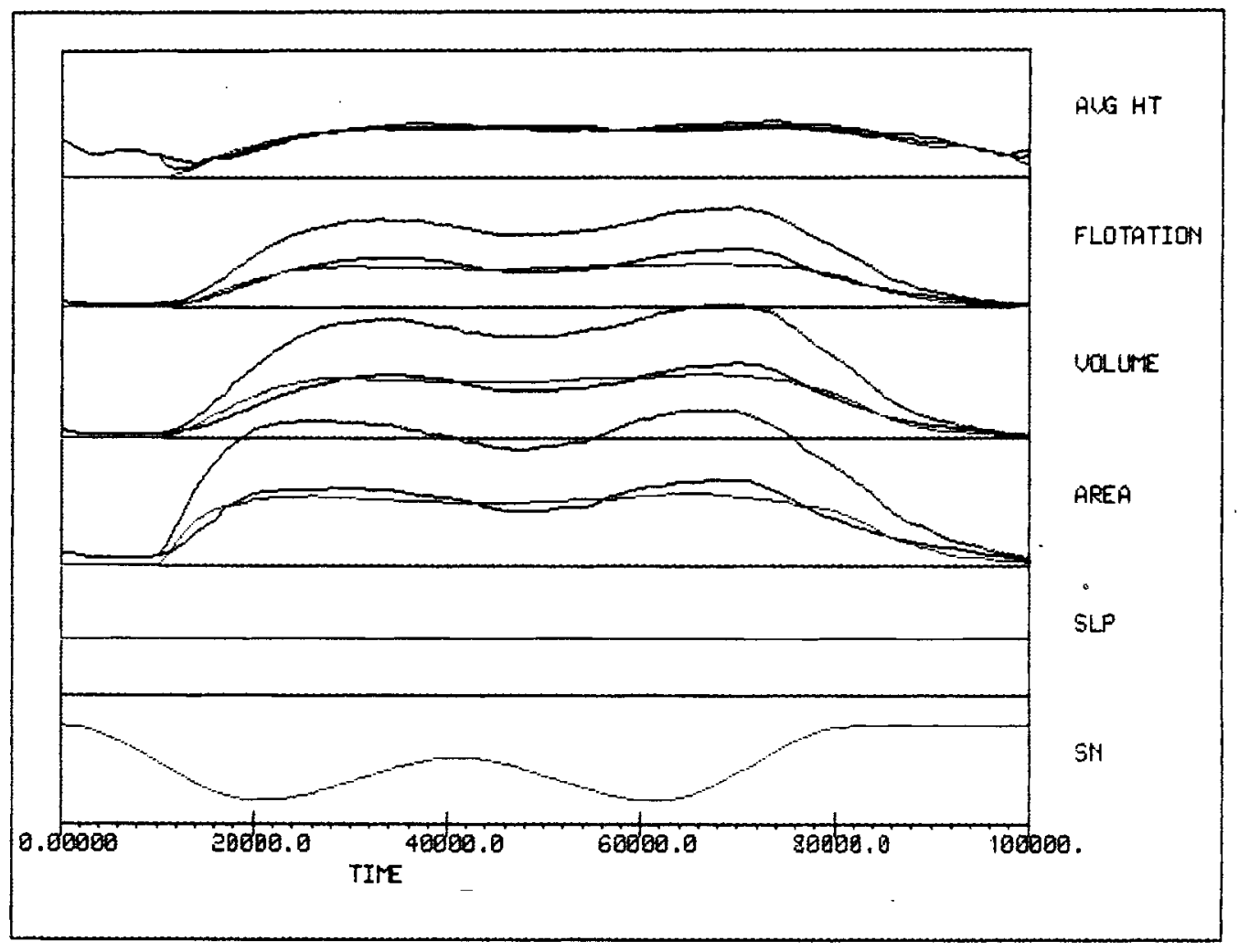

ElGURE 36. Arctic Model Input and Output When Tilt Modifies Dust. Variations over 100,000 years are shown for average ice-sheet height (AVG HT), icesheet volume contributing to sea level (FLOTATION), total ice-sheet volume (VOLUME), ice-sheet areal extent (AREA), sliding law parameter (SLP), and North Pole snowline elevation (SN). 


\section{FLOTATION VOLUME}

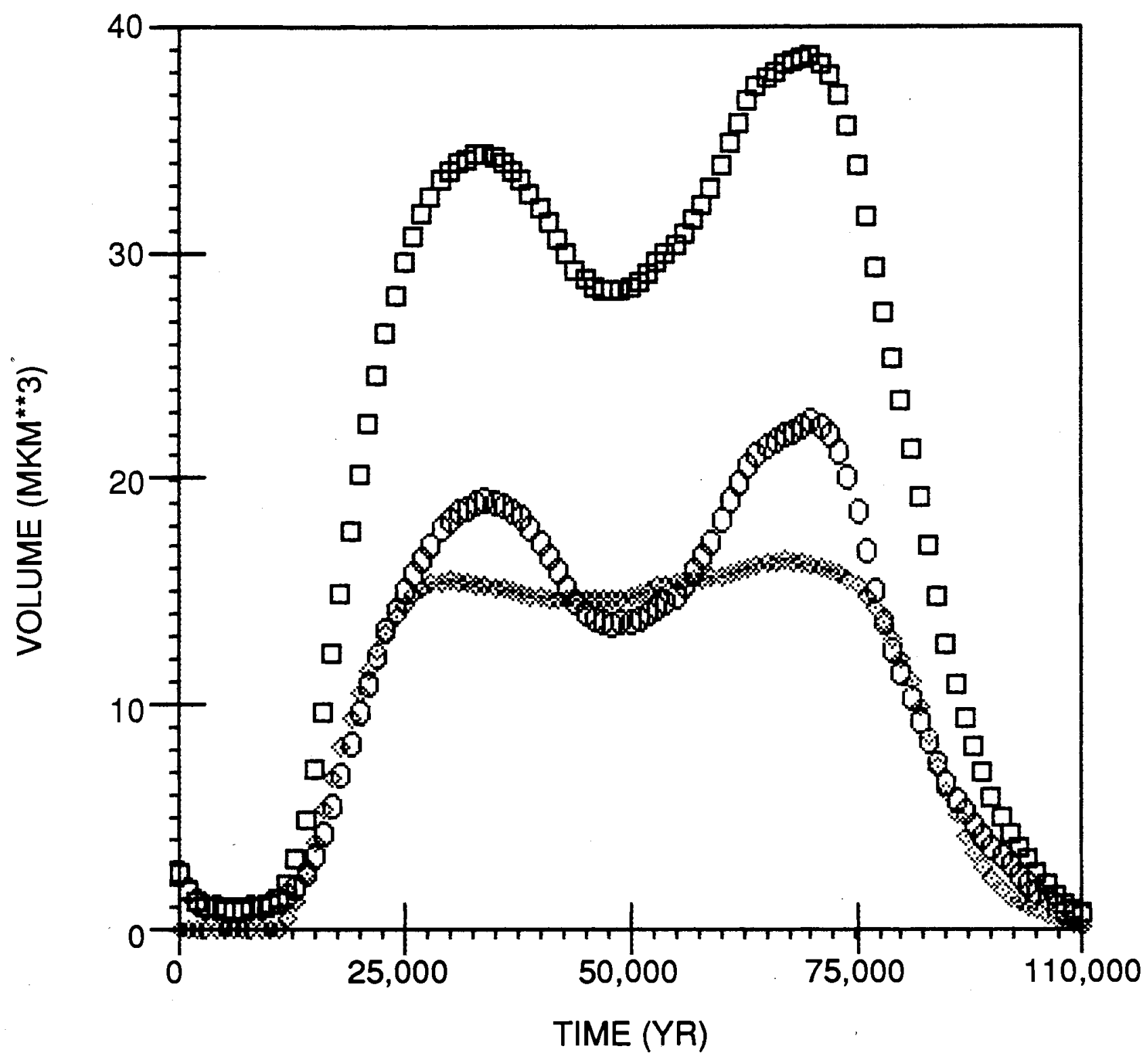

N. HEMISPHERE NORTH AMERICA EURASIAN

ElGURE 37. Arctic Flotation Ice Volume Over Time When Tilt Modifies Dust. Tilt gives a North Pole snowline amplitude of $0 \mathrm{~m}$ to $-1300 \mathrm{~m}$ in a cycle of 41,000 years. Dust lowers the North Pole snowline an additional $1000 \mathrm{~m}$ in a cycle of 100,000 years. 


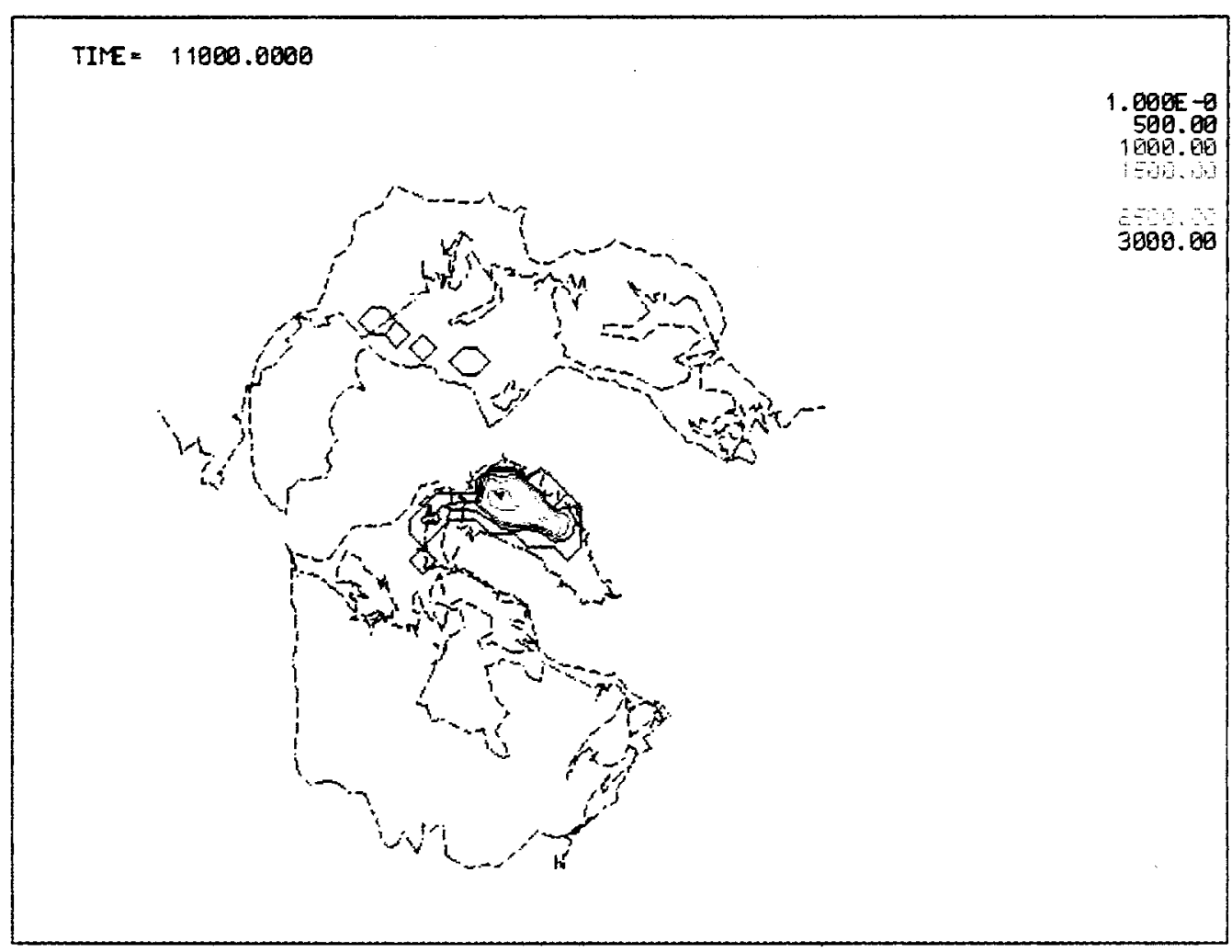

a) After 11,000 Years

TIEE $=12800.0000$

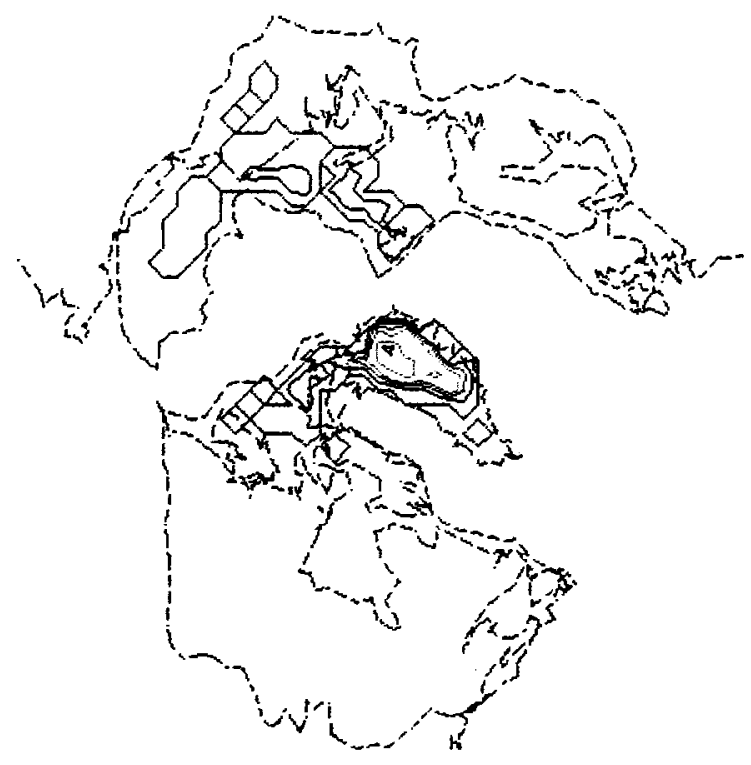

3000.00

b) After 12,000 Years

FIGURE 38. Arctic Glaciation Cycle When Tilt Modifies Dust. Ice thickness contoured every $500 \mathrm{~m}$. 


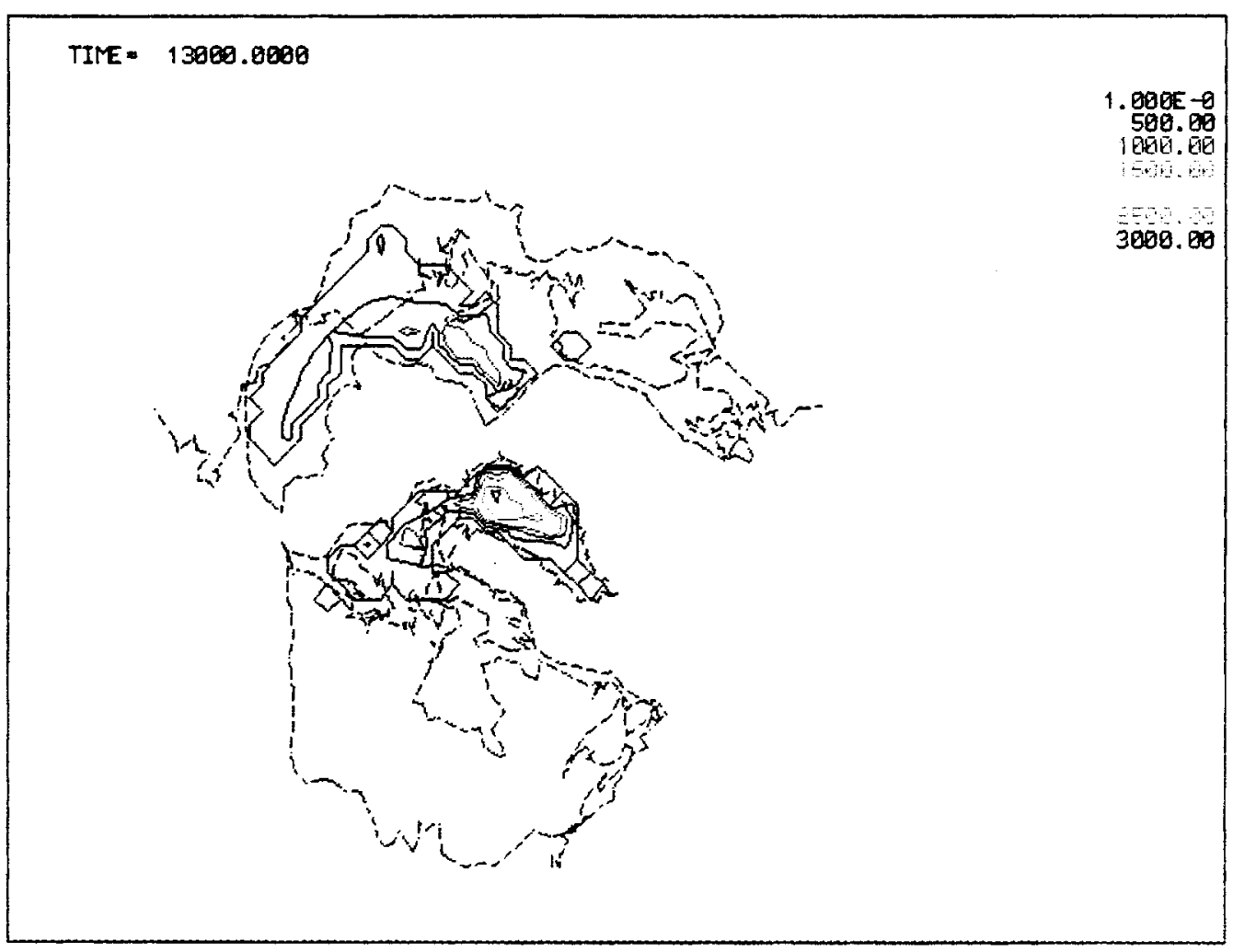

c) After 13,000 Years

TIME $=14089.9000$

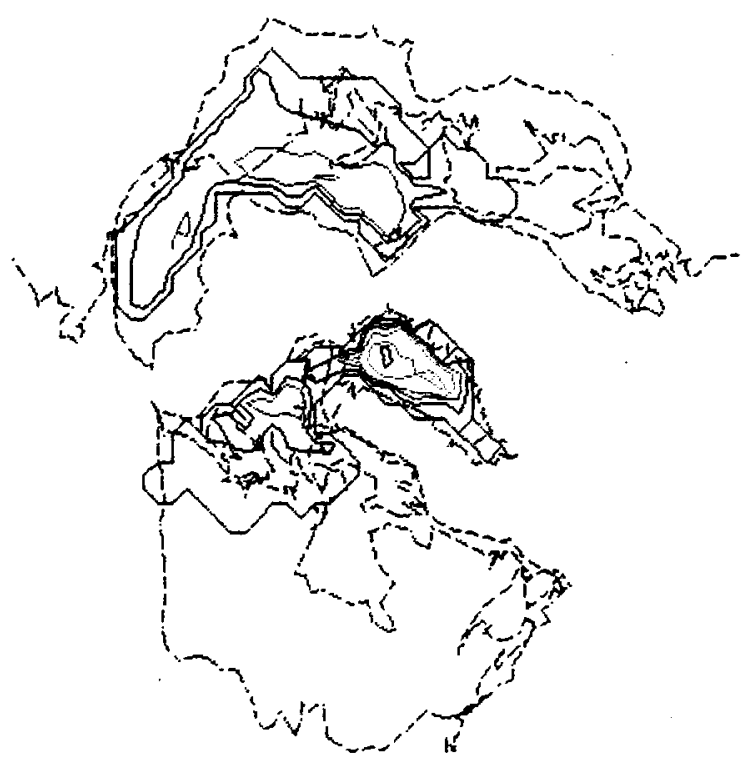

3909.00

d) After 14,000 Years 


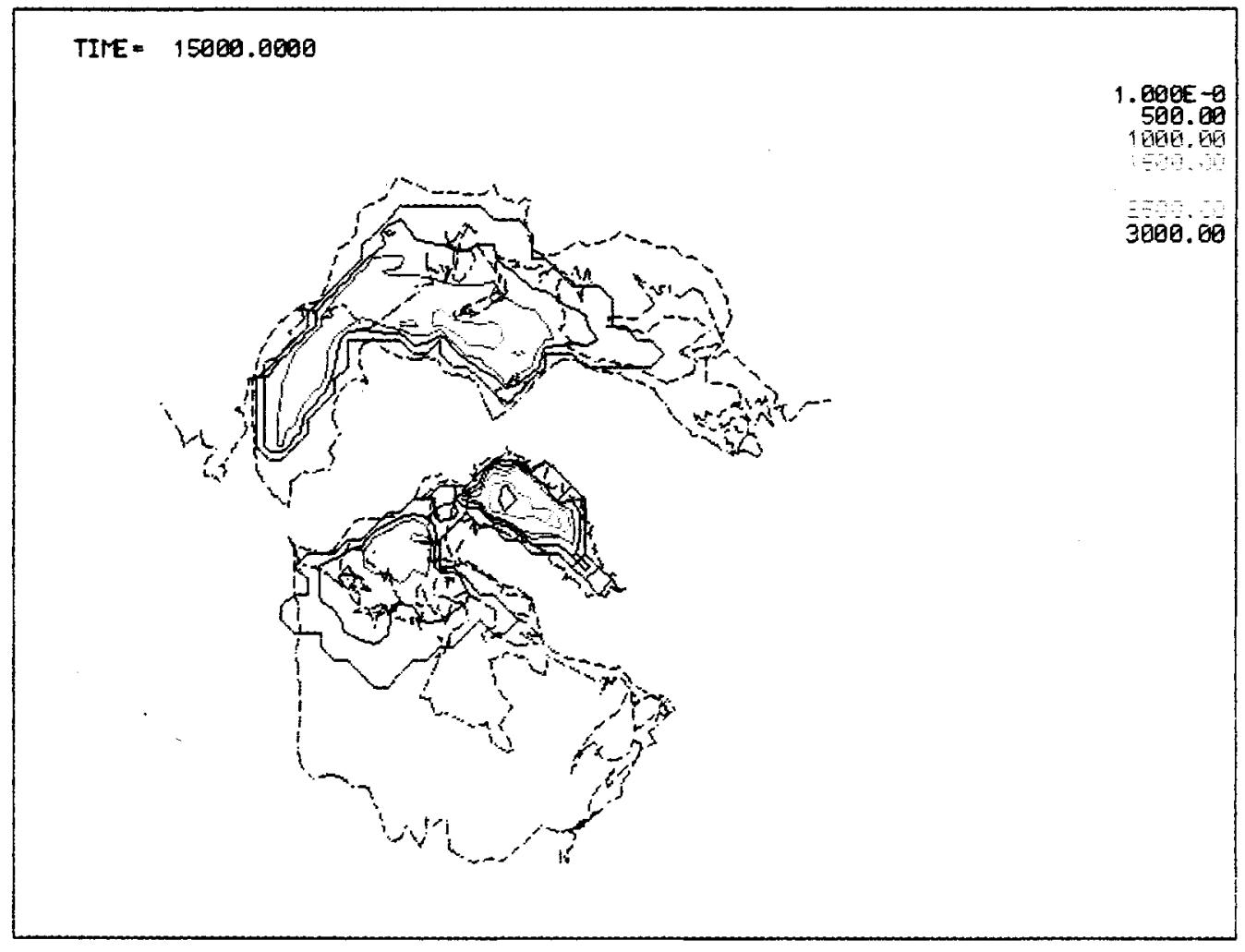

e) After 15,000 Years

TIME $=16080.0600$

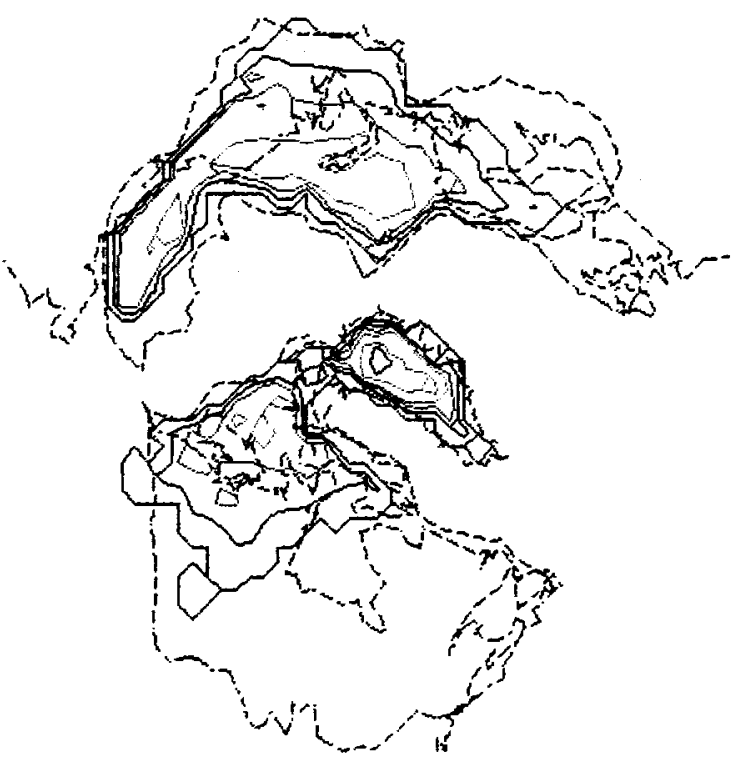

1. $000 \mathrm{E}-9$

500.09

1000.00

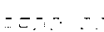

3000.00

f) After 16,000 Years 


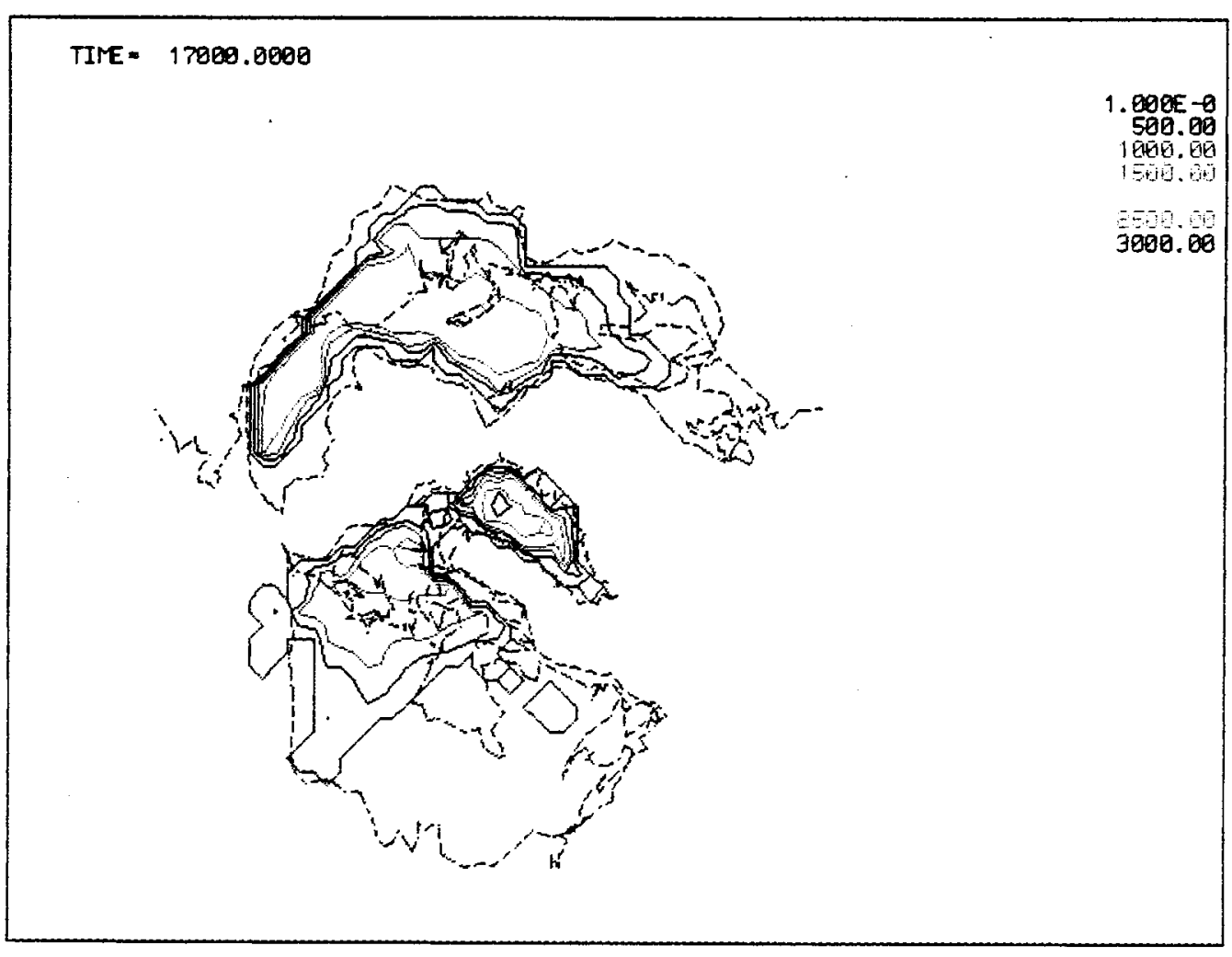

g) After 17,000 Years

TIFE $=18000.0800$

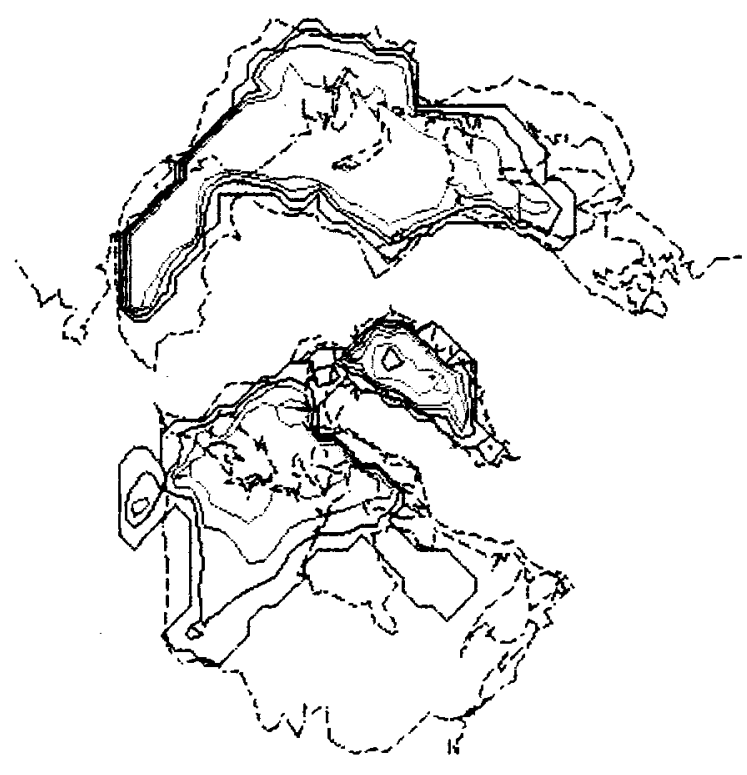

1. $000 E-9$

1000. EQ

100

3900.00

h) After 18,000 Years 


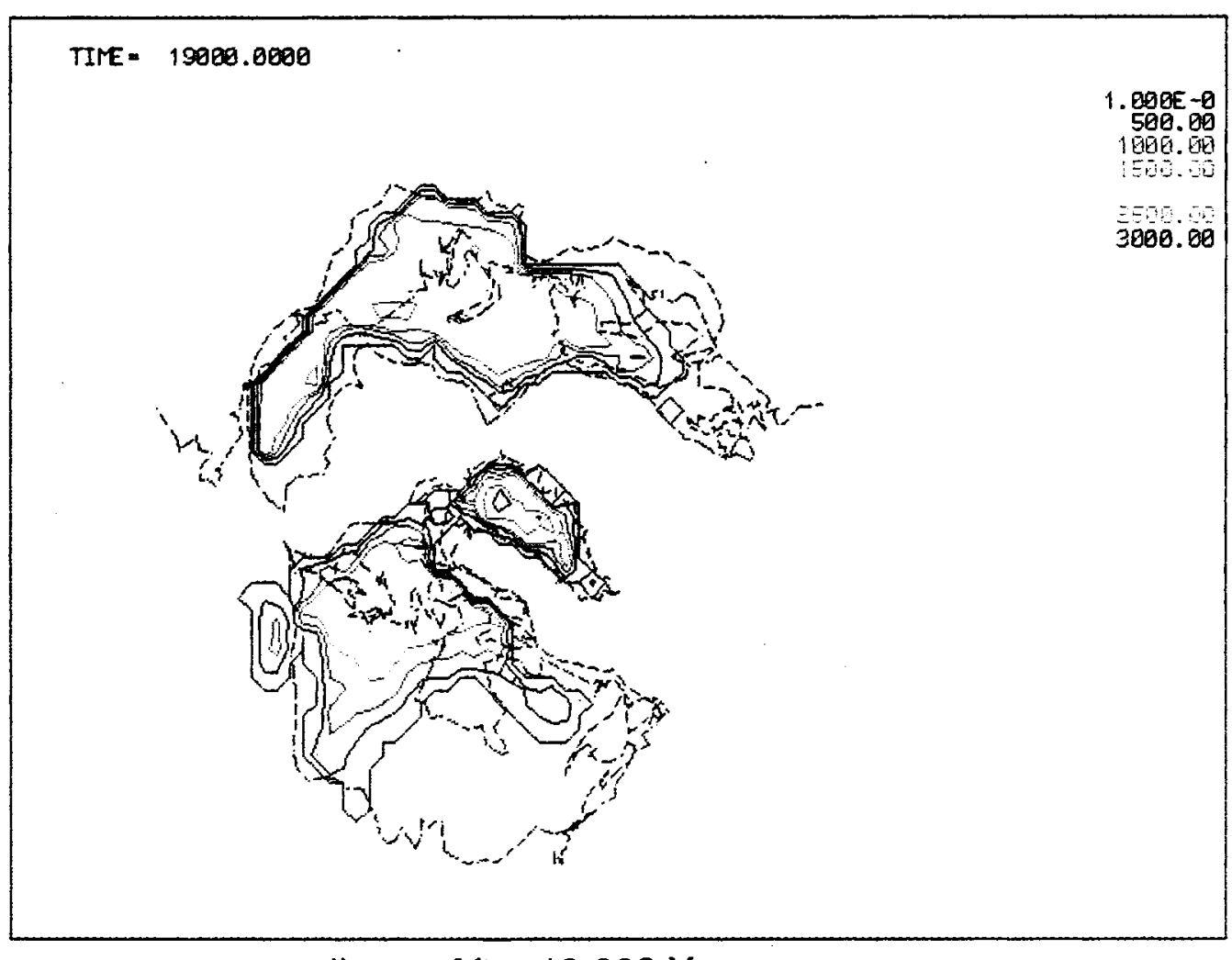

i) After 19,000 Years

TIME = 20000.0000

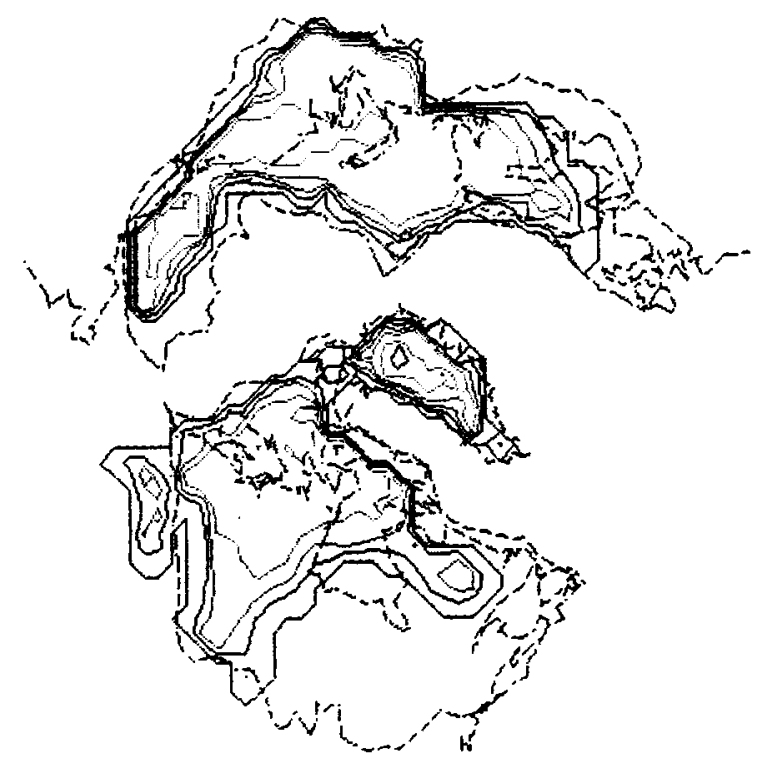

3000.00

j) After 20,000 Years 


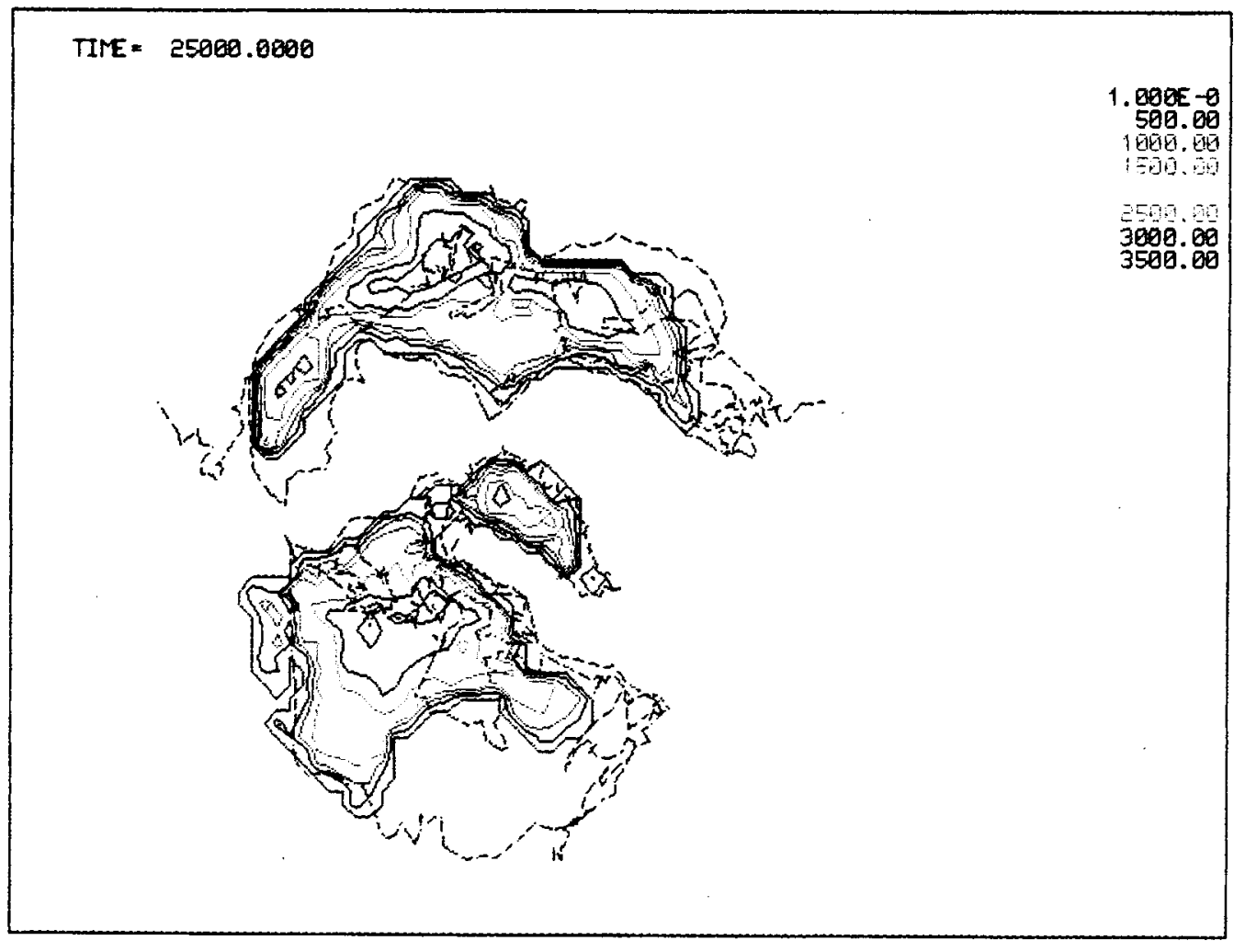

k) After 25,000 Years

TIME = 38090.0000

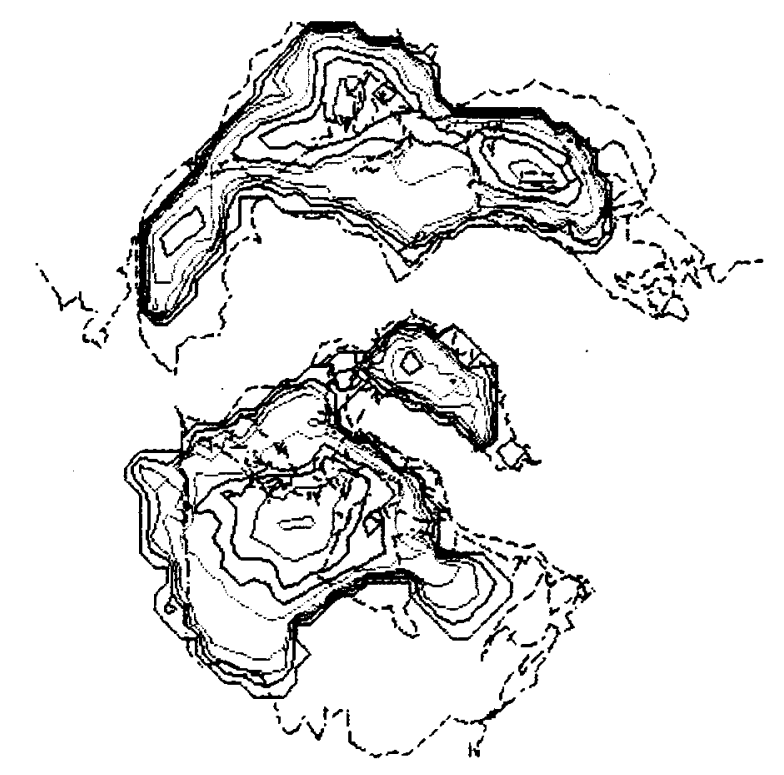

1. $9095-9$

$10 \mathrm{du}$. $\mathrm{alc}$

50.5

3509.69

4 대.

$+50.70$

I) After 30,000 Years 


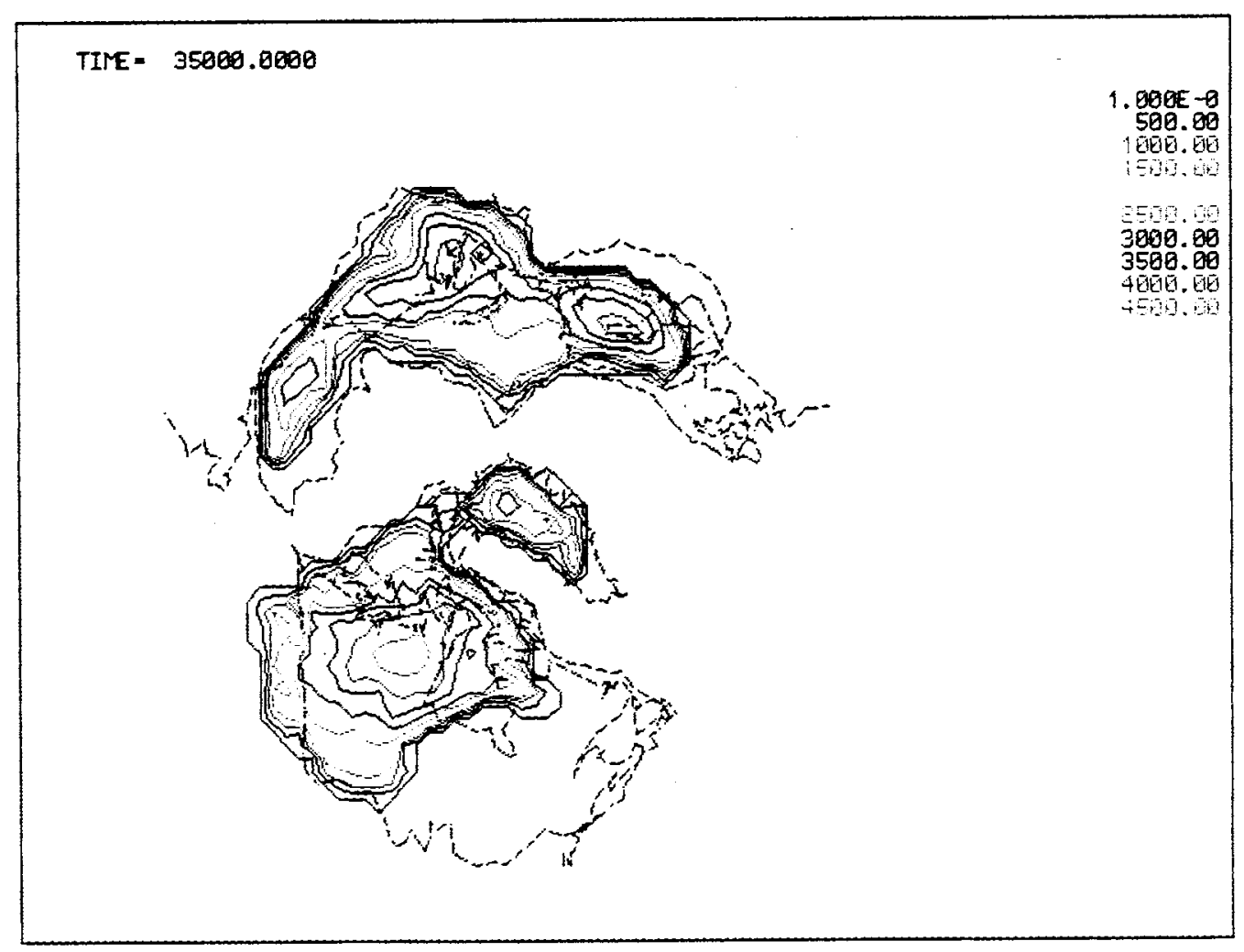

m) After 35,000 Years

TIME = 40000.0000

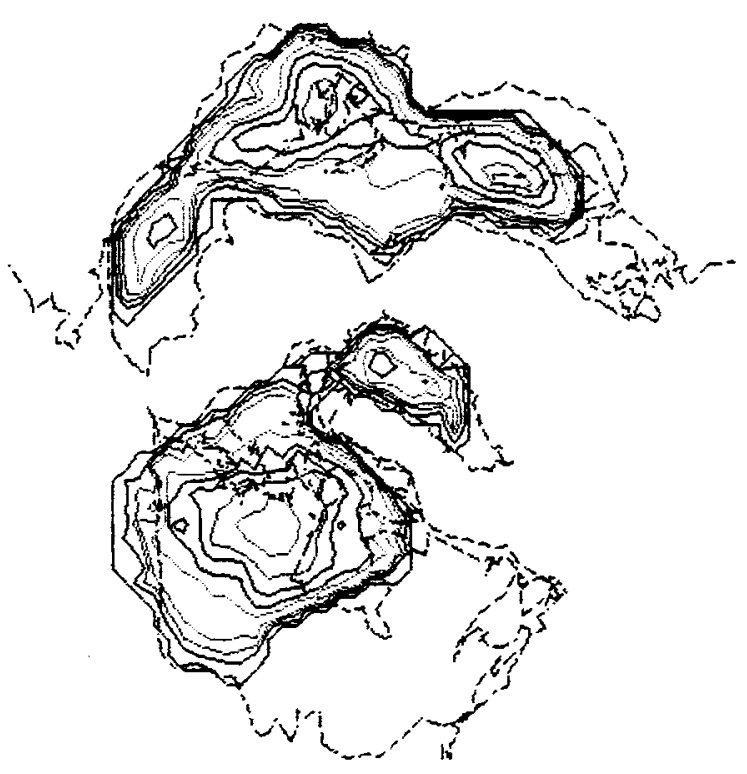

1. ODEE - 0

500.00

1060.80

$==-\pi, \quad 0$

3000.00

3500.00

4800.81

$+5.96 .6$

n) After 40,000 Years 


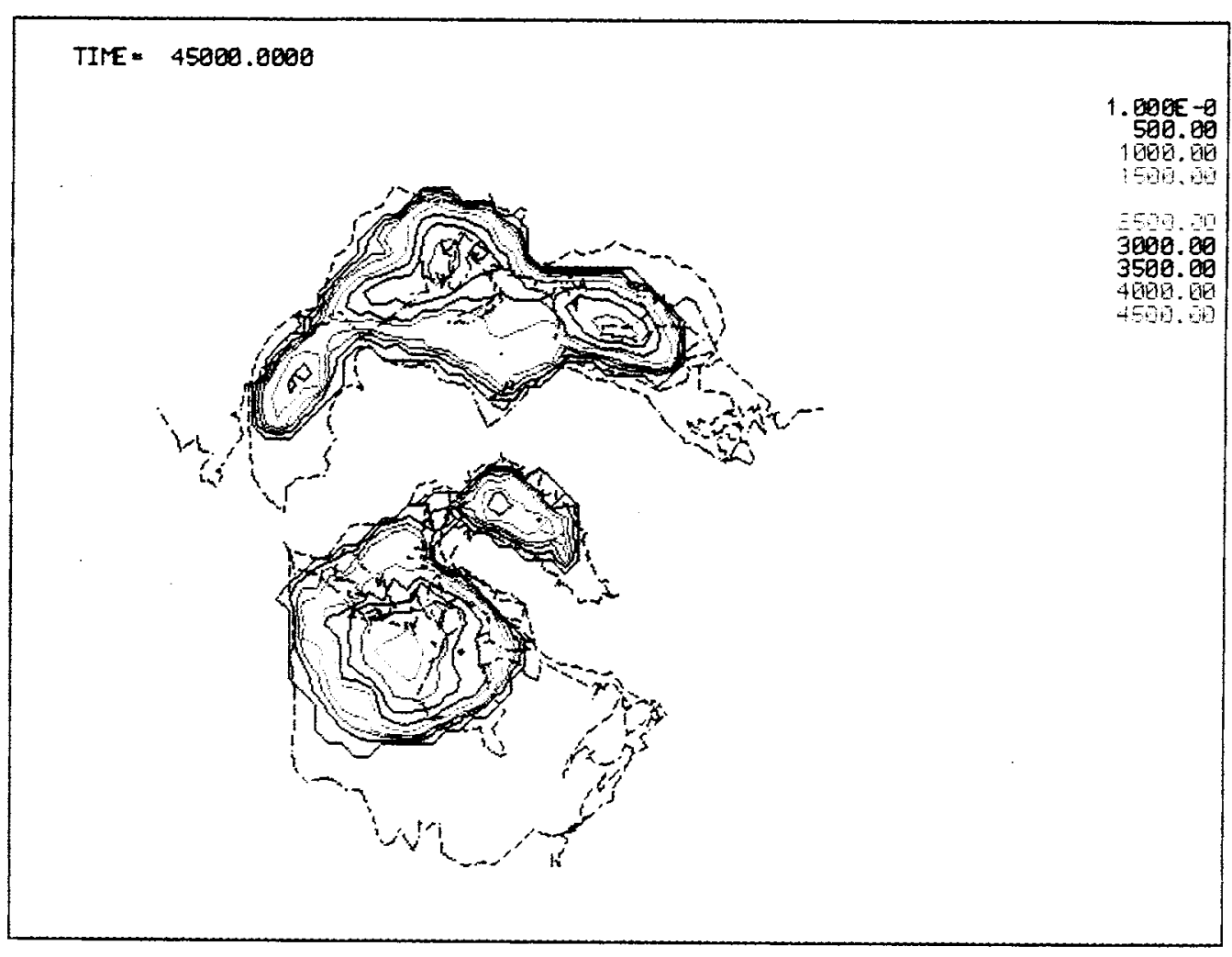

o) After 45,000 Years

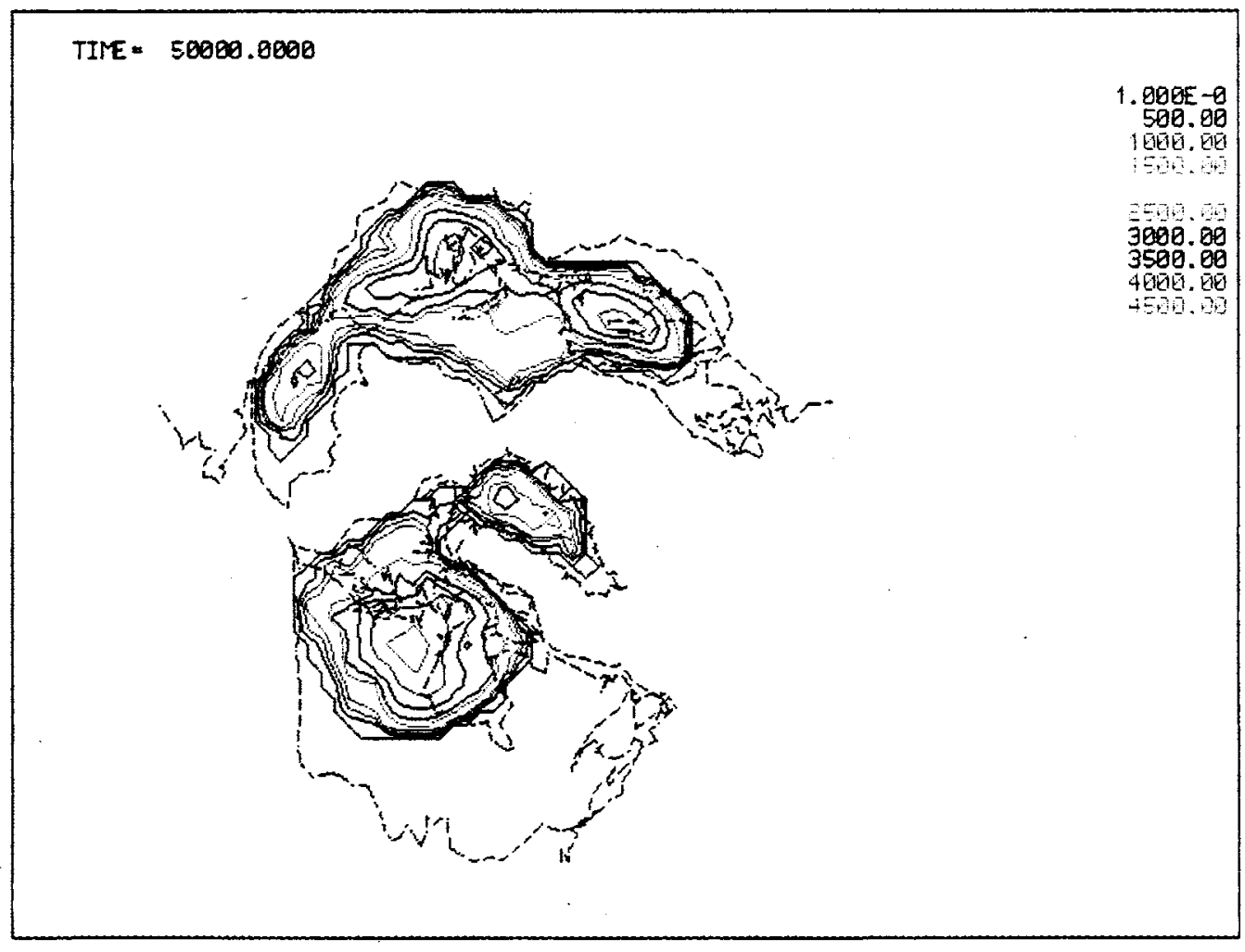

p) After 50,000 Years 


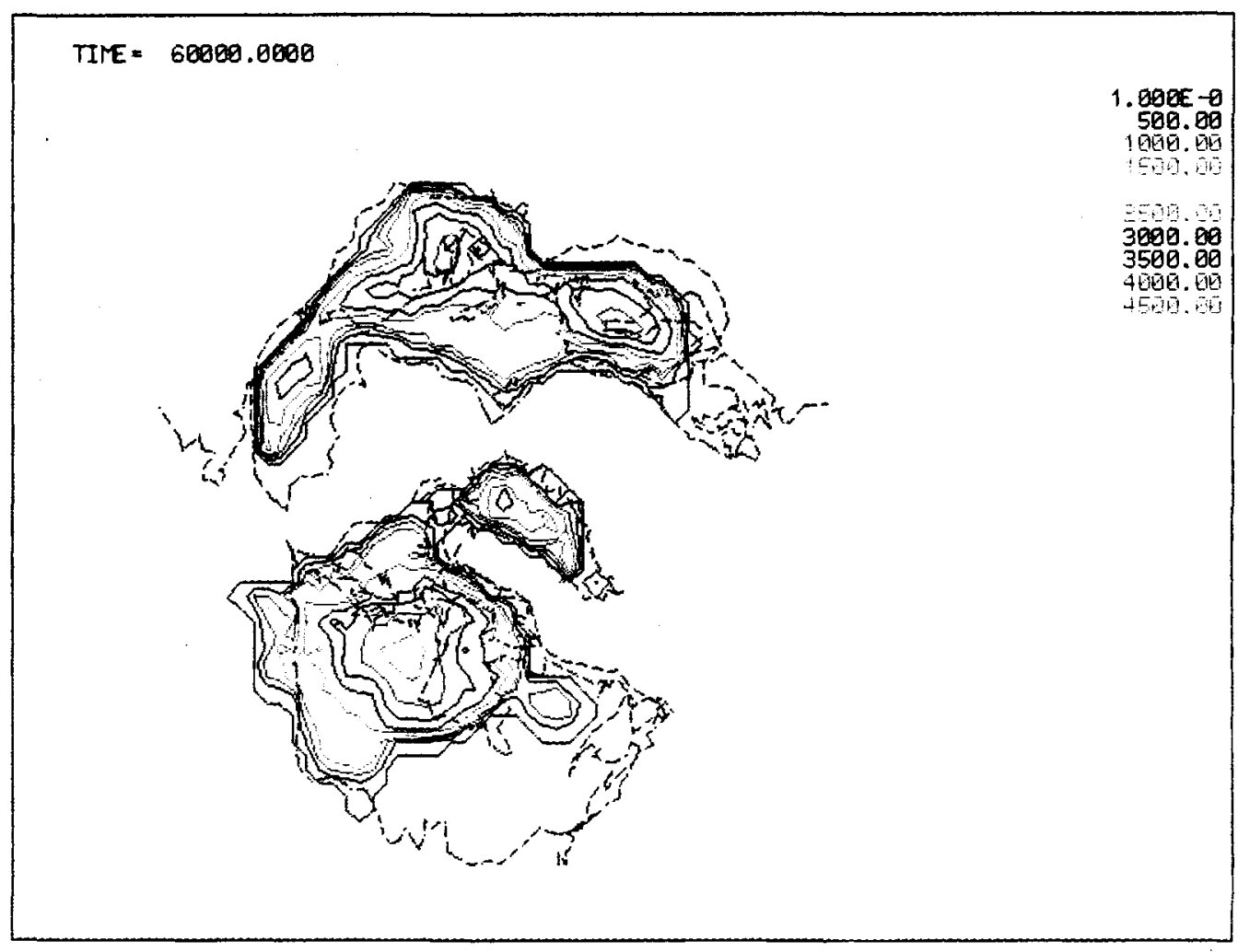

q) After 60,000 Years

TINE= 70000.0000

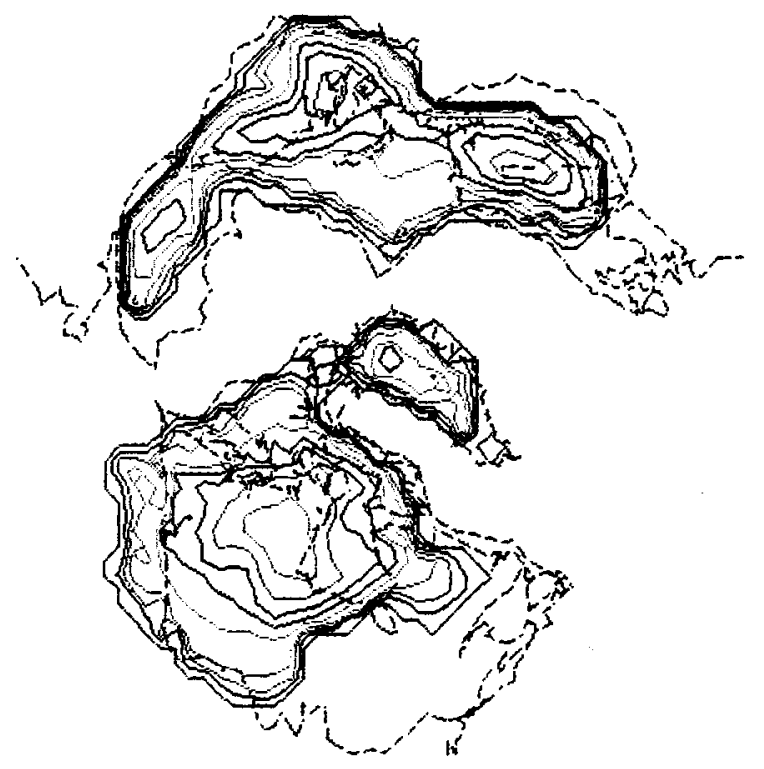

1. $000 \mathrm{E}-8$

1008.60

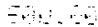

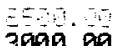

3500.00

4 बघำ. 69

$4=00.40$

r) After 70,000 Years 


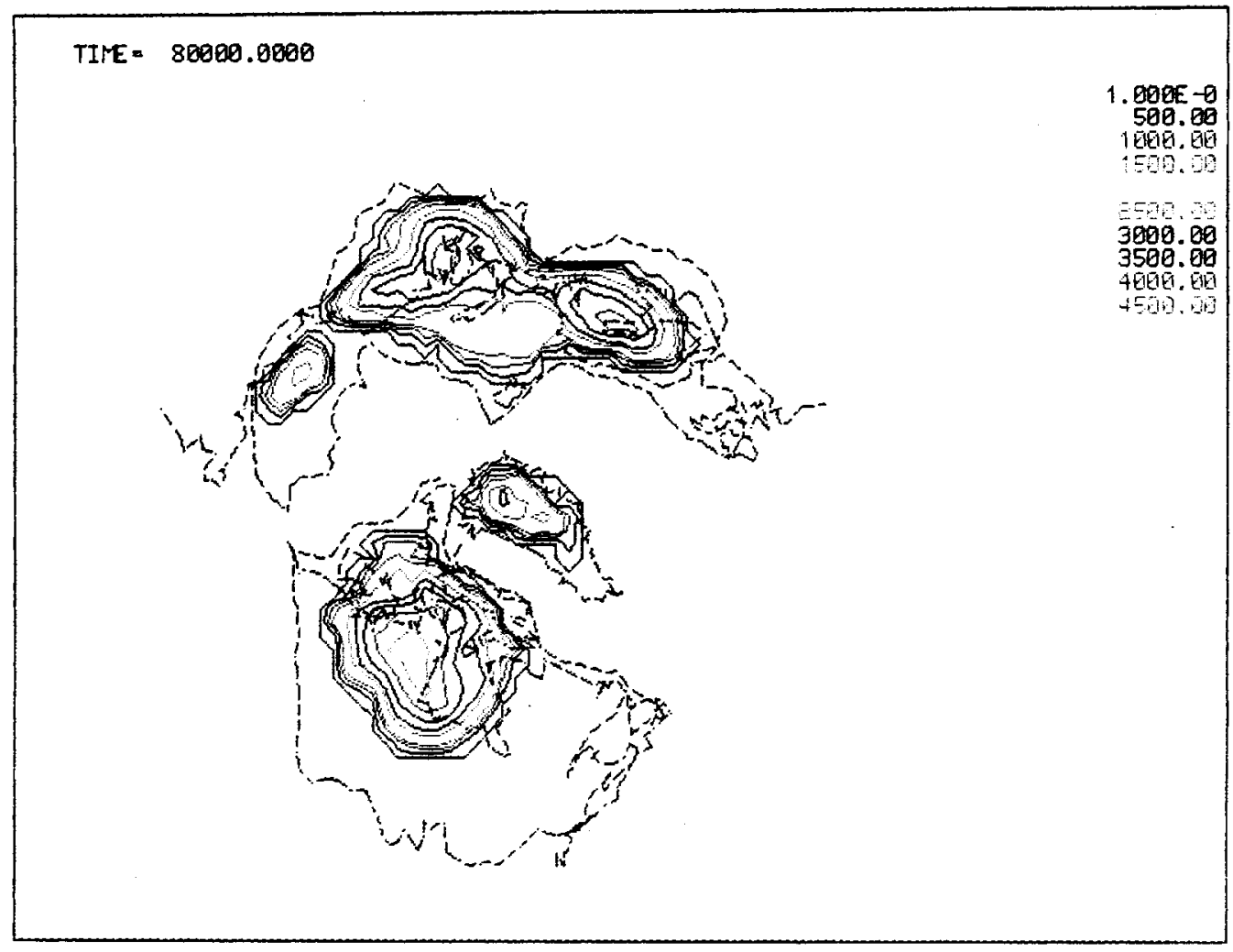

s) After 80,000 Years

TIME: 90980.0000

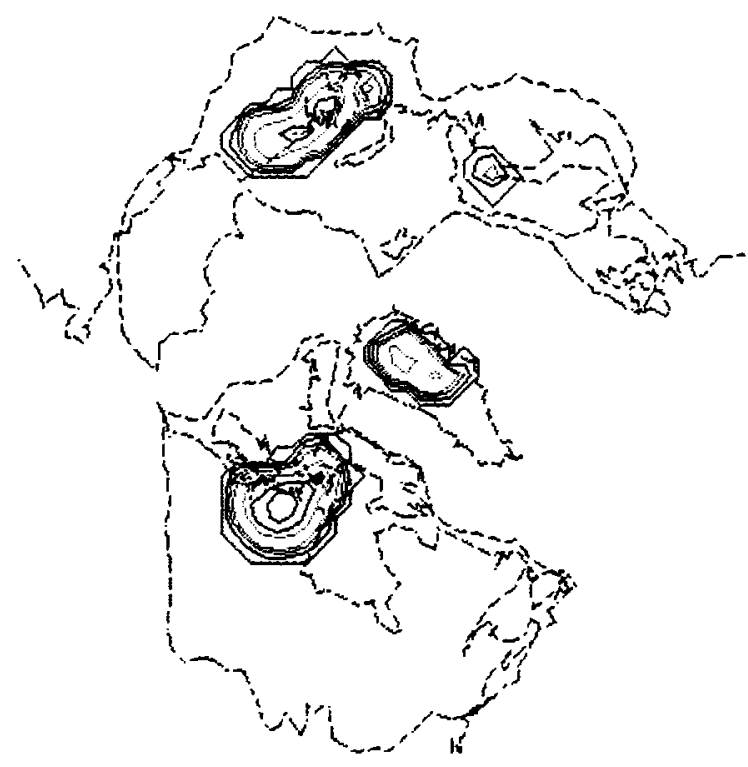

1. $900 \mathrm{E}-0$

1000.06

$=0.0$

3509.00

t) After 90,000 Years 


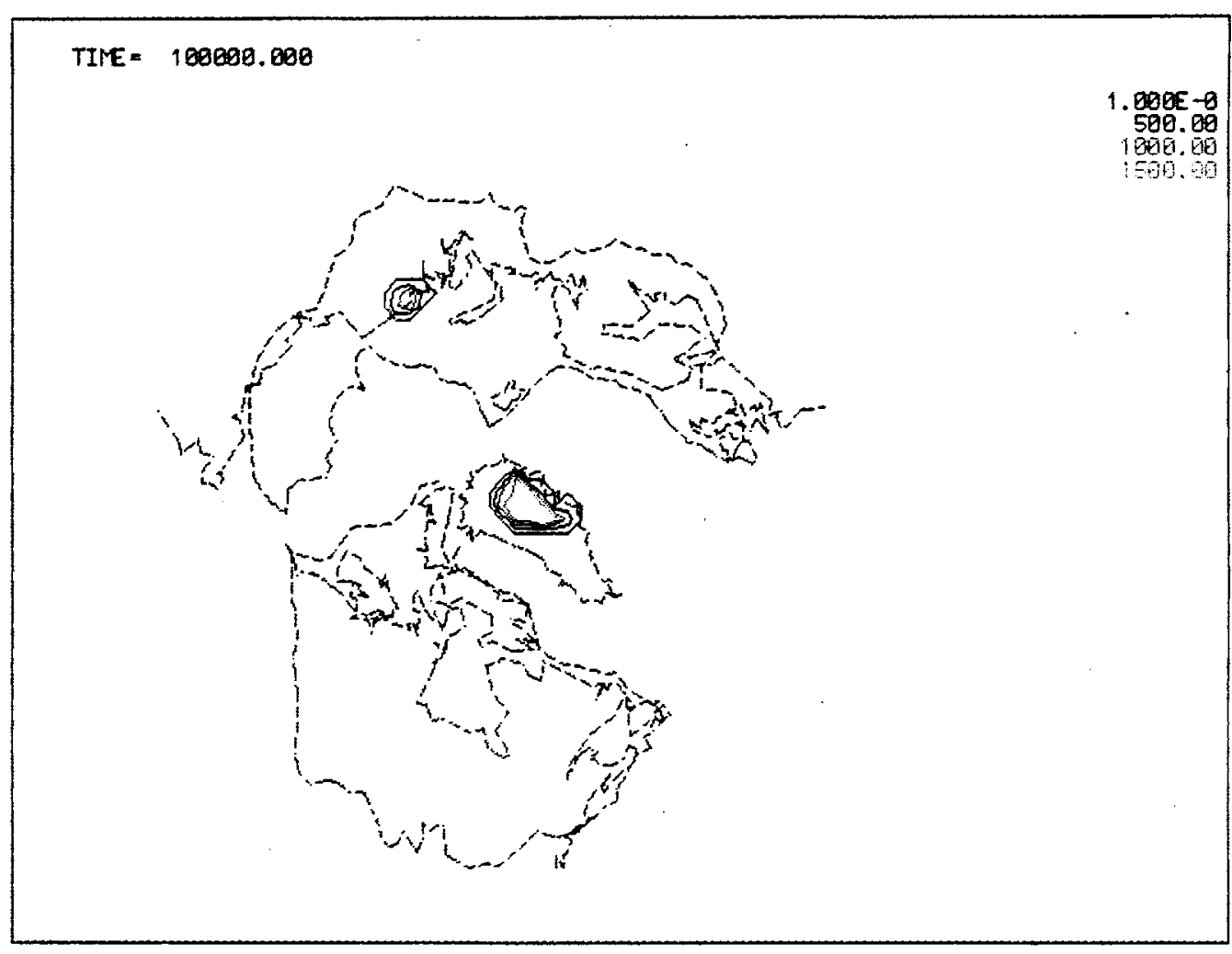

u) After 100,000 Years 


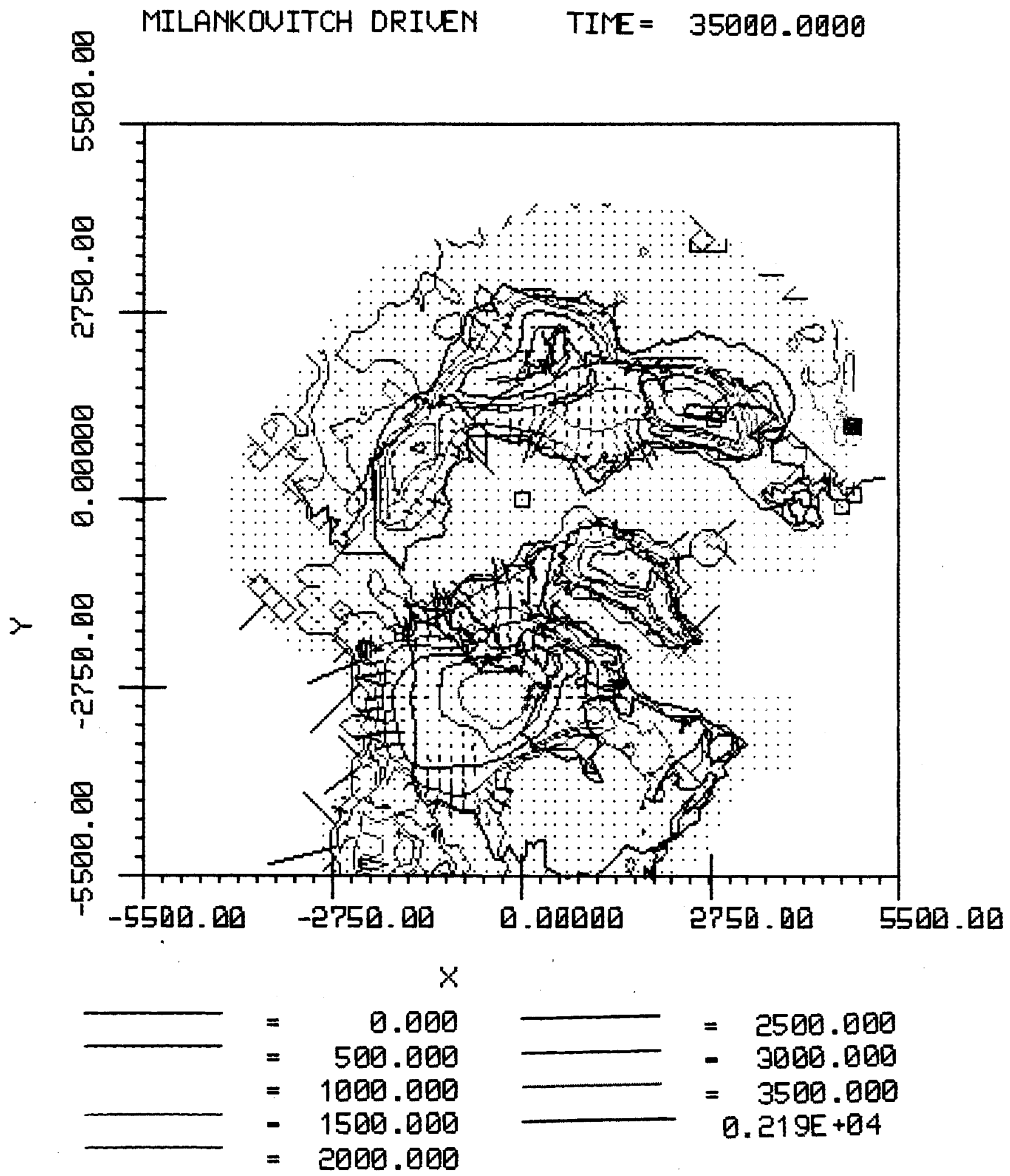

FIGURE 39. Maximum Arctic Ice Flow When Tilt Modifies Dust. Ice velocity vectors $(\mathrm{m} / \mathrm{a})$, ice elevations $(\mathrm{m})$, and $\mathrm{x}, \mathrm{y}$ coordinates $(\mathrm{km})$ are shown. 


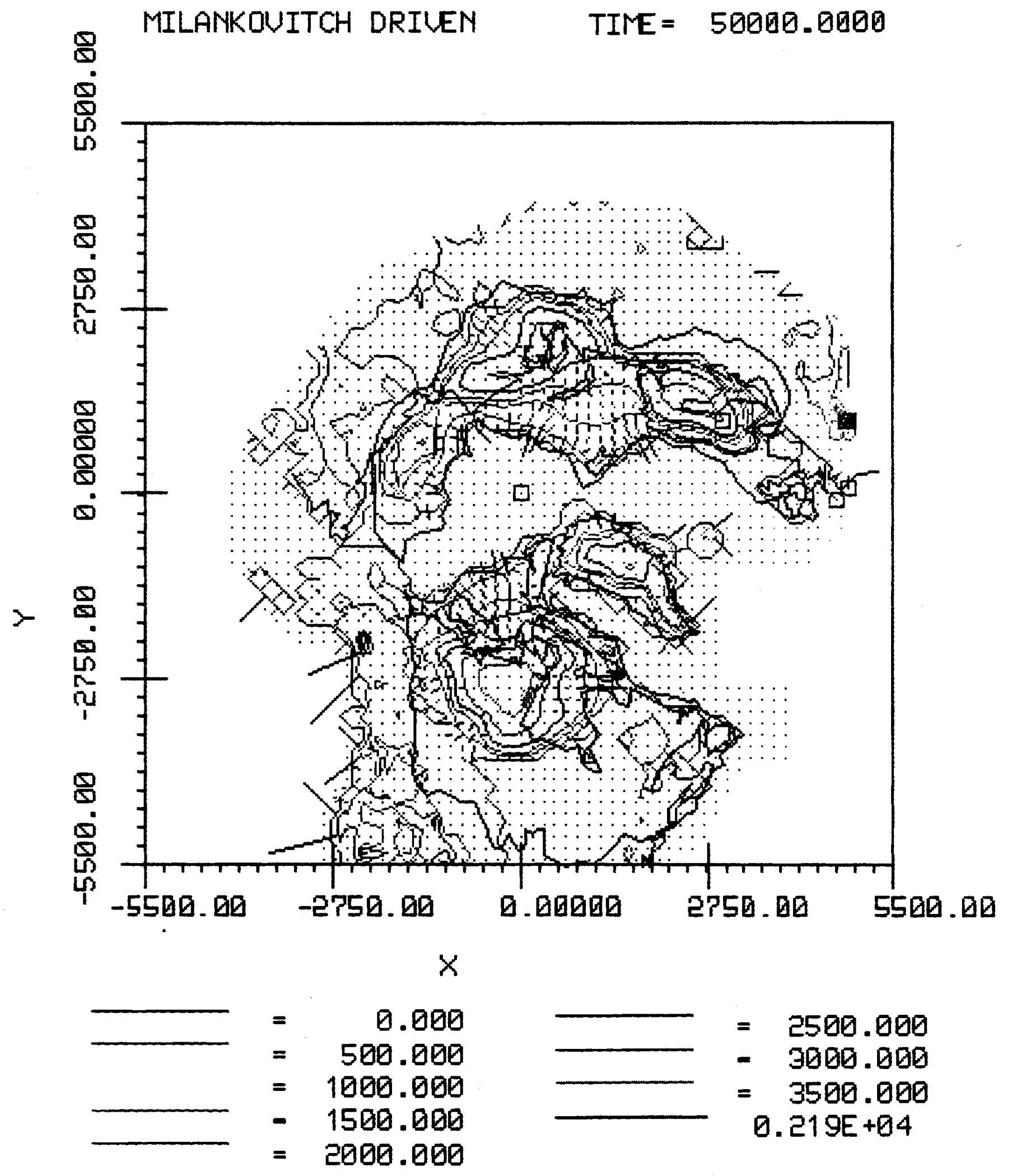

EIGURE 40. A Version of Figure 39 Without Basal Sliding in Norway. The model then puts the Scandinavian ice dome over the Gulf of Bothnia. 


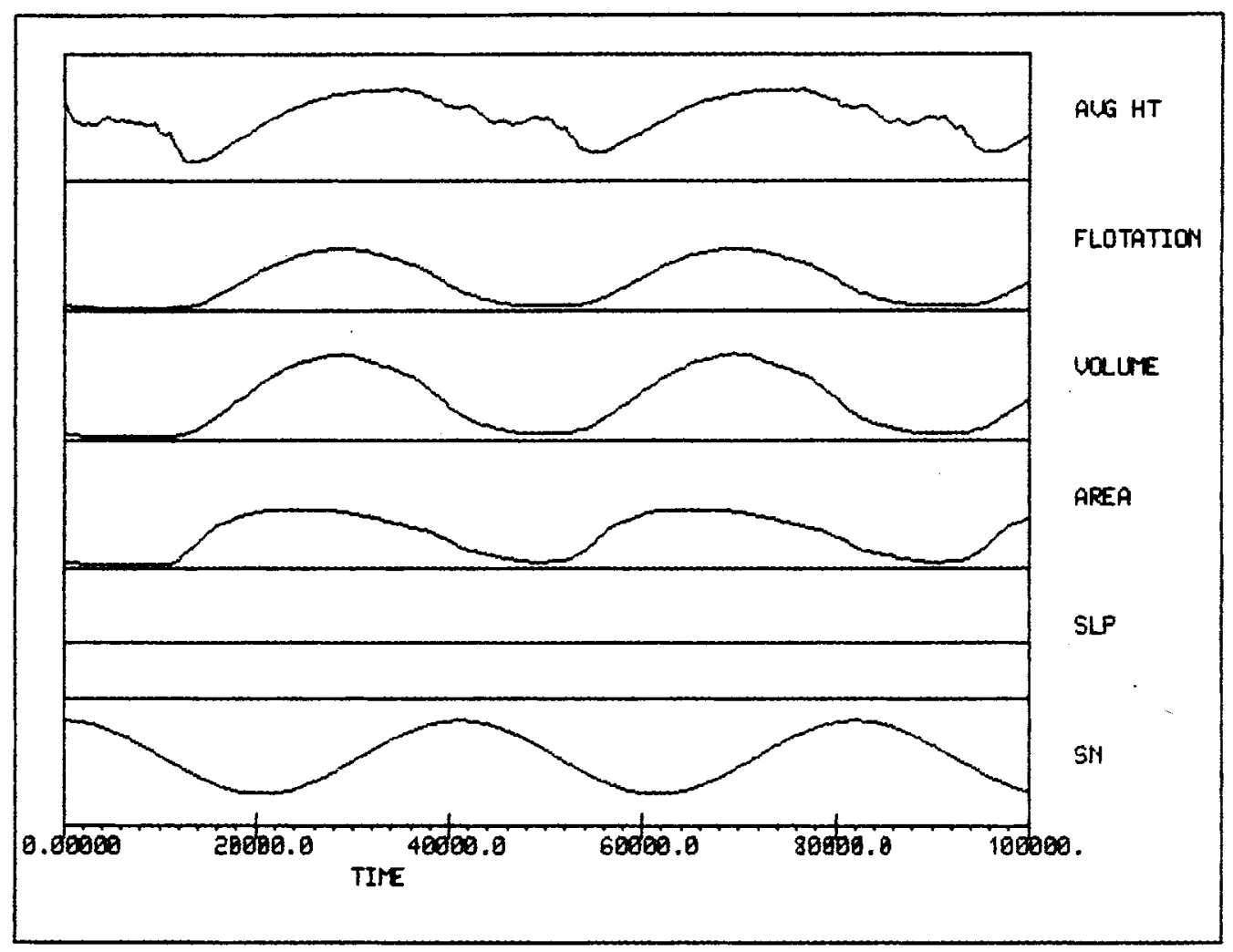

FIGURE 41. Arctic Model Input and Output When Tilt Dominates. Variations over 100,000 years are shown for average ice-sheet height (AVG HT), icesheet volume contributing to sea level (FLOTATION), total ice-sheet volume (VOLUME), areal extent (AREA), sliding law parameter (SLP), and North Pole snowline elevations (SN). 


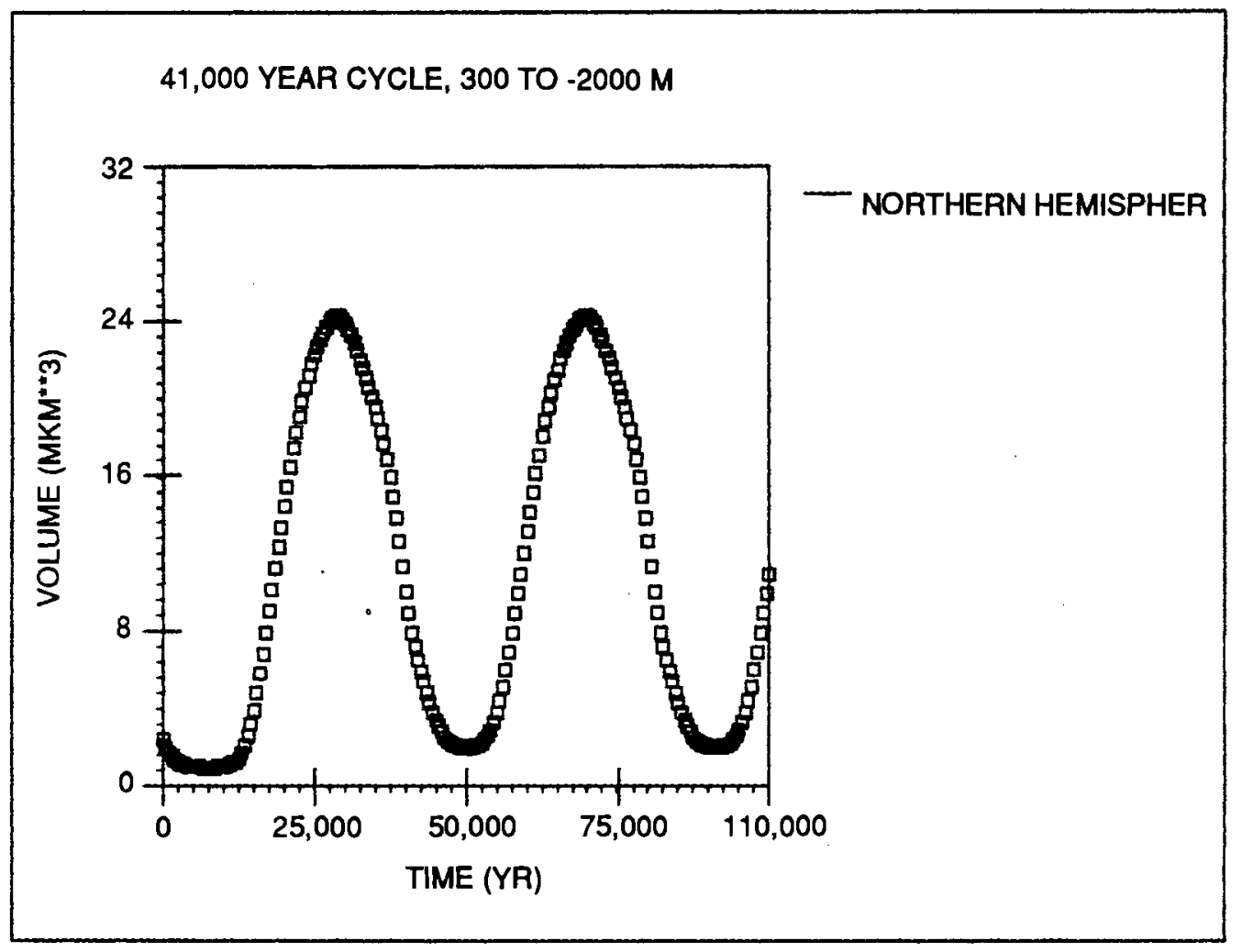

FIGURE 42. Arctic Flotation Ice Volume Over Time When Tilt Dominates. North Pole snowline amplitude of $+300 \mathrm{~m}$ to $-2800 \mathrm{~m}$ in cycle of 41,000 years. 


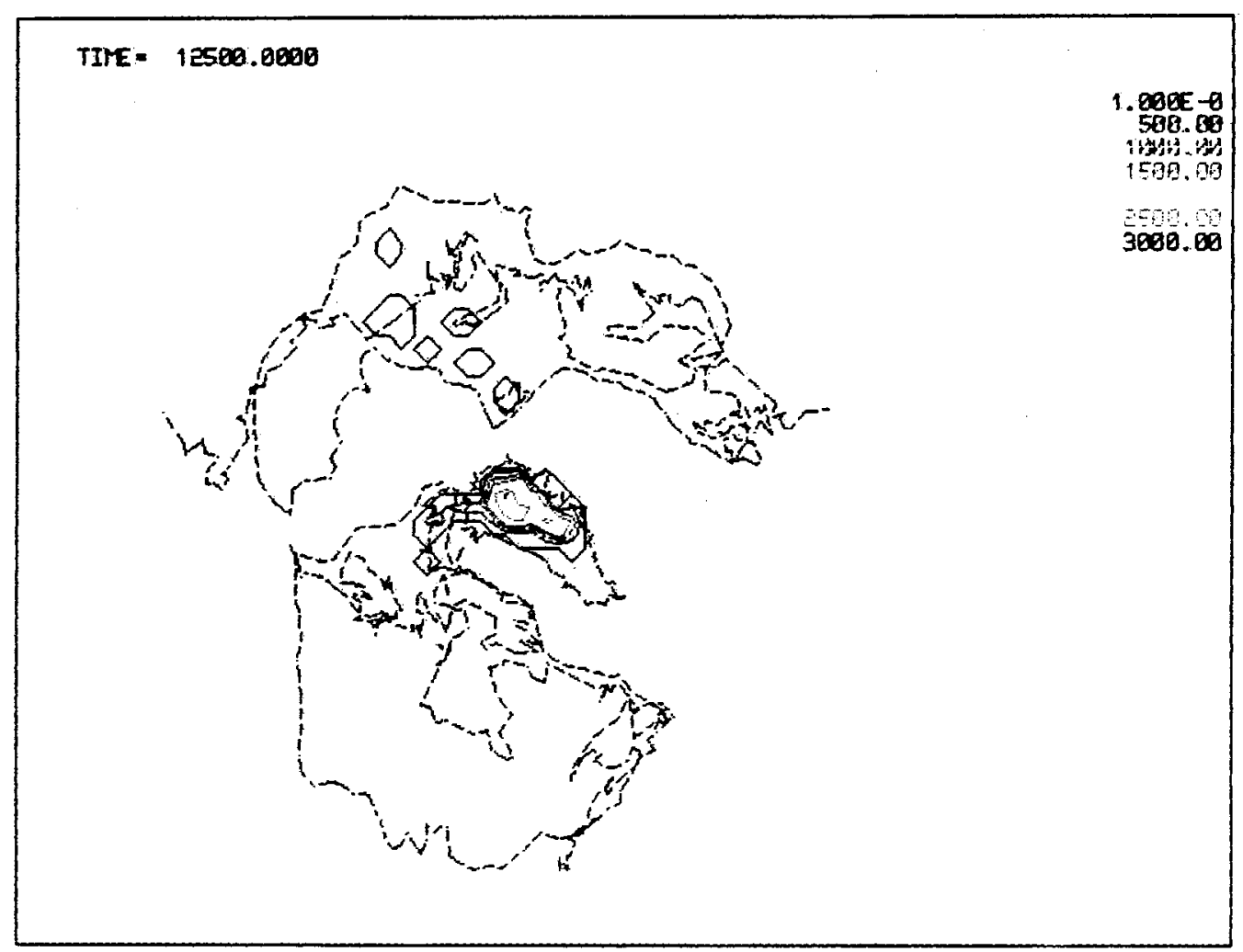

a) Ice Thickness at 12,500 years

TIRE $=12580.0800$

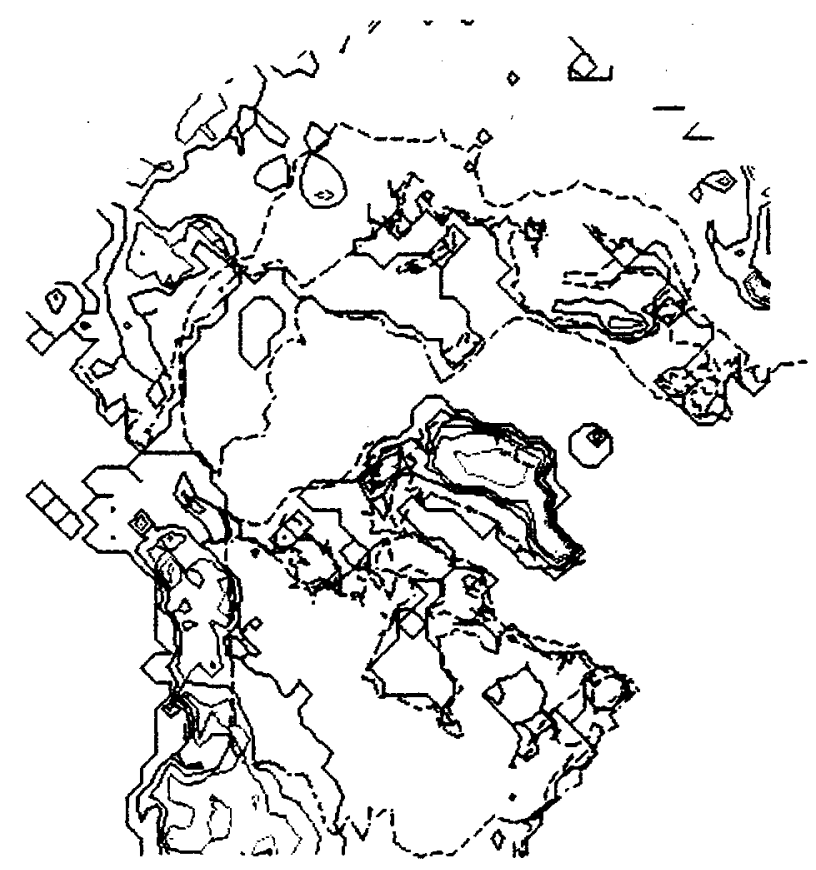

b) Ice and Land Elevation at 12,500 years

EIGURE 43. Arctic Ice Thicknesses and Elevations Over Time When Tilt Dominates. Contours every $500 \mathrm{~m}$. 


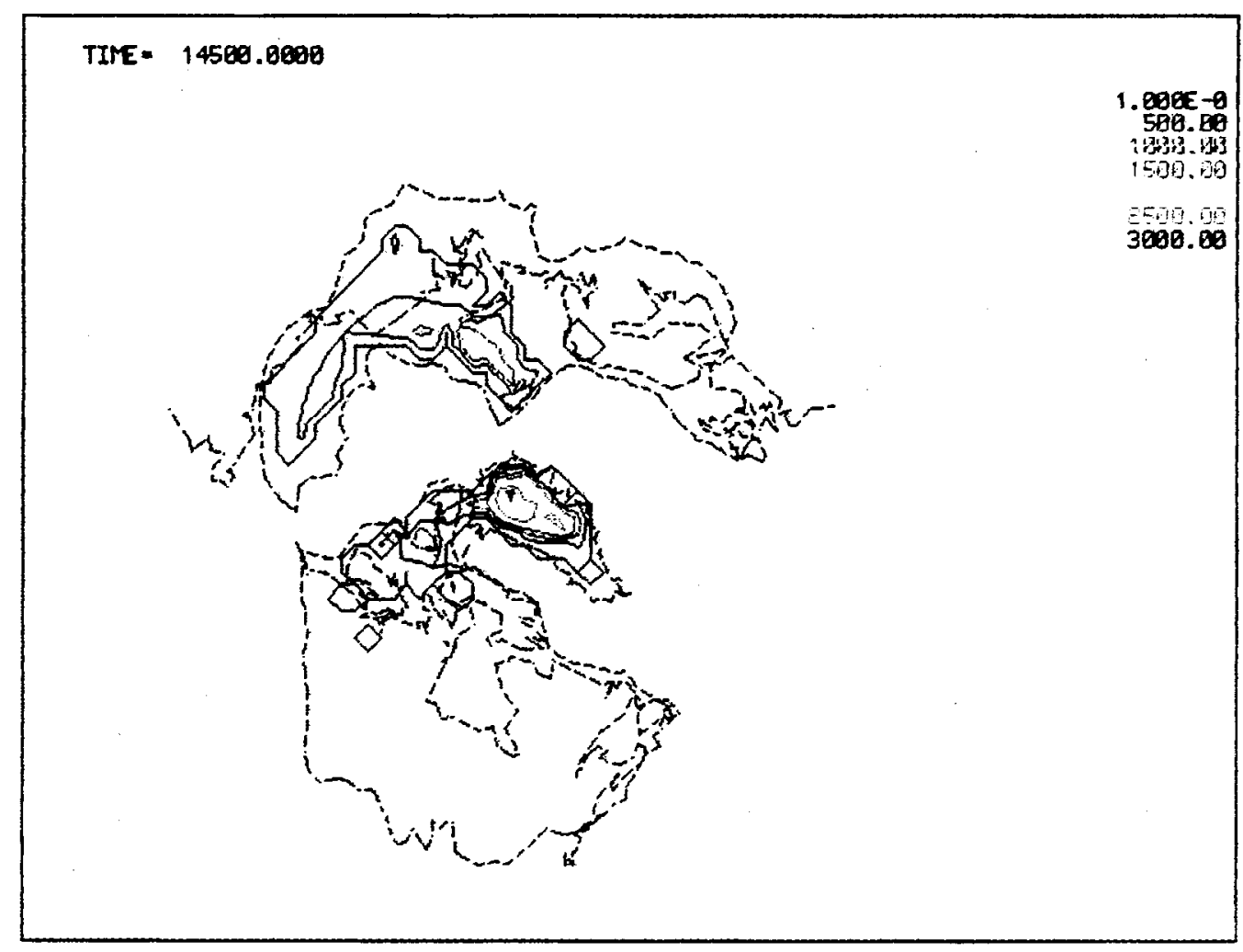

c) Ice Thickness at 14,500 years

TIIE $=14580.0800$

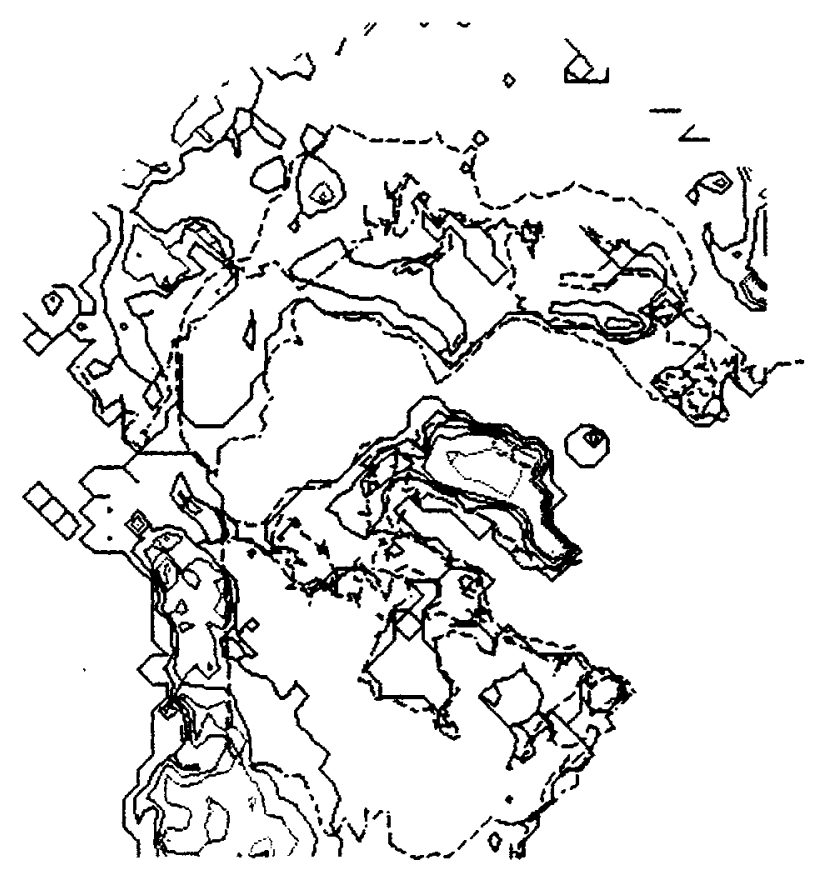




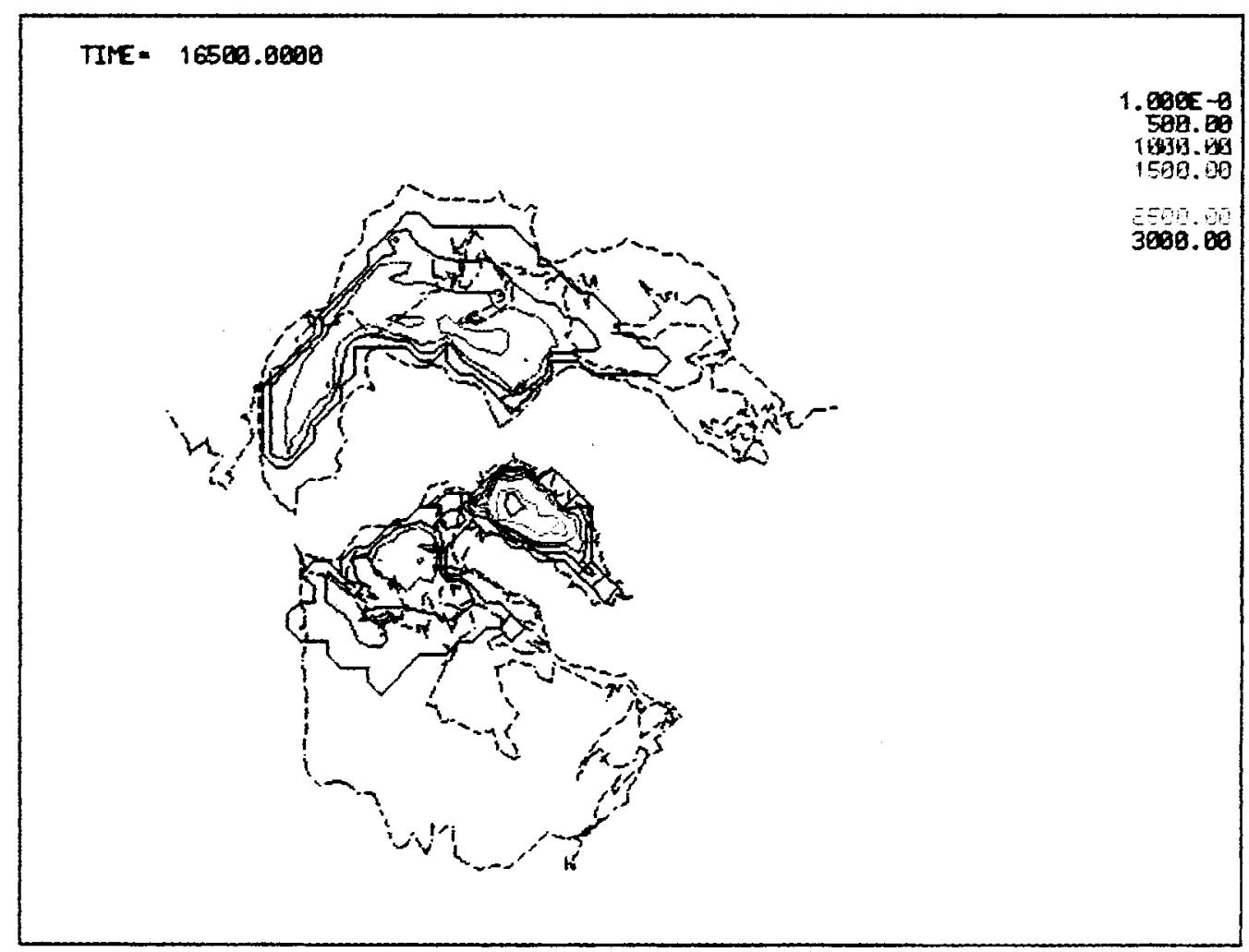

e) Ice Thickness at 16,500 years

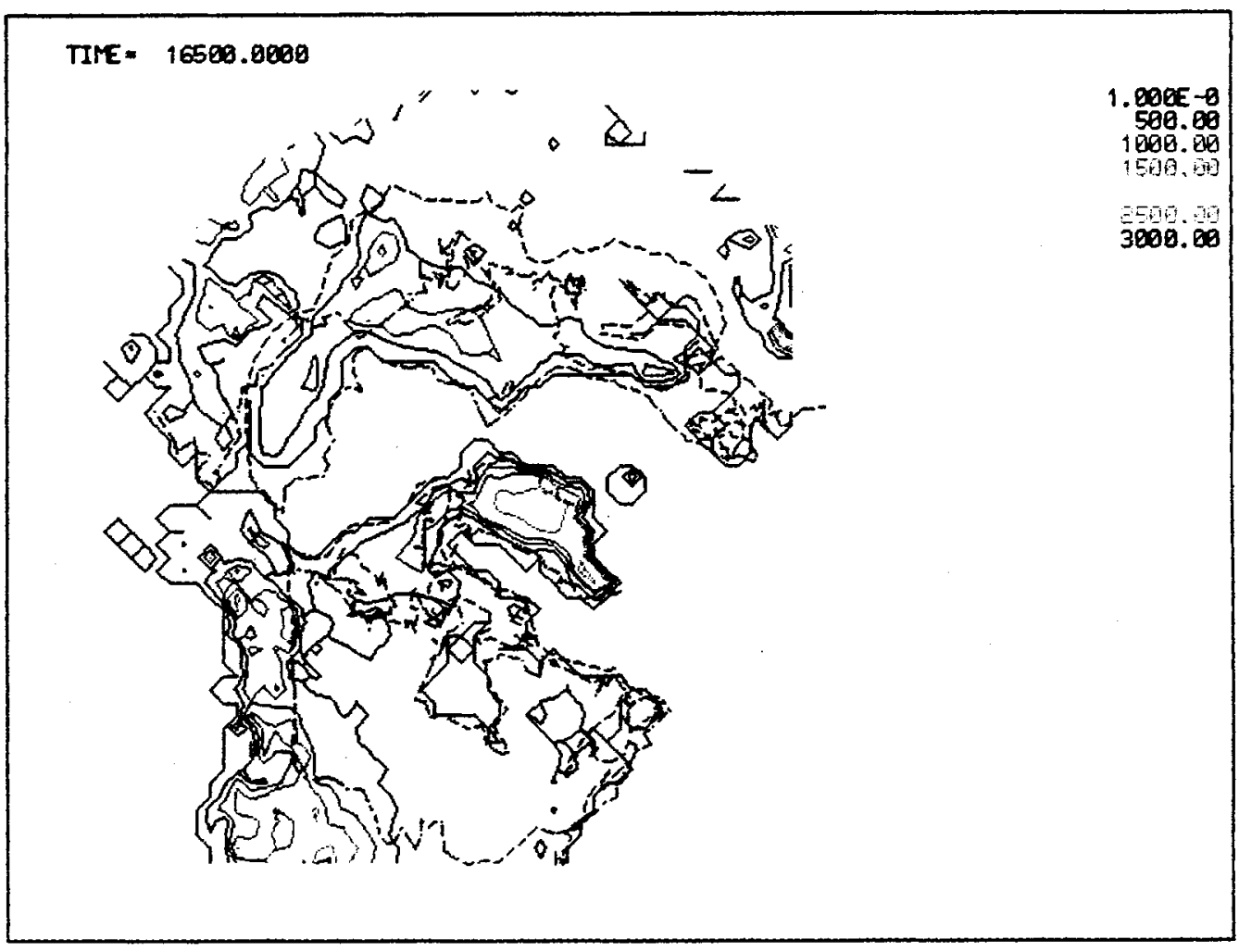

f) Ice and Land Elevation at 16,500 years 


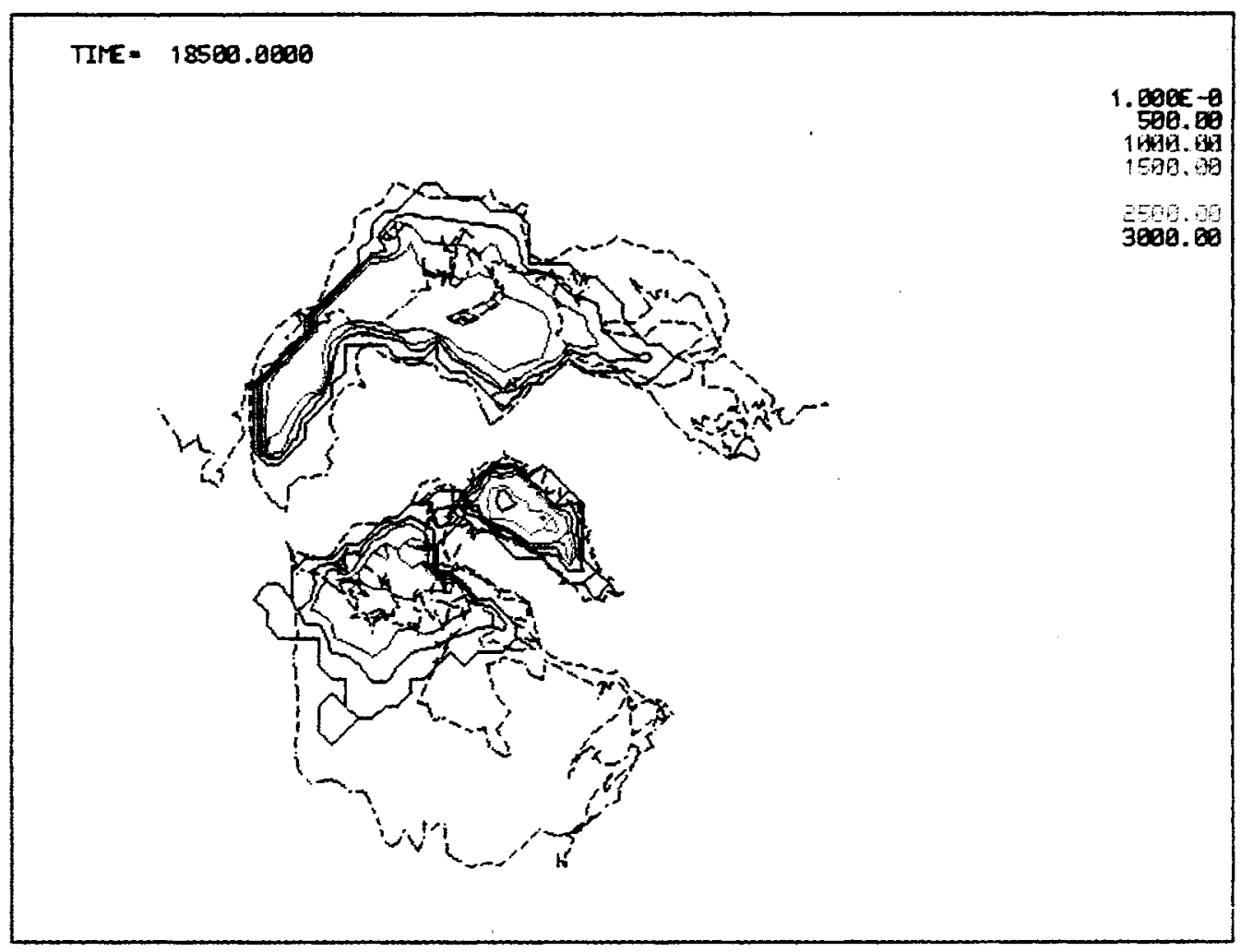

g) Ice Thickness at 18,500 years

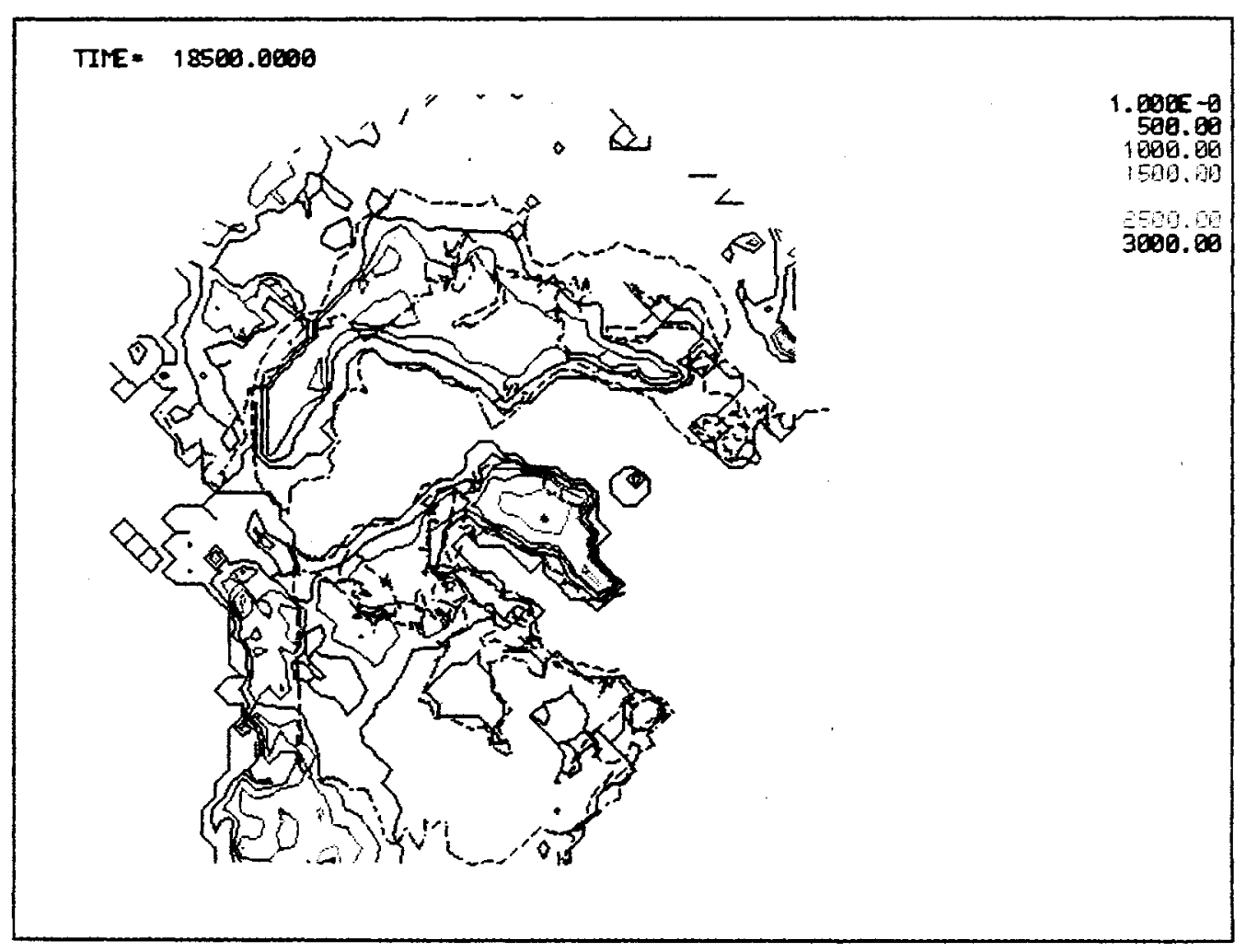

h) Ice and Land Elevation at 18,500 years 


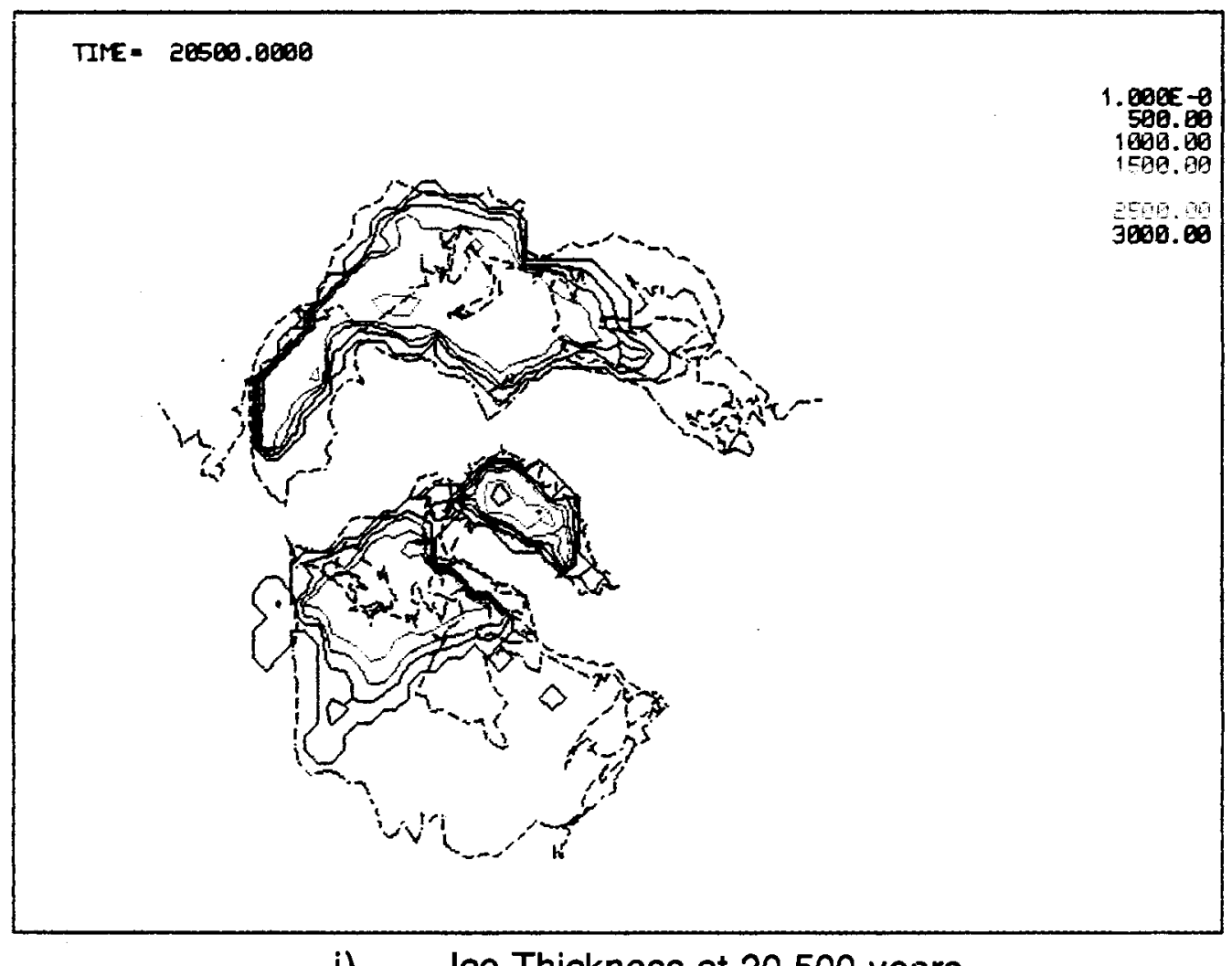

i) Ice Thickness at 20,500 years

TIRE = 28500.0800

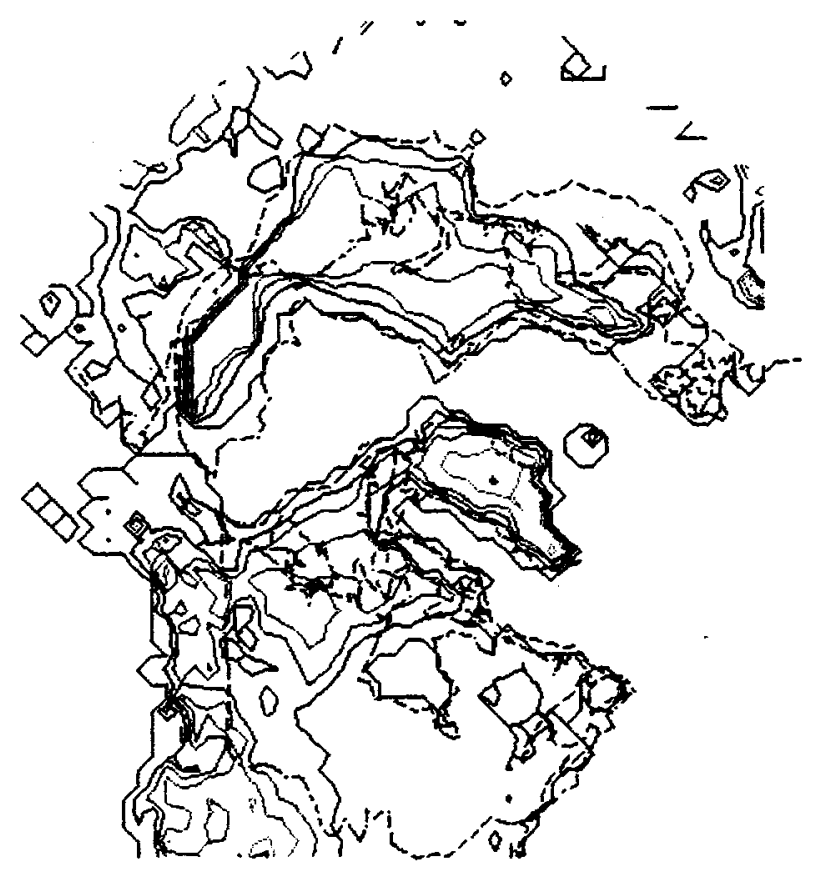




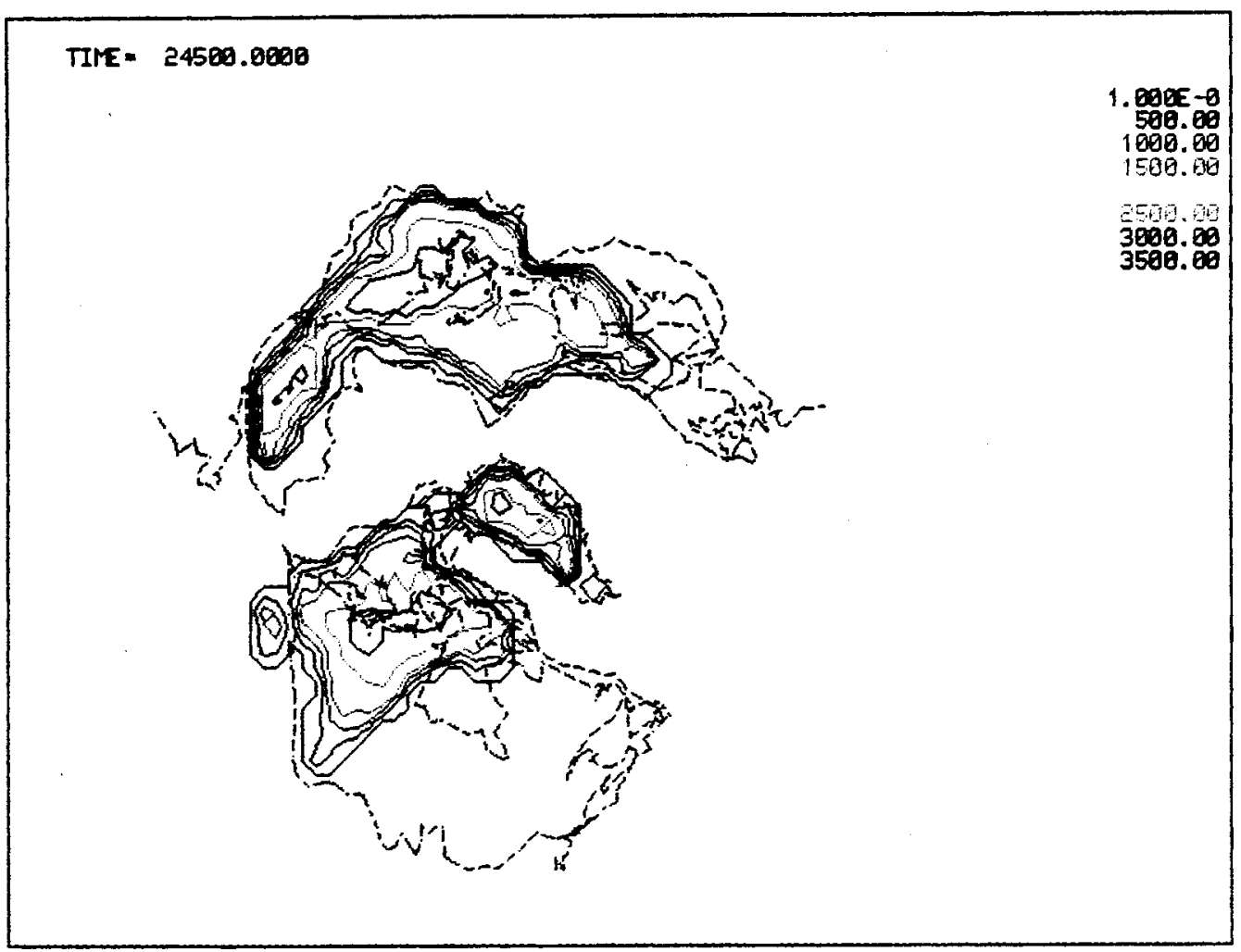

k) Ice Thickness at 24,500 years

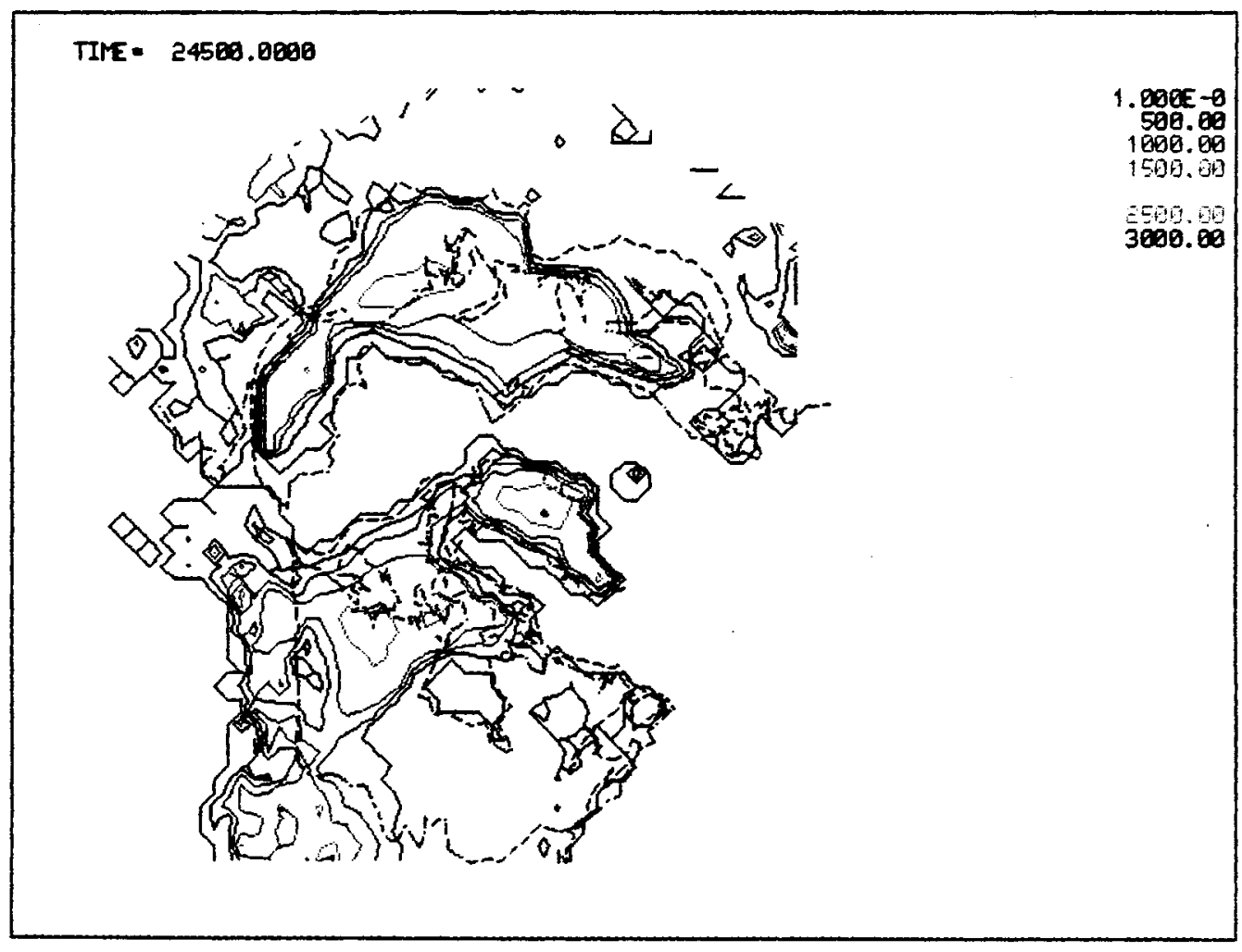

I) Ice and Land Elevation at 24,500 years 


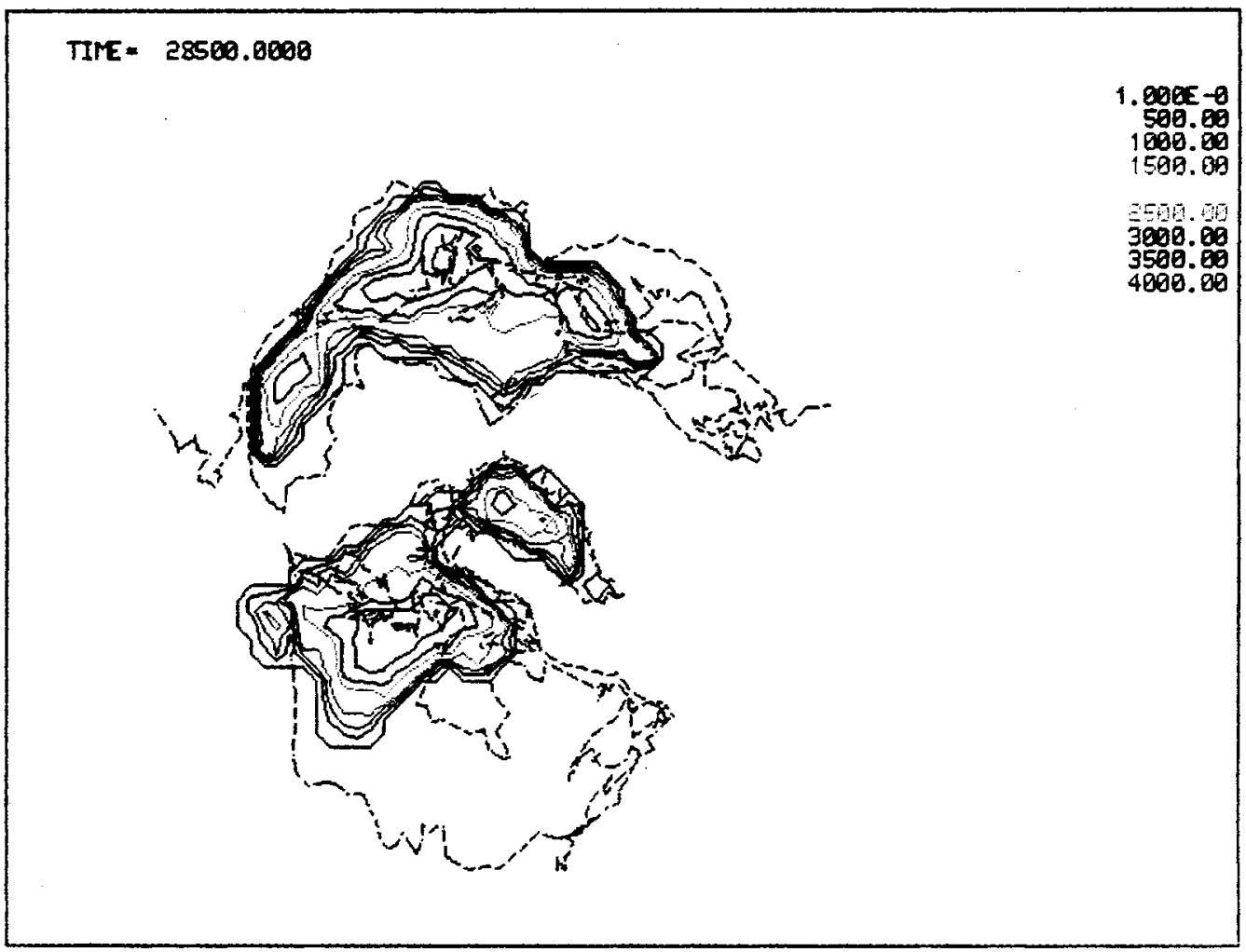

m) Ice Thickness at 28,500 years

TIPE $=28580.0800$

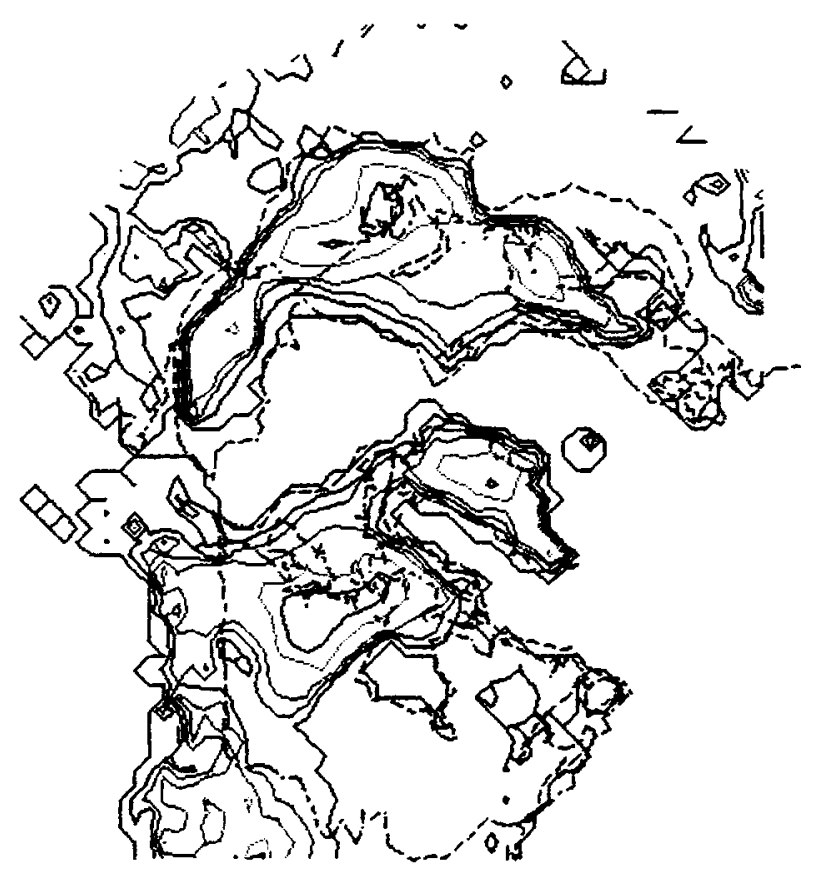

$1.8985-8$

500.80

1808.00

1509.06

Eso.

3900.80

n) Ice and Land Elevation at 28,500 years 
TIRE = 32500.0800

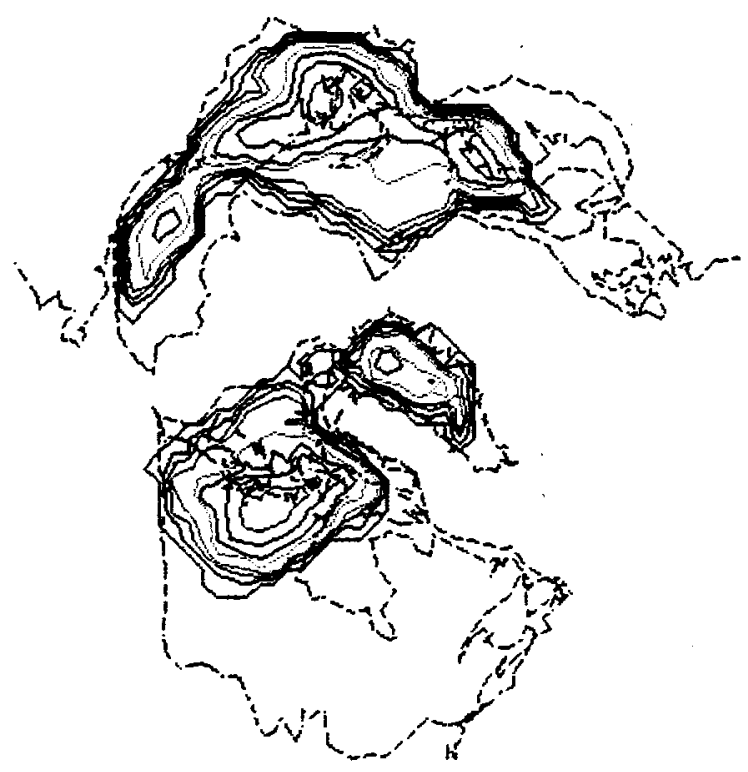

o) Ice Thickness at 32,500 years

TIME $=32580.0900$

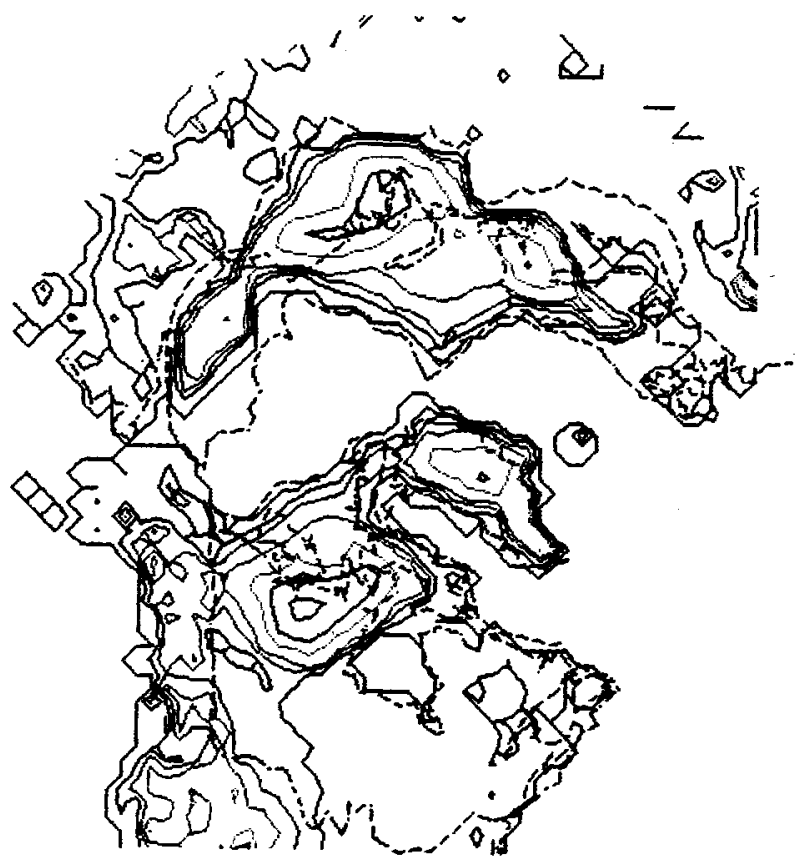

p) Ice and Land Elevation at 32,500 years 


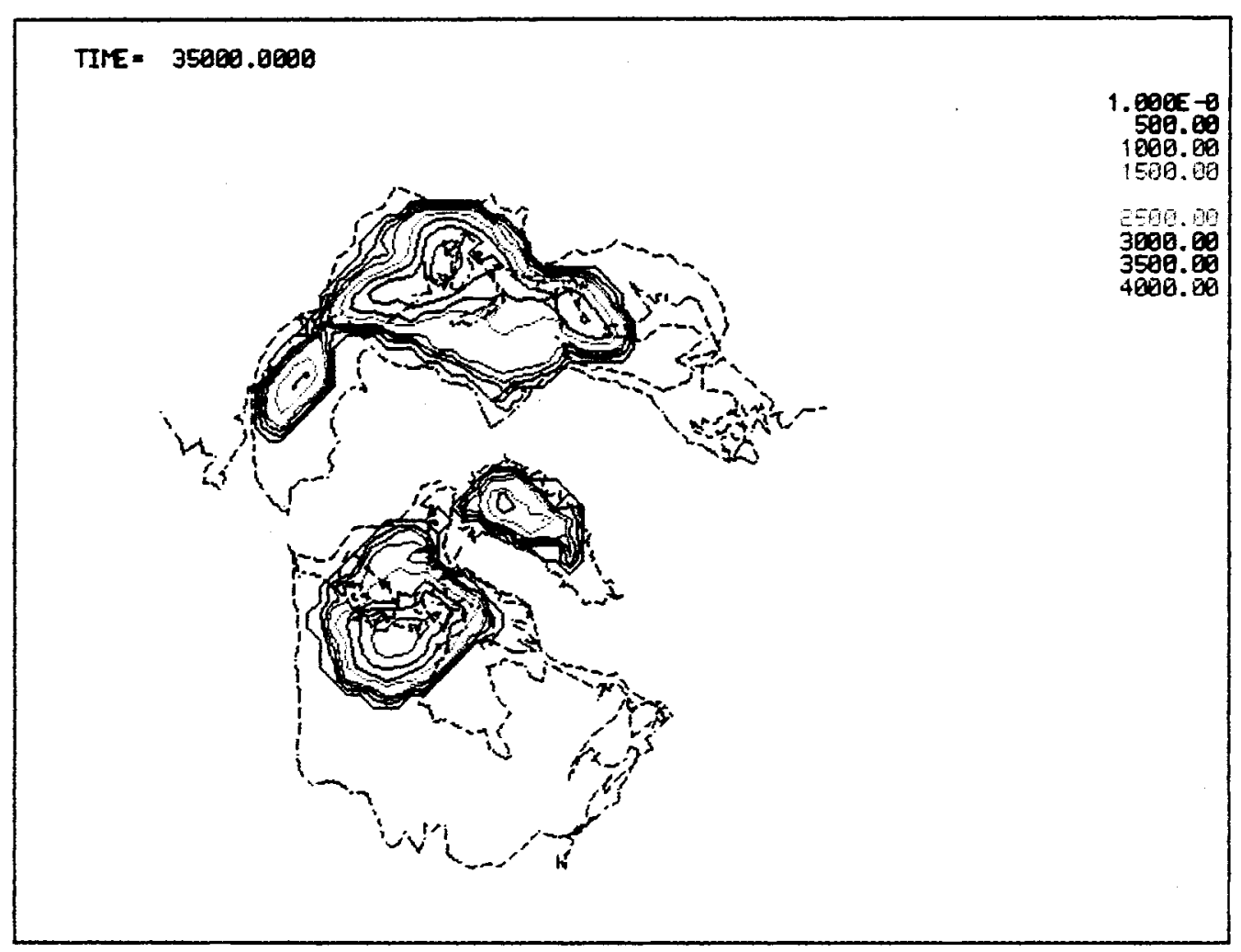

q) Ice Thickness at 35,000 years

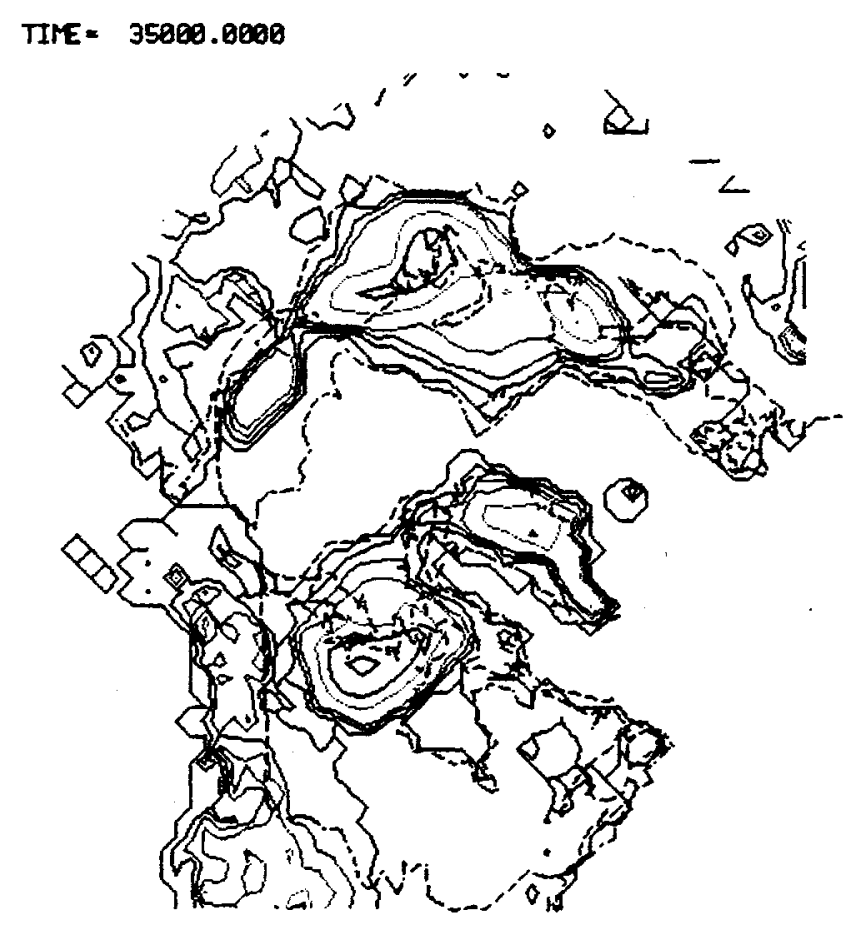

r) Ice and Land Elevation at 35,000 years 


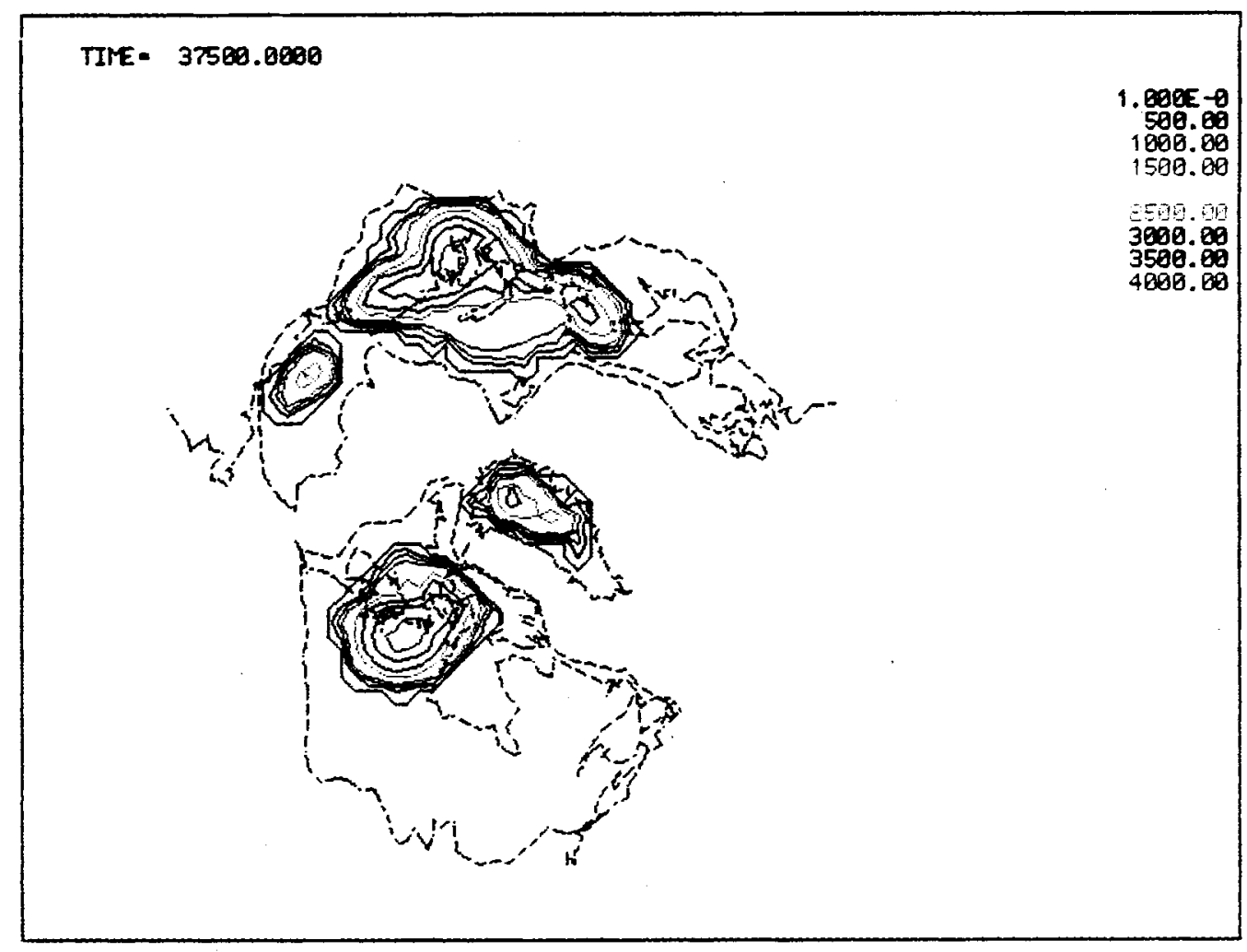

s) Ice Thickness at 37,500 years

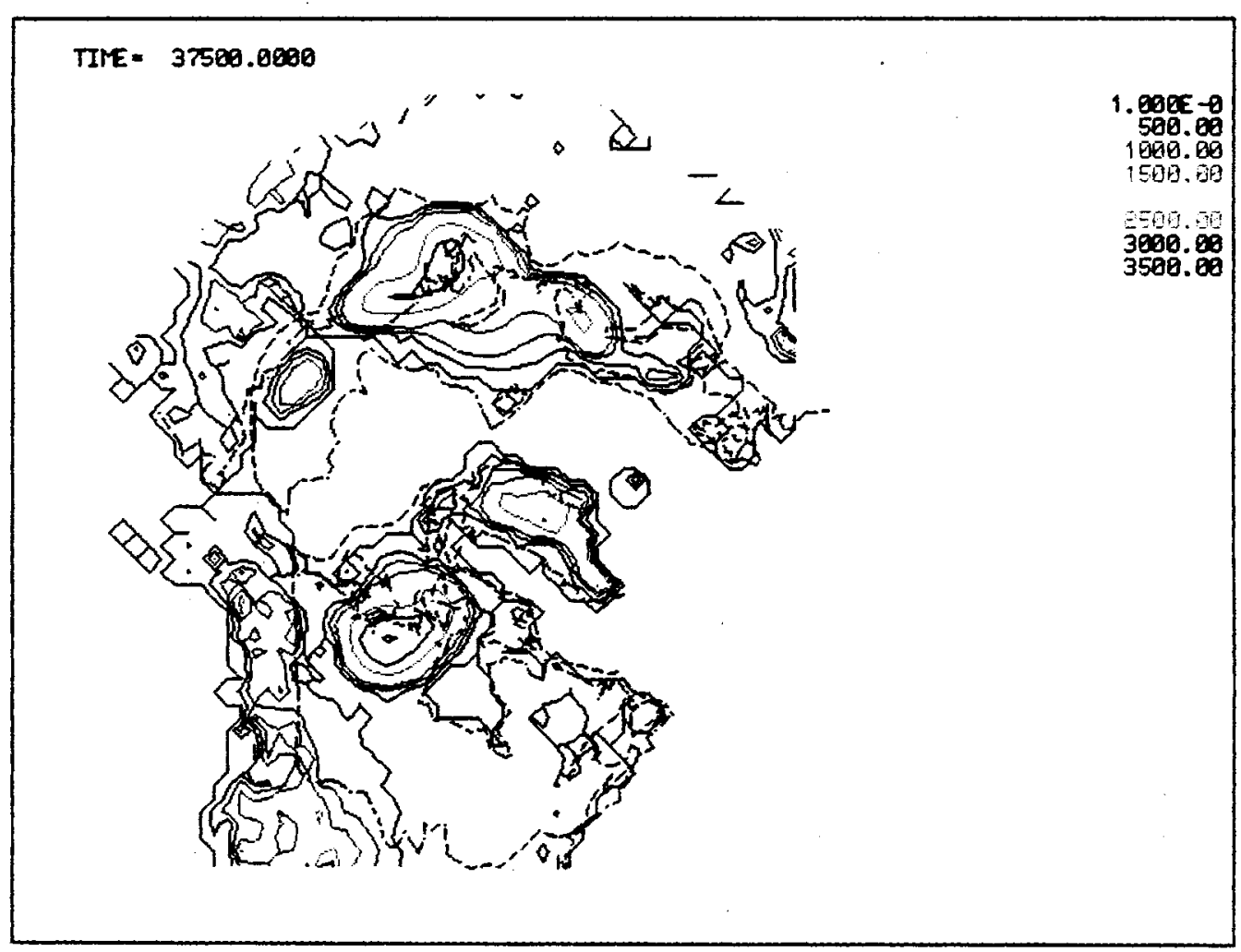

t) Ice and Land Elevation at 37,500 years 


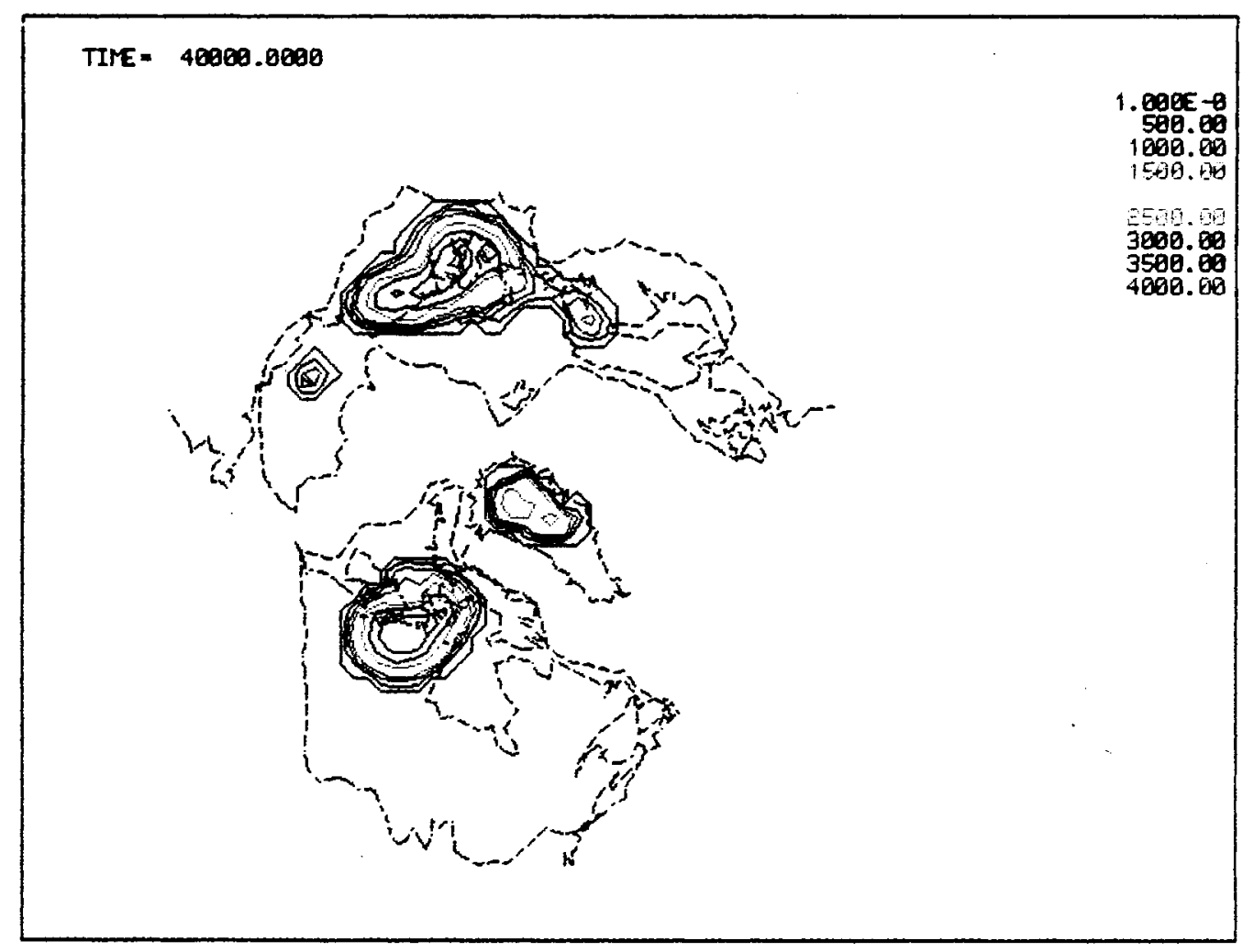

u) Ice Thickness at 40,000 years

TIPE = 48080.0800

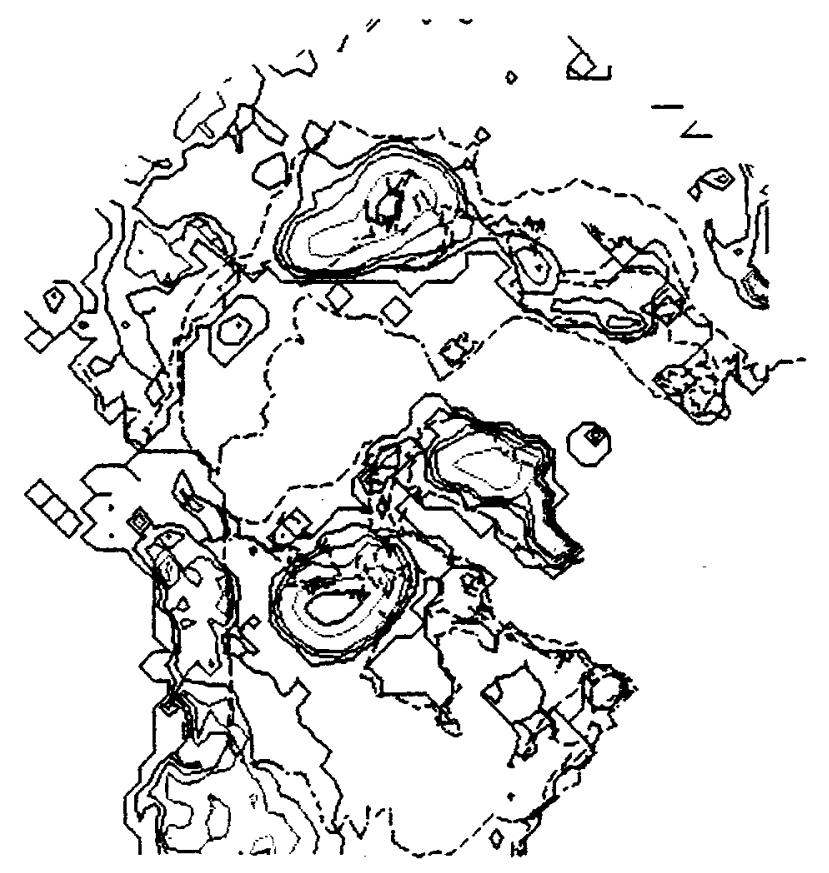




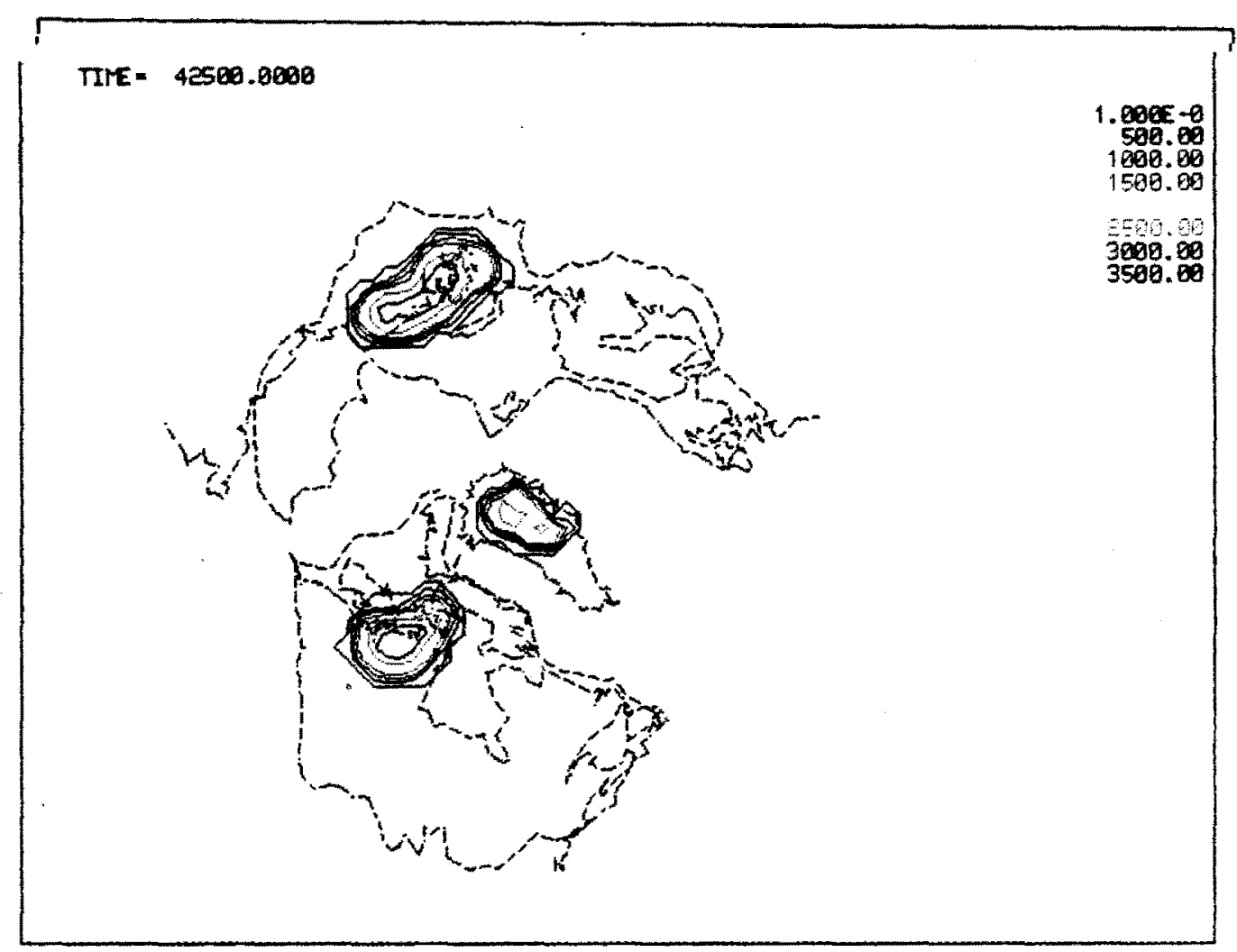

w) Ice Thickness at 42,500 years

TIRE * 42560.0000

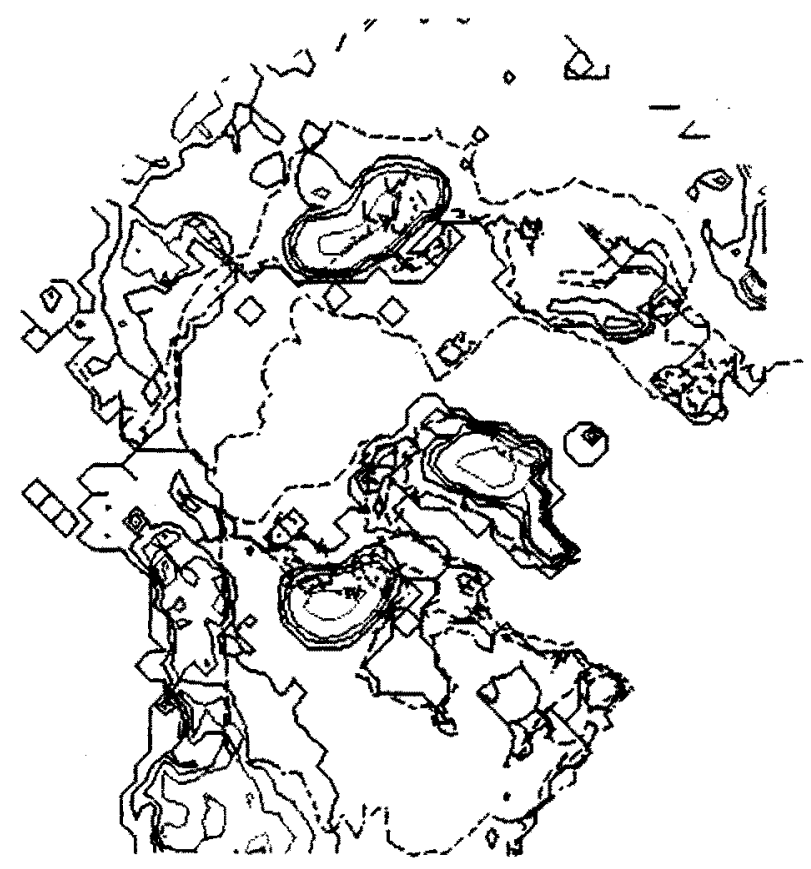

x) Ice and Land Elevation at 42,500 years 


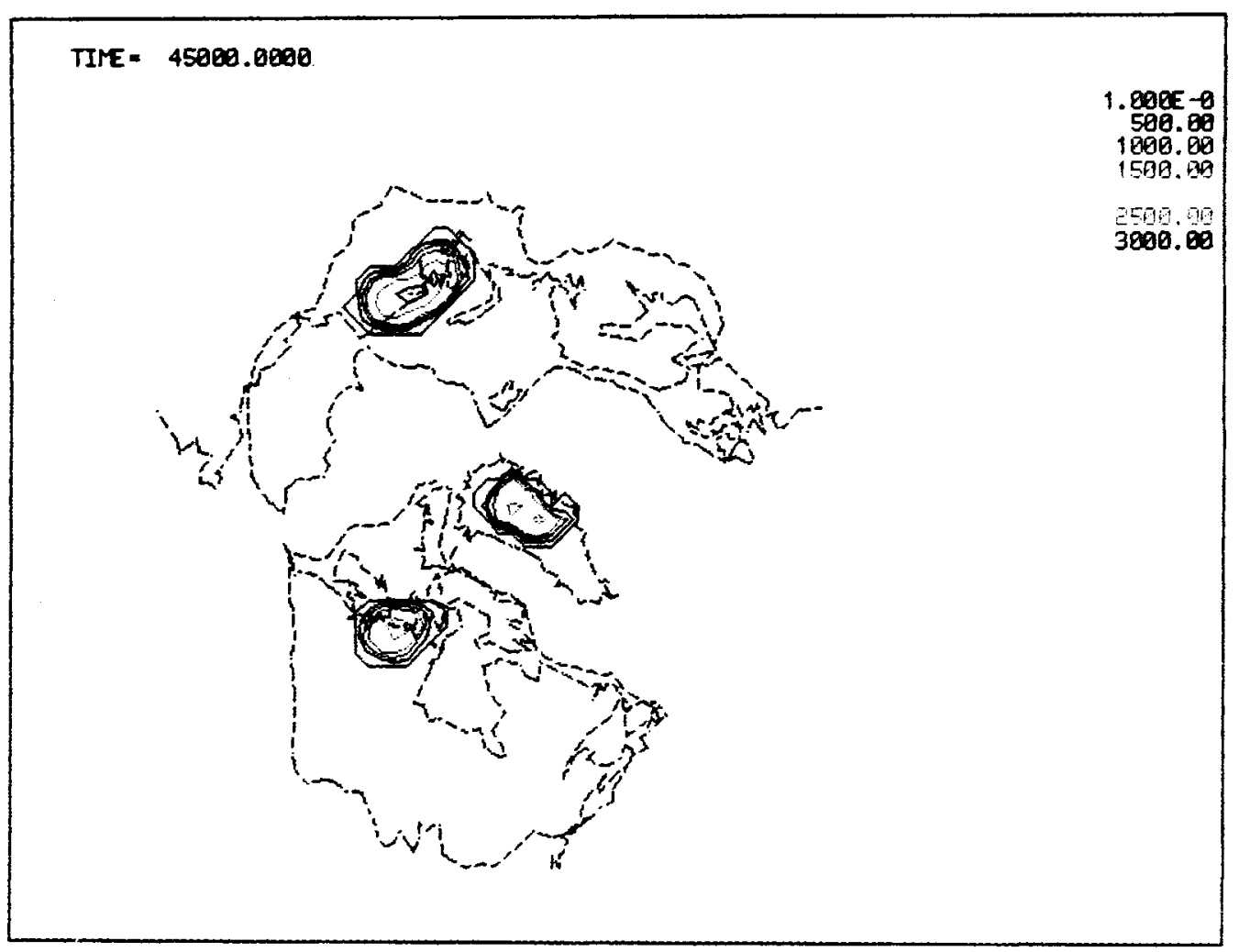

y) Ice Thickness at 45,000 years

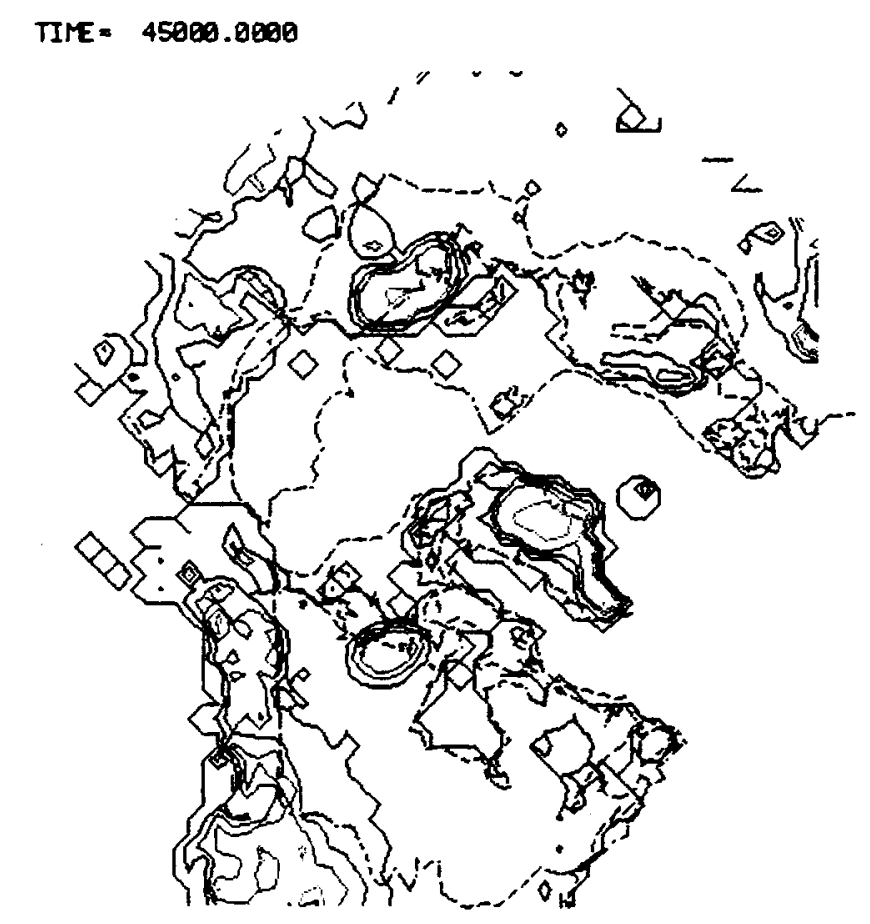

z) Ice and Land Elevation at 45,000 years 


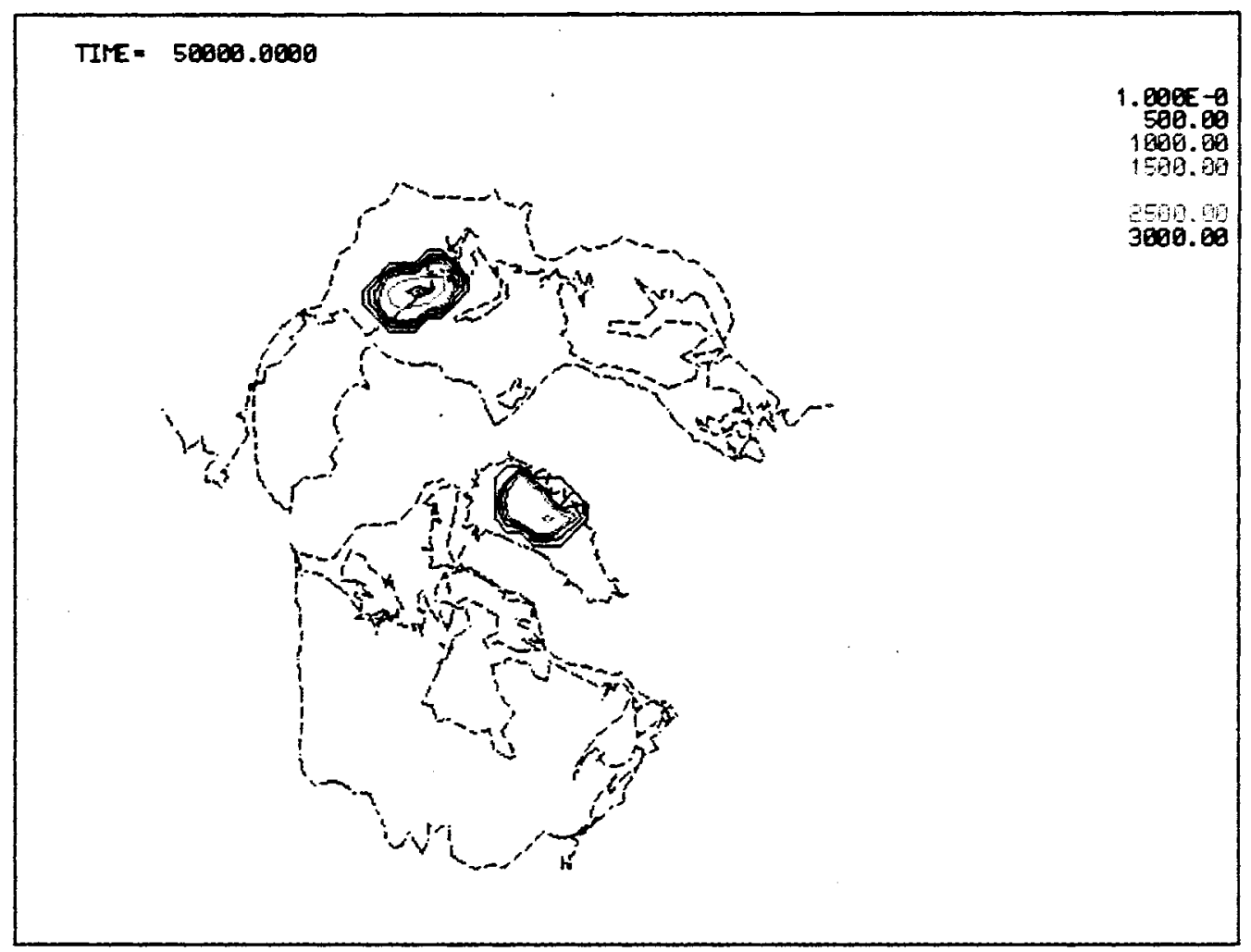

aa) Ice Thickness at 50,000 years

TIME $=56060.0600$

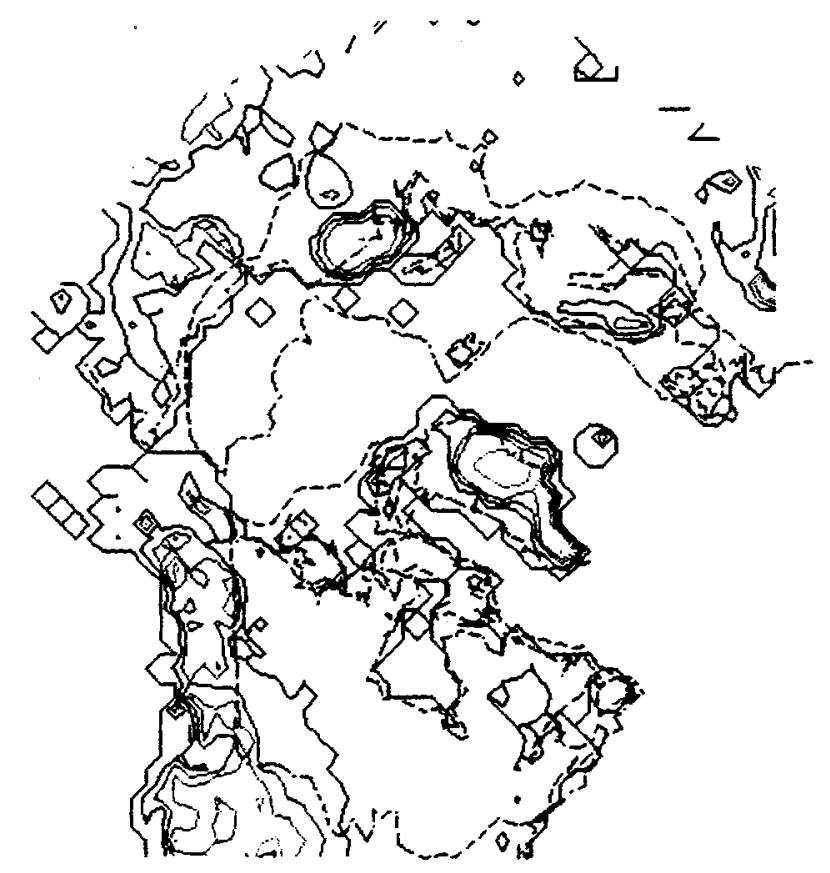

$1.0085-8$
500.89
1090.09

1500.09

2500.00

3000.09

bb) Ice and Land Elevation at 50,000 years 


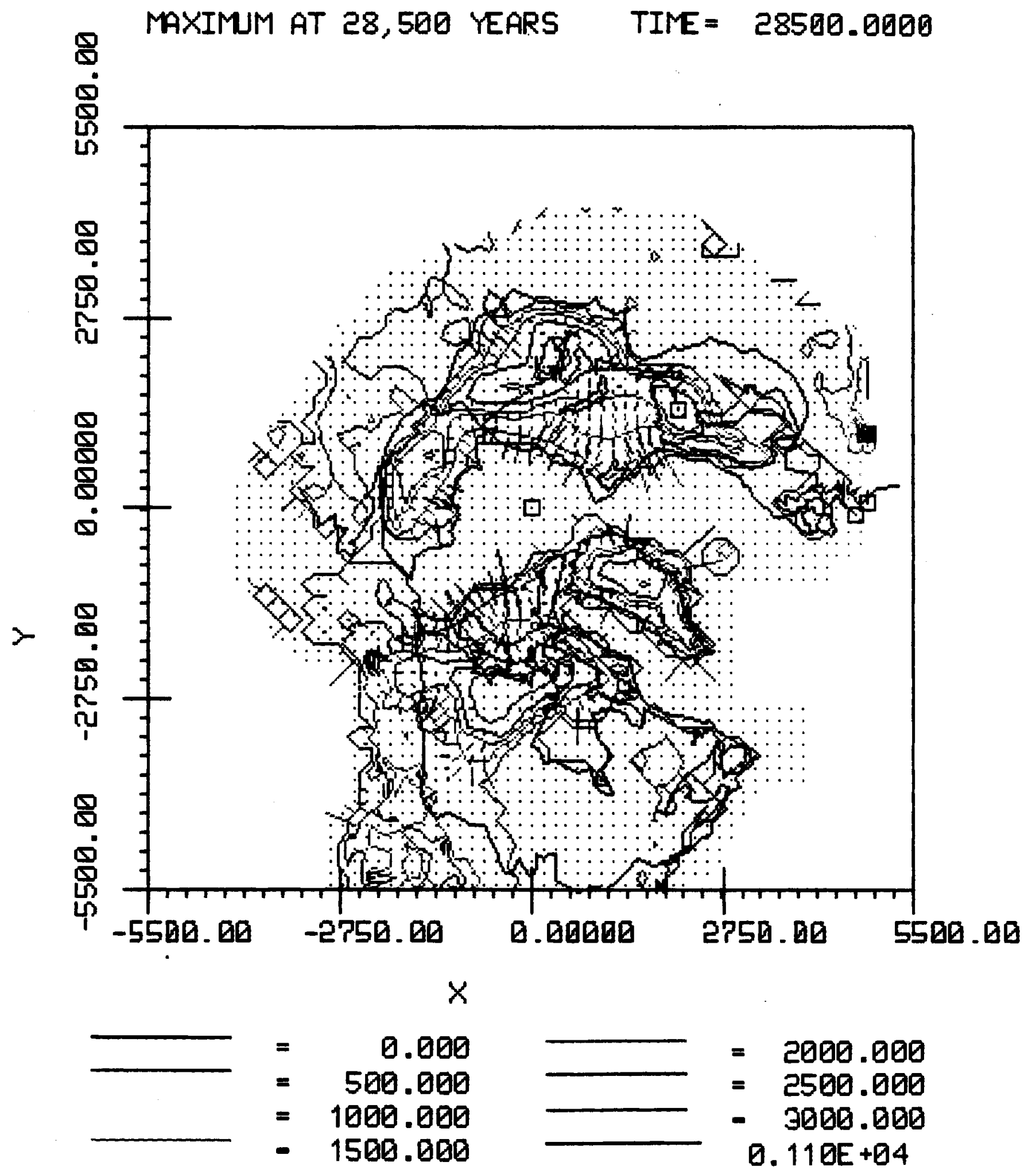

FlGURE 44. Maximum Arctic Ice Flow When Tilt Dominates. Ice velocity vectors (m/a), ice elevation $(\mathrm{m})$, and $x, y$ coordinates $(\mathrm{km})$ are shown. 

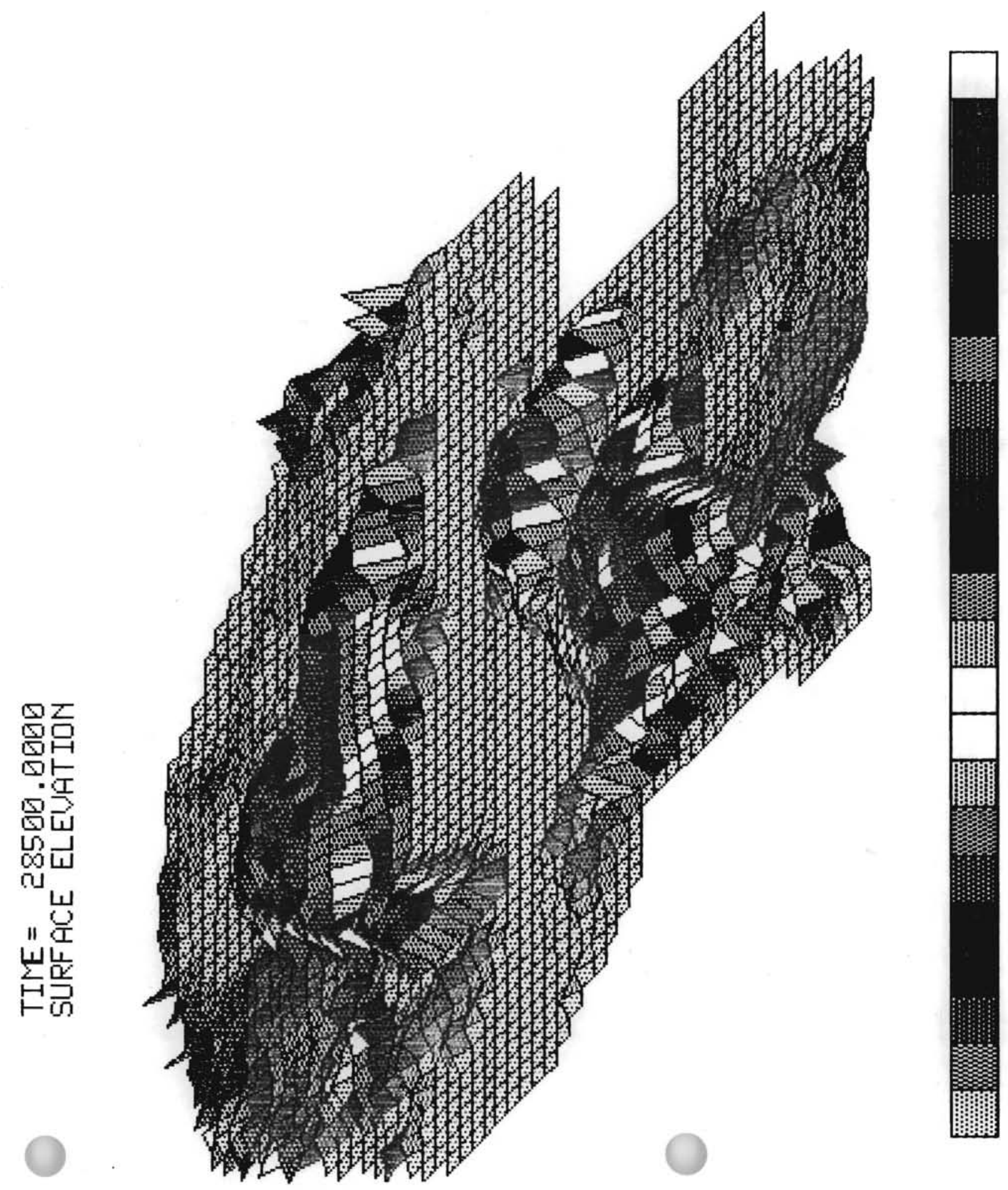

3450.

3900.

3150.

3000.

2850.

2700.

2550.

2400.

2250.

2100.

1950.

1800.

1650.

1500.

1350

1200.

1050.

900.

750.

600.

450.

300.

150.

‥ 


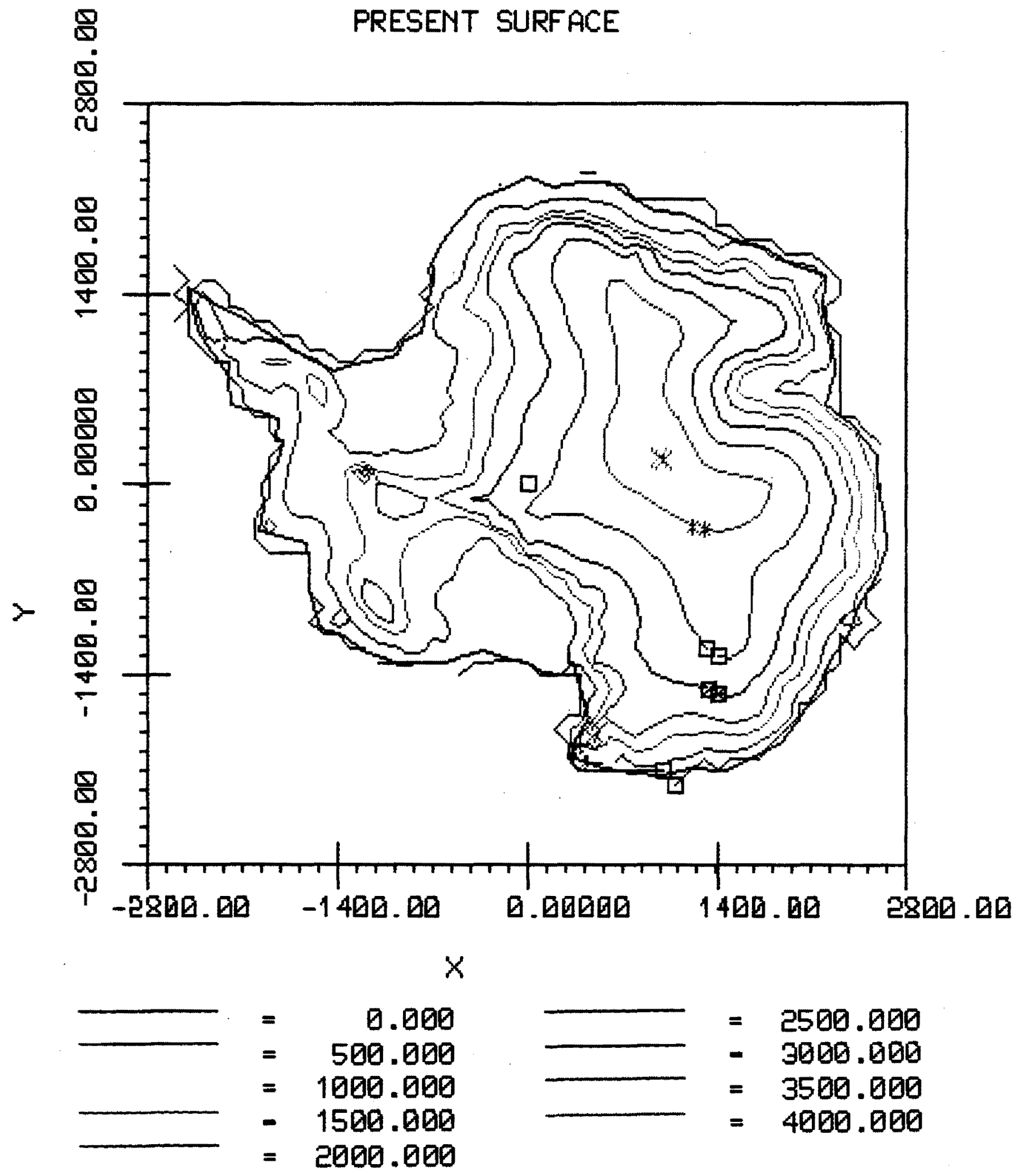

ElGURE 46. The $x, y$ Coordinate System for Antarctica. 


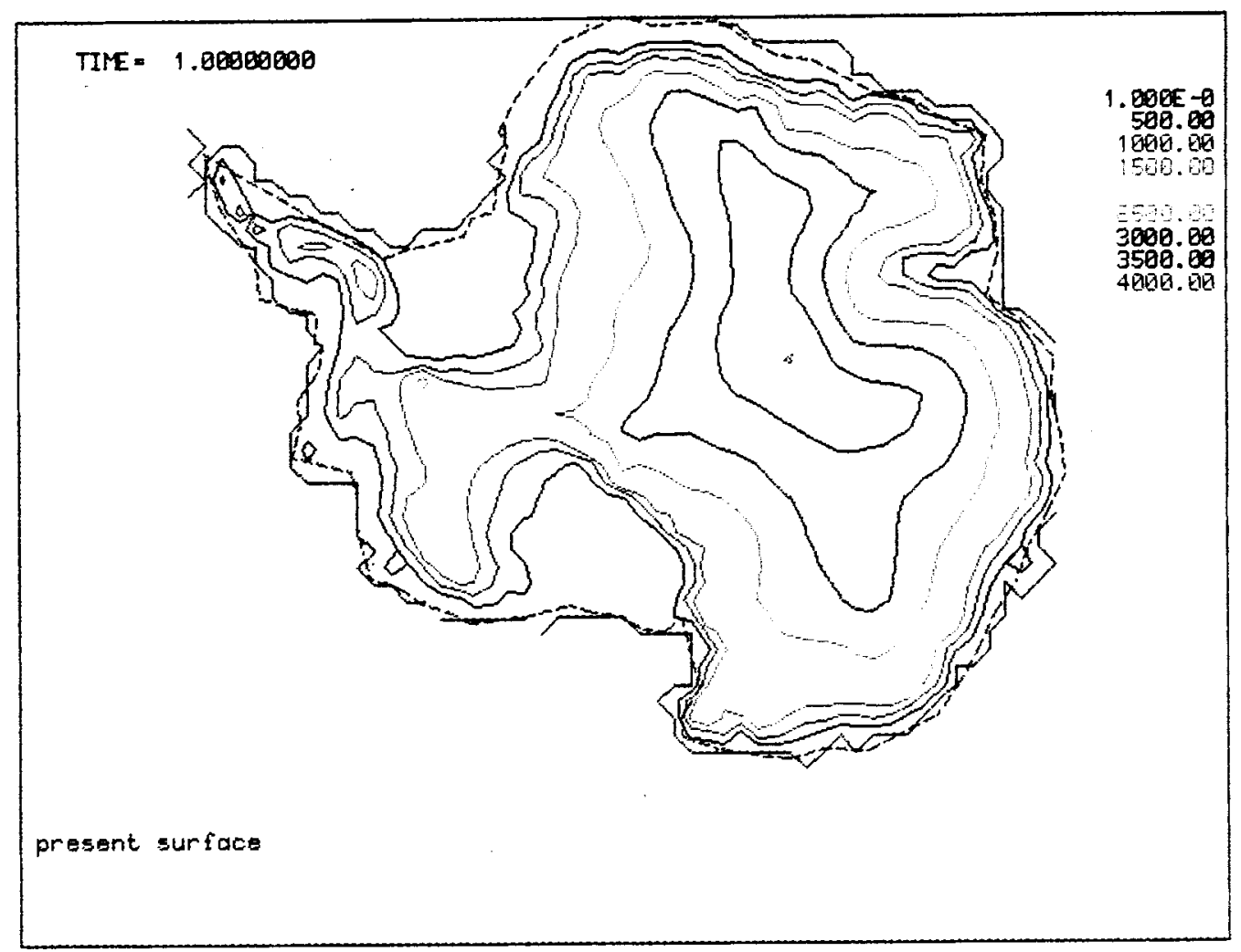

FIGURE 47. Present-Day lce Elevations in Antarctica.

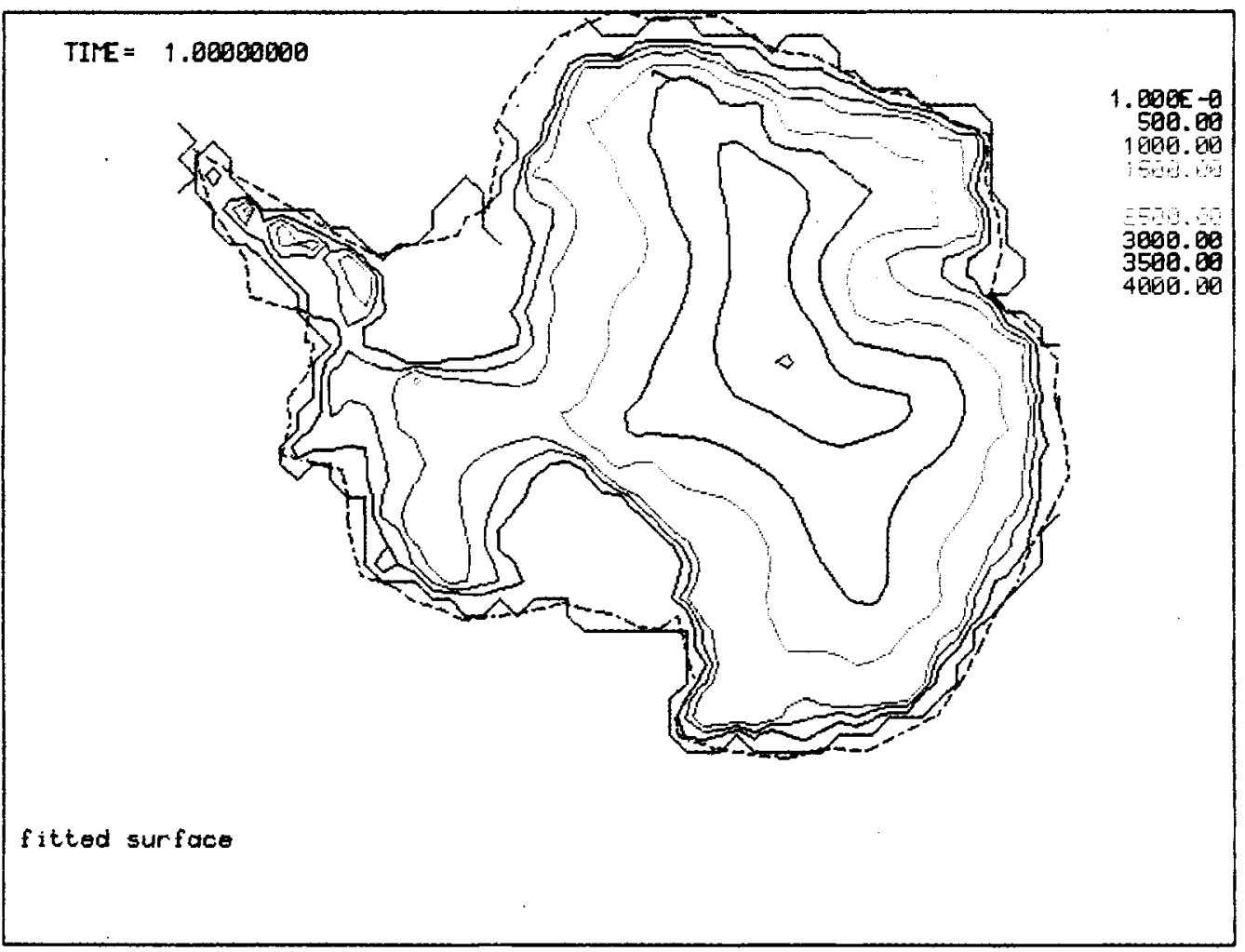

FIGURE 48. Best-Fit of Modeled to Actual Antarctic Ice Elevations. Contours every $500 \mathrm{~m}$. 


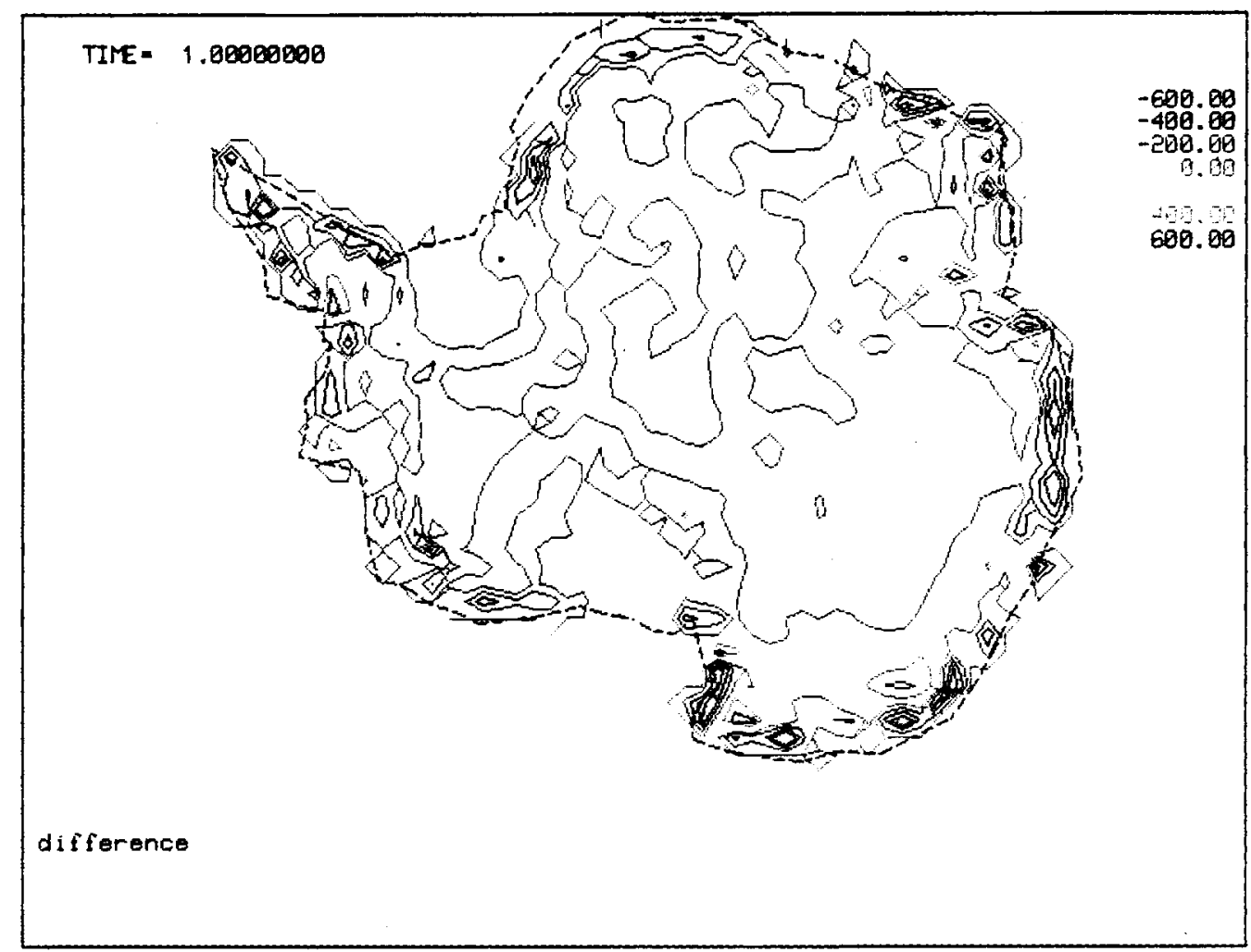

ElGURE 49. Elevation Difference Between Figures 47 and 48 . Contours (m) show regions too high (+) and too low (-).

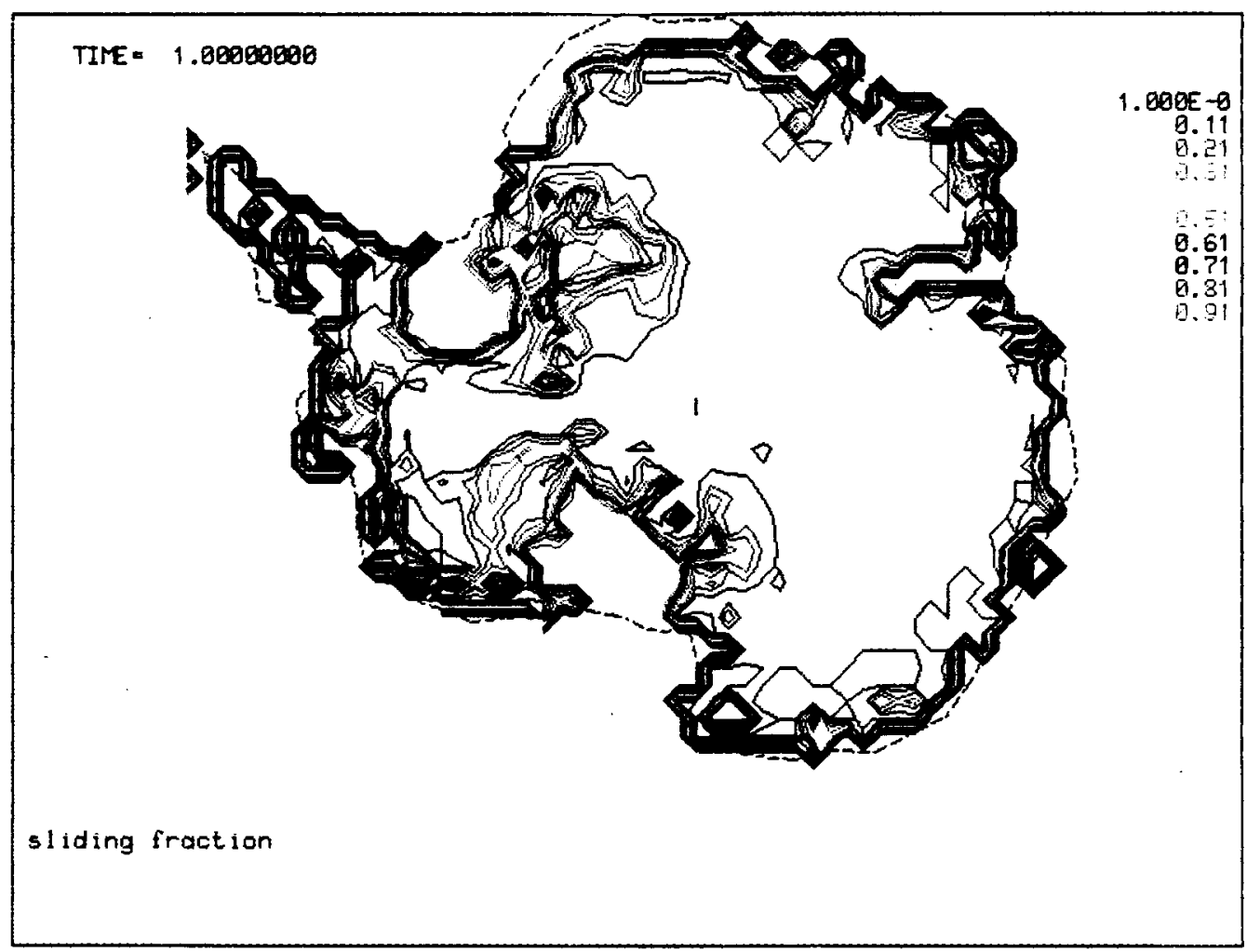

FIGURE 50. Fractional Velocity by Basal Sliding in Present-Day Antarctica. 


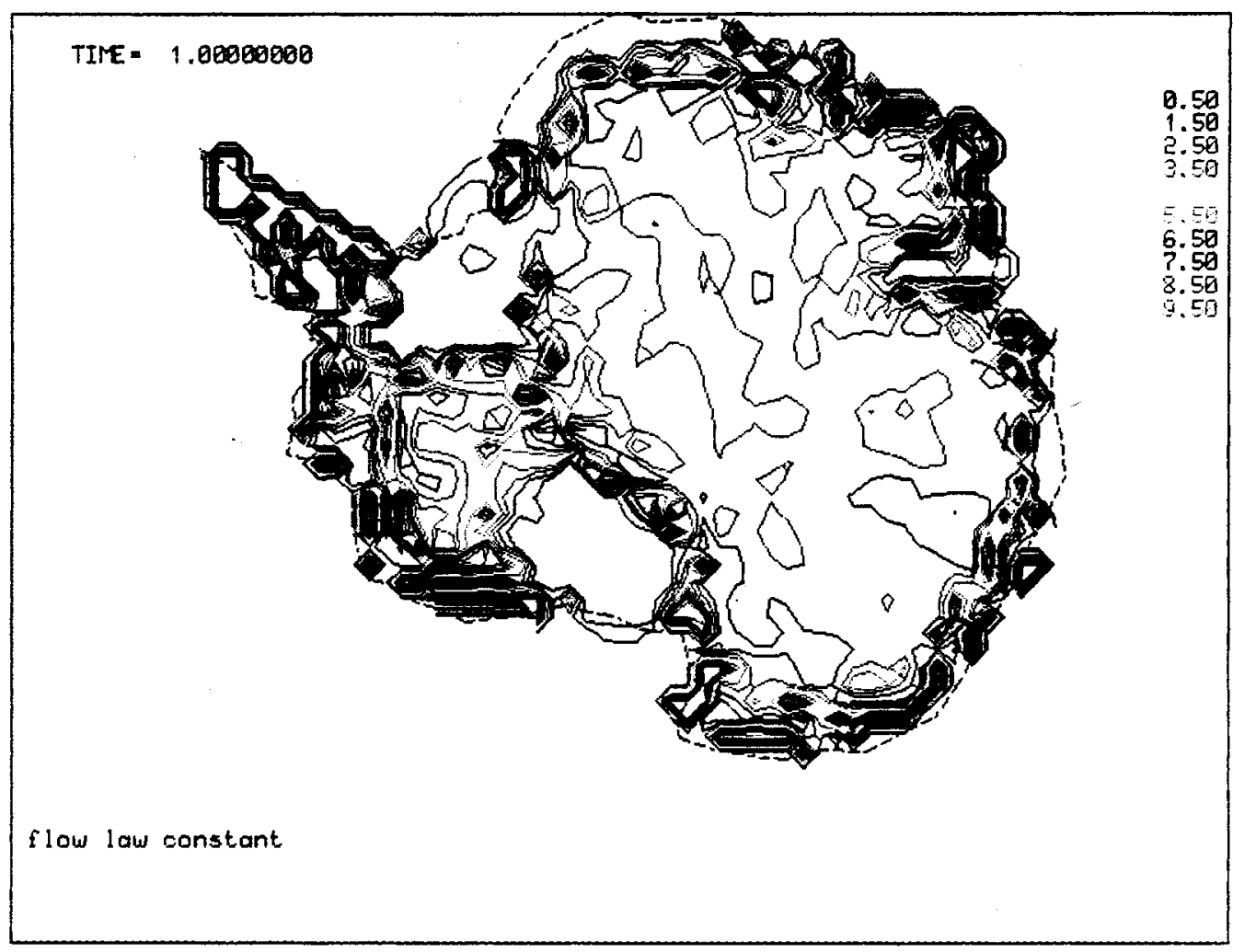

EIGURE 51. Values of Flow Law Constants in Present-Day Antarctica. Units are bar a ${ }^{1 / 3}$.

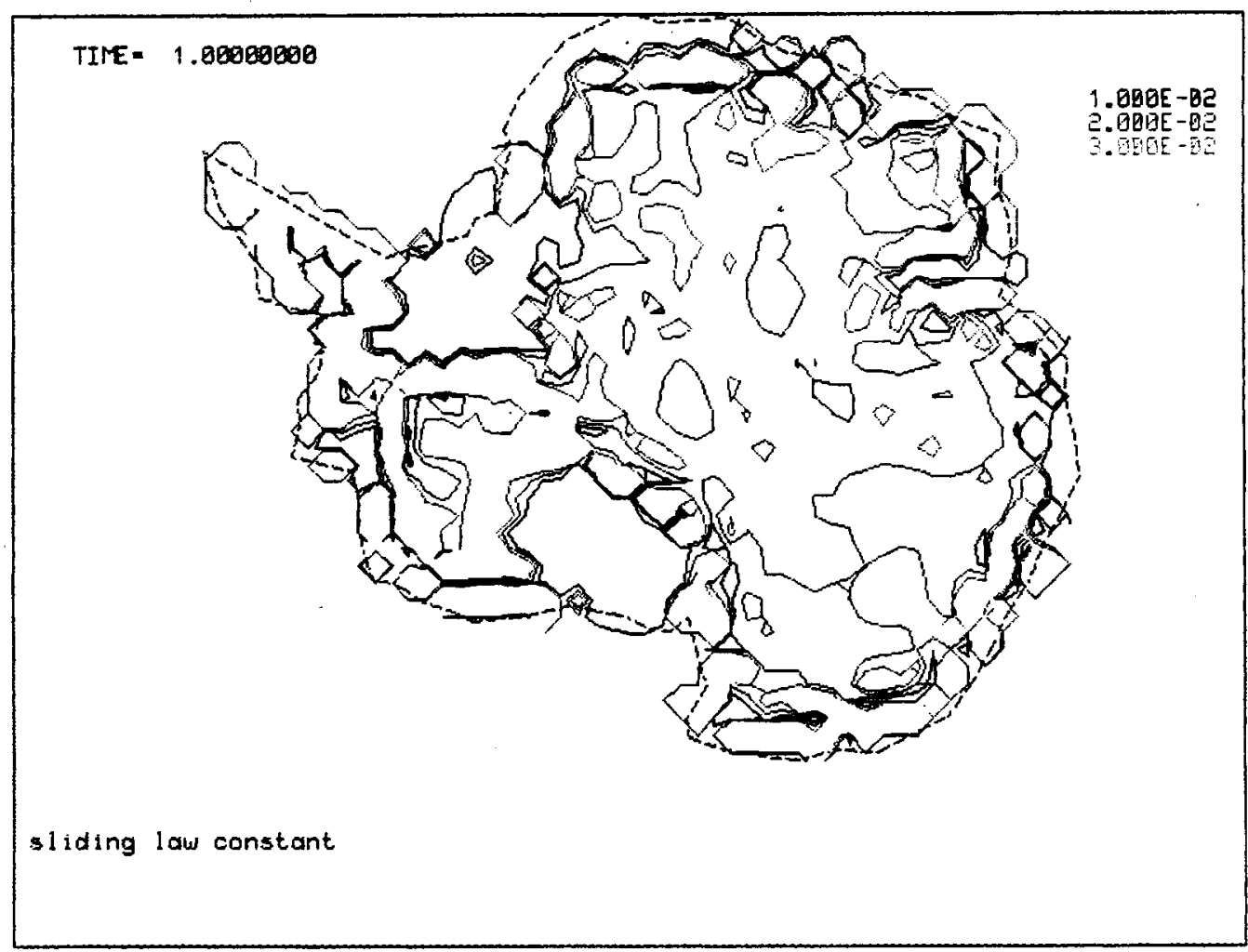

FIGURE 52. Values of Sliding Law Constants in Present-Day Antarctica. Units are bar a $1 / 2$. 


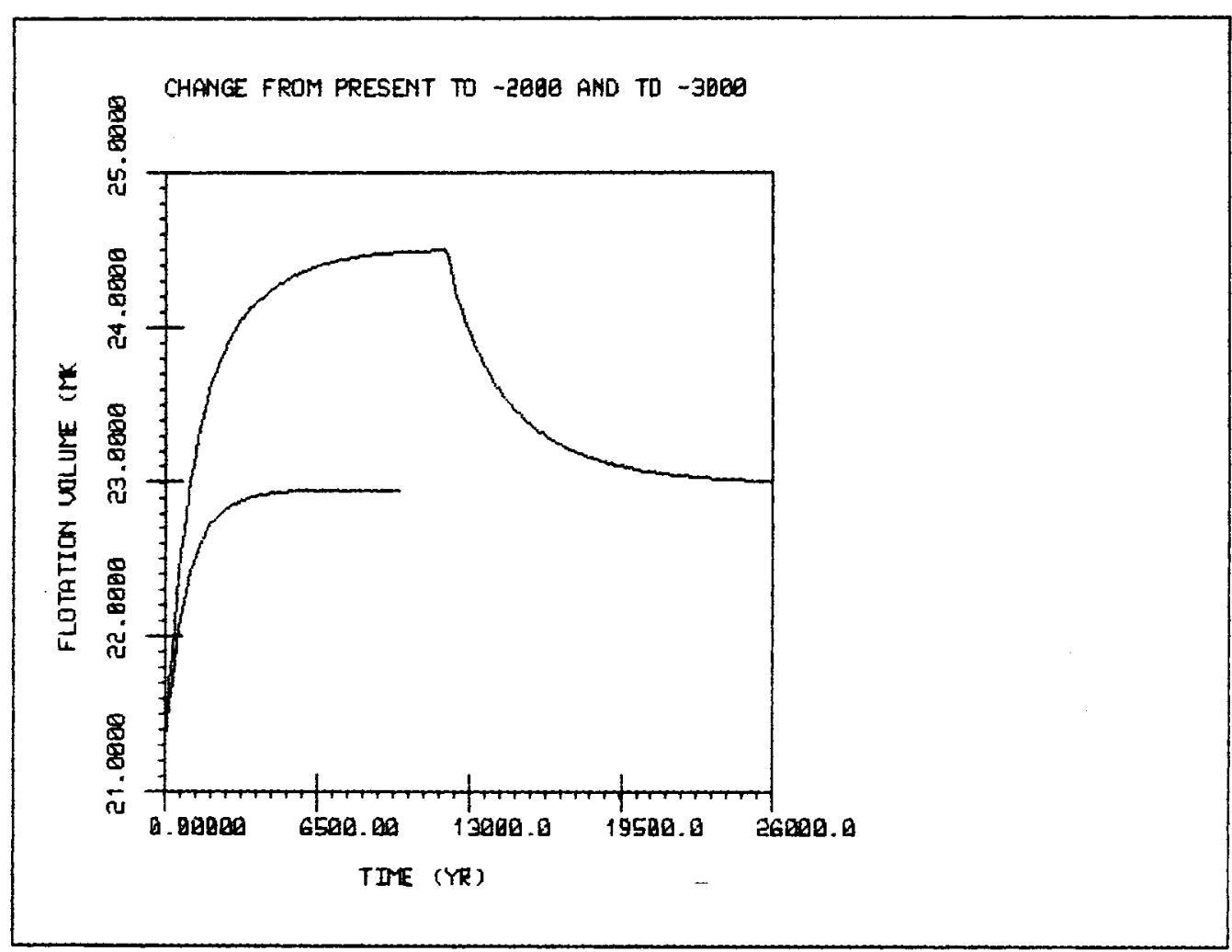

ElGURE 53. Antarctic Ice Volume Changes Over Time. Growth for South Pole snowline depression of $-2000 \mathrm{~m}$ (bottom curve). Growth for South Pole snowline depression of $-3000 \mathrm{~m}$, followed by decay when South Pole snowline elevation suddenly jumps to $-2000 \mathrm{~m}$ (top curve). Growth in both cases is caused by suppressing ice calving rates. 


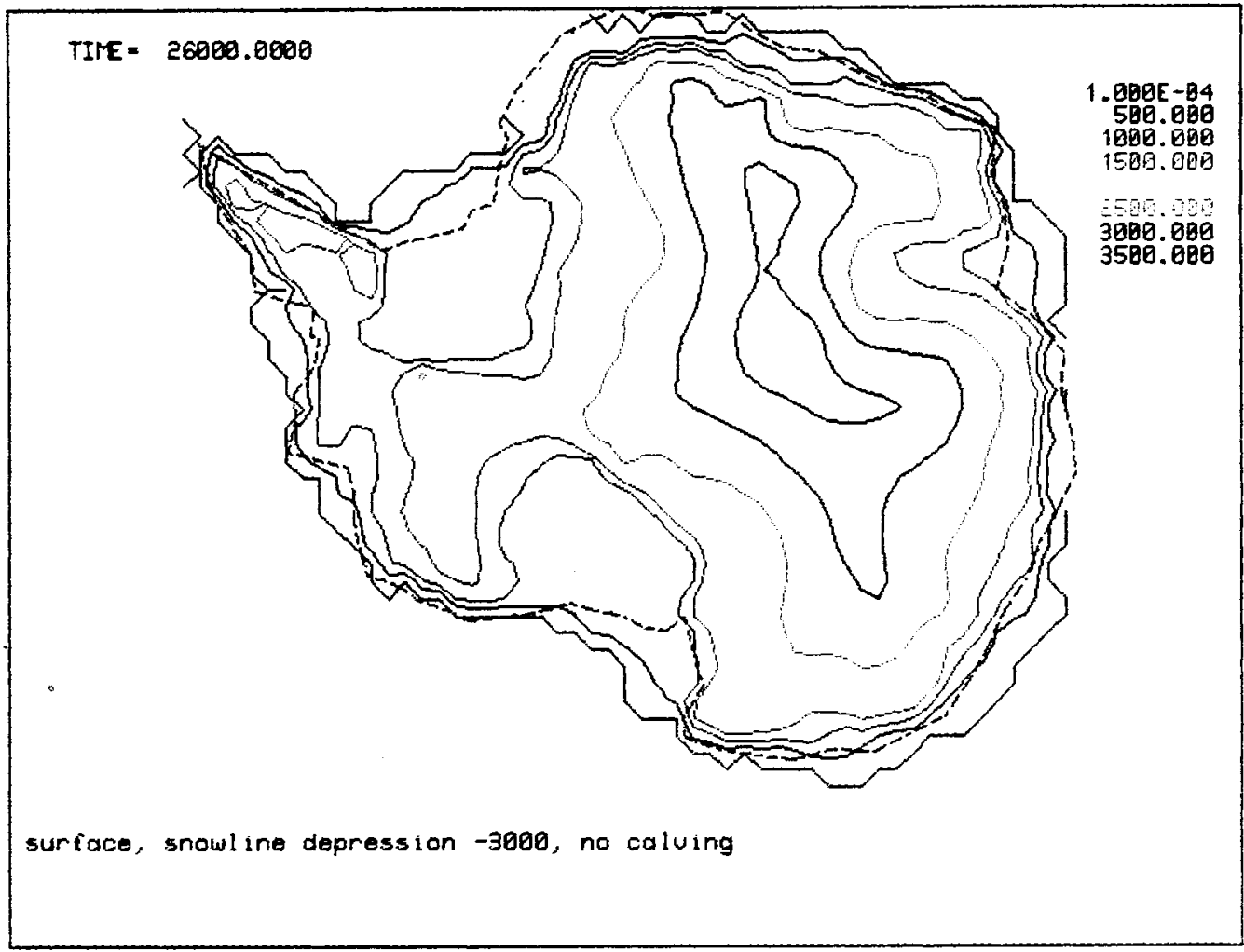

EIGURE 54. Antarctica for a South Pole Snowline at $-3000 \mathrm{~m}$ and No Calving. Ice elevation contour are every $500 \mathrm{~m}$.

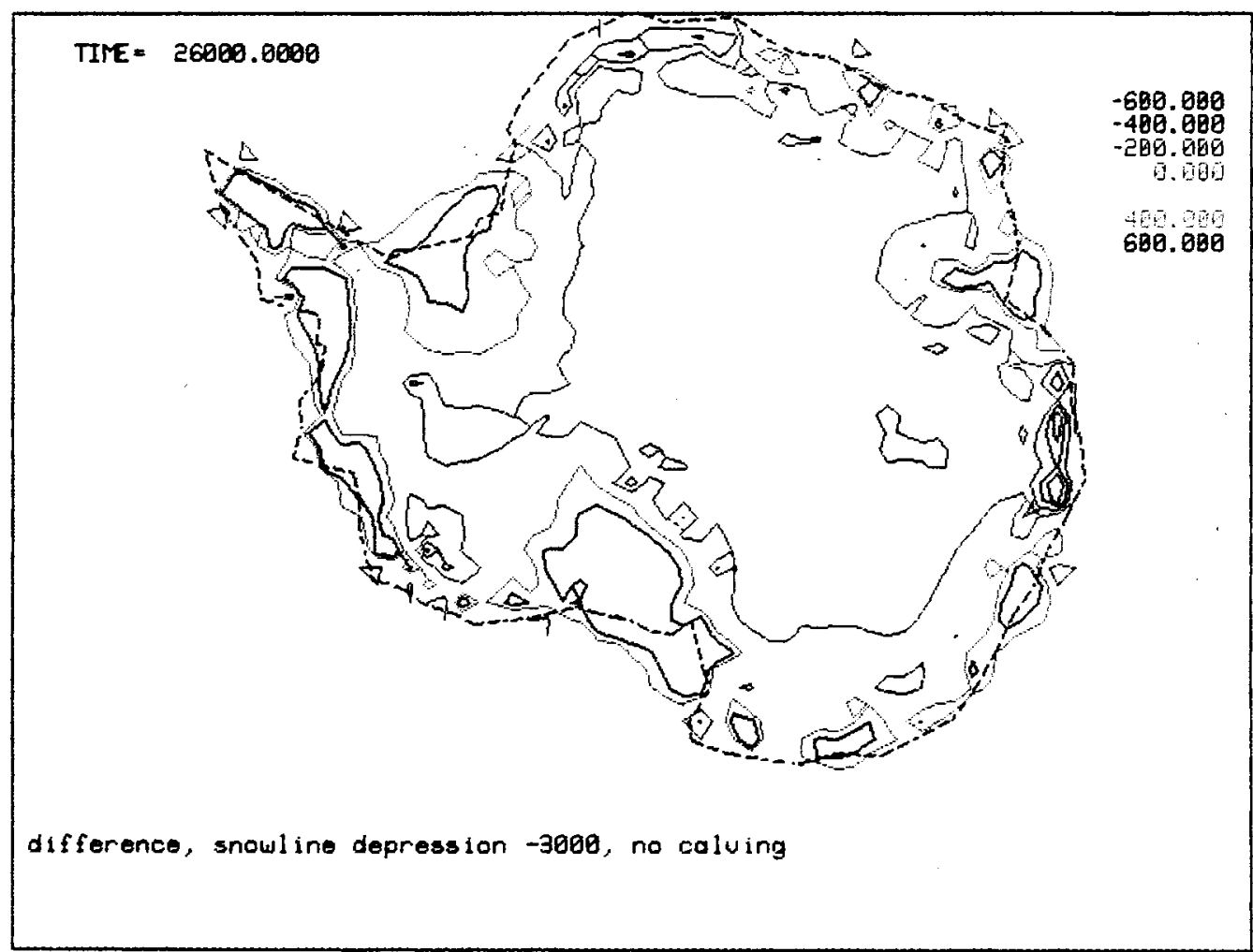

FIGURE 55. Elevation Differences Between Figures 47 and 54. Contours $(\mathrm{m})$ show regions higher $(+)$ and lower $(-)$ than at present. 


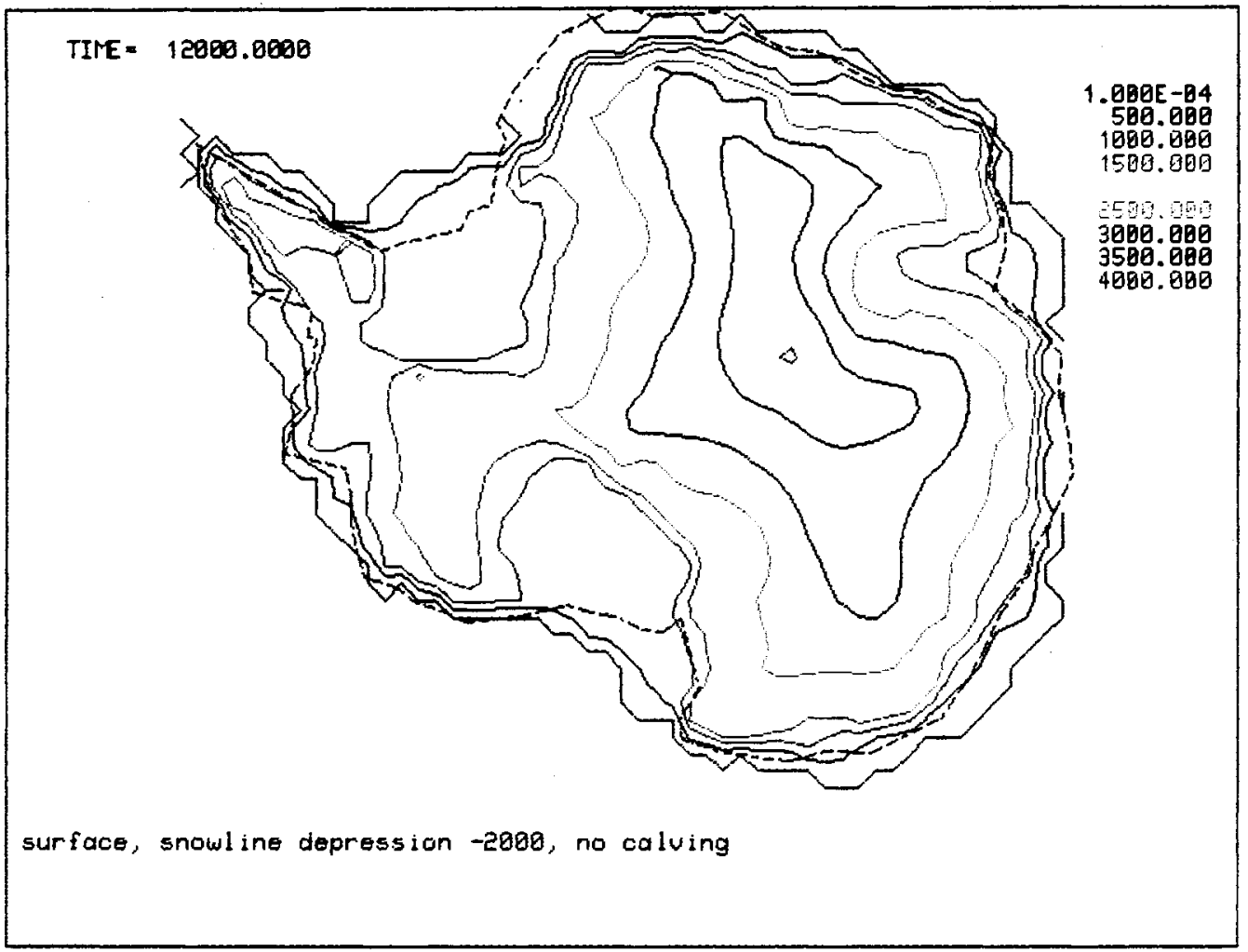

ElGURE 56. Antarctica for a South Pole Snowline at $-2000 \mathrm{~m}$ and No Calving. Ice elevation contours are every $500 \mathrm{~m}$.

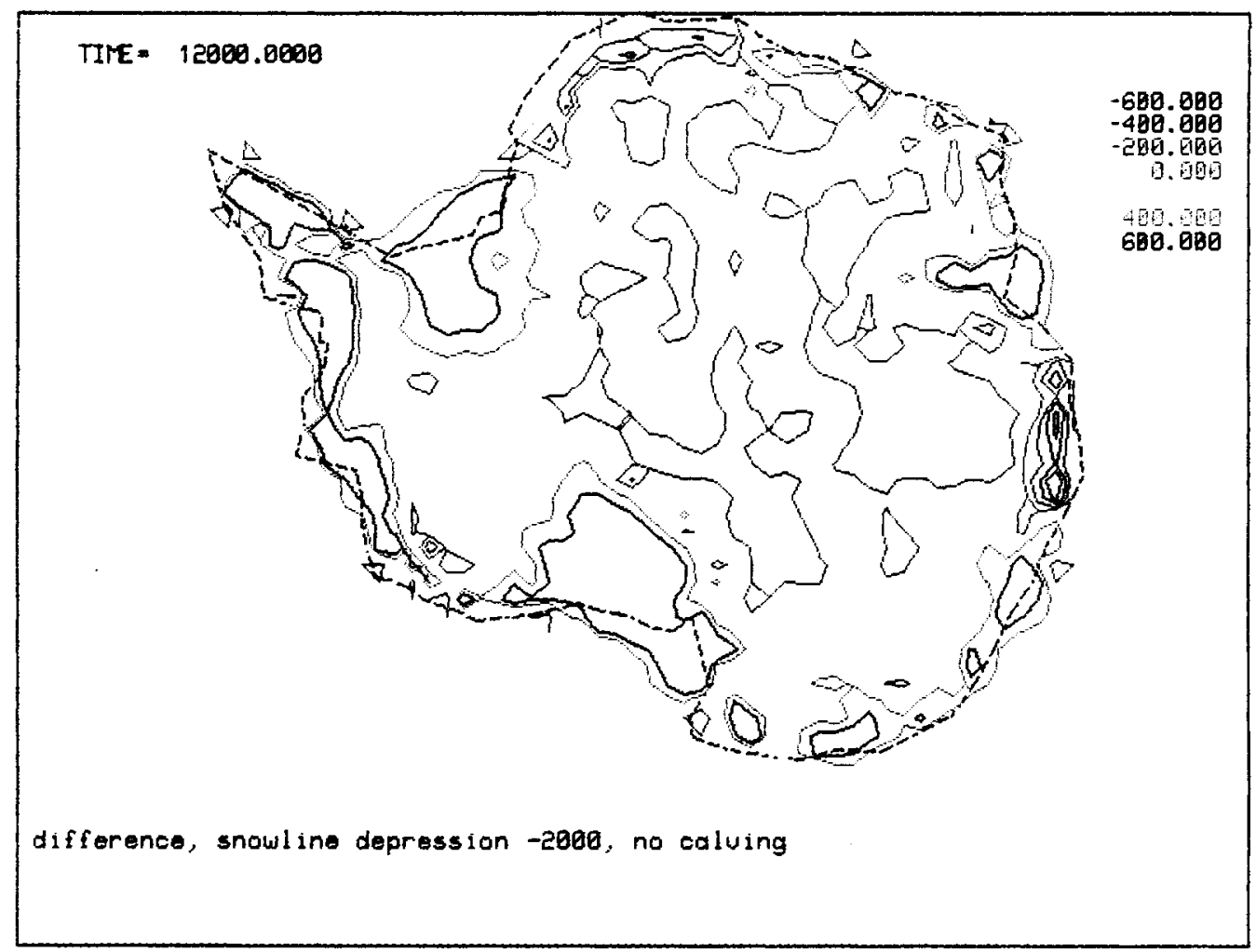

FIGURE 57. Elevation Differences Between Figures 47 and 56. Contours (m) show regions higher $(+)$ and lower $(-)$ than at present. 


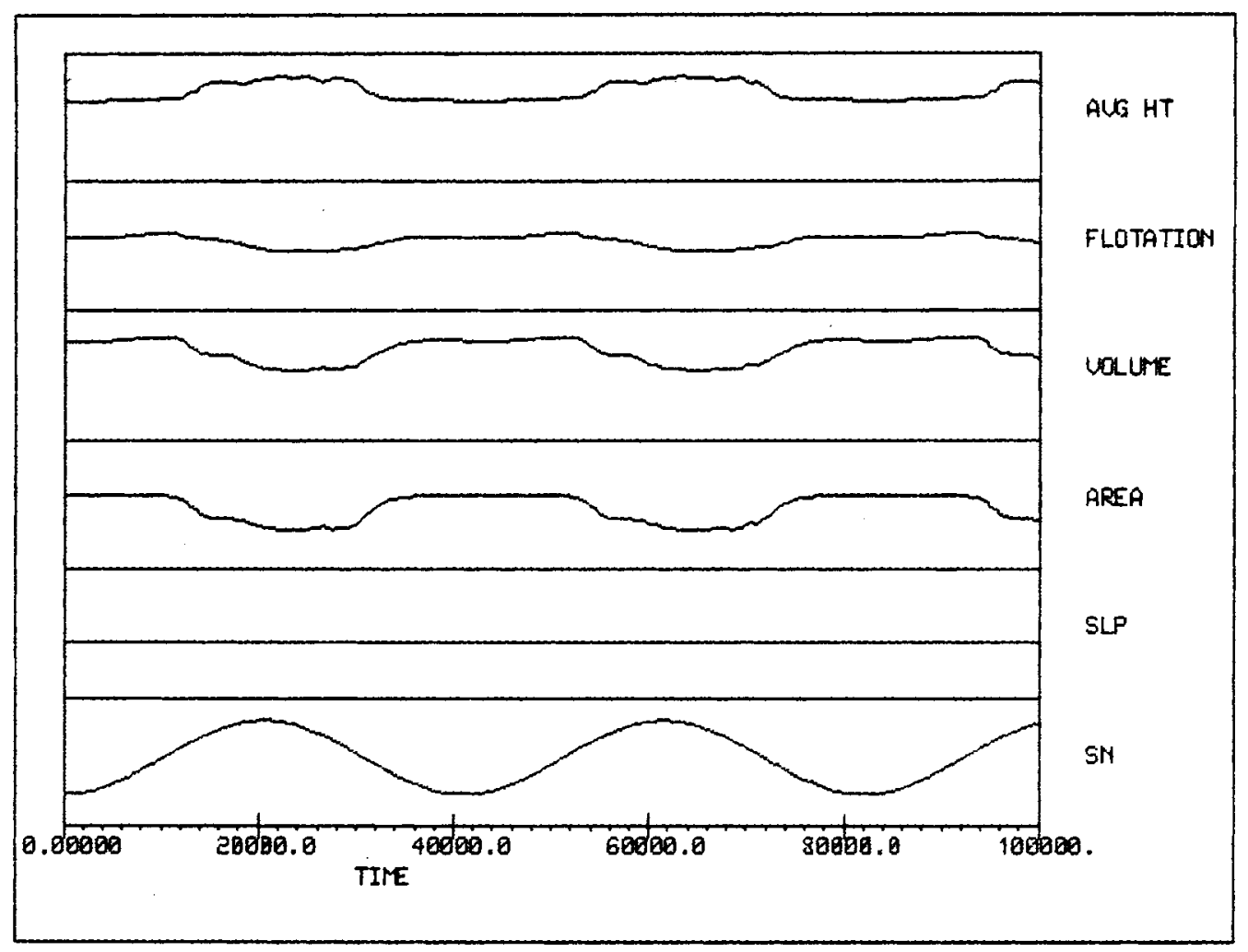

EIGURE 58. Antarctic Model Input and Output When Tilt Dominates. Variations over 100,000 years are shown for average ice-sheet height (AVG HT), icesheet volume contributing to sea level (FLOTATION), total ice-sheet volume (VOLUME), areal extent (AREA), sliding law parameter (SLP), and South Pole snowline elevation (SN). 


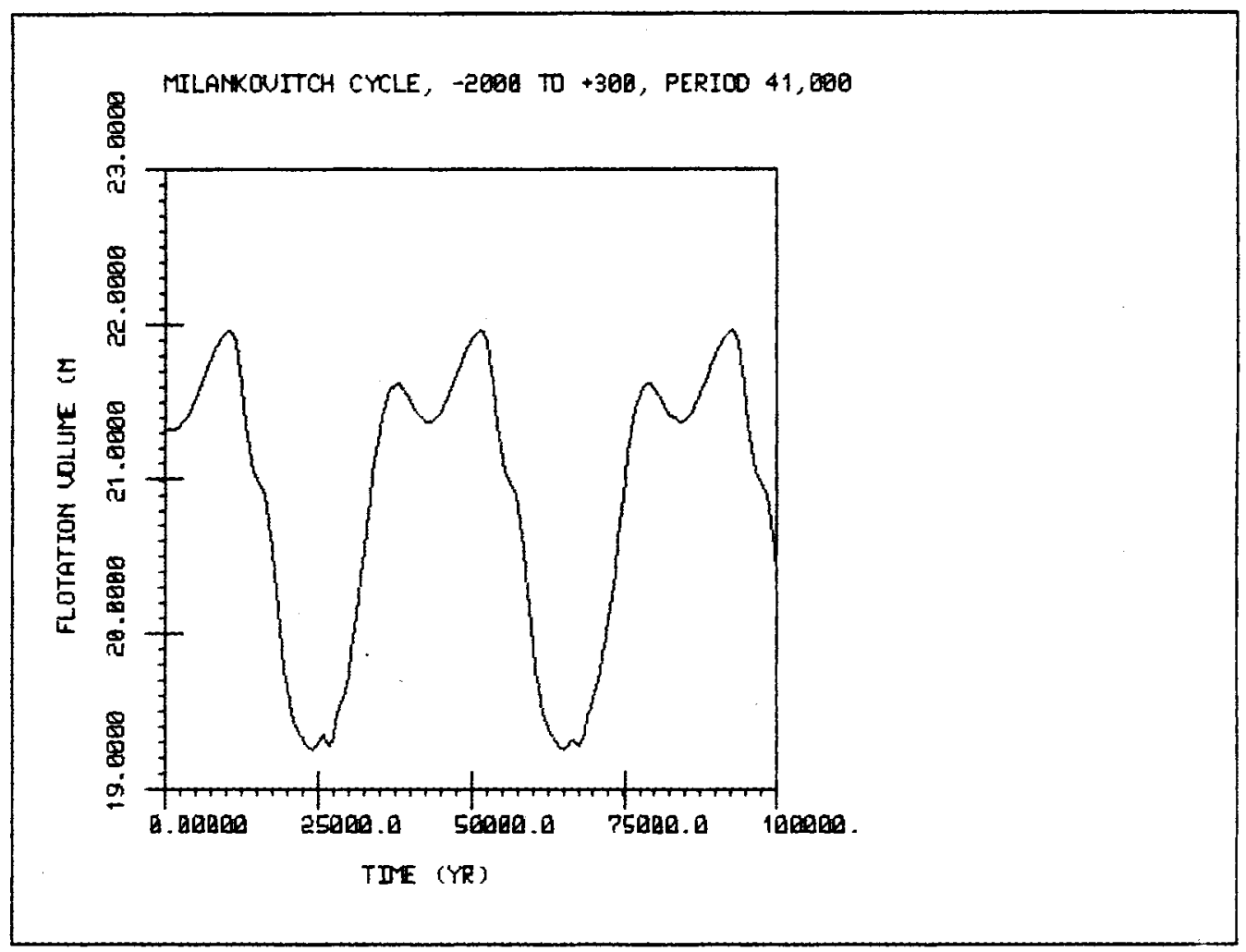

ElGURE 59. Antarctic Flotation Ice Volume Over Time When Tilt Dominates. South Pole snowline amplitude of $-2000 \mathrm{~m}$ to $+300 \mathrm{~m}$ in cycle of 41,000 years. 


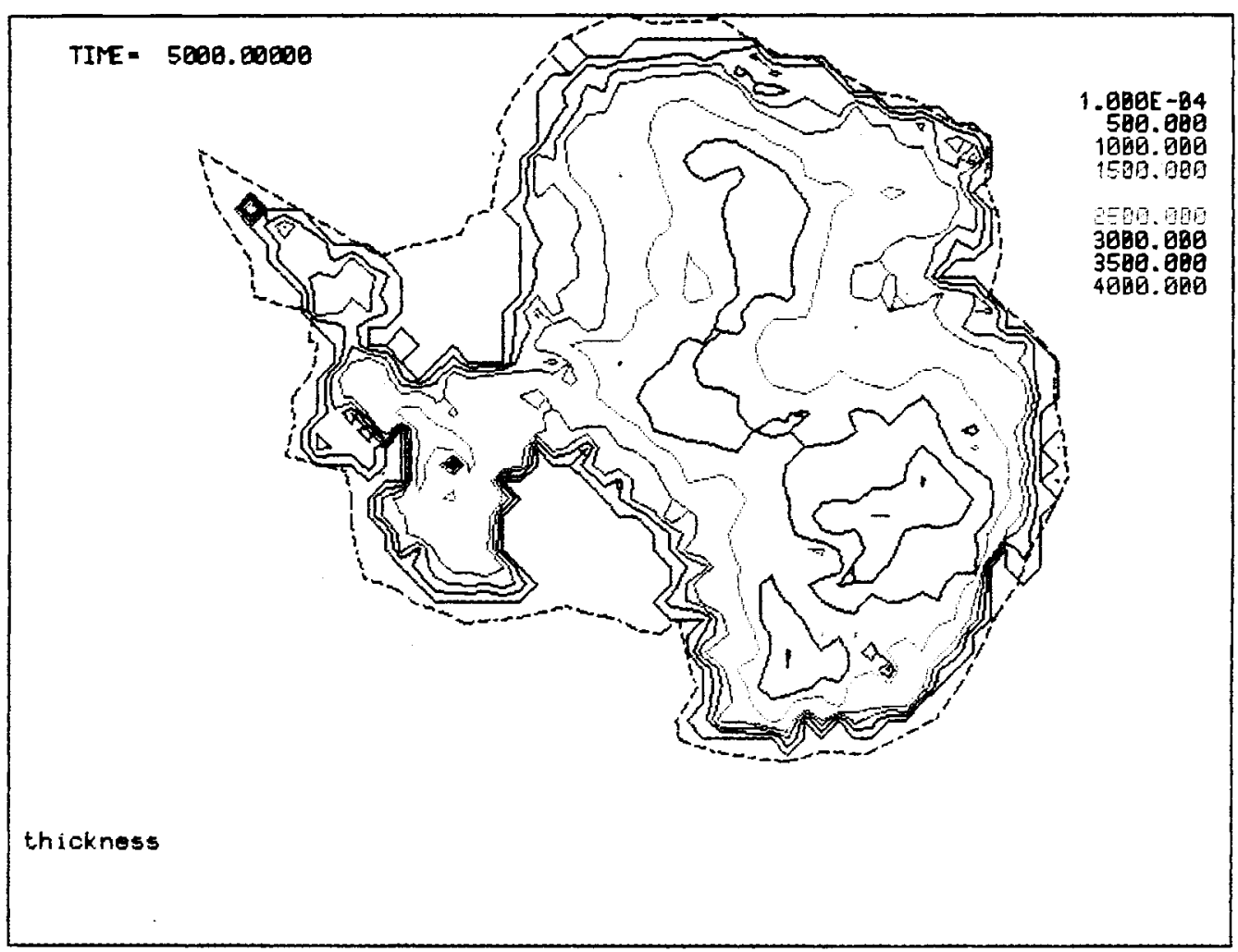

a) Ice Thickness at 5000 years

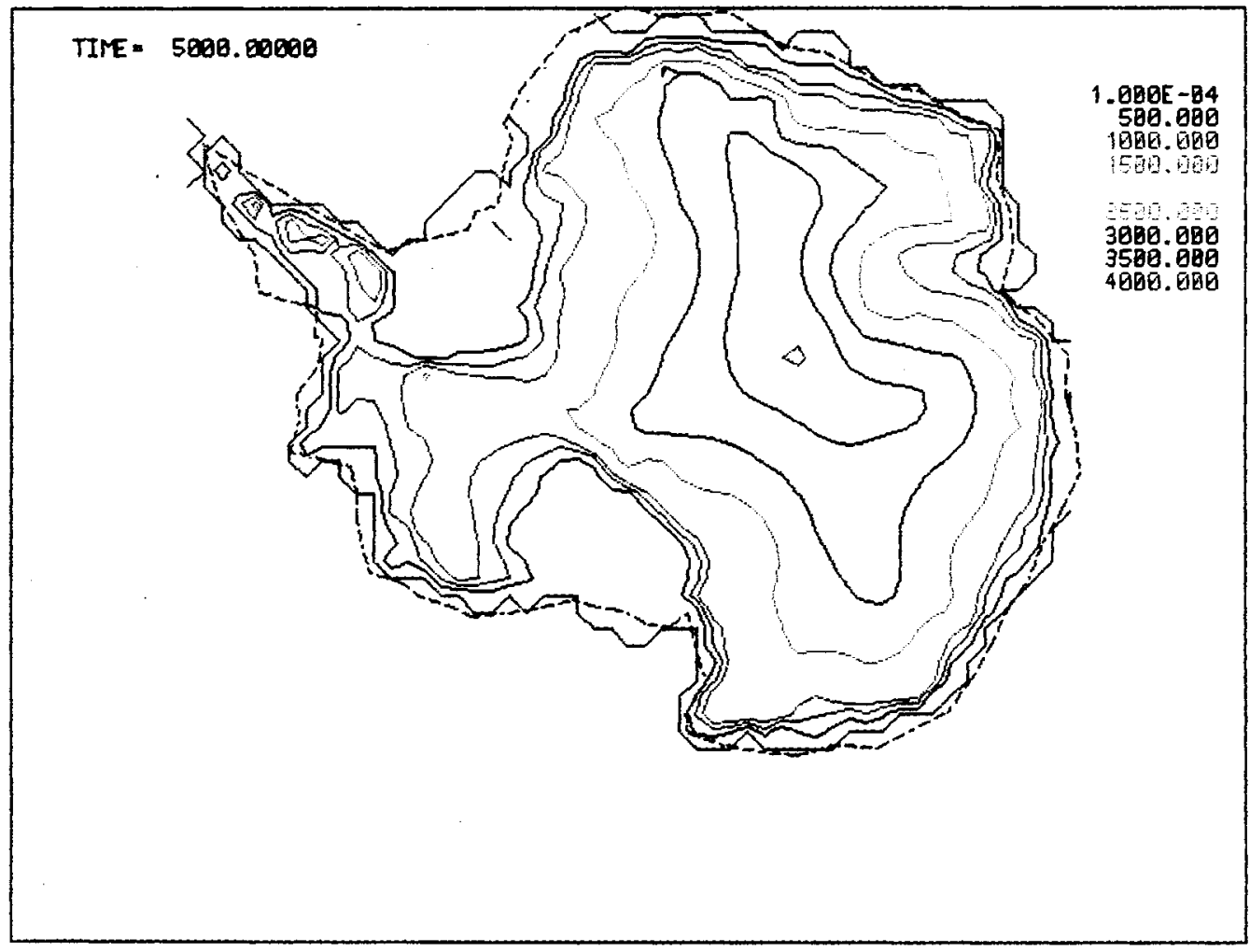

b) Ice and Land Elevation at 5000 years

FIGURE 60. Antarctic Ice Thicknesses and Elevations Over Time When Tilt Dominates. Contours every $500 \mathrm{~m}$. 


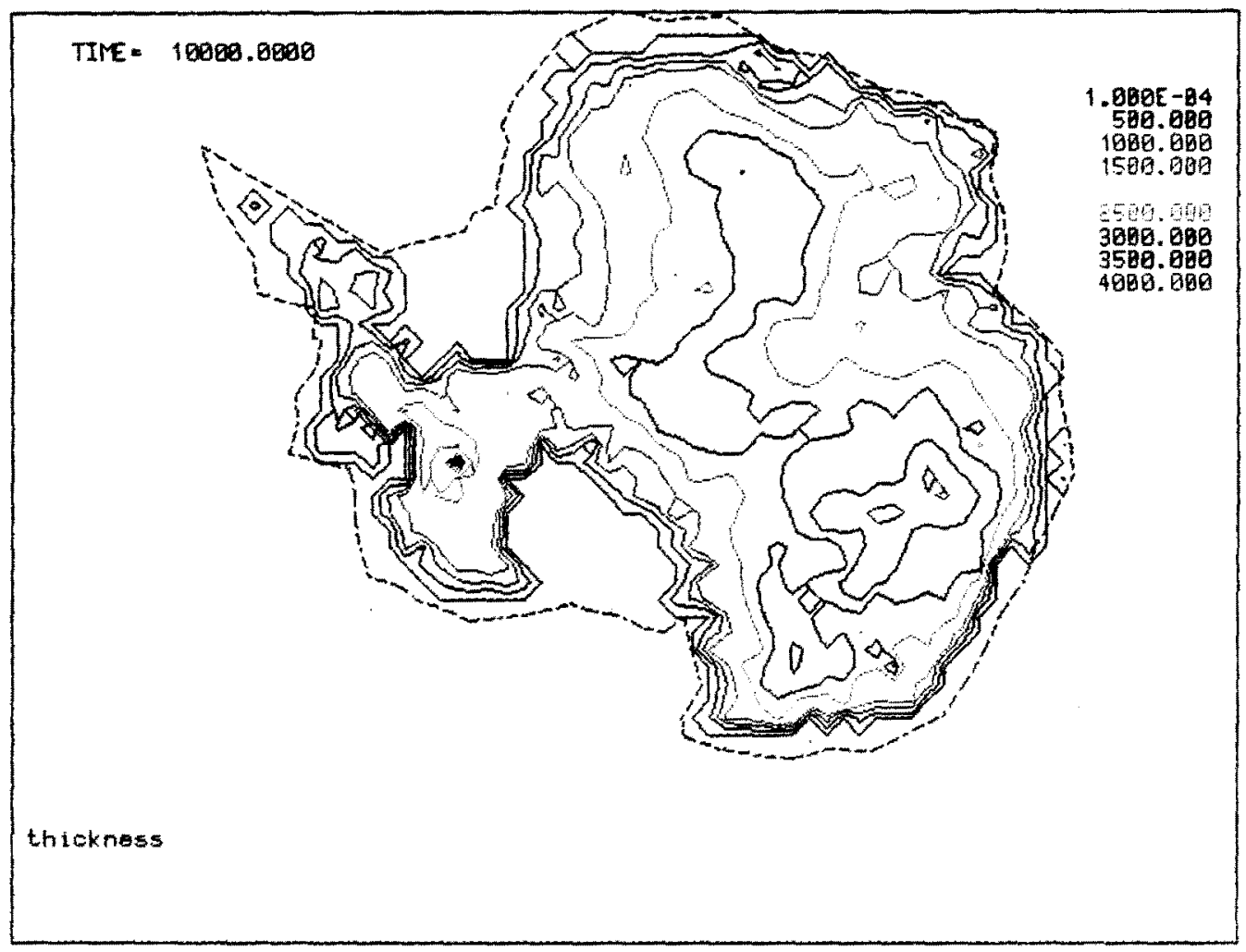

c) Ice Thickness at 10,000 years

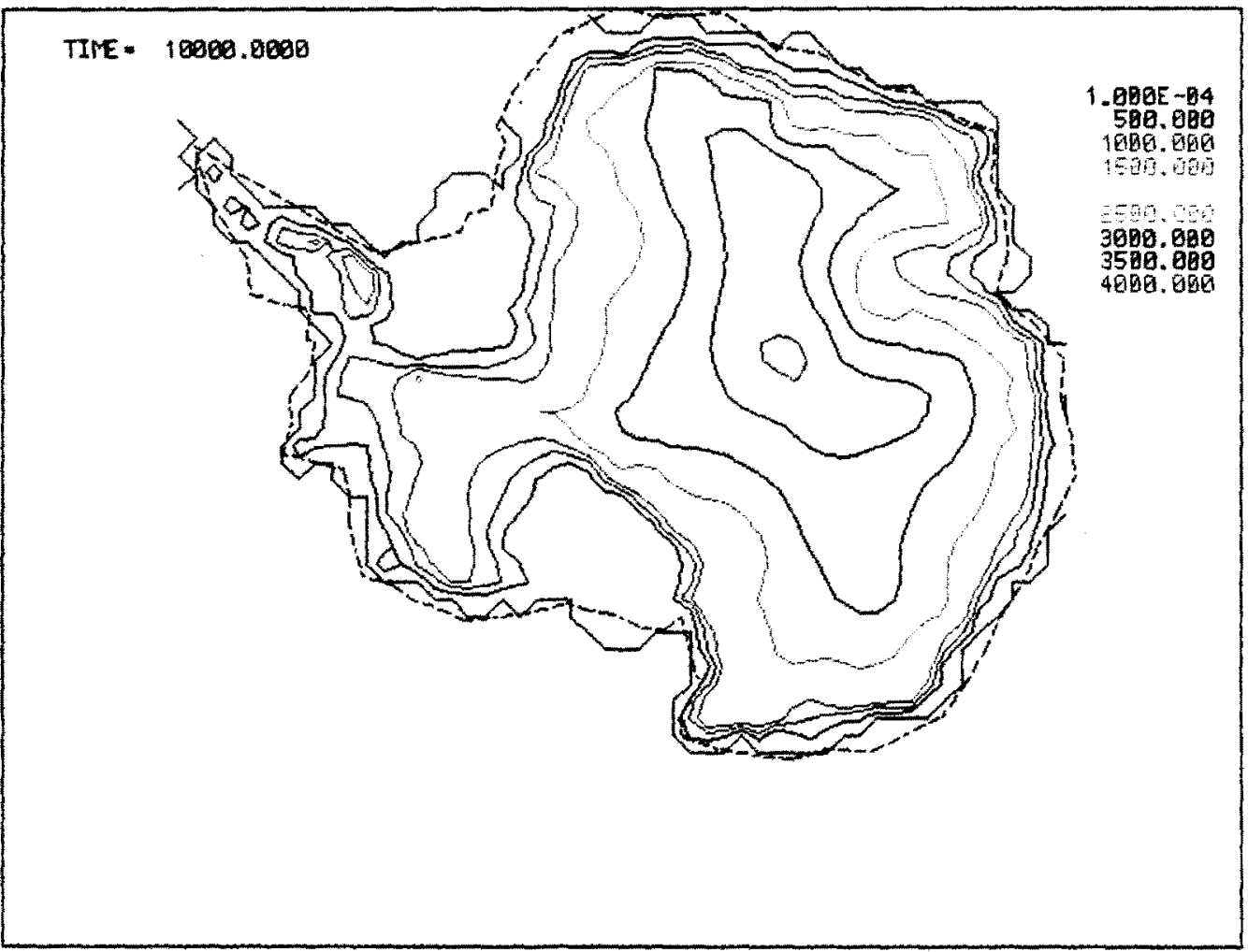

d) Ice and Land Elevation at 10,000 years 


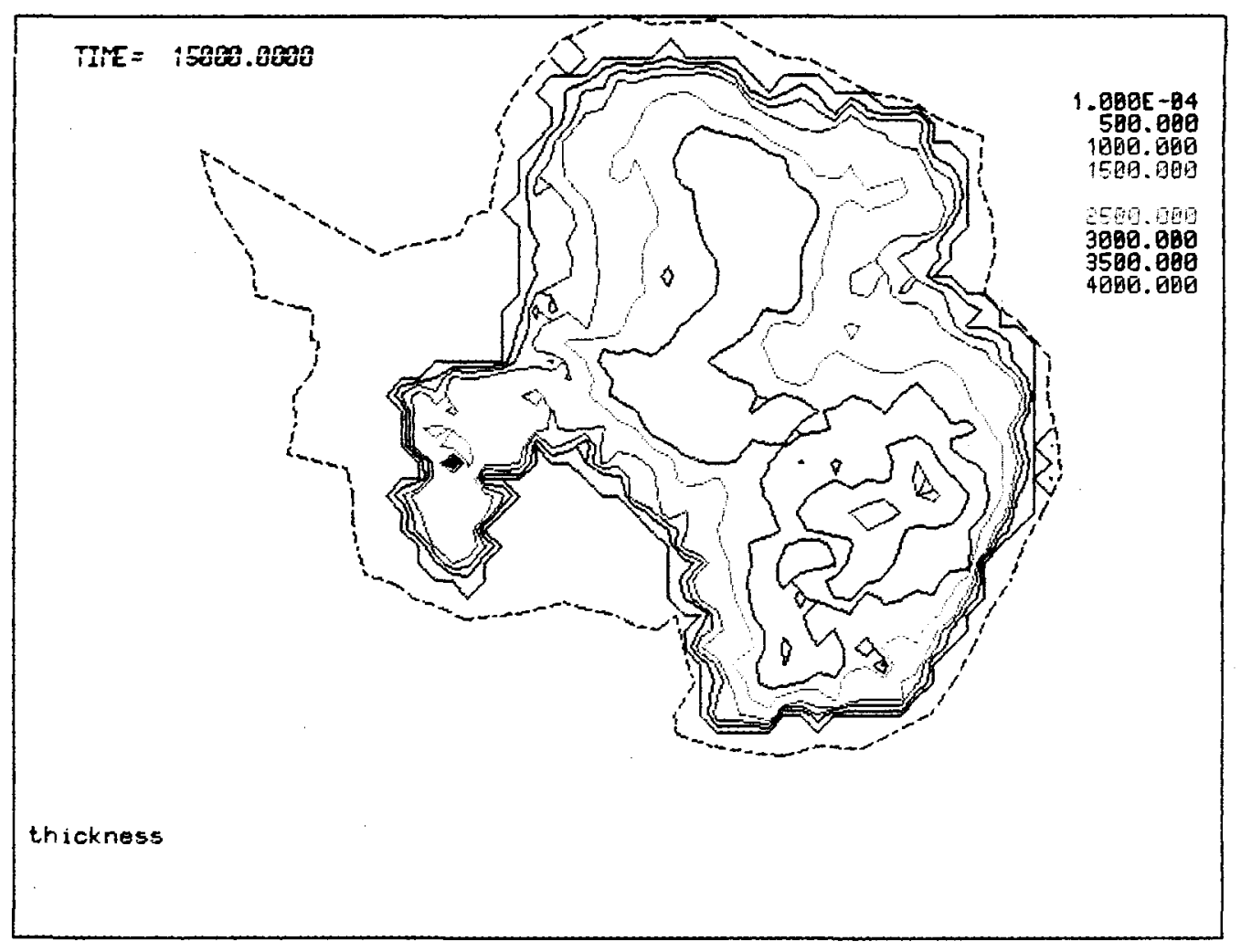

e) Ice Thickness at 15,000 years

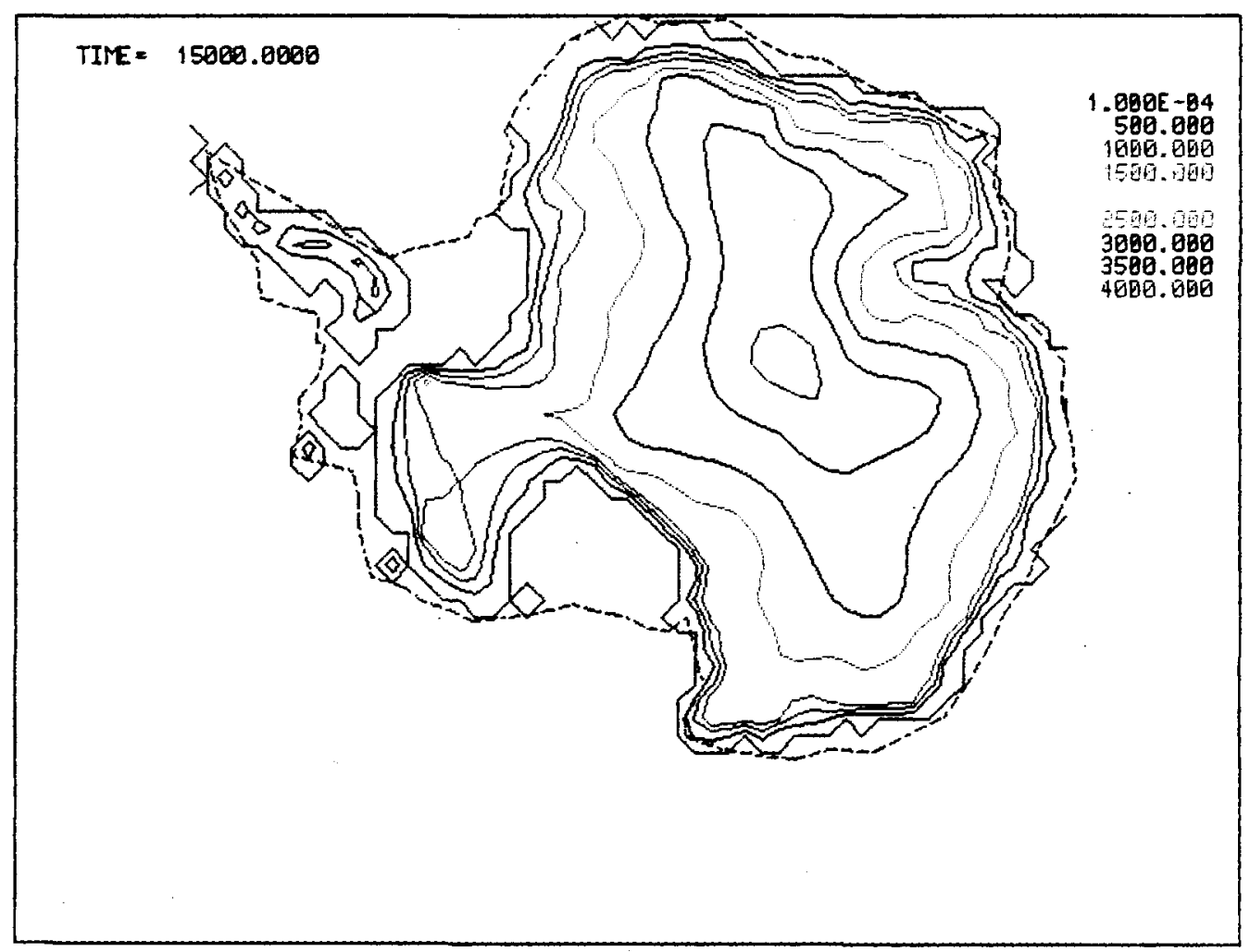

f) Ice and Land Elevation at 15,000 years 


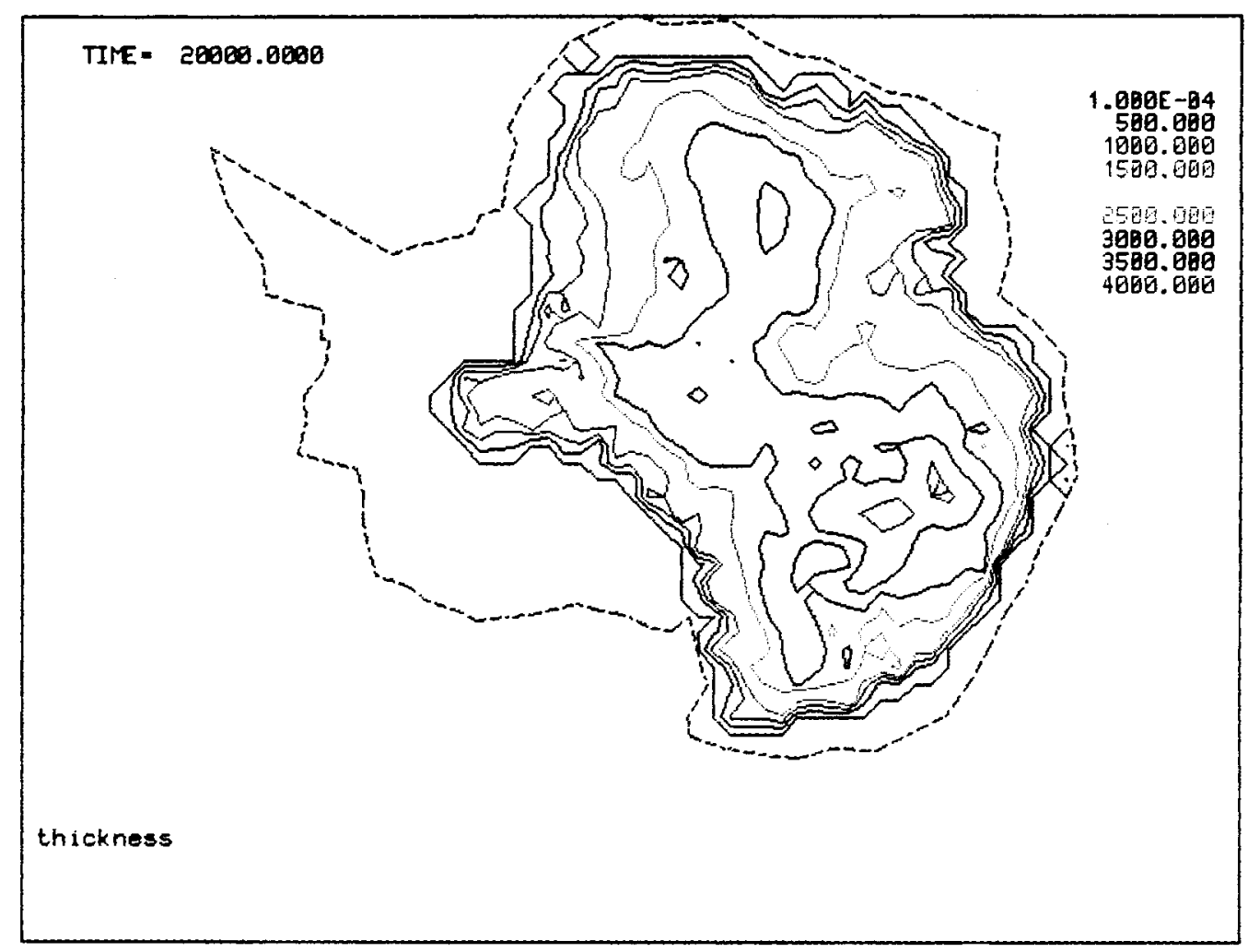

g) Ice Thickness at 20,000 years

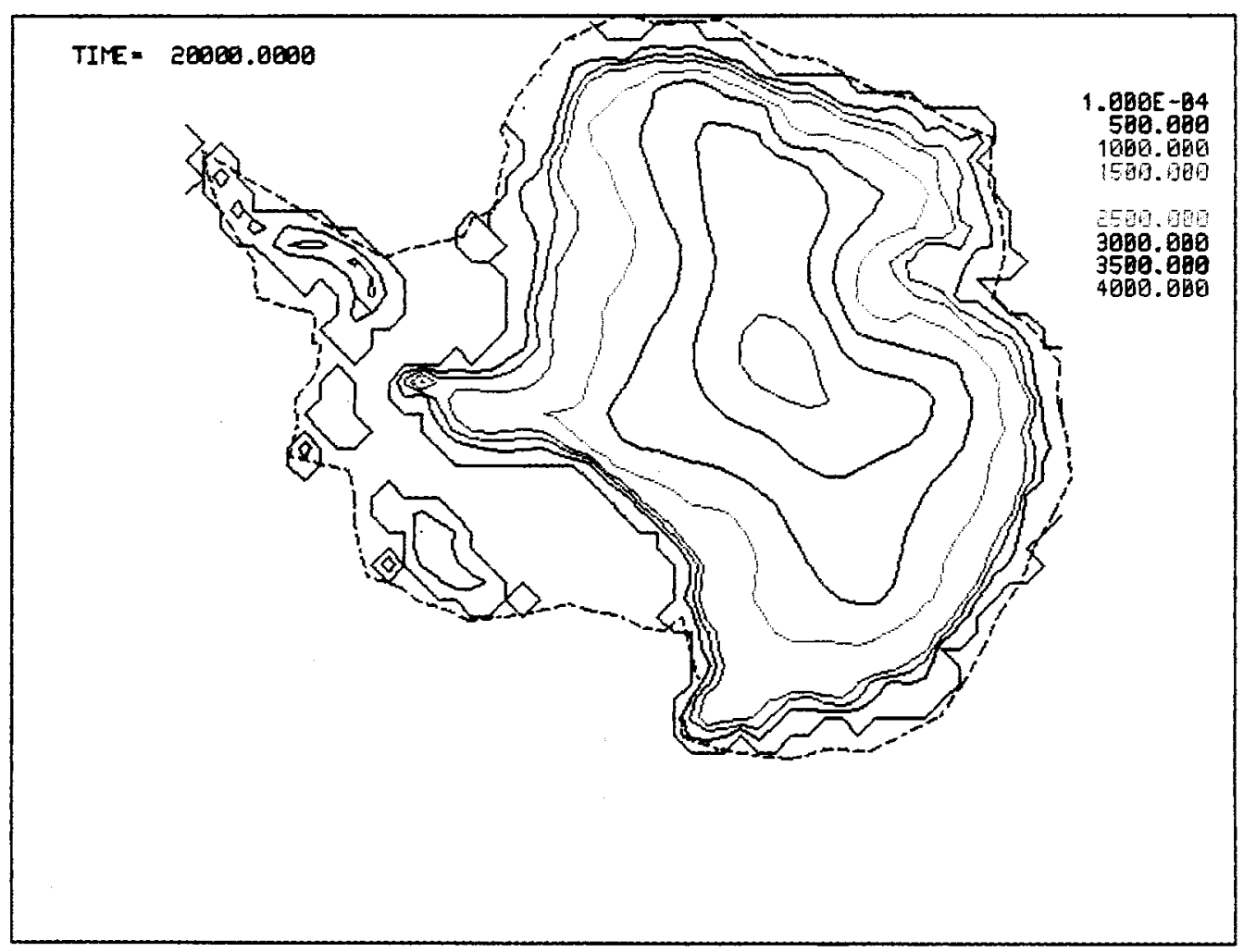

h) Ice and Land Elevation at 20,000 years 


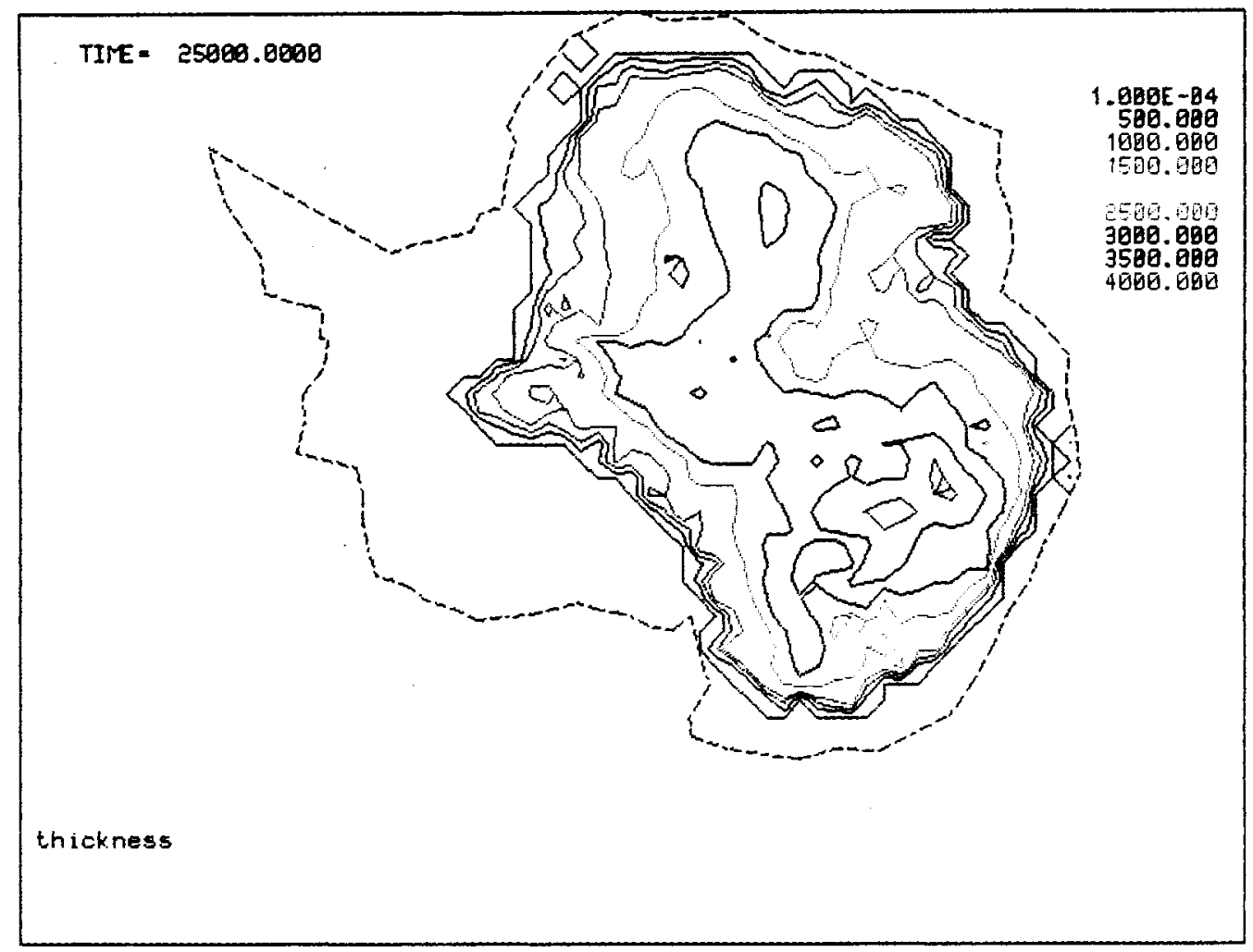

i) Ice Thickness at 25,000 years

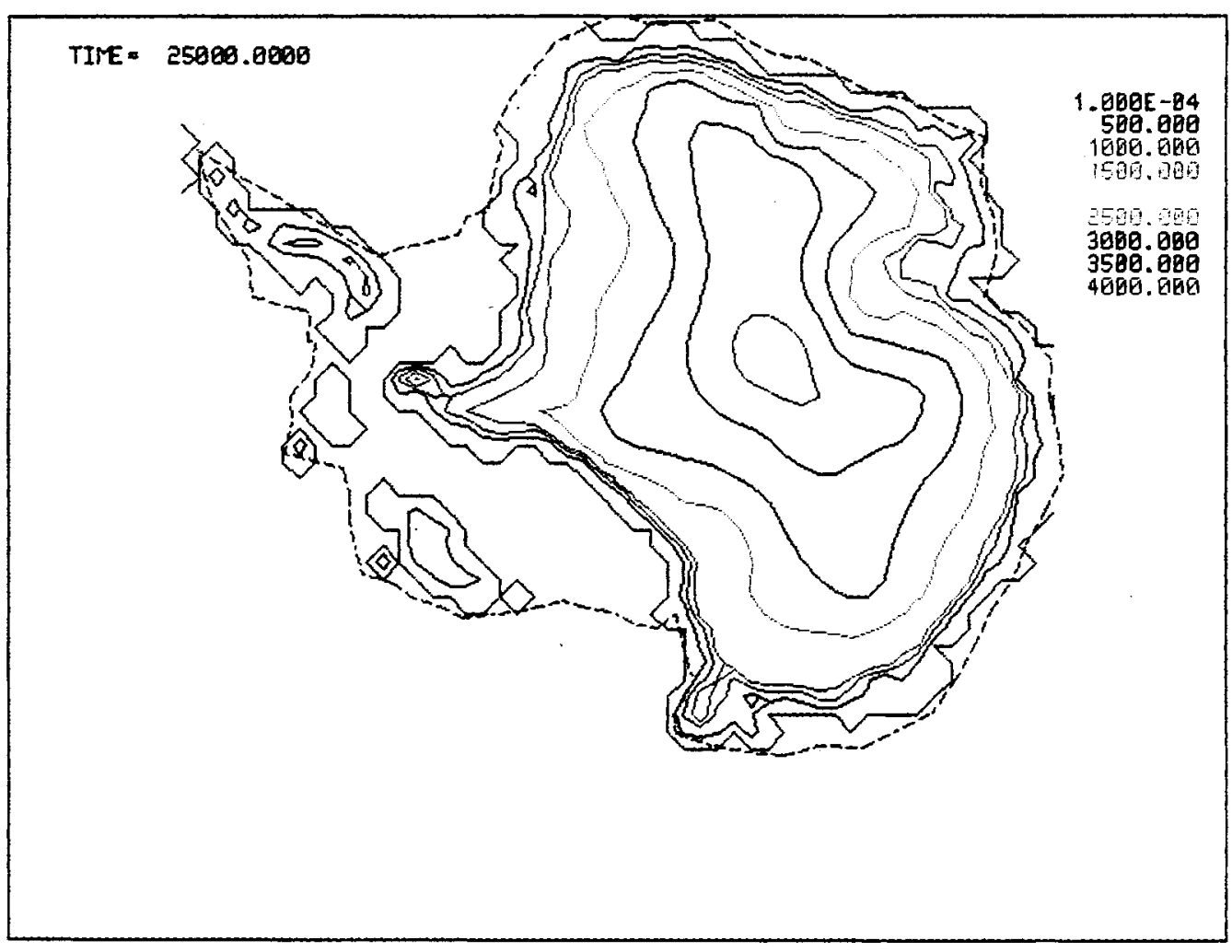

j) Ice and Land Elevation at 25,000 years 


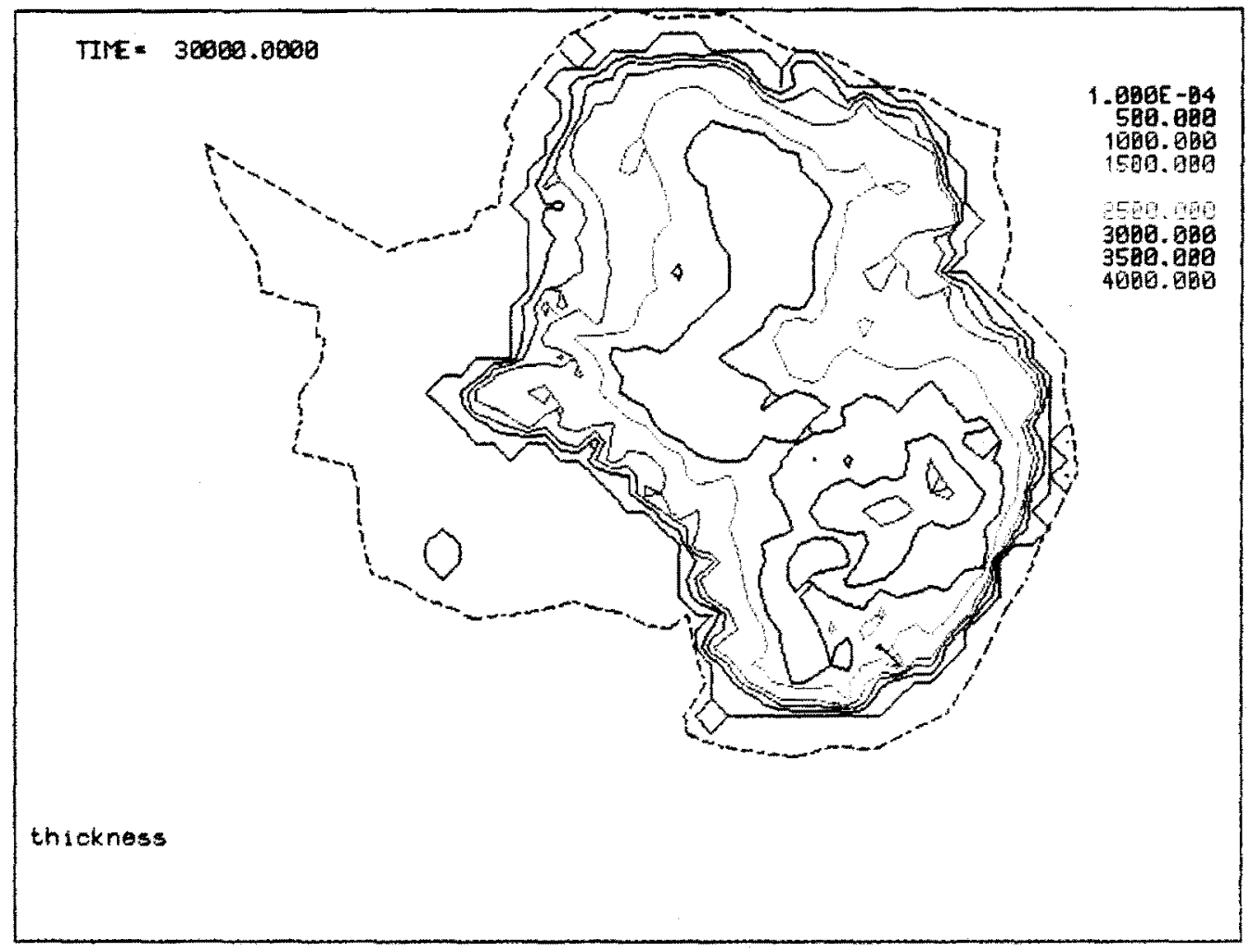

\section{k) Ice Thickness at 30,000 years}

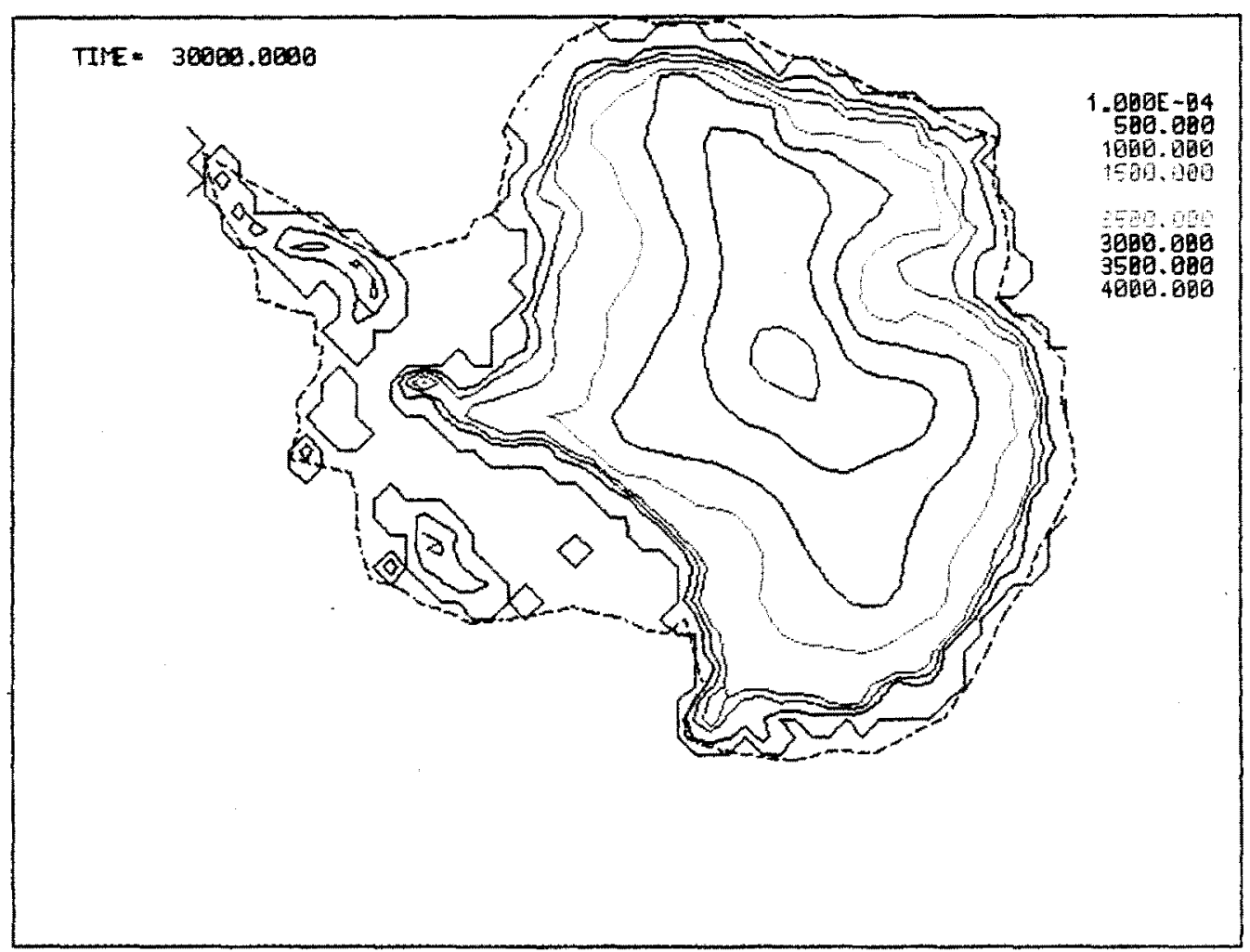

1) Ice and Land Elevation at 30,000 years 


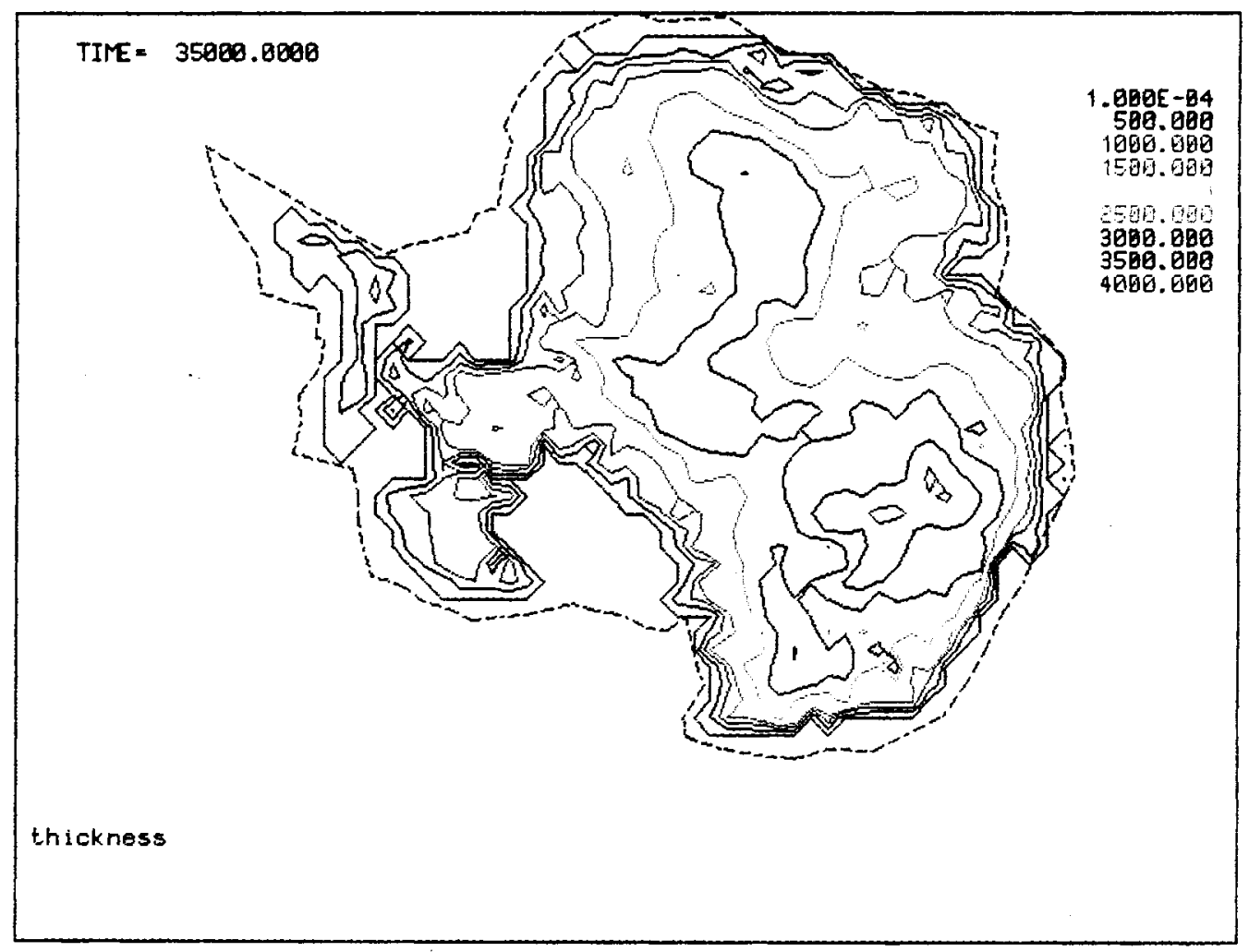

m) Ice Thickness at 35,000 years

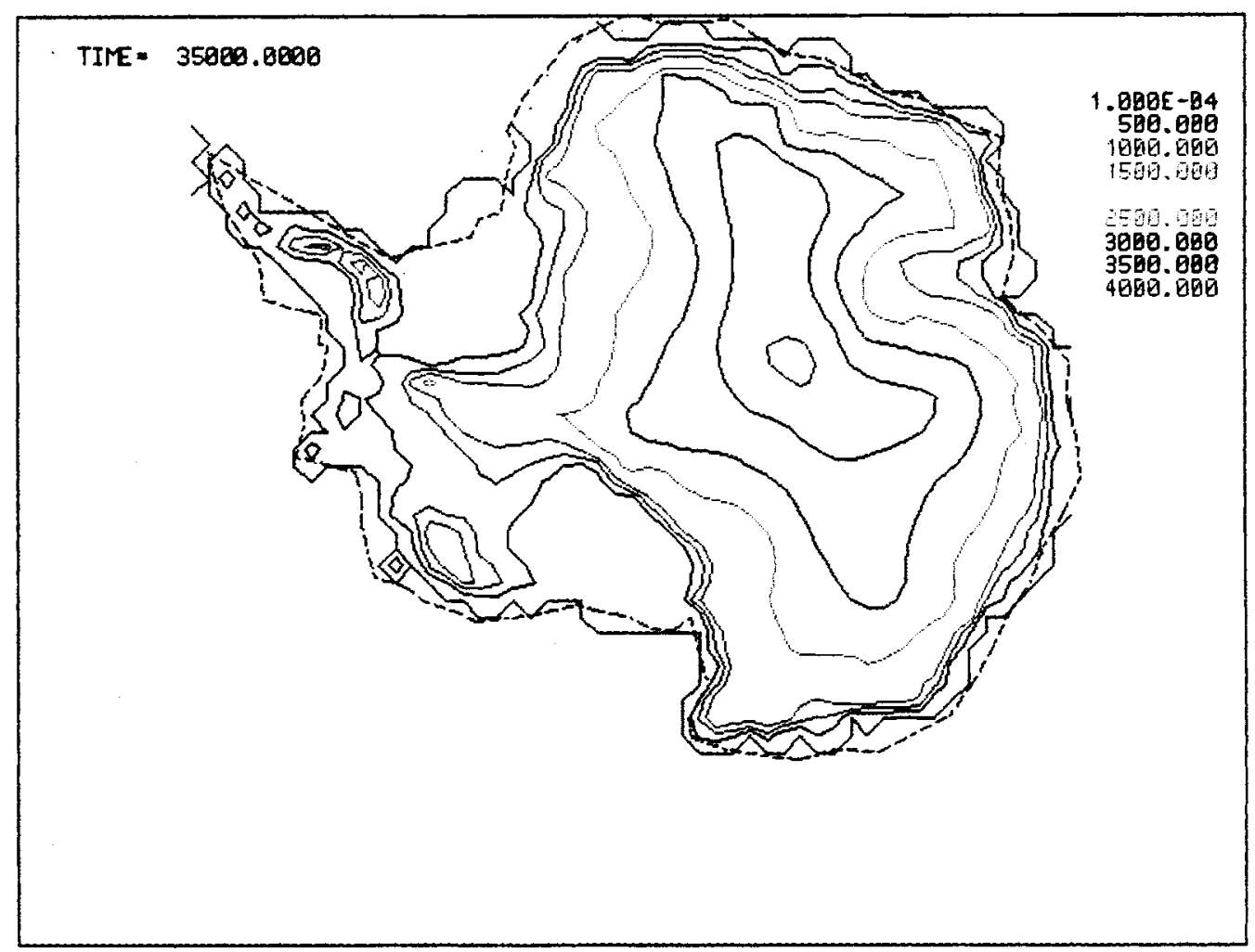

n) Ice and Land Elevation at 35,000 years 


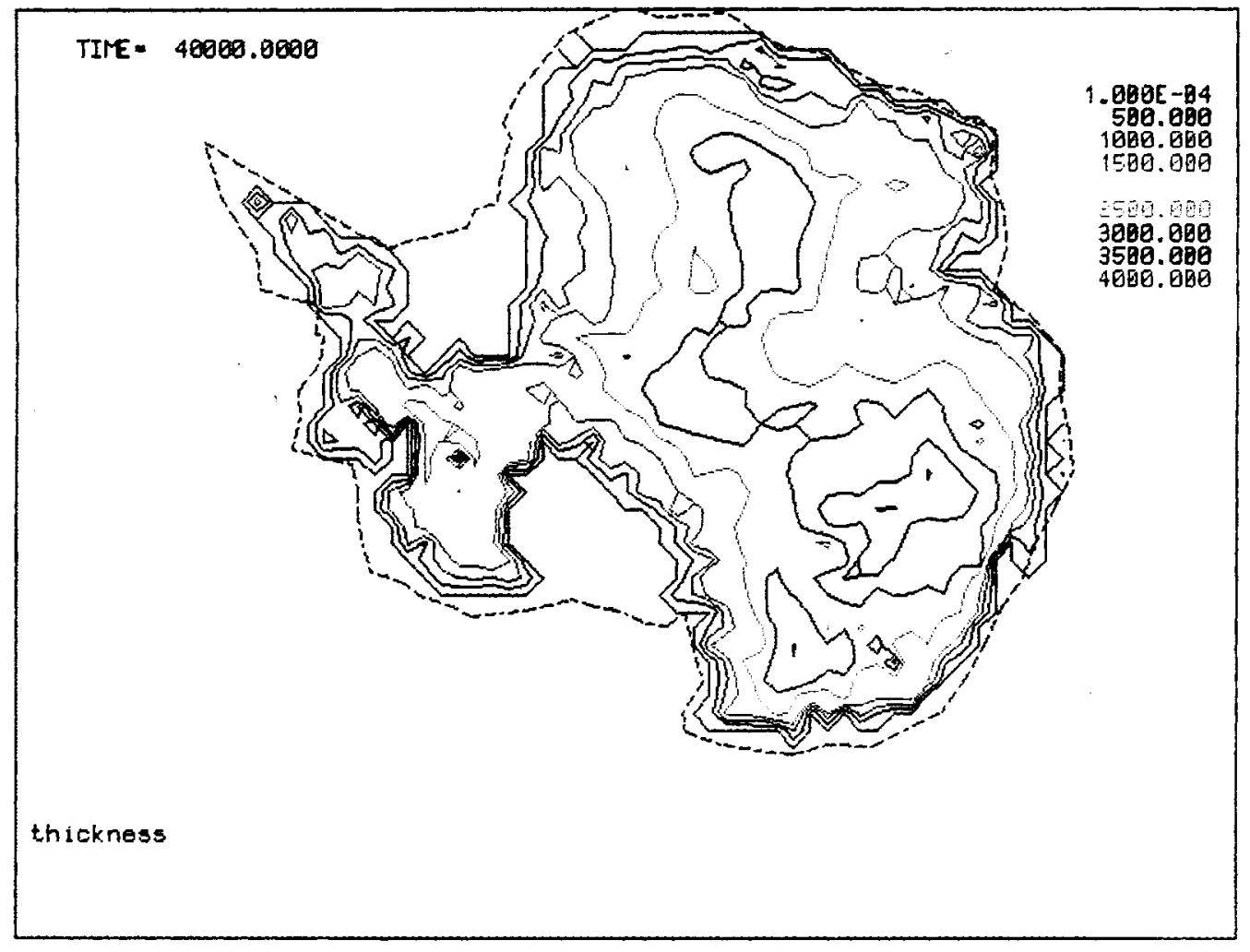

o) Ice Thickness at 40,000 years

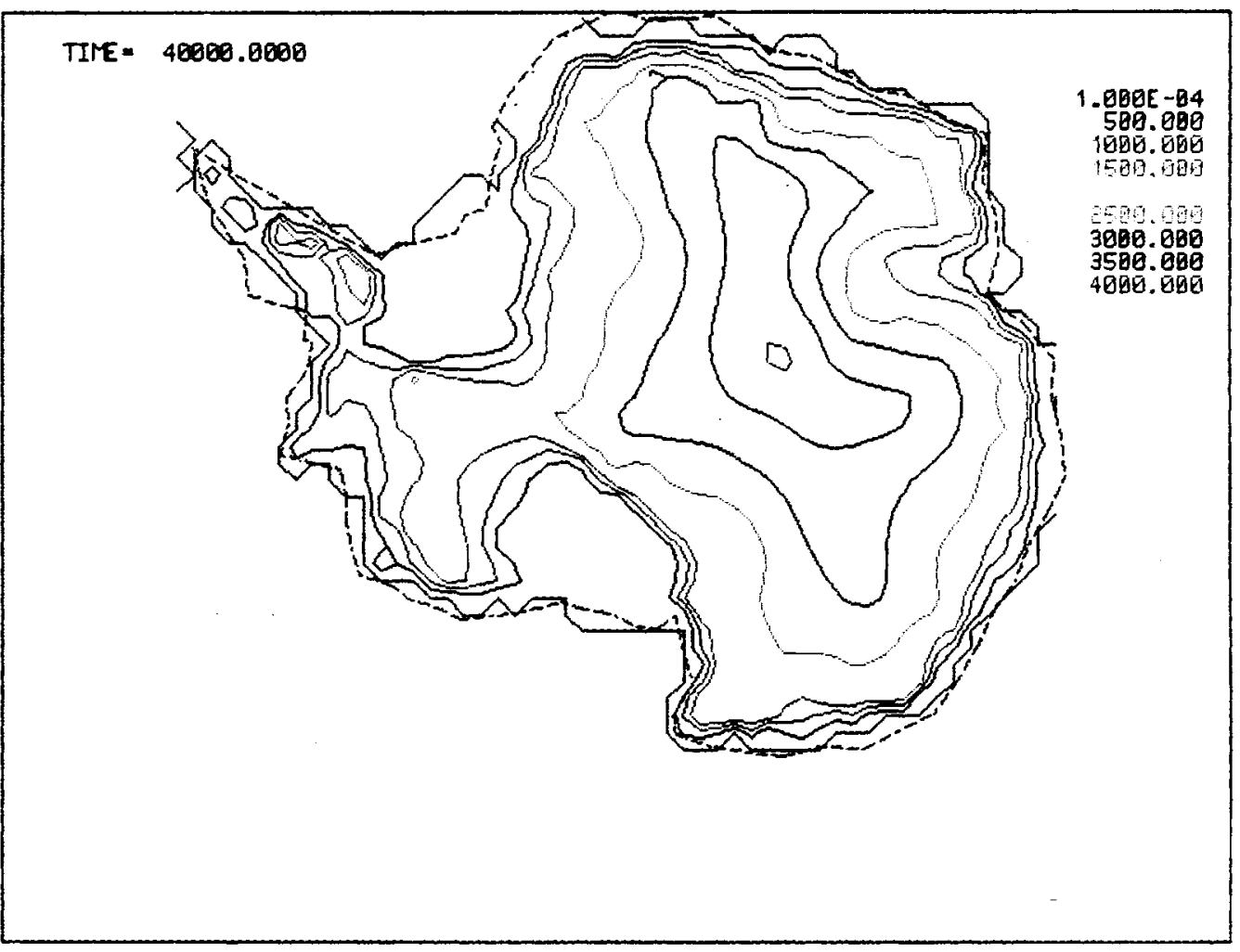

p) Ice and Land Elevation at 40,000 years 


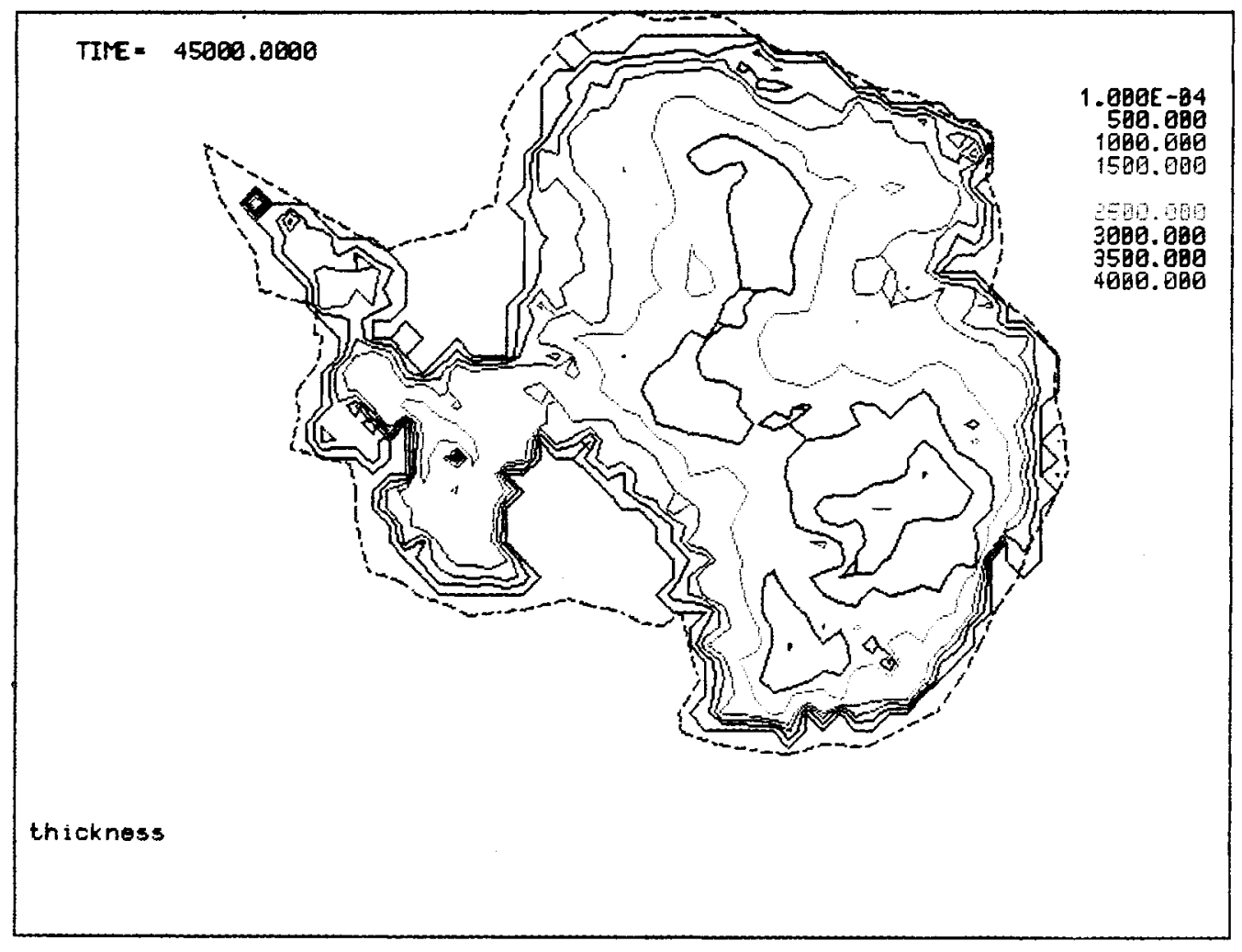

q) Ice Thickness at 45,000 years

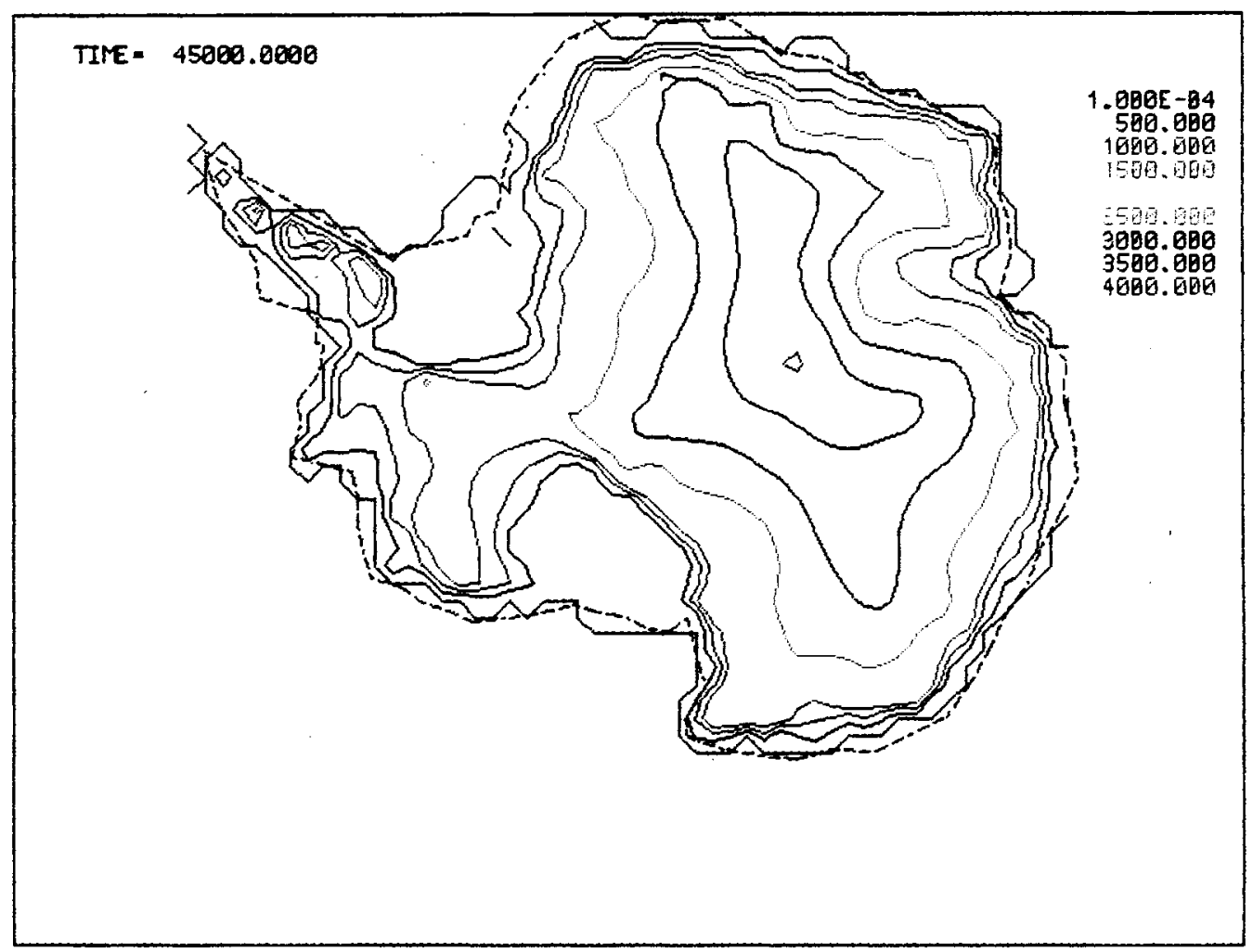

r) Ice and Land Elevation at 45,000 years 


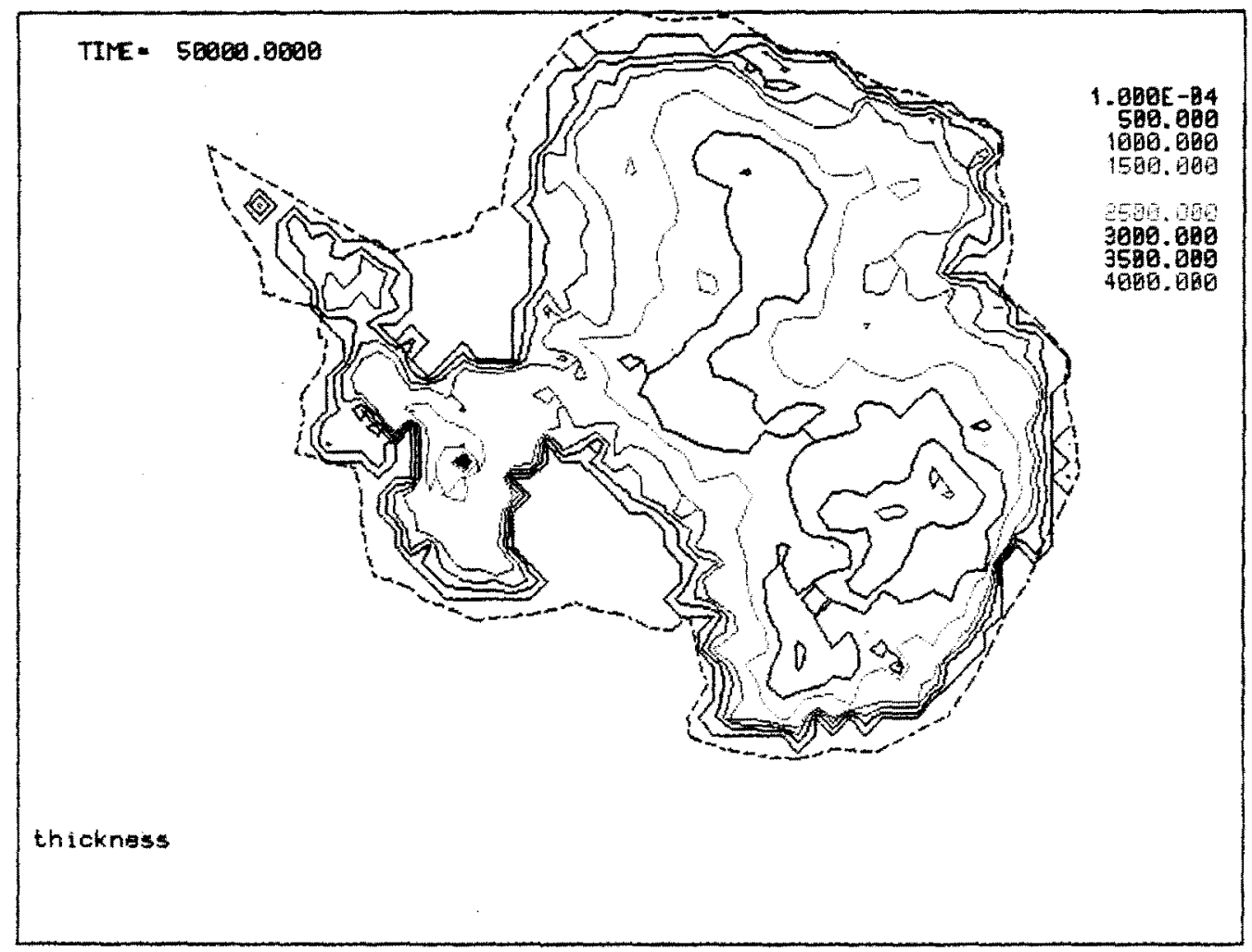

\section{s) Ice Thickness at 50,000 years}

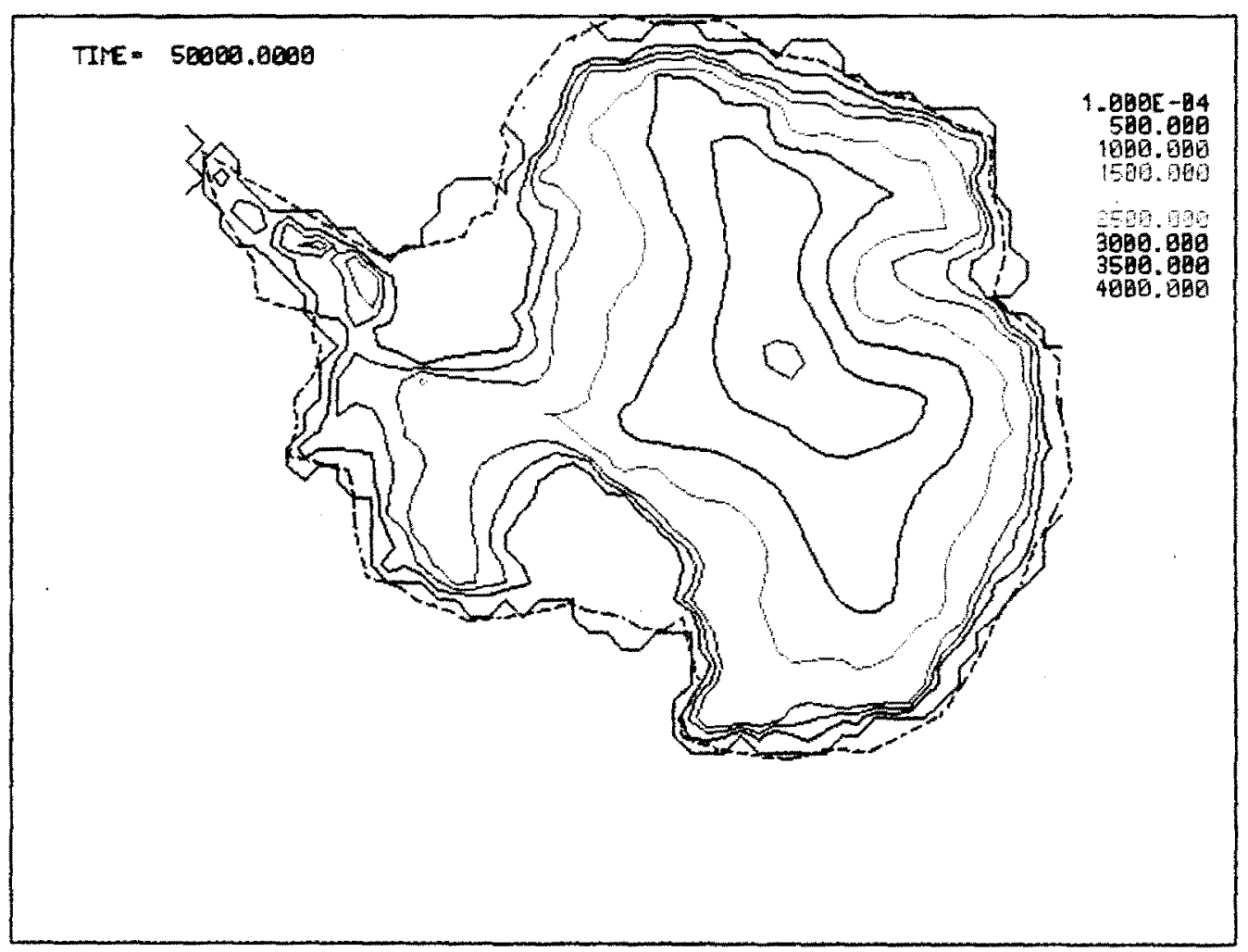

t) Ice and Land Elevation at 50,000 years 
APPENDIX

EXAMPLES OF THE TWO METHODS FOR SOLVING EQUATION (15) 


\section{APPENDIX}

\section{EXAMPLES OF THE TWO METHODS FOR SOLVING EQUATION (15)}

The first method is illustrated by substituting Equation (16) into Equation (15) giving:

$$
\theta=\frac{\int_{0}^{z} \exp \left\{\left(-w_{t} z / 2 \kappa\right)[z(1-r)+2 r] d z\right\}}{\int_{0}^{h} \exp \left\{\left(-w_{t} z / 2 \kappa\right)[z(1-r)+2 r] d z\right\}}
$$

and using the function:

$$
f=\left(R_{t} / 2\right)^{1 / 2}\left[Z(1-r)^{1 / 2}+r /(1-r)^{1 / 2}\right]
$$

allows the substitution:

$$
\left(w_{t} z / 2 \kappa\right)[Z(1-r)+2 r]=f^{2}-\left(R_{t} / 2\right)^{1 / 2} r^{2} /(1-r)
$$

so that Equation (A1) becomes:

$$
\theta=\frac{\int_{\zeta}^{\xi(z)} \exp \left(-f^{2} d f\right)}{\int_{\zeta}^{\xi(h)} \exp \left(-f^{2} d f\right)}
$$

where $\zeta$ replaces 0 and $\xi$ replaces $z$ or $h$ as the limits of integration. Equation (A4) can now be evaluated using Equation (23). 
The second method is illustrated by substituting Equation (18) into Equation (15), giving:

$$
\theta=\frac{\int_{0}^{z} \exp \left\{\left(+w_{t} z / 2 \kappa\right)[z(r-1)-2 r] d z\right\}}{\int_{0}^{h} \exp \left\{\left(+w_{t} z / 2 \kappa\right)[z(r-1)-2 r] d z\right\}}
$$

and using the function:

$$
f=\left(R_{t} / 2\right)^{1 / 2}\left[Z(r-1)^{1 / 2}-r /(r-1)^{1 / 2}\right]
$$

allows the substitution:

$$
\left(w_{t} z / 2 \kappa\right)[Z(r-1)-2 r]=f^{2}-\left(R_{t} / 2\right)^{1 / 2} r 2 /(r-1)
$$

so that Equation (A5) becomes:

$$
\theta=\frac{\int_{\zeta}^{\xi(z)} \exp \left(+f^{2} d f\right)}{\int_{\zeta}^{\xi(h)} \exp \left(+f^{2} d f\right)}
$$

where $\zeta$ replaces 0 and $\xi$ replaces $z$ or $h$ as the limits of integration. Equation (A8) can now be evaluated using Equation (31).

Transformation to Equation (A4) and (A8) is via the formula:

$$
\int_{\zeta}^{\xi} F(f) d f=\int_{M}^{N} F[\phi(z)] \phi^{\prime}(z) d z
$$

where $\zeta=\phi(M), \xi=\phi(N)$, and $f=\phi(z)$. 


\section{Distribution}

No. of

Copies

OFFSITE

2 DOE Office of Scientific and Technical Information
No. of

Copies

\section{ONSITE}

10 Pacific Northwest Laboratory

W. H. Walters (7)

K6-60

Publishing Coordination

Technical Report Files

(3)

Distr.1 